\title{
Physiologische, anatomische und chemische Aspekte der Regulation der Wurzelwasseraufnahme bei Rotbuche, Kiefer und Birke auf zwei unterschiedlich wasserversorgten Standorten
}

\author{
Dissertation \\ zur Erlangung des Doktorgrades \\ der Mathematisch-Naturwissenschaftlichen Fakultäten \\ der Georg-August-Universität zu Göttingen
}

\author{
vorgelegt von \\ Doris Burk
}

aus Pirna

Göttingen, 20.03.2006 
D 7

Referent: Prof. Dr. Ch. Leuschner

Korreferent: PD Dr. F. Thomas

Tag der mündlichen Prüfung: 03.05.2006 


\section{Inhalt}

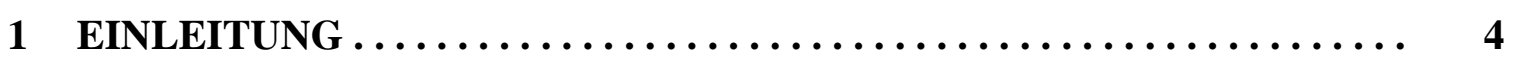

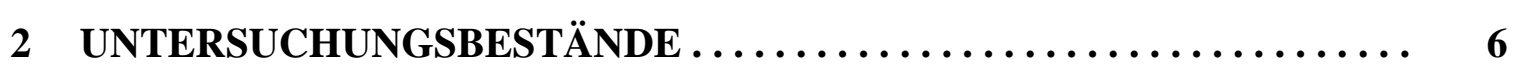

$2.1 \quad$ Auswahl der untersuchten Baumarten $\ldots \ldots \ldots \ldots \ldots \ldots \ldots \ldots \ldots$

$2.2 \quad$ Auswahl der Untersuchungsbestände $\ldots \ldots \ldots \ldots \ldots \ldots \ldots \ldots \ldots, 6,6 \ldots \ldots$

$2.3 \quad$ Topographische Lage der Untersuchungsbestände $\ldots \ldots \ldots \ldots \ldots \ldots \quad 8$

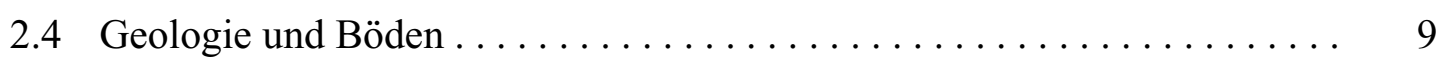

\begin{tabular}{lll}
\hline $2.5 \quad$ Vegetation der Untersuchungsbestände $\ldots \ldots \ldots \ldots \ldots \ldots \ldots \ldots$ & 10 \\
\hline
\end{tabular}

$2.6 \quad$ Regionalklima der Untersuchungsbestände $\ldots \ldots \ldots \ldots \ldots \ldots \ldots \quad \ldots$

2.6 .1 Witterung in den Untersuchungsjahren 2003 und $2004 \ldots \ldots \ldots$. . 11

2.6 .1 .1 Niederschlagsmengen $\ldots \ldots \ldots \ldots \ldots \ldots \ldots \ldots \ldots \ldots 11$

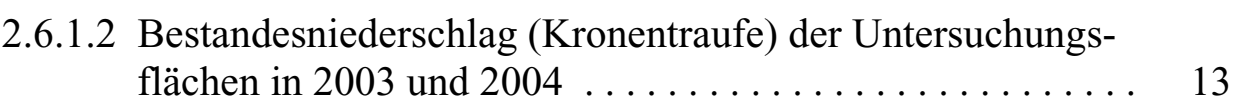

2.6.1.3 Wasserdampfdefizit der Luft (VPD), Temperatur und relative Luftfeuchte ...................... 14

2.6 .1 .4 Globalstrahlung ............................

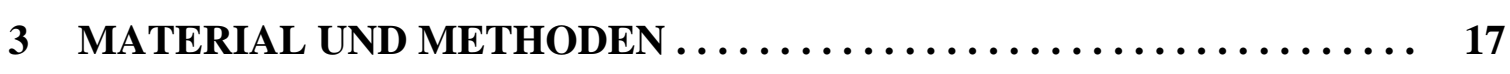

\begin{tabular}{ll}
\hline $3.1 \quad$ Mikroklimatische Parameter $\ldots \ldots \ldots \ldots \ldots \ldots \ldots \ldots \ldots \ldots \ldots$ & 17
\end{tabular}

\begin{tabular}{llll}
\hline 3.1 .1 & Bestandesniederschlag (Kronentraufe) der Untersuchungsflächen .. & 17 \\
\hline
\end{tabular}

3.1.2 Freilandniederschlag, Lufttemperatur, relative Luftfeuchte, VPD . . 17

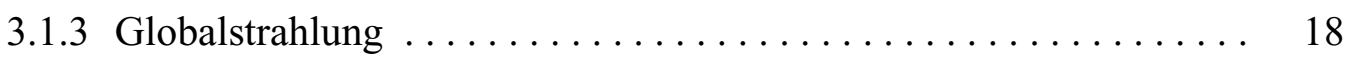

\begin{tabular}{lll}
\hline 3.2 & Bestimmung der Bodenwasserverfügbarkeit $\ldots \ldots \ldots \ldots \ldots \ldots \ldots$ & 18 \\
\hline
\end{tabular}

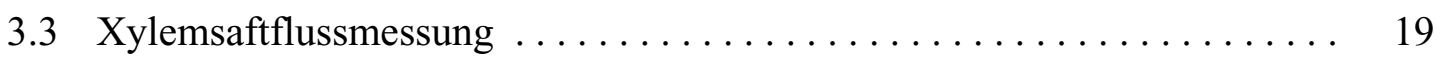

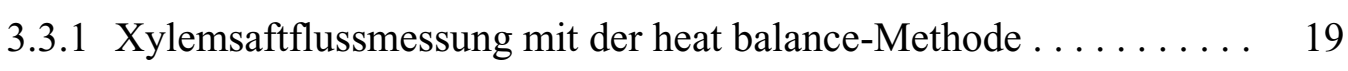

3.3 .2 Auswahl der Wurzeln und Installation der Sensoren .......... 22

3.3 .3 Kalibrierung der Saftflusssensoren im Gelände ............ 24

3.3 .4 Ernte und Verarbeitung der Messwurzeln $\ldots \ldots \ldots \ldots \ldots \ldots .24$

3.4 Wurzelwasserpotenzialmessung nach SCHOLANDER $\ldots \ldots \ldots \ldots \ldots 26$

3.5 Morphologisch-anatomische Untersuchung der Wurzeln .......... 26

\begin{tabular}{llll}
\hline 3.5 .1 & Bestimmung der Peridermschichtenanzahl $\ldots \ldots \ldots \ldots \ldots$ & 26 \\
\hline
\end{tabular} 
3.5.2 Suberinbestimmung des Periderms $\ldots \ldots \ldots \ldots \ldots \ldots \ldots \ldots \ldots$

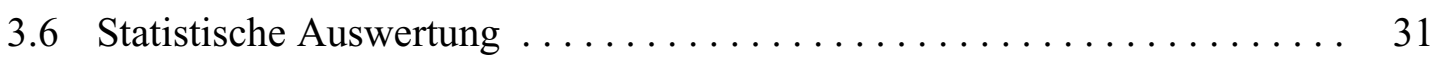

$4 \quad$ ERGEBNISSE $\ldots \ldots \ldots \ldots \ldots \ldots \ldots \ldots \ldots \ldots \ldots \ldots \ldots \ldots \ldots \ldots, 32$

4.1 Bodenwasserzustand der Untersuchungsbestände Söhre und Ziegelrodaer

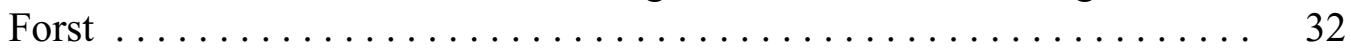

4.1 .1 Volumetrischer Bodenwassergehalt und Bodenmatrixpotenzial . . . 32

4.1.2 Beziehung zwischen Bodenwassergehalt und Bodenmatrixpotenzial

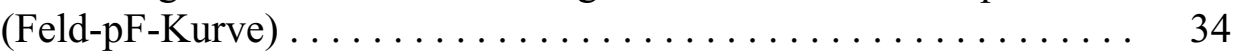

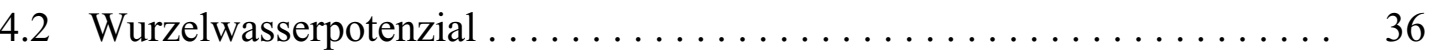

$4.3 \quad$ Wasseraufnahme durch Feinwurzeln $\ldots \ldots \ldots \ldots \ldots \ldots \ldots \ldots \ldots$. 41

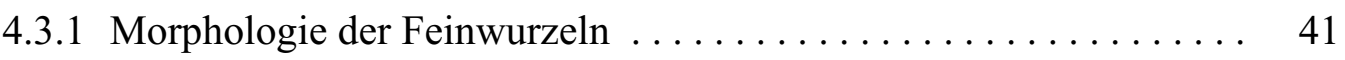

4.3 .2 Geländekalibrierung der Saftflusssensoren $\ldots \ldots \ldots \ldots \ldots \ldots 42$

4.3.3 Saftflussdichten in Buchen-, Birken- und Kiefernwurzeln . . . . . . . 43

4.3.3.1 Mittelwerte von Saftflussdichten in Buchen-, Birken- und Kiefernfeinwurzeln in ihrer Abhängigkeit von klimatischen

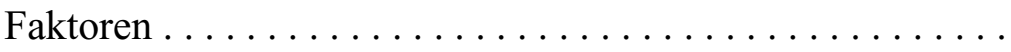

4.3.4 Oberflächenbezogener Saftfluss in Buchen-, Birken- und Kiefern-

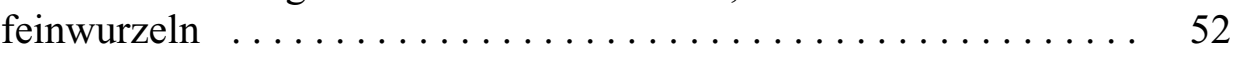

4.3.5 Vergleich der Einflussfaktoren auf den oberflächenbezogenen Saftfluss und die Saftflussdichte $\ldots \ldots \ldots \ldots \ldots \ldots \ldots \ldots$

4.3.6 Wasseraufnahmeraten in Abhängigkeit von Globalstrahlung, VPD und Bodenfeuchte ....................... 60

$4.4 \quad$ Anatomische und chemische Eigenschaften der Wurzeln ........... 62

4.4 .1 Anatomische Untersuchung des Wurzelperiderms ........... 62

4.4.2 Chemische Zusammensetzung des Wurzelperiderms von Buche,

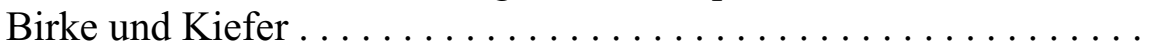

4.4.2.1 Gesamtsuberinmengen von Buchen-, Birken- und Kiefernwurzeln

4.4.2.2 Suberinmengen pro Peridermschicht von Buchen-, Birkenund Kiefernwurzeln

4.4.2.3 Suberinzusammensetzung von Buchen-, Birken- und Kiefernwurzeln .......................

4.4.2.4 Suberinzusammensetzung von Buchen-, Birken- und Kiefernwurzeln im Jahresvergleich 2003 und 2004

4.4.2.5 Zusammensetzung des Suberins pro Peridermschicht in Buchen-, Birken- und Kiefernwurzeln .............. 
4.4.2.6 Mengenanteile der häufigsten Stoffklassen des Suberins: $\omega$-OH Säuren und Trihydroxysäuren . . . . . . . . . 72

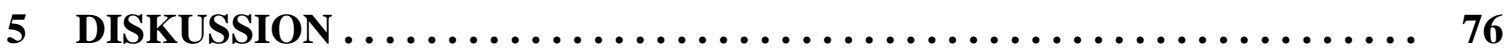

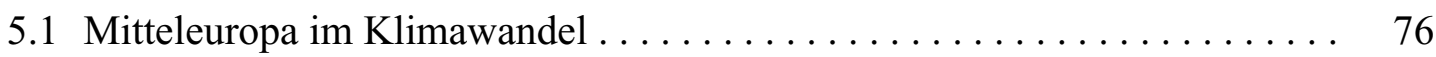

5.1 .12003 als Beispiel für den vorhergesagten Klimatrend . . . . . . . . 76

5.1 .2 Wasserversorgung der beiden Untersuchungsbestände . . . . . . . 77

5.2 Charakterisierung der drei untersuchten Baumarten . . . . . . . . . . . . 79

5.3 Anpassung der Wasseraufnahme an Trockenstress ............... 81

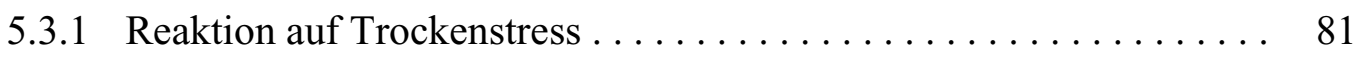

$5.3 .2 \quad$ Wasseraufnahme ........................ 82

5.3.2.1 Potenzial und Limitierungen derzeit verfügbarer

Methoden ........................ 82

5.3.2.2 Veränderung des Wasserpotenzials im Wurzelxylem bei Trockenheit

5.3.2.3 Einfluss von Embolien auf die hydraulische Leitfähigkeit . . 88

5.3.2.4 Artspezifische Wasseraufnahmeraten von Buche, Birke und Kiefer . . . . . . . . . . . . . . . . . . . . . 89

5.3.2.5 Wasseraufnahme in Abhängigkeit von Globalstrahlung, VPD und Bodenfeuchte

5.3 .3 Morphologische Anpassung der Wurzeln an Trockenheit ........ 93

5.3 .4 Anatomische und chemische Anpassung an Trockenstress . . . . . . 94

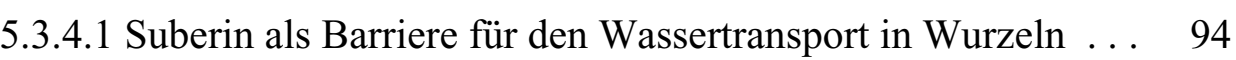

5.3.4.2 Suberinkomponenten als Biomarker ............ 96

$6 \quad$ ZUSAMMENFASSUNG $\ldots \ldots \ldots \ldots \ldots \ldots \ldots \ldots \ldots \ldots \ldots \ldots \ldots$

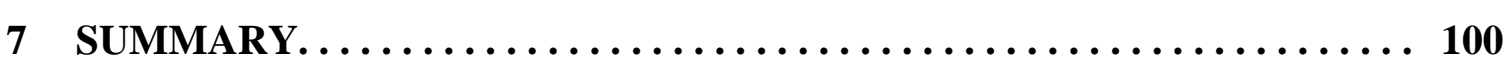

$8 \quad$ LITERATUR $\ldots \ldots \ldots \ldots \ldots \ldots \ldots \ldots \ldots \ldots \ldots \ldots \ldots \ldots \ldots \ldots$

Abbildungsverzeichnis ........................... 116

Tabellenverzeichnis ................................ 119

Abkürzungsverzeichnis .............................. 120 


\section{EINLEITUNG}

Anthropogen bedingte Klimaveränderungen könnten in Zukunft in Mitteleuropa zu einer Umverteilung der Niederschläge im Jahresverlauf führen. Neueste Modelle prognostizieren bis zum Ende des 21. Jahrhunderts eine Zunahme der Winterniederschläge um bis zu 40\% und eine Abnahme der Sommerniederschläge um bis zu 50\% gegenüber 1961-1990 (RÄISÄNEN et al. 2004). In zahlreichen Studien wird der Einfluss lokaler veränderter Klimaänderungen auf das Wachstum von Pflanzen besprochen (SchOlz 1993, MÖHREN \& KRAMER 1997). LEUSCHNER \& SCHIPKA (2004) erwarten eine erhebliche Erhöhung der Trockenstressbeanspruchung für Pflanzen in Mitteleuropa.

Wasser wird durch Feinwurzeln von Pflanzen aus dem Boden aufgenommen und über die Blätter an die Atmosphäre abgegeben. Wurzeln und Blätter stellen dabei die wichtigsten Grenzflächen im soil-plant-atmosphere continuum (SPAC) für den Wasserfluss in Ökosystemen dar.

Während im Bereich der Messung der Wasserabgabeseite in den vergangenen Jahrzehnten große Fortschritte erzielt werden konnten und Trockenheitsanpassungen der Blätter in vielen Studien (u.a. SCHRAML \& RENNENBERG 2000, 2002, SCHIPKA 2002, Serrano \& PenUelas 2005, Aspelmeier \& LeUSChNER 2006) untersucht werden konnten, ist die Kenntnis über die Prozesse der Wasseraufnahme durch die Wurzeln und deren Regulation vergleichsweise gering. Ursache für diesen Mangel war besonders das Fehlen einer geeigneten Methode zur Wasserabsorption im ungestörten Boden. In vorangegangenen Studien erfolgten vor allem Messungen an Grobwurzeln mit Durchmessern über 20 mm (u.a. ONG \& KAHN 1993, GREEN et al. 1997). Als ein wesentlicher Fortschritt in der Messtechnik erwies sich die Weiterentwicklung von Miniatur-Saftflussmesssystemen und deren Einsatz an Wurzeln mit Durchmessern unter 5 mm (SENOCK \& LeUSCHNER 1999, CONERS \& LEUSCHNER 2002, KorN 2004). Diese Methode erlaubt kontinuierliche Messungen der Wasseraufnahme unter natürlichen Bedingungen mit anschließender Freilegung der untersuchten Wurzelstränge. Dies ermöglichte erstmalig den Bezug der Flussrate auf die Feinwurzeloberfläche.

Eine Vergleichsstudie hinsichtlich der oberflächenbezogenen Wasseraufnahme von Baumarten mit unterschiedlichen Wasseransprüchen fand bisher jedoch noch nicht statt. In der vorliegenden Arbeit werden oberflächenbezogene Wurzelwasseraufnahmeraten an drei forstwirtschaftlich und ökologisch bedeutenden Baumarten untersucht. Physiologische, morphologische, anatomische und chemische Eigenschaften von Feinwurzeln der trockenheitstoleranten Birke und Kiefer und der trockenheitsempfindlichen Buche (KozlowsKi et al. 1991, EllenBERG 1996) werden 
gegenübergestellt, um Anpassungsmechanismen des Wurzelsystems an zunehmende Austrocknung des Bodens zu untersuchen.

Mit Hilfe von Miniatursaftfluss-Sensoren konnte nach dem Prinzip der „heat balance“ Methode (SENOCK \& HAM 1993, SenOCK \& LeusCHNER 1999, LeusCHNER \& CONERS 2002) die Wasseraufnahme an Feinwurzeln $(2-5 \mathrm{~mm})$ durchgeführt werden. Die Untersuchungen dazu fanden auf einem niederschlagsreichen Standort in der Söhre nahe Kassel und einem niederschlagsarmen Standort im Ziegelrodaer Forst bei Halle im mitteldeutschen Trockengebiet statt. Bei der Auswahl der Bestände wurde großer Wert auf die Vergleichbarkeit bezüglich des geologischen Untergrunds und der Bodenverhältnisse gelegt, um gezielt die Reaktion der Wasseraufnahme in situ auf unterschiedliche Niederschlagsregime $\mathrm{zu}$ untersuchen. Des weiteren wurden in begleitenden Messungen Daten zum Wurzelwasserpotenzial, Bodenwassergehalt, Wasserdampfsättigungsdefizit der Luft (VPD) und Globalstrahlung erhoben, um die steuernden Einflussgrößen der Wasseraufnahme genauer differenzieren zu können. Um artspezifische Unterschiede zu erfassen, wurden neben anatomischen Untersuchungen auch chemische Untersuchungen zum Suberingehalt und zur Zusammensetzung des Suberins in den Wurzeln durchgeführt.

Im Rahmen dieser Arbeit soll folgenden Fragen nachgegangen werden:

1) Wie unterscheiden sich die Feinwurzeln trockenheitstoleranter (Birke und Kiefer) und trockenheitsempfindlicher (Buche) Baumarten hinsichtlich ihrer physiologischen, morphologischen, anatomischen und chemischen Eigenschaften?

2) Ist ein und dieselbe Baumart in der Lage, ihr Feinwurzelsystem an trockene Standorte anzupassen, um eine verbesserte Wasseraufnahme zu gewährleisten? 


\section{UNTERSUCHUNGSBESTÄNDE}

\subsection{Auswahl der untersuchten Baumarten}

\section{Rotbuche (Fagus sylvatica L.) (Abb. 2-1, a))}

Die Rotbuche gehört zu den weitverbreiteten Waldbaumarten in Mitteleuropa. Trotz der großen Standortsbreite, der die Rotbuche gewachsen ist, erweist sich die Wasserversorgung in vielen Untersuchungen als limitierender Faktor. Dies tritt verstärkt in Regionen mit unregelmäßigen oder nicht ausreichenden sommerlichen Niederschlägen auf (ELLENBERG 1996, PETERS 1997).

Hängebirke (Betula pendula Roth) (Abb. 2-1, b))

Die Hängebirke kommt in Mitteleuropa als ausgesprochene Pionierbaumart vor. Durch ihre Anspruchslosigkeit gedeiht sie auf sehr trockenen, nährstoffarmen, sauren, aber auch kalkreichen Böden ebenso wie auf sehr feuchten Böden. Durch ihre Konkurrenzschwäche wird sie von konkurrenzstärkeren Baumarten häufig auf Extremstandorte (z.B. Sandböden) verdrängt (RÖHRIG \& BARTSCH 1992, WAGNER 1994).

Waldkiefer (Pinus sylvestris L.) (Abb. 2-1, c))

Die Waldkiefer weist das größte Standortsspektrum der in Mitteleuropa einheimischen Baumarten auf. Sie vermag Extremstandorte wie trockene Sandböden, Moore, Kalkoder Kieselböden zu besiedeln (LEIBUNDGUT 1991, MAYER 1992). Die Waldkiefer ist in der Lage, eine Pfahlwurzel von bis zu 15 m Länge auszubilden. Somit macht sie sich weitgehend unabhängig vom Wasser- und Nährstoffangebot des Oberbodens (LEIBUNDGUT 1991).

\subsection{Auswahl der Untersuchungsbestände}

Für die Untersuchungen wurden zwei Bestände ausgewählt, die sich lediglich im Niederschlagsregime unterscheiden sollten.

Es wurden dazu eine Fläche im Gebiet der Söhre südöstlich von Kassel mit einem mittleren Jahresniederschlag von über $800 \mathrm{~mm}$ und als bodentrockene Vergleichsfläche ein Bestand im Ziegelrodaer Forst im Mitteldeutschen Trockengebiet bei Jahresniederschlägen unter $500 \mathrm{~mm}$ ausgewählt. In beiden Waldbeständen wurde je eine Untersuchungsfläche ausgesucht, die die drei Baumarten Rotbuche, Waldkiefer und Hängebirke in Form von Altbäumen aufwies. Beide Untersuchungsbestände stocken auf dem gleichen geologischen Substrat (mittlerer Buntsandstein), und weisen somit eine Vergleichbarkeit hinsichtlich der Bodennährstoffbedingungen auf. 


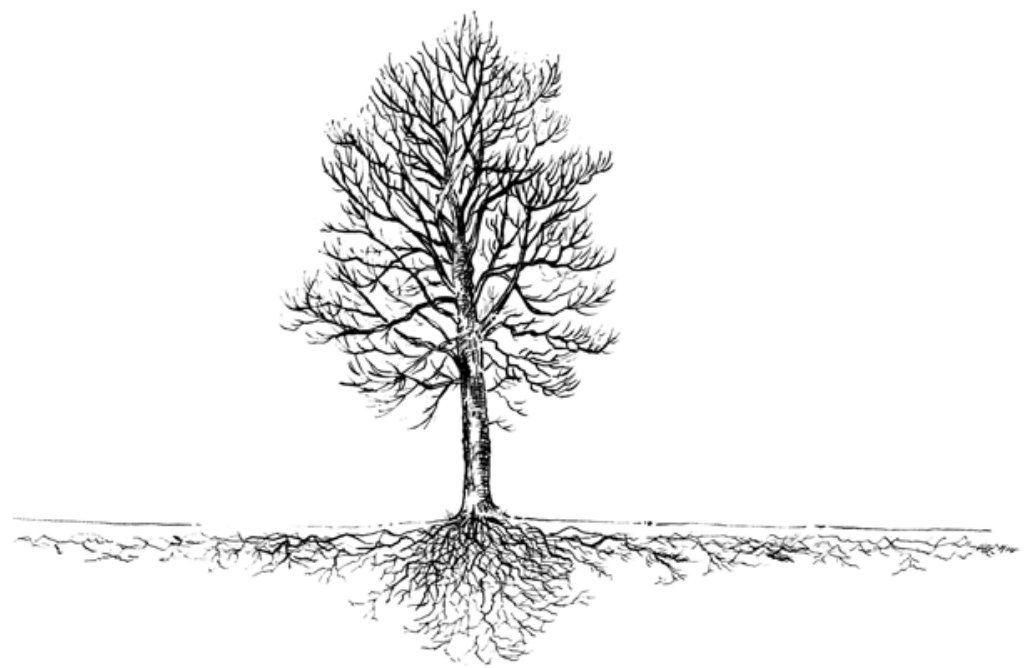

a)

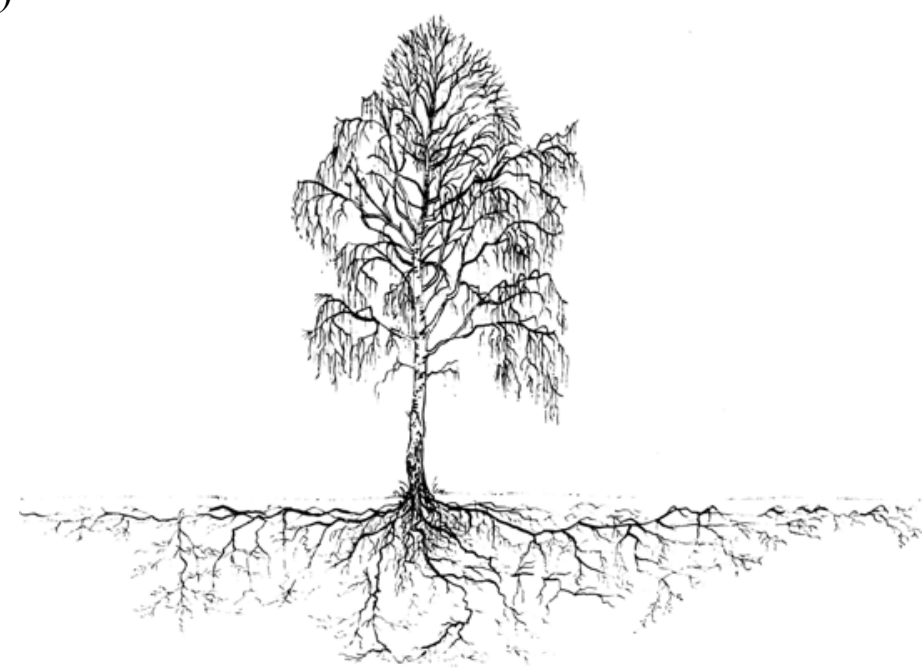

b)

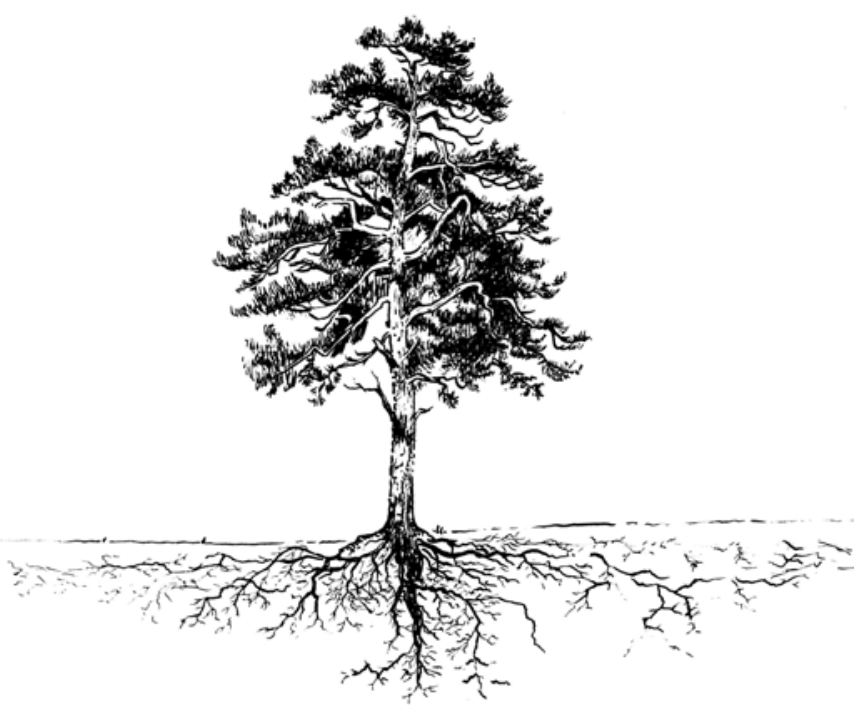

c)

Abb. 2-1. a) Habitus der Buche mit Herzwurzelsystem b) Habitus der Birke mit Senkerwurzelsystem c) Habitus der Kiefer mit Pfahlwurzelsystem (Zeichnungen von H. KRELL 2005). 


\subsection{Topographische Lage der Untersuchungsbestände}

Der Untersuchungsbestand in der Söhre liegt in Nordhessen, $12 \mathrm{~km}$ südöstlich von Kassel und etwa $1 \mathrm{~km}$ entfernt vom Ort Wellerode (51 $\left.{ }^{\circ} 15^{\prime} \mathrm{N}, 9^{\circ} 35^{\prime} \mathrm{E}\right)$ (Abb. 2-2). Die Söhre stellt ein großes waldreiches Bergland mit Erhebungen bis $470 \mathrm{~m}$ Höhe dar; die Versuchsfläche liegt in 340 m ü.M.

Der zweite Untersuchungsbestand befindet sich in Sachsen-Anhalt im Ziegelrodaer Forst im Bereich des Mitteldeutschen Trockengebietes am Rand des Thüringer Beckens, $8 \mathrm{~km}$ südöstlich von Artern und etwa $2 \mathrm{~km}$ entfernt von dem Ort Ziegelroda $\left(51^{\circ} 20^{\prime} \mathrm{N}\right.$, $11^{\circ} 25^{\prime}$ E) (Abb. 2-2). Diese Untersuchungsfläche liegt auf einer Höhe in 260 m ü.M.

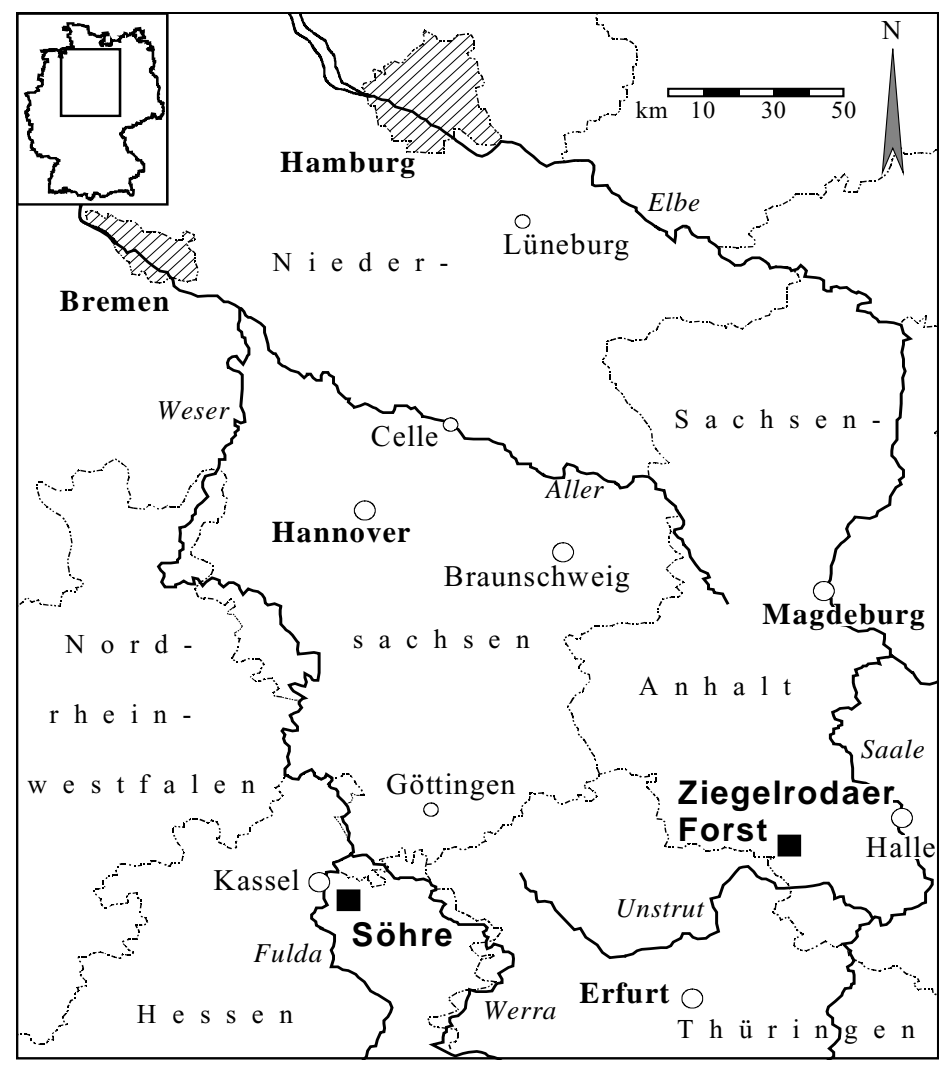

Abb. 2-2. Topographische Lage der Untersuchungsbestände in der Söhre und im Ziegelrodaer Forst (verändert nach HERTEL 1999). 


\subsection{Geologie und Böden}

Beide Untersuchungsflächen befinden sich auf mittlerem Buntsandstein mit Lößanwehungen. Als Bodentyp hat sich in der Söhre eine schwach podsolige Braunerde-Pararendzina mit einer Horizontabfolge $\mathrm{A}_{(\mathrm{e}) \mathrm{h}}-\mathrm{B}_{(\mathrm{s}) \mathrm{v}}-\mathrm{C}_{\mathrm{v}}$ gebildet. Als Bodenart liegt schwach toniger Schluff vor (I. MEIER, mündl. Mitt.). Der Mineralboden wird bedeckt von einer $4.5 \mathrm{~cm}$ mächtigen organischen Auflage mit den Schichten $\mathrm{O}_{\mathrm{l}}, \mathrm{O}_{\mathrm{f}}$ und $\mathrm{O}_{\mathrm{h}}(1,0,1,0$ und 2,5 cm Dicke). Die Humusform ist ein typischer Moder (Tab. 2-1).

Tabelle 2-1. Geologische und pedologische Charakteristika der Untersuchungsbestände in der Söhre und im Ziegelrodaer Forst (nach I. MEIER, mündl. Mitt.).

\begin{tabular}{lcccc}
\hline $\begin{array}{c}\text { UNTERSUCHUNGS- } \\
\text { GEBIET }\end{array}$ & $\begin{array}{c}\text { GEOLOGISCHER } \\
\text { UNTERGRUND }\end{array}$ & BODENART & BODENTYP & HUMUSFORM \\
Söhre & $\begin{array}{c}\text { Löß auf } \\
\text { mittlerem } \\
\text { Buntsandstein }\end{array}$ & $\begin{array}{c}\text { schwach } \\
\text { toniger } \\
\text { Schluff }\end{array}$ & $\begin{array}{c}\text { schwach } \\
\text { podsolige } \\
\text { Braunerde- } \\
\text { Pararendzina }\end{array}$ & $\begin{array}{c}\text { typischer } \\
\text { Moder }\end{array}$ \\
& & & & \\
Ziegelrodaer & Löß auf & schwach & Pararendzina & F-Mull \\
Forst & mittlerem & sandiger & & \\
& Buntsandstein & Lehm & & \\
& & & & \\
& & &
\end{tabular}

Mit der Horizontabfolge $A_{h}-C_{v 1}$ liegt im untersuchten Bestand des Ziegelrodaer Forstes eine Pararendzina vor. Die Bodenart ist als schwach sandiger Lehm zu beschreiben (I. MEIER, mündl. Mitt.). Über dem Mineralboden befindet sich eine geringe organische Auflage. Als Humusform liegt ein F-Mull vor (Tab. 2-1). 


\subsection{Vegetation der Untersuchungsbestände}

In der Söhre wurde eine Stammdichte von 126 Stämmen ha ${ }^{-1}$ gezählt, wobei die Buche deutlich dominiert und die Kiefer vereinzelt im Altbestand vorhanden ist.

Unter Buche und Kiefer fehlt eine Krautschicht ebenso wie eine Strauchschicht.

Unter der Birkengruppe, etwa 25 m von Buchen und Kiefern entfernt, befindet sich eine Krautschicht mit Deschampsia flexuosa, Deschampsia cespitosa, Vaccinium myrtillus, Calamagrostis epigejos und Luzula luzuloides. Über der Krautschicht ist eine dünne Strauchschicht aus Rubus idaeus, Picea abies und Betula pendula ausgebildet.

Im Bestand des Ziegelrodaer Forstes treten neben den dominierenden Buchen auch Traubeneichen im Mittelstand und beigemischt Kiefern auf, so dass man von einem Buchen-Eichen-Mischbestand sprechen kann.

Mit 358 Stämmen ha ${ }^{-1}$ ist die Stammdichte dort wesentlich höher als in der Söhre. Unter Buche und Kiefer befindet sich eine sehr dünne Krautschicht aus Impatiens parviflora und Alliaria petiolata. Eine Strauchschicht ist nicht vorhanden.

Die Birkengruppe, ca. $15 \mathrm{~m}$ von den Buchen und Kiefern entfernt, besitzt eine mächtige Krautschicht mit Urtica dioica, Impatiens parviflora, Galeopsis tetrahit, Stellaria holostea, Mycelis muralis, Fragaria vesca, Dactylis polygama, Dryopteris carthusiana, Senecio fuchsii, Hypericum perforatum, Rumex obtusifolius, Galium aparine, Anthriscus sylvestris und eine dünne Strauchschicht aus Tilia cordata.

\subsection{Regionalklima der Untersuchungsbestände}

Die Söhre ist durch ein schwach subatlantisches Klima geprägt. An der Klimastation in Kassel (ca. $12 \mathrm{~km}$ vom Bestand entfernt) beträgt die Jahrestemperatur im langjährigen Mittel $8.9^{\circ} \mathrm{C}$ und es herrscht ein mittlerer Jahresniederschlag von $698 \mathrm{~mm}$ (Abb. 2-3). Die Messstation in Wellerode (ca. 1 km von der Untersuchungsfläche entfernt, seit 1996 eingestellt), wies eine mittlere Jahrestemperatur von $7^{\circ} \mathrm{C}$ und einen mittleren Jahresniederschlag von $822 \mathrm{~mm}$ (nach VOß 1998) auf. Die mittlere Niederschlagssumme im Untersuchungsbestand in der Söhre dürfte daher etwas über $800 \mathrm{~mm}$ liegen. 

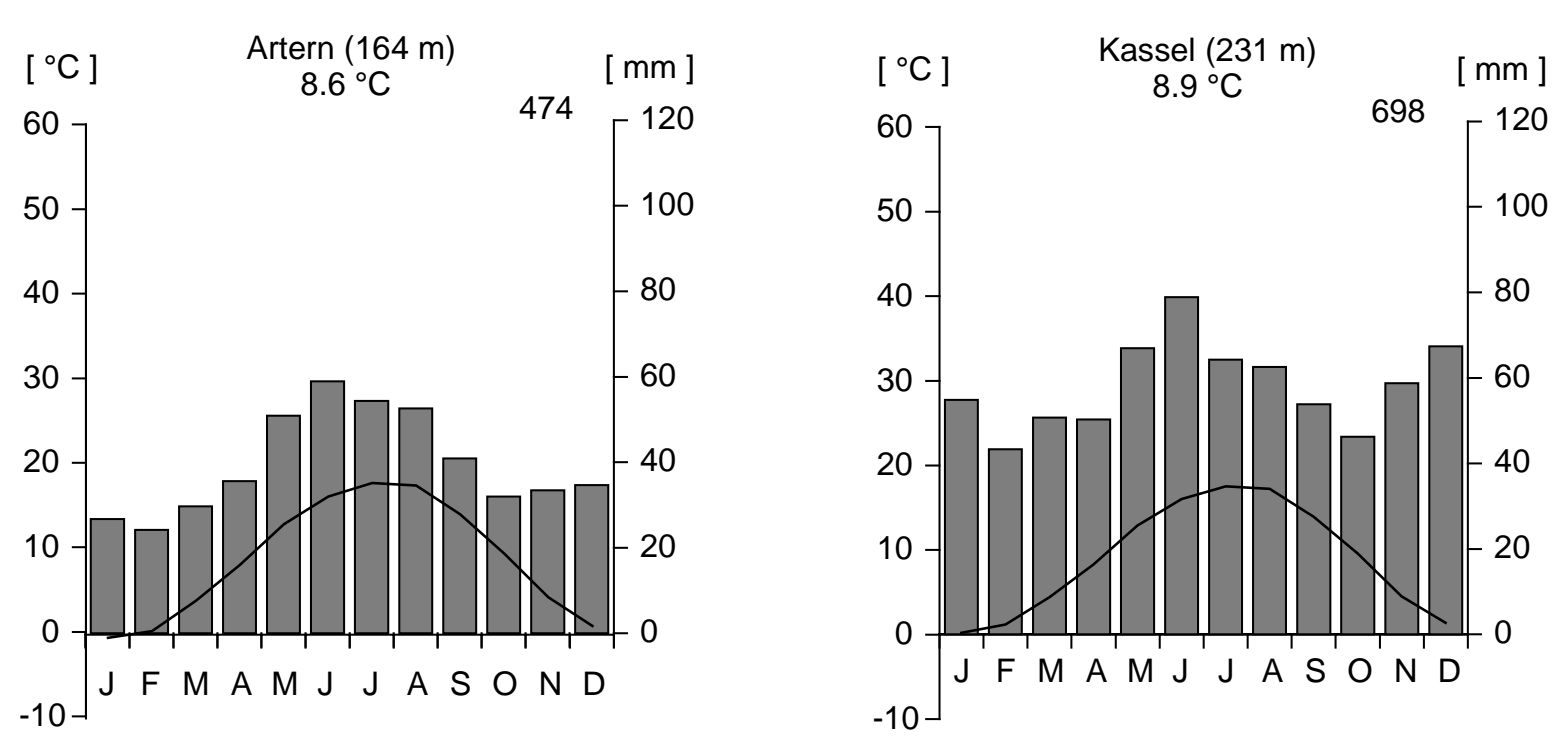

Abb. 2-3. Klimadiagramme (langjährige Mittel von 1961-1990) der beiden Messstationen Artern (im Bereich der Untersuchungsfläche im Ziegelrodaer Forst) und Kassel (im Bereich der Untersuchungsfläche in der Söhre). Werte des Deutschen Wetterdienstes (DWD).

Der Ziegelrodaer Forst liegt im Mitteldeutschen Trockengebiet. Sein Klima ist geprägt durch seine Lage im Regenschatten des Harzes. Die Klimawerte der Wetterstation Artern (ca. $8 \mathrm{~km}$ vom Bestand entfernt) zeigen deutliche subkontinentale Züge (Abb. 2-3).

Artern gilt mit $474 \mathrm{~mm}$ Niederschlag im langjährigen Mittel (1961-1990) als zweittrockenste Messstation Deutschlands (OELKE 1997).

\subsubsection{Witterung in den Untersuchungsjahren 2003 und 2004}

\subsubsection{Niederschlagsmengen}

Die Witterung im Bestand in der Söhre (Werte der Klimastation Kassel) im Jahr 2003 war mit $524 \mathrm{~mm}$ Niederschlag deutlich trockener als im langjährigen Mittel, wobei besonders die Monate Juli und August mit zusammen $64 \mathrm{~mm}$ Niederschlag durch ein deutliches Niederschlagsdefizit gegenüber dem langjährigen Mittel (127 mm) auffielen. Auch die Vegetationsperiode 2003 wies mit 245 mm von Mai bis September einen deutlich geringeren Niederschlag auf als im langjährigen Mittel. Im Jahr 2004 wurde 
mit $755 \mathrm{~mm}$ Niederschlag die mittlere Jahresniederschlagssumme etwas überschritten (Tab. 2-2). Der Niederschlag in der Vegetationsperiode von Mai bis September lag im Jahr 2004 mit 335 mm Niederschlag geringfügig über dem langjährigen Mittel von 327 mm. Gegenüber dem Trockenjahr 2003 fiel im Juli und August 2004 die dreifache Menge Regen (180 mm).

Tabelle 2-2. Monatliche Niederschlagssummen in den Untersuchungsjahren 2003 und 2004 der Klimastationen Kassel für die Fläche in der Söhre sowie Artern für die Fläche im Ziegelrodaer Forst, jeweils mit Angabe des prozentualen Anteils vom langjährigen Mittel. Werte des Deutschen Wetterdienstes (DWD).

\begin{tabular}{|c|c|c|c|c|}
\hline \multicolumn{5}{|c|}{ NIEDERSCHLAG [mm] } \\
\hline \multirow[t]{2}{*}{ KASSEL } & \multirow{2}{*}{$\begin{array}{c}2003 \\
{[\mathrm{~mm}]}\end{array}$} & [\%] langj. & 2004 & [\%] langj. \\
\hline & & \multicolumn{3}{|c|}{ [mm] } \\
\hline Januar & 69 & 125 & 100 & 182 \\
\hline Februar & 17 & 40 & 63 & 147 \\
\hline März & 30 & 59 & 38 & 75 \\
\hline April & 23 & 46 & 48 & 96 \\
\hline Mai & 37 & 55 & 44 & 66 \\
\hline Juni & 98 & 124 & 56 & 71 \\
\hline Juli & 51 & 80 & 135 & 211 \\
\hline August & 13 & 21 & 45 & 71 \\
\hline September & 46 & 85 & 55 & 102 \\
\hline Oktober & 47 & 102 & 50 & 109 \\
\hline November & 30 & 51 & 88 & 149 \\
\hline Dezember & 63 & 94 & 33 & 49 \\
\hline Jahr & 524 & 75 & 755 & 108 \\
\hline \multirow[t]{2}{*}{ ARTERN } & 2003 & [\%] langj. & 2004 & [\%] langj. \\
\hline & [mm] & \multicolumn{3}{|c|}{ [mm] } \\
\hline Januar & 38 & 141 & 31 & 115 \\
\hline Februar & 5 & 21 & 21 & 88 \\
\hline März & 12 & 40 & 18 & 60 \\
\hline April & 42 & 117 & 26 & 72 \\
\hline Mai & 54 & 106 & 77 & 151 \\
\hline Juni & 47 & 80 & 40 & 68 \\
\hline Juli & 23 & 43 & 89 & 165 \\
\hline August & 21 & 40 & 44 & 83 \\
\hline September & 43 & 105 & 21 & 51 \\
\hline Oktober & 21 & 66 & 14 & 44 \\
\hline November & 33 & 100 & 48 & 145 \\
\hline Dezember & 24 & 69 & 11 & 31 \\
\hline Jahr & 363 & 77 & 440 & 93 \\
\hline
\end{tabular}


Im Bestand des Ziegelrodaer Forstes (Werte der Klimastation Artern) wurden im Jahr 2003 die mittlere Jahresniederschlagssumme mit $363 \mathrm{~mm}$ deutlich unterschritten. Dies spiegelt sich insbesondere in der Vegetationsperiode wider. Mit $188 \mathrm{~mm}$ lag der Niederschlag deutlich unter dem langjährigen Mittel $(258 \mathrm{~mm})$. In den Hochsommermonaten Juli und August fielen mit $44 \mathrm{~mm}$ Niederschlag über die Hälfte weniger als im langjährigen Mittel (107 mm).

Im Jahr 2004 wurde die Jahresniederschlagssumme mit $440 \mathrm{~mm}$ Niederschlag nur geringfügig unterschritten. Die Niederschläge in der Vegetationsperiode lagen mit $271 \mathrm{~mm}$ dagegen etwas über dem langjährigen Mittel. Besonders die Hochsommermonate Juli und August lagen mit $133 \mathrm{~mm}$ deutlich über dem langjährigen Niederschlagsmittel.

\subsubsection{Bestandesniederschlag (Kronentraufe) der Untersuchungs- flächen in 2003 und 2004}

Die gemessenen Niederschlagswerte der Kronentraufe unterscheiden sich in den Jahren 2003 und 2004 deutlich voneinander (Abb. 2-4).

Auf beiden Flächen erkennt man, dass im August 2003 (sogenannter „Jahrhundertsommer“) der Niederschlag weit unter 10 mm lag. Im August 2004 wurde dagegen in der Söhre mit $15 \mathrm{~mm}$ Niederschlag etwas mehr Niederschlag und im Ziegelrodaer Forst etwa die vierfache Menge $(32 \mathrm{~mm})$ ermittelt.

Von Juli bis September 2004 konnten in der Söhre $335 \mathrm{~mm}$ und im Ziegelrodaer Forst 166 mm Niederschlag gemessen werden. Im Jahr 2003 ergab sich in der Söhre in dem gleichen Zeitraum ein Niederschlag von $100 \mathrm{~mm}$ sowie im Ziegelrodaer Forst ein Niederschlag von $81 \mathrm{~mm}$.
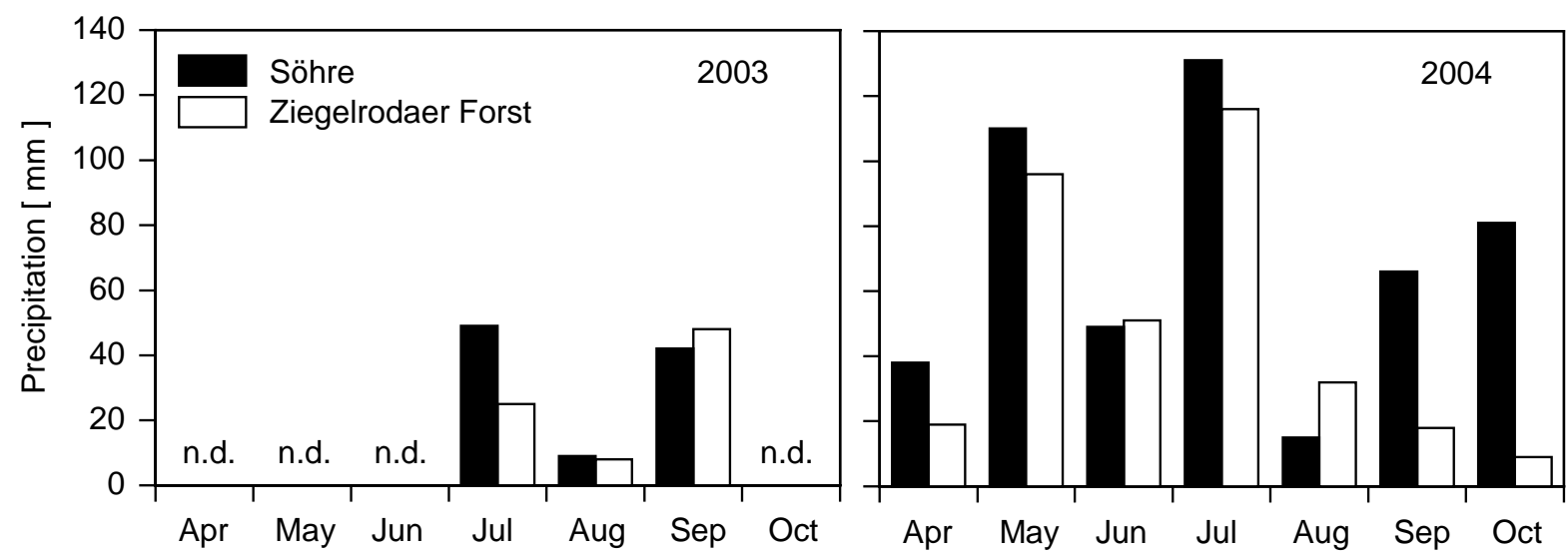

Abb. 2-4. Niederschlagswerte (Kronentraufe) in der Söhre (schwarz) und im Ziegelrodaer Forst (weiß) in den Jahren 2003 und 2004, (n.d. = ,not determined“). 


\subsubsection{Wasserdampfsättigungsdefizit der Luft (VPD), Temperatur und relative Luftfeuchte}

Die Werte des Wasserdampfsättigungsdefizits der Luft (VPD), der Temperatur und der relativen Luftfeuchte zeigen in beiden Untersuchungsjahren deutliche Übereinstimmungen des zeitlichen Verlaufs zwischen den beiden untersuchten Standorten (Abb. 2-5).
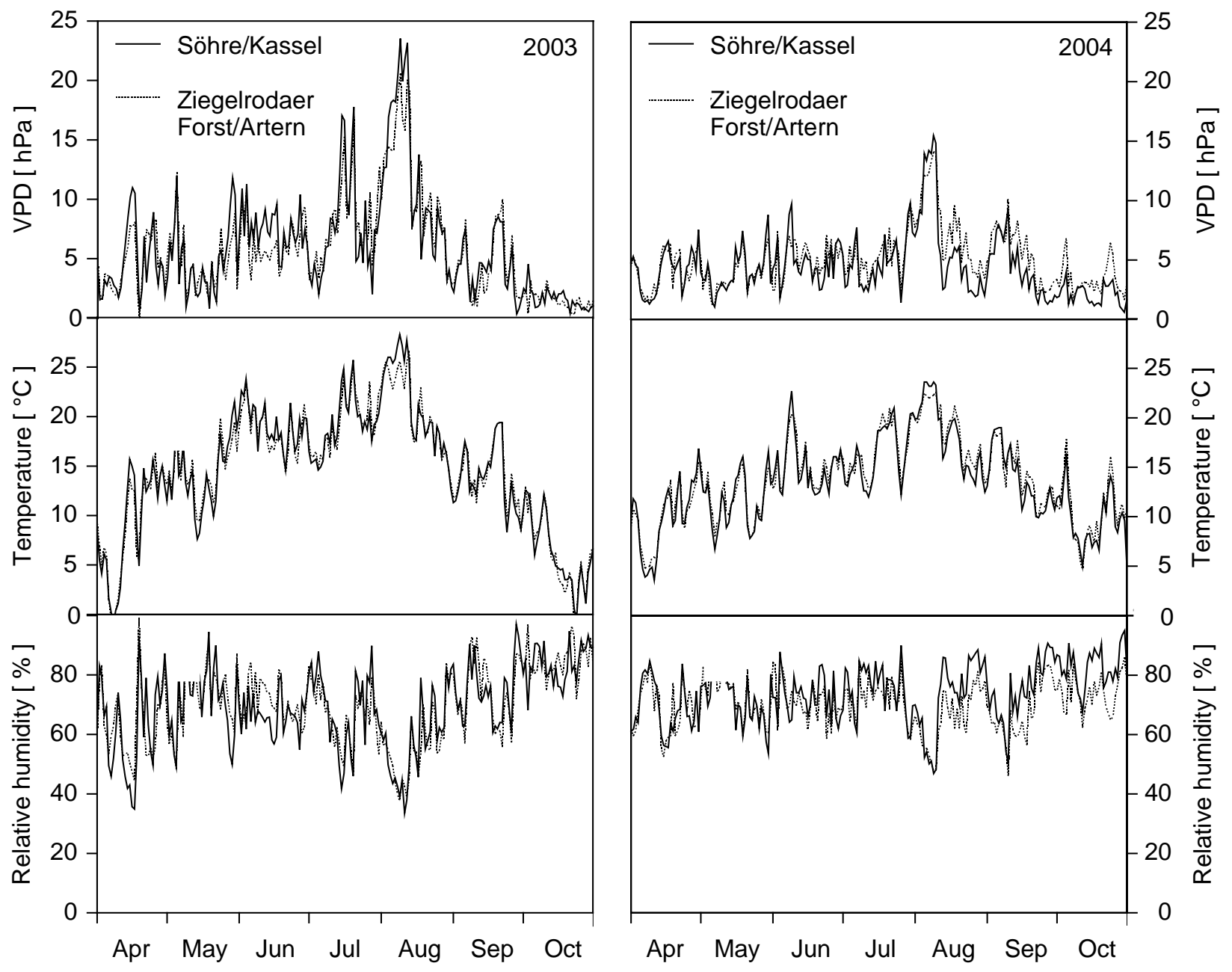

Abb. 2-5. Wasserdampfsättigungsdefizit der Luft (VPD), Lufttemperatur und relative Luftfeuchte (Tagesmittelwerte) in den Untersuchungsbeständen in der Söhre (Klimastation Kassel) und im Ziegelrodaer Forst (Klimastation Artern) in den Vegetationsperioden 2003 und 2004. Werte des Deutschen Wetterdienstes (DWD). 
2003 ging hinsichtlich der Temperatur beim DWD als Rekordsommer ein. Die drei Sommermonate (Juni-August) waren erheblich wärmer als im langjährigen Mittel. Die Mittelwerte der Lufttemperatur im Zeitraum Juli und August lagen an der Klimastation Kassel $\left(20.2^{\circ} \mathrm{C}\right)$ um $3^{\circ} \mathrm{C}$ und im Ziegelrodaer Forst $\left(20.0^{\circ} \mathrm{C}\right)$ um $2.5^{\circ} \mathrm{C}$ über dem langjährigen Mittel. Auch die Jahresmitteltemperatur lag auf beiden Flächen um $1^{\circ} \mathrm{C}$ höher als im langjährigen Mittel.

Die Jahresmitteltemperatur im Jahr 2004 lag auf beiden Flächen höher als im langjährigen Mittel, in der Söhre um $0.5^{\circ} \mathrm{C}$ und im Ziegelrodaer Forst um $1.0^{\circ} \mathrm{C}$. Dabei zeigten jedoch in der Vegetationsperiode sowohl der Bestand in der Söhre als auch der im Ziegelrodaer Forst keine Temperaturunterschiede gegenüber den Werten im langjährigen Mittel. Dies spiegelt sich ebenso für die Sommermonate Juli und August auf beiden Flächen wider.

Die Mittelwerte der relativen Luftfeuchte des Jahres 2003 unterschieden sich zwischen den Untersuchungsflächen über die gesamte Vegetationsperiode nicht (Werte der Klimastation Kassel und Artern jeweils 68\%), in den Sommermonaten Juli und August nur geringfügig (Söhre: 63\% und Ziegelrodaer Forst: 62\%).

Im Jahr 2004 lagen die Mittelwerte der relativen Luftfeuchte im Vegetationszeitraum mit 74\% in der Söhre und mit 70\% im Ziegelrodaer Forst höher als im Jahr 2003. Dies spiegelte sich ebenfalls in den Sommermonaten Juli und August wider (Söhre: 74\% und Ziegelrodaer Forst: 69\%).

Das mittlere Wasserdampfsättigungsdefizit der Luft (VPD) im Jahr 2003 lässt ein erstes deutliches Maximum im Juli (20.07.) erkennen mit Werten von $17.8 \mathrm{hPa}$ in der Söhre und $17.4 \mathrm{hPa}$ im Ziegelrodaer Forst. Zu einem zweiten deutlichen Maximum kam es im August (09.08.) mit Maximalwerten von $23.5 \mathrm{hPa}$ in der Söhre und $20.6 \mathrm{hPa}$ im Ziegelrodaer Forst. Ab Mitte August kam es zu einem deutlichen Abfall des VPD (Abb. 2-5).

Das Jahr 2004 zeichnet sich durch ein insgesamt deutlich geringeres mittleres VPD aus (Jahresmittel in der Söhre 2003: $6.0 \mathrm{hPa}$ und 2004: $4.3 \mathrm{hPa}$ bzw. im Ziegelrodaer Forst: 2003: $5.8 \mathrm{hPa}$ und 2004: $5.0 \mathrm{hPa}$ ). Zu einen starken Anstieg des mittleren VPD kommt es im August (09.08. bzw. 10.08.) mit Maximalwerten von $15.5 \mathrm{hPa}$ in der Söhre und $14.3 \mathrm{hPa}$ im Ziegelrodaer Forst (Abb. 2-5).

Das mittlere VPD der Vegetationsperiode (Mai-September) im Jahr 2003 lag auf beiden Flächen (Söhre $7.2 \mathrm{hPa}$ und Ziegelrodaer Forst $6.9 \mathrm{hPa}$ ) deutlich über den Mittelwerten der Vegetationsperiode von 2004 (Söhre: $4.8 \mathrm{hPa}$ und Ziegelrodaer Forst: $5.5 \mathrm{hPa}$ ). 


\subsubsection{Globalstrahlung}

Deutliche Unterschiede traten zwischen der Globalstrahlung (Werte der Klimastation

Weimar für den Untersuchungsbestand Ziegelrodaer Forst und Söhre) zwischen den Untersuchungsjahren 2003 und 2004 auf (Abb. 2-6).

Außer im Monat September lagen die Monatssummen von April bis September im Jahr 2003 deutlich über denen des Jahres 2004. Die Summen über die gesamte Vegetationsperiode (Mai bis September) von 2003 überstiegen mit $2810 \mathrm{MJ} \mathrm{m}^{-2} \mathrm{~d}^{-1}$ die Werte von 2004 (2390 $\left.\mathrm{MJ} \mathrm{m}^{-2} \mathrm{~d}^{-1}\right)$.
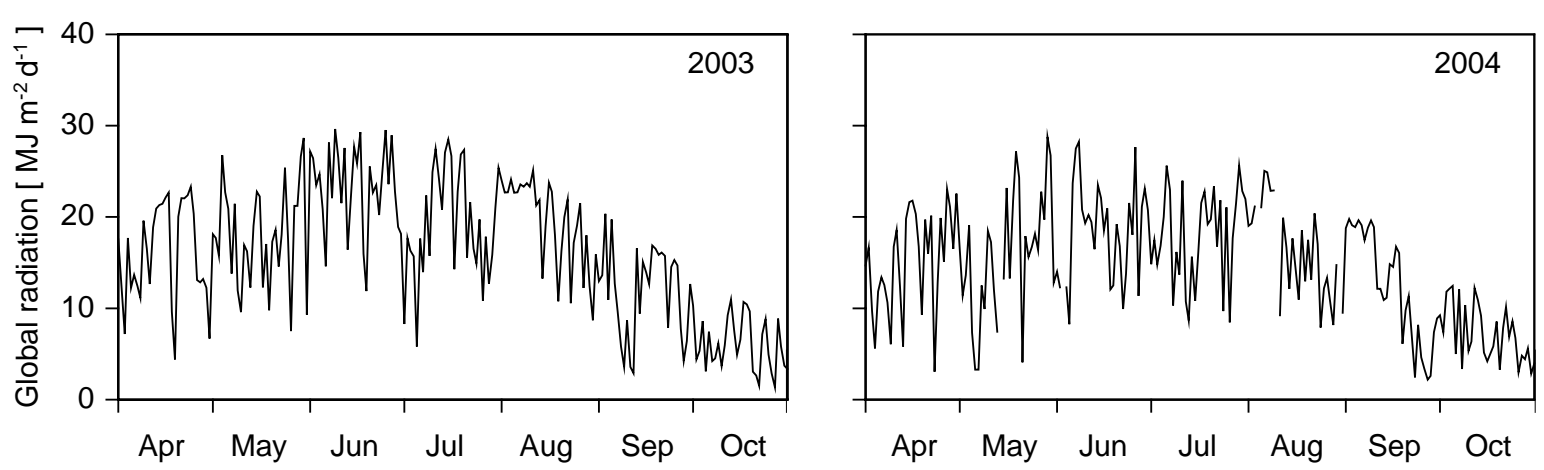

Abb. 2-6. Tagessummen der Globalstrahlung $\left[\mathrm{MJ} \mathrm{m}^{-2} \mathrm{~d}^{-1}\right]$ für die Untersuchungsbestände Ziegelrodaer Forst und Söhre (Klimastation Weimar) in den Jahren 2003 und 2004 im Messzeitraum von April bis November (Werte des Deutschen Wetterdienstes, DWD). 


\section{MATERIAL UND METHODEN}

\subsection{Mikroklimatische Parameter}

\subsubsection{Bestandesniederschlag (Kronentraufe) der Untersuchungsflächen}

Zur Bestimmung des Niederschlages im Bestand (Kronentraufe) wurden pro Plot je fünf Regensammler (Durchmesser: $10 \mathrm{~cm}$ ) zufällig auf einer Fläche von 50 x $50 \mathrm{~m}$ verteilt und 4-7 mal monatlich geleert. Zur Minimierung von Verlusten durch Verdunstung wurde das Reservoir der Sammler mit einem Kunststoffball geschützt.

\subsubsection{Freilandniederschlag, Lufttemperatur, Luftfeuchte, VPD}

In den Messjahren 2003 und 2004 wurden tägliche Niederschlagssummen sowie die Mittelwerte der Lufttemperatur und Luftfeuchte von den jeweils nächstgelegenen Klimastationen des deutschen Wetterdienstes (Kassel und Artern) übernommen. Auch die langjährigen Mittel des Niederschlages, der Lufttemperatur und der Luftfeuchte stammen von den Klimastationen (Kassel und Artern).

Aus den Tagesmittelwerten von Lufttemperatur und Luftfeuchte wurde das Tagesmittel des Wasserdampfsättigungsdefizits der Luft (VPD) nach der Magnusformel berechnet:

$V P D=e_{s}-e_{a}$

mit $e_{\mathrm{s}}=610.8 \cdot 10^{(7.5 \cdot T) /(237.3+T)} \quad$ und $\quad e_{a}=\frac{e_{s} \cdot r F}{100}$

wobei gilt:

$\begin{array}{lll}V P D & = & \text { Wasserdampf-Sättigungsdefizit der Luft }[\mathrm{Pa}] \\ e_{s} & = & \text { Sättigungsdampfdruck bei gegebener Temperatur }[\mathrm{Pa}] \\ e_{a} & = & \text { aktueller Dampfdruck }[\mathrm{Pa}] \\ T & = & \text { Temperatur }\left[{ }^{\circ} \mathrm{C}\right] \\ r F & = & \text { relative Luftfeuchte }[\%]\end{array}$




\subsubsection{Globalstrahlung}

Die nächstgelegene Klimastation mit verfügbaren Globalstrahlungsdaten liegt etwa $40 \mathrm{~km}$ vom Ziegelrodaer Forst entfernt und etwas mehr als $100 \mathrm{~km}$ vom Standort Söhre. Daher konnten diese Werte für die Auswertung nur unter Vorbehalt verwendet werden.

\subsection{Bestimmung der Bodenwasserverfügbarkeit}

Als wichtige Kenngröße zur Bestimmung der Bodenwasserverfügbarkeit wurden der volumetrische Bodenwassergehalt und das Bodenmatrixpotenzial ermittelt.

Auf den Untersuchungsflächen in der Söhre und im Ziegelrodaer Forst erfolgte in den Jahren 2003 und 2004 eine kontinuierliche Messung des volumetrischen Bodenwassergehalts in drei unterschiedlichen Bodentiefen $(5 \mathrm{~cm}, 20 \mathrm{~cm}, 30 \mathrm{~cm}) \mathrm{mit}$ Hilfe von je 2 TDR-Sonden mit $10 \mathrm{~cm}$ langen Messstäben (Modell P2Z, betrieben über einen Trime-MUX6 Multiplexer, Fa. Imko, Ettlingen). Die TDR-Sonden wurden an einer Bodenprofilwand installiert (Abb. 3-1).

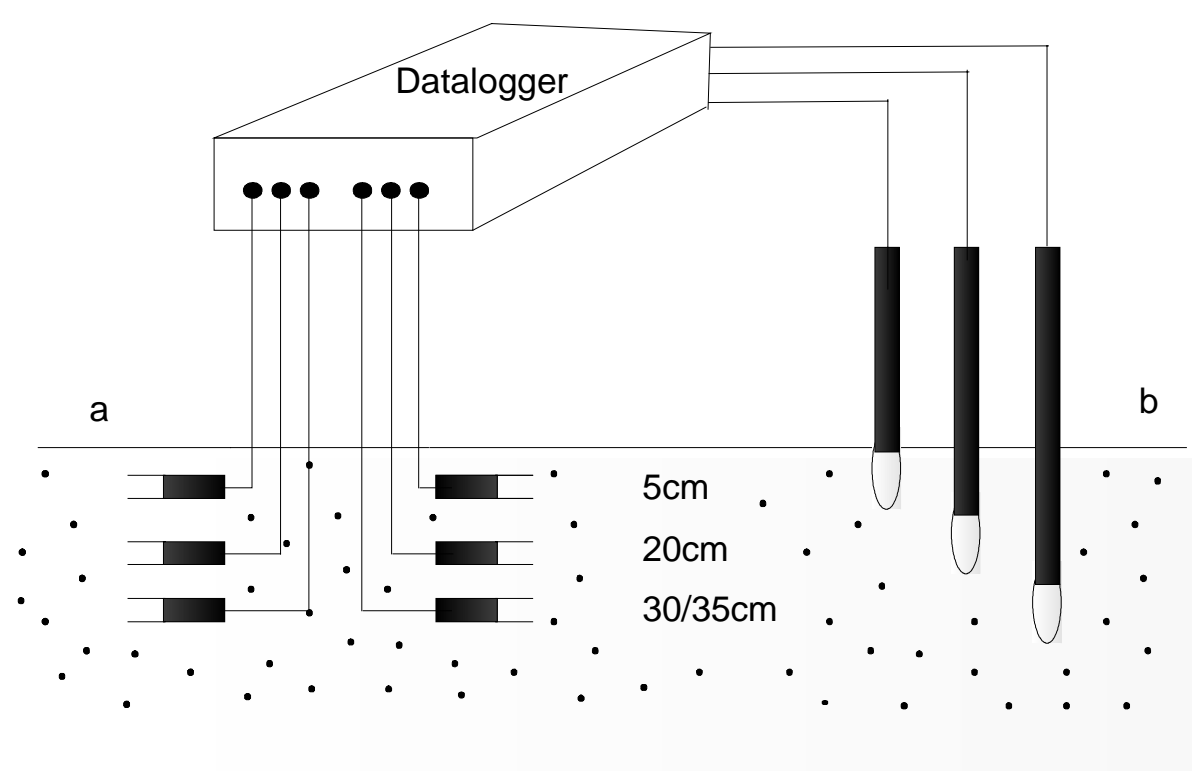

Abb. 3-1. Schematische Darstellung der Messeinrichtung zur Bestimmung der Bodenwasserverfügbarkeit an den zwei Standorten. a) TDR-Messungen in $5 \mathrm{~cm}, 20 \mathrm{~cm}$ und $30 \mathrm{~cm}$ Bodentiefe. Die Sonden waren von April 2003 bis November 2004 durchgehend installiert. b) Tensiometer-Messungen in drei Bodentiefen $(5 \mathrm{~cm}, 20 \mathrm{~cm}$ und $35 \mathrm{~cm}$ ). 
Die TDR-Sonden waren mit einem Campbell-Datalogger (CR-10X, Campbell Scientific Inc., Logan, Utha, USA) verbunden, der die Messwerte automatisch zweimal täglich (12.00 Uhr und 24.00 Uhr) abspeicherte.

Das Bodenmatrixpotenzial wurde parallel zum volumetrischen Bodenwassergehalt in drei Bodentiefen $(5 \mathrm{~cm}, 20 \mathrm{~cm}, 35 \mathrm{~cm})$ mit 2 bzw. 3 selbstgefertigten DruckaufnehmerTensiometern (Keramikmesskopf: $l=5 \mathrm{~cm}, d=2 \mathrm{~cm}$ ) bestimmt. Die Aufzeichnung der Messwerte erfolgte alle 15 min durch einen Campbell-Datalogger.

\subsection{Xylemsaftflussmessung}

\subsubsection{Xylemsaftflussmessung mit der heat balance-Methode}

Der Saftfluss im pflanzlichen Leitgewebe (Xylem) kann mit Hilfe der „,heat balance Methode“ direkt bestimmt werden (CERMAK et al. 1973) und berechnet sich nach folgender Formel:

$$
F=\frac{Q}{c\left(T_{s o}-T_{s i}\right)}
$$

wobei gilt:

$$
\begin{aligned}
F= & \text { Xylemsaftflussrate }\left[\mathrm{kg} \mathrm{s}^{-1}\right] \\
Q \quad= & \text { zugeführte Wärmemenge }[\mathrm{W}] \\
c \quad= & \text { Wärmekapazität des Wassers }\left[4187 \mathrm{~J} \mathrm{~kg}^{-1} \mathrm{~K}^{-1}\right] \\
T_{s o}-T_{s i}= & \text { Temperaturdifferenz des Saftflusses zwischen dem unbeheizten und } \\
& \text { dem beheizten Xylem }
\end{aligned}
$$

Für die Berechnung der „heat balance“ (Wärmebilanz) wird einem Teil des Stammes, einer Wurzel oder eines Astes eine konstante, bekannte Energiemenge in Form von Wärme zugeführt. Somit wird der Xylemsaft konstant erwärmt. Je mehr Wasser durch das Gewebe strömt, je größer demnach der Saftfluss ist, um so mehr Wärme wird dem beheizten Gewebe entzogen. Die so entstandene Temperaturdifferenz wird mit Hilfe von Thermoelementen vor und hinter dem beheizten Abschnitt erfasst. 
Für die Berechnung von kleinen Xylemsaftflüssen an Wurzeln mit geringen Durchmessern ist es nötig, auch die radialen und axialen Wärmeströme mit zu erfassen. Somit ergibt sich die Gesamtwärmebilanz für das beheizte Wurzelsegment:

$Q=Q_{f}+Q_{r}+Q_{v}+Q_{s}$

wobei gilt:

$Q=$ gesamte, zugeführte Wärmemenge [ $\mathrm{W}$ ]

$Q_{f} \quad=$ mit dem Xylemsaftfluss abgeführte Wärmemenge [ W ]

$Q_{r} \quad=\quad$ in radialer Richtung abgeführte Wärmemenge [ W ]

$Q_{v} \quad=$ in axialer Richtung abgeführte Wärmemenge [ W ]

$Q_{s} \quad=$ im Gewebe gespeicherte Wärmemenge [ W ]

$Q_{s}$ kann bei geringem Durchmesser vernachlässigt werden, da sie weniger als 3\% der Gesamtwärmebilanz ausmacht (SENOCK \& HAM 1993). Aus den Gleichungen (3.2) und (3.3) erhält man folgende Gleichung für den Xylemsaftfluss:

$$
F=\frac{Q-Q_{r}-Q_{v}}{c\left(T_{s o}-T_{s i}\right)} \quad F=\frac{Q_{f}}{c\left(T_{s o}-T_{s i}\right)}
$$

wobei gilt:

$$
\begin{aligned}
F= & \text { Xylemsaftflussrate }\left[\mathrm{kg} \mathrm{s}^{-1}\right] \\
c= & \text { Wärmekapazität des Wassers }\left[4187 \mathrm{~J} \mathrm{~kg}^{-1} \mathrm{~K}^{-1}\right] \\
T_{s o}-T_{s i}= & \text { Temperaturdifferenz zwischen dem unbeheizten und dem beheizten } \\
& \text { Xylem }
\end{aligned}
$$

Um den axialen Wärmeverlust $Q_{v}$ zu ermitteln, müssen der Abstand der Thermoelemente vom Ort der Heizung $(0.003 \mathrm{~m})$ und die Wärmeleitfähigkeit des Pflanzengewebes (Holz) bekannt sein. 
Für die Bestimmung der Wärmeleitfähigkeit von verholztem Gewebe wurde die Summe der Leitfähigkeiten der einzelnen Gewebekomponenten gebildet. SAKURATANI (1984) und STEINBERG et al. (1990) geben hierfür einen Wert von ca. $0.42 \mathrm{~W} \mathrm{~m}^{-1} \mathrm{~K}^{-1}$ an.

$Q_{v}=A \cdot K_{r} \cdot \frac{\triangle T}{\triangle x}$

wobei gilt:

$\begin{array}{lll}A & = & \text { Querschnittsfläche des Wurzelsegments }\left[\mathrm{m}^{2}\right] \\ K_{r} & = & \text { Wärmeleitfähigkeit des Gewebes }\left[\mathrm{W} \mathrm{m}^{-1} \mathrm{~K}^{-1}\right] \\ \Delta T & = & \text { Temperaturdifferenz [ K ] } \\ \Delta x & = & \text { Abstand der Thermoelemente vom Ort der Heizung [ } \mathrm{m} \text { ] }\end{array}$

Der radiale Wärmeverlust $Q_{r}$ ergibt sich aus der Wärmeleitfähigkeitskonstante $\mathrm{K}_{\mathrm{g}}$ und der Thermosäulenspannung E:

$Q_{r}=K_{g} \cdot E$

wobei gilt:

$K_{g} \quad=\quad$ Wärmeleitfähigkeitskonstante des Sensors [ $\mathrm{W} \mu \mathrm{V}^{-1}$ ]

$E \quad=\quad$ Thermosäulenspannung $[\mu \mathrm{V}]$

Die Wärmeleitfähigkeitskonstante $\mathrm{K}_{\mathrm{g}}$ wird ermittelt, wenn der Xylemsaftfluss gleich Null ist. Dann ist $Q_{f}$ gleich Null und die Gleichung (3.3) wird mit der Gleichung (3.6) kombiniert zu:

$K_{g}=\frac{Q-Q_{v}}{E}$

Obwohl $K_{g}$ eine Materialkonstante ist, kann sie sich vor allem bei längerfristigen Messungen ändern (SAKURATANI 1984). Sie wurde deshalb täglich bestimmt. Zur Vermeidung von Fehlern bei der Bestimmung der Konstanten, z.B. bei trockenem und 
windigem Wetter, wenn die Transpirationsleistung hoch ist, entwickelte CONERS (2001) ein Computerprogramm, welches diese Werte korrigiert.

CONERS \& LEUSCHNER (2002) führten zur Kalibrierung dieser Methode Untersuchungen im Labor und Freiland durch. Dabei konnten sie bei Saftflussraten $>2 \mathrm{~g} \mathrm{~h}^{-1}$ eine sehr gute Übereinstimmung des so gemessenen Saftflusses und einer gravimetrischen Bestimmung feststellen. Für kleinere Saftflussmengen $<2 \mathrm{~g} \mathrm{~h}^{-1}$ funktioniert diese Methode allerdings nicht, so dass CONERS (2001) eine modifizierte Berechnungsmethode für diese kleinen Flüsse entwickelte:

$F^{*}=\beta \cdot\left(T_{s o}-T_{s i}\right)$

wobei gilt:

$F^{*} \quad=\quad$ alternativ berechnete Xylemsaftflussrate $\left[\mathrm{g} \mathrm{h}^{-1}\right]$

$\beta \quad=\quad$ empirischer Faktor $\left[0.897 \mathrm{~g} \mathrm{~h}^{-1} \mathrm{~K}^{-1}\right]$

Alle Saftflussberechnungen wurden mit dem Computerprogramm Msapca10.9 (CONERS 2001) durchgeführt.

\subsubsection{Auswahl der Wurzeln und Installation der Sensoren}

An den Wurzeln der vorliegenden Untersuchung wurde die Messmethode nach SENOCK \& HAM $(1993,1995)$ angewandt. Verfeinerungen dieser Methode wurden von CONERS (2001), CONERS \& LEUSCHNER (2002) und KORN $(1999,2004)$ vorgenommen.

Die Sensoren wurden „im Eigenbau“ gefertigt. Sie bestehen aus 2 mm starkem KorkNeopren-Mischgewebe (3.5 x $5 \mathrm{~cm}$ ), auf das ein Kapton-Heizfilm (Fa. Heater Design Inc., Bloomington, CA, USA) aufgeklebt wurde. Mit Hilfe von Gleichstrom wird so eine konstante Heizkraft von $0.07 \mathrm{~W}$ gewährleistet. Für die Bestimmung der Temperaturdifferenz wurden ober- und unterhalb des Heizfilmes (Abstand jeweils $3 \mathrm{~mm}$ bzw. $6 \mathrm{~mm}$ ) zwei Thermoelementpaare angebracht. Für die Messung der Temperaturdifferenz zwischen der Innen- und Außenseite der Isolation wurde in Höhe des Heizfilmes eine Thermosäule befestigt (Abb. 3-2).

Mit einem Druckluftstrom konnten $10 \mathrm{~cm}$ lange unverzweigte Wurzelsegmente ohne Beschädigung freigelegt werden. Daran wurden die Sensoren befestigt.

Nach Anbringen des Sensors an die Wurzel im Gelände wurde eine Isolation (Polyurethan-Schaum, $5 \mathrm{~mm}$ dick) um den gesamten Sensor angebracht und mit einer 
Klammer befestigt. Die Bodenlöcher wurden mit Holzplatten und Aluminiumfolie zum Schutz vor direkter Sonneneinstrahlung und Regengüssen abgedeckt (Abb. 3-3).

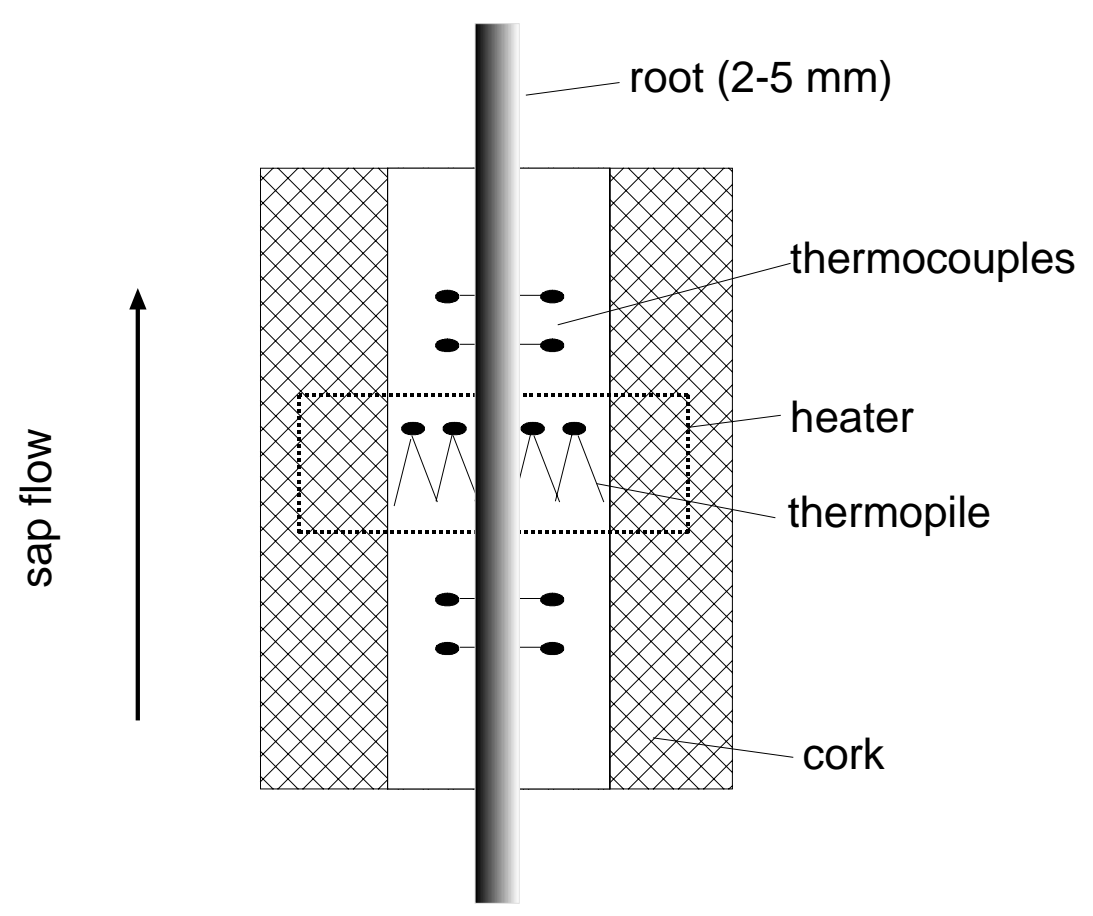

Abb. 3-2. Schematische Darstellung des Miniatur-Saftflusssensors nach SENOCK \& $\operatorname{HAM}(1993)$.

Von jeder Baumart wurden 10 Wurzeln pro Fläche (Durchmesser 2-5 mm) mit einem Saftflusssensor versehen. Die Messungen erfolgten in den Vegetationsperioden der Jahre 2003 und 2004. Im Jahr 2003 wurden die Saftflusssensoren nach der Hälfte der Vegetationsperiode an jeweils 10 neuen Wurzeln angebracht. Im Jahr 2004 wurde die Vegetationsperiode in 3 Messperioden eingeteilt.

Die Messung erfolgte im Abstand von 15 Sekunden, wobei die Daten alle 15 min als Mittelwerte gespeichert wurden. Für die Datenspeicherung wurden Campbell CR10xDatalogger (Fa. Campbell Scientific Inc., Leicestershire, UK) verwendet. 
Die Stromversorgung für die Saftflusssensoren erfolgte im Ziegelrodaer Forst mit Batterien, die regelmäßig gewechselt wurden, in der Söhre mit einer Solaranlage. Leider kam es bei der Solaranlage in den Jahren 2003 und 2004 immer wieder zu technischen Ausfällen, die mit Datenverlust verbunden waren.

\subsubsection{Kalibrierung der Saftflusssensoren im Gelände}

Die Kalibrierung der Sensoren im Gelände erfolgte im August 2005 auf der Untersuchungsfläche in der Söhre.

Dafür wurden vier Buchenfeinwurzeln (Durchmesser 2-5 $\mathrm{mm}$ ) vor dem Sensor unter Wasser abgeschnitten, um Embolien zu vermeiden. Danach erfolgte die quantitative Bestimmung der Wasseraufnahme aus einem $30 \mathrm{ml}$-Wasservorratsgefäß in anfangs 5-minütigen, später 15-minütigen Abständen. Diese Messung wurde für 2-3 h durchgeführt. Parallel dazu erfolgte die indirekte Bestimmung der Wasseraufnahme durch den Sensor. Diese Daten wurden im gleichen Zeitintervall vom Datalogger aufgezeichnet.

\subsubsection{Ernte und Verarbeitung der Messwurzeln}

Das Freilegen und Ernten aller Messwurzeln (Abb. 3-3) wurde mittels Druckluft durchgeführt. Es wurde darauf geachtet, dass keine Feinwurzeln von der Messwurzel abgerissen wurden. Die Wurzeln wurden vollständig ausgegraben. Wurzeln aus der organischen Auflage und Wurzeln aus dem Mineralboden wurden getrennt erfasst. Im Labor wurden die Wurzeln in Wasserbecken sorgfältig vom noch anhaftenden Boden gesäubert und von verfilzten Fremdwurzeln getrennt. 


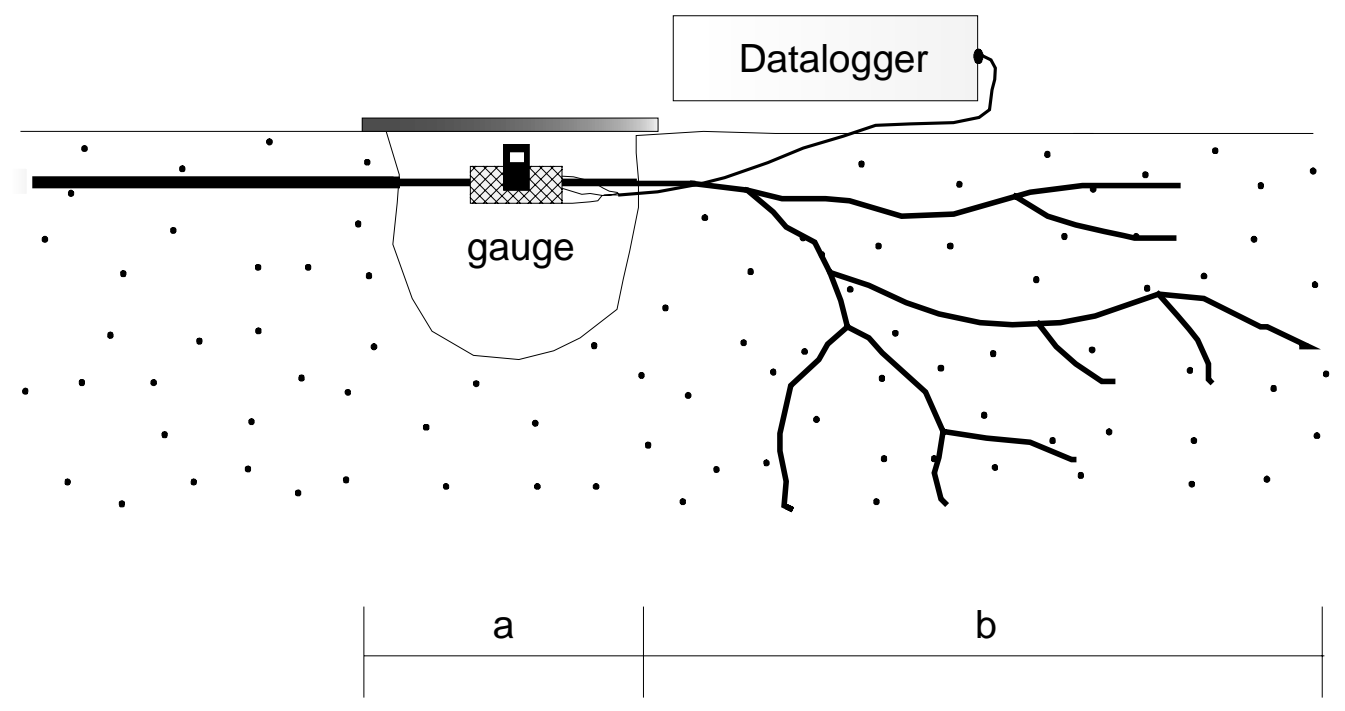

Abb. 3-3. Schematische Darstellung der Wurzelsaftflussmessungen nach der Methode von CONERS (2001). Im Abschnitt a) ist der Messsensor an der Wurzel zu sehen, dessen Daten mit einem Datenlogger aufgezeichnet wurden. Abschnitt b) zeigt die wasseraufnehmende Wurzeloberfläche, die nach der Messung ausgegraben und deren Oberfläche anschließend mit dem Programm WinRhizo 5.5 bestimmt wurde.

\section{Lebend-Tot-Bestimmung}

Nach der Säuberung wurden unter dem Binokular tote von lebenden Wurzelabschnitten getrennt. Diese Untersuchung basierte auf der Methode von HeRTEL (1999) und LEUSCHNER et al. (2001), wobei Merkmale wie Elastizität und Farbe der Wurzeln herangezogen wurden. Tote Wurzelabschnitte wurden verworfen, da diese nicht an der Wasseraufnahme beteiligt sind.

Bis zur Weiterverarbeitung der Wurzeln wurden diese bis zu maximal sieben Tage gekühlt aufbewahrt.

\section{Bestimmung der Wurzeloberfläche}

Die Wurzeln wurden nass eingescannt und anhand der digitalen Bilder mit dem Programm WinRhizo 5.5 (Fa. Régent, Quebec, Canada) deren Oberfläche bestimmt. Dabei wurden die Wurzeln in folgende Fraktionen nach BöHM (1979) aufgeteilt: Feinstwurzeln $(<1 \mathrm{~mm})$, Feinwurzeln $(1-2 \mathrm{~mm})$ und Schwachwurzeln $(2-5 \mathrm{~mm})$. 


\section{Bestimmung des Trockengewichtes der Wurzeln}

Nach der Oberflächenbestimmung wurden die Wurzeln bei $105^{\circ} \mathrm{C}$ für $48 \mathrm{~h}$ im Trockenschrank getrocknet und das Trockengewicht bestimmt. Zuvor wurden die Wurzeln per Hand und mit Hilfe einer Schieblehre in verschiedene Größenklassen nach BÖHM (1979) eingeteilt.

Anhand der ermittelten Trockengewichte wurde die spezifische Oberfläche der Wurzeln $\left(\mathrm{cm}^{2} \mathrm{~g} \mathrm{TM}^{-1}\right)$ berechnet.

\subsection{Wurzelwasserpotenzialmessung nach SCHOLANDER}

Die Bestimmung des Wasserpotenzials in den Wurzeln erfolgte mit der DruckkammerMethode nach ScHOLANDER et al. (1965). Von jeder Baumart (Buche, Birke, Kiefer) wurden je fünf feine Wurzelstränge (Maximallänge $8 \mathrm{~cm}$, Wurzeldurchmesser 1-2 mm) vorsichtig freigelegt, um keine Wurzelverzweigungen zu verletzen. Direkt nach der Freilegung wurde der Wurzelstrang abgeschnitten und mit Hilfe einer Silikondichtung in die Druckkammer (Fa. PMS-Instruments, Corvallis, Oregon, USA) eingespannt, so dass die Schnittstelle nach außen ragte und mit einer Lupe beobachtet werden konnte. Der Druck in der Kammer wurde durch Einleiten von Druckluft langsam und gleichmäßig um 0.2 MPa pro Minute erhöht, bis Xylemsaft an der Schnittstelle austrat.

Das angenommene Wasserpotenzial-Minimum wurde stets zur Mittagszeit (zwischen 12.00 und 14.00 Uhr), bei höchster Transpirationsbeanspruchung ermittelt. Im Jahr 2003 wurde es auf beiden Flächen an jeweils drei Terminen, im Jahr 2004 an sieben Terminen im Ziegelrodaer Forst und an acht Terminen in der Söhre bestimmt.

\subsection{Morphologisch-anatomische Untersuchung der Wurzeln}

\subsubsection{Bestimmung der Peridermschichtenanzahl}

Für die anatomische Untersuchung wurden für alle drei Baumarten Querschnitte von Wurzeln der Durchmesserklasse $<1 \mathrm{~mm}$ angefertigt. Diese Querschnitte wurden mit Sudan-III Lösung gefärbt. Nach dem Erhitzen bei $70^{\circ} \mathrm{C}$ auf einer Heizplatte färben sich die lipophilen Zellwandbestandteile mit Sudan-III intensiv rot. Die ebenfalls lipophilen Suberinschichten sind nun deutlich zu erkennen. Im Lichtmikroskop konnte so die 
Anzahl der Peridermschichten bei 1000-facher Vergrößerung bestimmt werden. Diese konnte später in Bezug zum Suberingehalt gesetzt werden.

Die Altersbestimmung der Wurzelabschnitte $(<1 \mathrm{~mm})$ erfolgte über die Zählung der Jahresringe (Färbung mit $0.1 \%$ Toluolblau in $0.1 \%$ Borax).

\subsubsection{Suberinbestimmung des Periderms}

Für die chemische Untersuchung mussten die Messwurzeln vorbereitet werden. In $4 \mathrm{ml}$ Rollrandglässchen mit Silikondeckel wurden die abgewogenen Proben (0.5-1.0 g) mit einem Chloroform/Methanol-Gemisch (1:1) in einer Schüttelanlage gleichmäßig 15 Tage extrahiert. Das Chloroform/Methanol-Gemisch wurde alle drei Tage gewechselt. Nach der Extraktion wurden die Proben auf Silikagel getrocknet und im Dunkeln aufbewahrt.

Von jeder Baumart und jedem Standort wurden für 2003 und 2004 je drei Wurzelproben der Durchmesserklasse $<1 \mathrm{~mm}$ untersucht. Von diesem Wurzelmaterial wurden je $10 \mathrm{mg}$ mit einer Feinwaage (Fa. Sartorius MC 21S) in sogenannten Reactivials (1 ml) abgewogen.

Dem Wurzelmaterial wurde nun $1 \mathrm{ml}$ 10\% BF3/Methanol (Borontrifluoride $[10 \%(\sim 1.3$ $\mathrm{M})$ ] in Methanol) zugegeben und mit einem teflonbeschichteten Schraubverschluss fest verschlossen. Dieser Ansatz wurde bei $70^{\circ} \mathrm{C}$ für $16 \mathrm{~h}$ erhitzt.

Die so gewonnene Lösung wurde anschließend auf $2 \mathrm{ml}$ gesättigte Natriumhydrogencarbonatlösung gegeben. In jede Probe wurden $100 \mu \mathrm{l}$ vom internen Standard (Dotriaconton) zugegeben und das ganze viermal mit $1 \mathrm{ml} \mathrm{CHCl}_{3}$ extrahiert. Die vereinigten organischen Phasen wurden mit zweimal $2 \mathrm{ml}$ Wasser gewaschen und anschließend über wasserfreiem $\mathrm{Na}_{2} \mathrm{SO}_{4}$ getrocknet. Die so gewonnene Lösung wurde mit Hilfe eines Stickstoffstroms bis auf $50 \mu \mathrm{l}$ eingeengt und bei $4^{\circ} \mathrm{C}$ bis zur Weiterverarbeitung höchstens vier Tage gelagert.

\section{Depolymerisationsreaktion}

Das Suberin-Polymer besteht aus miteinander veresterten Alkoholen, langkettigen aliphatischen gesättigten und ungesättigten $\omega$-Hydroxysäuren, Disäuren, 2-Hydroxysäuren, gesättigten und ungesättigten Carbonsäuren sowie einem aromatischen Anteil aus Zimtderivaten (Ferulasäure, Kaffeesäure).

Um das Suberin zu depolymerisieren, muss eine Umesterungsreaktion erfolgen. Bei dieser Reaktion werden die Esterbindungen des Suberinpolymers aufgebrochen. Danach kommt es zu einer neuen Esterbindung mit dem Lösungsmittel Methanol (Abb. 3-4). 
Die so gewonnenen Methylester lassen sich anschließend mittels Gaschromatographie analysieren. Als Katalysator für diese Reaktion dient das Bortrifluorid $\left(\mathrm{BF}_{3}\right)$, eine starke Lewis-Säure.

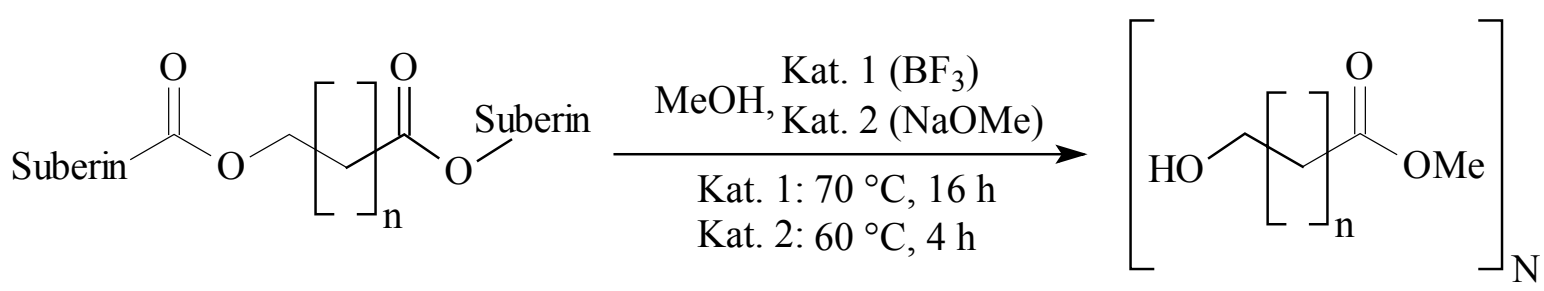

Abb. 3-4. Methanolumesterung eines $\omega-\mathrm{OH}-\mathrm{Säureesters} \mathrm{aus} \mathrm{dem} \mathrm{Polymer.} \mathrm{Als}$ Katalysator wurde Bortrifluorid eingesetzt (SCHREIBER et al. 1994).

\section{Gaschromatographie}

Um die Reaktivität der Abbauprodukte aus der Umesterungsreaktion mit der Säulenbeschichtung zu verringern, wurden den Proben $20 \mu 1$ BSTFA (N,OBistrimethylsilyltrifluoracetamid) zugegeben. Dies bewirkt eine Umesterung von Hydroxyl- und Carboxylgruppen in stabile, leicht flüchtige Derivate (Trimethylsilylether bzw. -ester). Als Katalysator für diese Reaktion wird eine organische Base, das Pyridin $(20 \mu \mathrm{l})$, zugegeben. Dieses Gemisch wurde 40 min auf $70^{\circ} \mathrm{C}$ erhitzt.

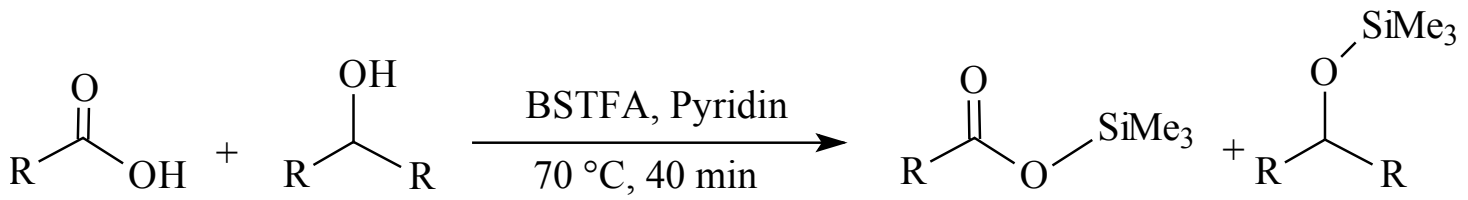

Danach wurde $1 \mu 1$ der vorbereiteten Probe mittels einer Kapillarspritze (on columnInjektion) direkt auf die Kapillarsäule (DB-1, Fused-Silica, Länge $30 \mathrm{~m}$, Innendurchmesser $0.32 \mathrm{~mm}$, Filmschichtdicke $0.10 \mu \mathrm{m}$ aus $100 \%$ Polymetylsiloxan, J\&W Scientific, Folsom, CA, USA) eines druck- und temperaturgesteuerten Gaschromatographen (Fa. Hewlett-Packard 5890 Series II, CA, USA) gegeben, um die Proben so gaschromatoraphisch zu trennen.

Die Trennung der verschiedenen Substanzen erfolgt dabei nach Unterschieden ihrer Polarität und ihrer Kettenlänge. Die Bestimmung ihrer Quantität, der Substanzmenge, erfolgt mit Hilfe eines Flammenionisationsdektors (FID); als Trägerstoff dient Wasserstoff.

Die vom Detektor abgegebenen Signale in $\mathrm{mA}$ wurden digitalisiert und von einem Computer aufgezeichnet. Mit Hilfe eines Auswertungsprogramms (Fa. GC/FID: HP- 
Chemstation, GC/MS: Version A.06.03 [273]) konnten die Flächen der Einzelsubstanzsignale mittels Integrationsalgorithmen berechnet werden und so die jeweilige Stoffmenge in Relation zur Fläche des zugegebenen internen Standards (Menge bekannt) mit folgender Gleichung ermittelt werden:

$$
\frac{\mathrm{A}_{\mathrm{st}}}{\mathrm{A}_{\mathrm{su}}} \cdot \frac{\mathrm{m}_{\mathrm{ST}}}{\mathrm{mA}}=\mathrm{m}
$$

wobei gilt:

$$
\begin{array}{lll}
\mathrm{A}_{\mathrm{ST}} & = & \text { Fläche des Standard-Signales im Gaschromatogramm }\left[\mathrm{m}^{2}\right] \\
\mathrm{A}_{\mathrm{SU}} & = & \text { Fläche des Substanz-Signales im Gaschromatogramm }\left[\mathrm{m}^{2}\right] \\
\mathrm{m}_{\mathrm{ST}} & = & \text { zugegebene Stoffmenge/Masse der Standardsubstanz }[\mathrm{nmol}] ;[\mathrm{g}] \\
\mathrm{m} & & \text { Stoffmenge/Masse Substanz pro Bezugsgröße }\left[\mathrm{nmol} \mathrm{m}{ }^{-2}\right] ;\left[\mathrm{nmol} \mathrm{g}^{-1}\right] ; \\
& & {\left[\mu \mathrm{g} \mathrm{g}^{-1}\right] ;\left[\mu \mathrm{g} \mathrm{m}^{-2}\right]} \\
\mathrm{mA} & & \text { Einwaage bzw. berechnete Oberfläche des Zellwandmaterials }[\mathrm{g}] ;\left[\mathrm{m}^{-2}\right]
\end{array}
$$

Die Druck- und Temperaturprogramme der GC/FID-Analysen, und der GC/MSAnalysen wurden nach HARTMANN (2002) eingestellt.

Die Säulenqualität wurde vor jeden Ansatz mit Hilfe der Signalstärke eines Triacontansäuresignals mit einem Alkan (Tetracosan = Stammlösung) verglichen.

\section{Auswertung des Gaschromatogrammes}

Die verschiedenen Suberinmonomere werden, während sie die Säule passieren, räumlich voneinander getrennt. Dadurch treten sie in einer charakteristischen Zeitabfolge am Säulenende aus und man erhält ein typisches Chromatogramm mit unterschiedlichen Zeitpeaks. Die Beispiel-Chromatogramme in Abb. 3-5 stammen von Buchen-, Birken- und Kiefernwurzeln. 

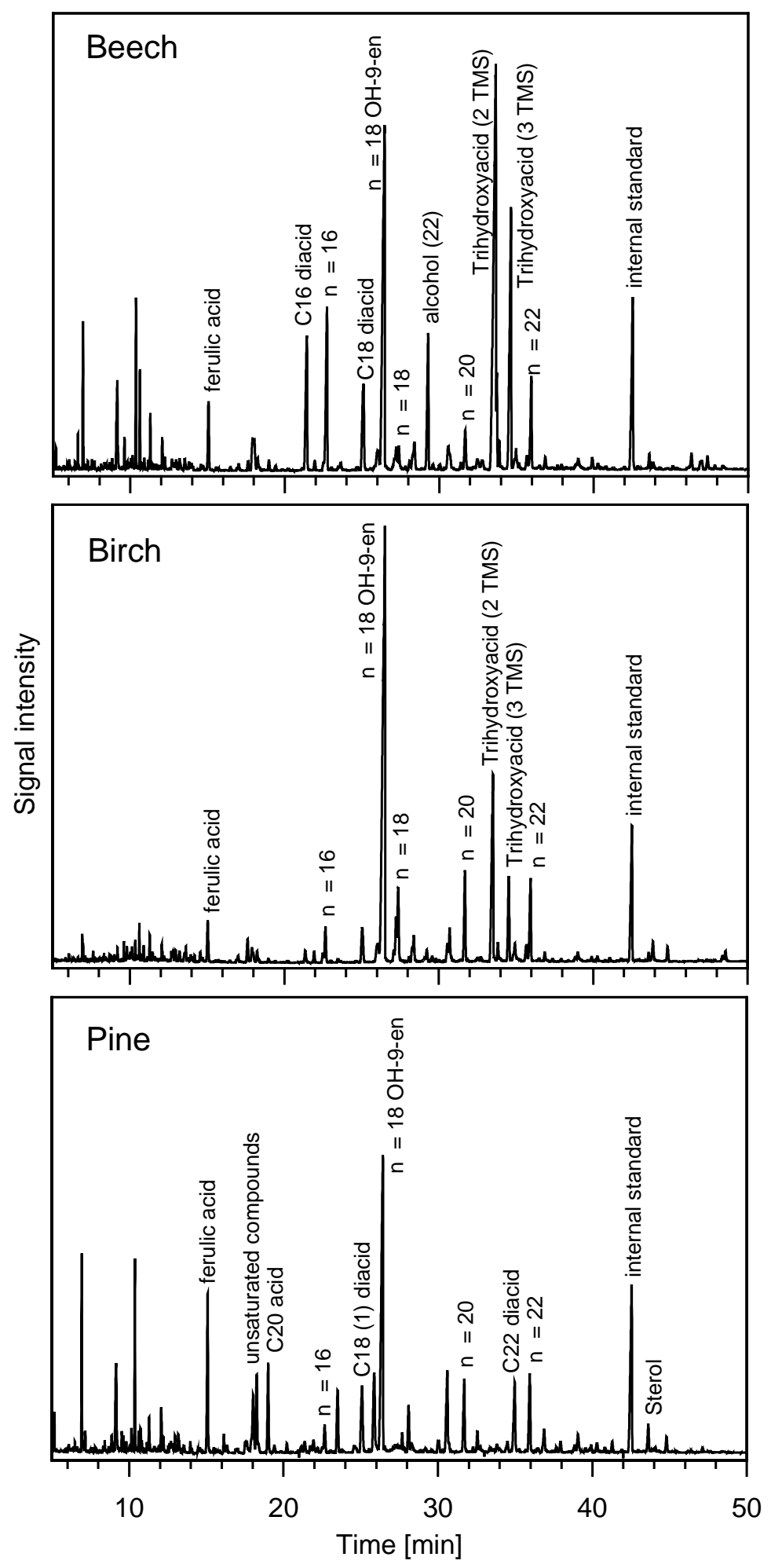

Abb. 3-5. Beispiel-Chromatogramme der freigesetzten Suberinmonomere einer $\mathrm{BF}_{3}$ $\mathrm{MeOH}$ Umesterungsreaktion von Buchen-, Birken-, und Kiefernwurzeln mit einem Durchmesser $<1 \mathrm{~mm}$. n steht jeweils für die Kettenlängen der $\omega$-Hydroxysäuren. Als interner Standard diente ein $\mathrm{C}_{32} \mathrm{n}$-Alkan (Dotriacontan). 
Mit Hilfe der Gaschromatogramme erfolgt die quantitative Beurteilung der Peaks. Vom Standard (zugegebene Menge bekannt) ausgehend, werden alle Flächen unter den Peaks integriert und so die Gesamtmenge pro Peak bestimmt. Um die qualitative Bestimmung der einzelnen Peaks vorzunehmen, wird ein Massenspektrometer herangezogen.

\section{Qualitative Auswertung mit einem Massenspektrometer}

Die qualitative Analyse wurde mit einem Gaschromatogramm und einem daran angeschlossenen Quadrupol-Massenspektrometer (GC/MS; Hewlett-Packard 5971A) durchgeführt. Für das Massenspektrometer wurde Helium als Treibgas verwendet.

$1 \mu 1$ Probe wurde über eine DB 1 Kapillarsäule $(30 \mathrm{~m}$, Innendurchmesser $0.32 \mathrm{~mm}$, $0.10 \mu \mathrm{m}$ Beschichtung mit 100\% Polymethylsiloxan) aufgetrennt und bei $70 \mathrm{eV}$ Beschleunigungsspannung die Massenbereiche von 35 bis $550 \mathrm{U}$ in Intervallen von 1.2 sec gemessen. Die so gewonnenen Spektren wurden am Computer mit einem Auswertungsprogramm (Enhanced ChemStation G1701 AA Version A.03.00, Hewlett Packard) ausgewertet (HARTMANN 2002) und zusätzlich mit Literaturangaben von HOLLOWAY (1982) verglichen.

Besonders typisch für ein Suberinchromatogramm aus Wurzeln sind die homologe Abfolge von $\omega$-Hydroxysäuren sowie die C18-ungesättigten Di- und $\omega$-Hydroxysäuren. Insgesamt konnten so in jedem Chromatogramm bis zu 40 Suberinmonomere eindeutig analysiert werden.

\subsection{Statistische Auswertung}

Die statistische Auswertung erfolgte mit dem Computerprogramm SAS (Statistical Analysis System, SAS-Institute Inc. Cary, NC, USA, Version 8.2).

Für die Untersuchung auf Normalverteilung wurde der Anpassungstest von Shapiro \& Wilk verwendet. Um auf signifikante Unterschiede (Signifikanzniveau 5\%) schließen zu können, wurde bei normalverteilten Daten ein ANOVA-Test, für unbalancierte Stichproben der Test nach Scheffé durchgeführt. Bei nicht normalverteilten Daten wurde der Mann-Whitney (Wilcoxon)- two sample-Test angewandt.

Regressionsanalysen zwischen Datensätzen wurden mit dem Auswertungs- und Grafikprogramm Xact (Version 7.3, SciLab, Hamburg) durchgeführt. 


\section{ERGEBNISSE}

\subsection{Bodenwasserzustand der Untersuchungsbestände Söhre und Ziegelrodaer Forst}

\subsubsection{Volumetrischer Bodenwassergehalt und Bodenmatrixpotenzial}

Die durch TDR (time-domain reflectometry) erhaltenen volumetrischen Bodenwassergehalte in der Söhre wiesen 2003 von Ende Juni bis Anfang September eine Phase intensiver und langanhaltender Bodenaustrocknung auf (Abb. 4-1). Die Werte in den drei Bodentiefen unterschieden sich merklich voneinander. Von Juli bis Anfang September wies der Boden in einer Tiefe von $5 \mathrm{~cm}$ die geringsten Wassergehalte mit 7 vol\% bis maximal 12 vol\% auf. Auch in den Bodentiefen $20 \mathrm{~cm}$ und $35 \mathrm{~cm}$ erkennt man die ausgeprägte Bodentrockenheit in den Monaten Juli bis Anfang September, wobei hier die Werte mit deutlich über 15 vol\% höher lagen als in $5 \mathrm{~cm}$ Bodentiefe und somit der Boden in den tieferen Lagen weniger austrocknete. Die Bodentrockenheit spiegelte sich ebenfalls in den Matrixpotenzialen von -400 bis $-600 \mathrm{hPa}$ in einer Bodentiefe von $5 \mathrm{~cm}$ wider.

Einen deutlich abfallenden Jahresverlauf im Jahr 2003 zeigten die Werte des volumetrischen Wassergehaltes im Ziegelrodaer Forst (Abb.4-1). Durch höhere Niederschläge im April und Mai als in der Söhre lagen die Wassergehaltswerte im Ziegelrodaer Forst am Anfang der Vegetationsperiode 2003 in allen Bodentiefen deutlich über 25 vol\%. Im April wies der Boden in $35 \mathrm{~cm}$ Tiefe die höchsten Werte mit zum Teil mehr als 32 vol\% auf. Die Bodenwassergehalte in $20 \mathrm{~cm}$ und $5 \mathrm{~cm}$ Bodentiefe lagen mit Werten um 28 vol\% bzw. 26 vol\% deutlich niedriger. Während der Austrocknungsphase bis Anfang August fiel der Wassergehalt in allen Bodentiefen kontinuierlich auf Werte unter 15 vol\% ab, lag damit aber immer noch höher als in der Söhre. Das Bodenmatrixpotenzial fiel im gleichen Zeitraum auf $-700 \mathrm{hPa}$ in $5 \mathrm{~cm}$ Bodentiefe. Messwerte unter $-800 \mathrm{hPa}$ wurden verworfen, da sie bereits die Messbereichsgrenze der Tensiometer überschreiten.

Ab dem 11.09.2003 erfolgte eine intensive Wiederbefeuchtung des Bodens auf beiden Flächen, wobei es vor allem in der Söhre in $5 \mathrm{~cm}$ Bodentiefe zu einem deutlichen Feuchteanstieg bis auf $20 \mathrm{vol} \%$ kam. In $5 \mathrm{~cm}$ Bodentiefe wurden hier Bodenmatrixpotenziale bis $-200 \mathrm{hPa}$ gemessen. In $20 \mathrm{~cm}$ Bodentiefe stieg der Wassergehalt auf 16 vol\%, in $35 \mathrm{~cm}$ sogar auf über $30 \mathrm{vol} \%$ an. Im gleichen Zeitraum stieg der Bodenwassergehalt im Ziegelrodaer Forst nur in $5 \mathrm{~cm}$ Bodentiefe und nur kurzzeitig auf etwa $20 \mathrm{vol} \%$ an. 


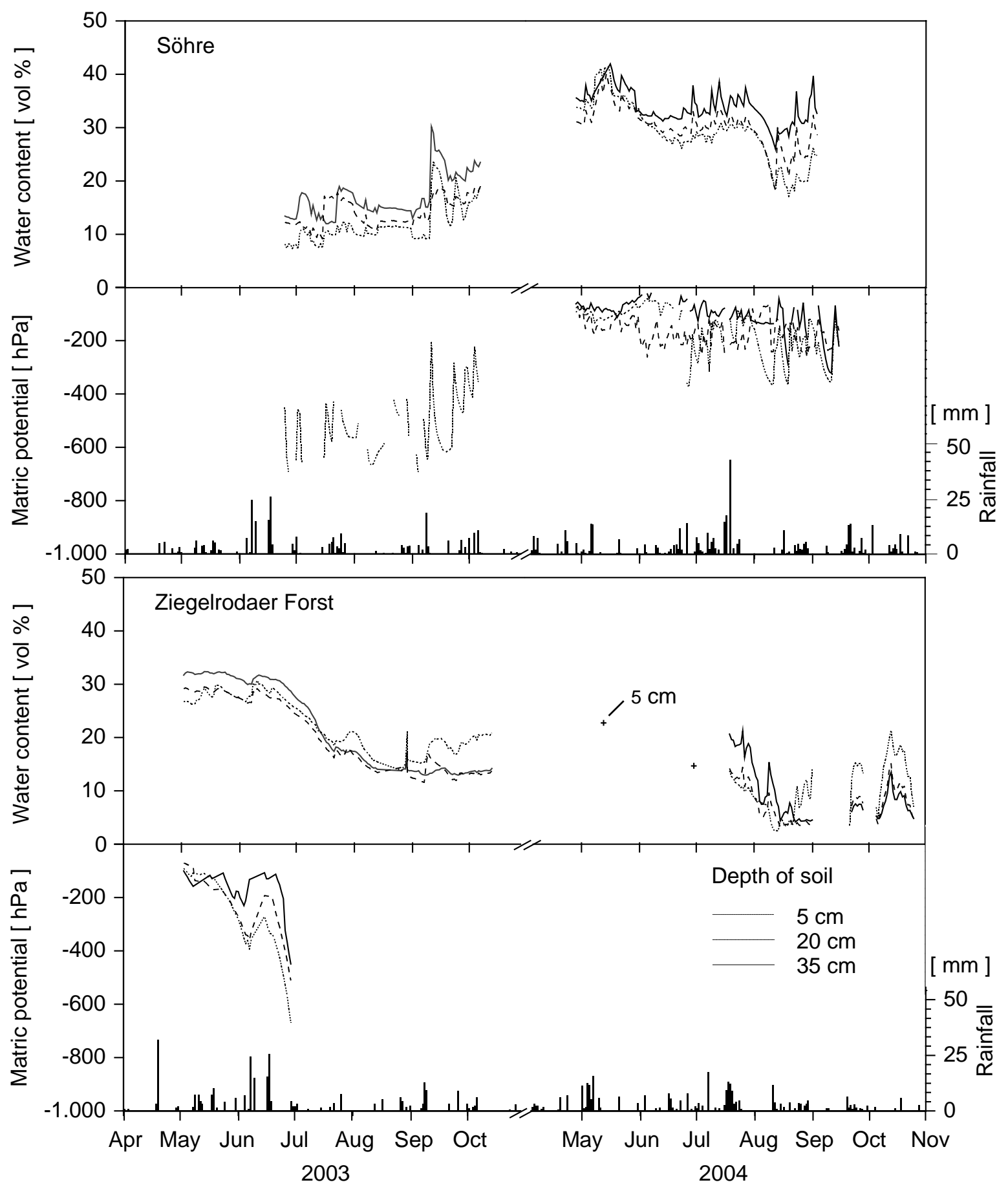

Abb. 4-1. Volumetrischer Bodenwassergehalt und Bodenmatrixpotenzial in der Söhre und im Ziegelrodaer Forst in der Vegetationsperiode 2003 und 2004 in 5, 20 und $35 \mathrm{~cm}$ Bodentiefe. Der Bodenwassergehalt wurde mittels 2-TDR-Sonden je Bodentiefe gemessen und die Tagesmittelwerte aufgetragen. Das Bodenmatrixpotenzial wurde von 2 bis 3 Tensiometern je Tiefe bestimmt und die Tagesmittelwerte aufgetragen, zusätzlich die täglichen Niederschlagssummen (DWD). Die mit einem , ,+“ markierten Werte repräsentieren zusätzliche Punktmessungen mit einem mobilen TDR-System in den oberen $5 \mathrm{~cm}$ (Werte von I. MEIER). 
In der Vegetationsperiode 2004 herrschte in der Söhre durch ausgeglichene Niederschlagsverhältnisse bis Ende Juli eine günstige Bodenwasserversorgung. Insgesamt waren somit die Bodenwassergehalte im Jahr 2004 in der Söhre deutlich höher als im Jahr 2003 (Abb. 4-1). Am Anfang der Vegetationsperiode lagen hier die Werte noch weit über 35 vol\%, fielen von Mitte Mai bis Mitte Juli 2004 leicht ab, aber nie unter 25 vol\%. Ab Ende Juli bis Mitte August sanken die Bodenwassergehalte rasch auf $18 \mathrm{vol} \%$ in den Bodentiefen $5 \mathrm{~cm}$ und $20 \mathrm{~cm}$, stiegen aber ab Ende August wieder deutlich an. Ab Ende Mai 2004 wurden in $35 \mathrm{~cm}$ Bodentiefe die höchsten Bodenwassergehalte bestimmt, während in $5 \mathrm{~cm}$ Bodentiefe die geringsten Bodenwassergehalte gemessen wurden.

Während der ganzen Vegetationsperiode 2004 fielen in der Söhre die Bodenmatrixpotenziale nie unter $-400 \mathrm{hPa}$ ab. Bis Ende Juni schwankten sie in $5 \mathrm{~cm}$ Bodentiefe nur zwischen Werten von -50 bis -100 hPa. In der Desorptionsphase Anfang August sanken die Werte in $5 \mathrm{~cm}$ Bodentiefe von Höchstwerten um -100 hPa auf $-400 \mathrm{hPa}$ deutlich ab.

Der Bodenwassergehalt im Ziegelrodaer Forst (Abb. 4-1) wies im Jahr 2004 deutliche Unterschiede sowohl gegenüber den Werten von 2003 als auch gegenüber der Untersuchungsfläche Söhre auf. Bereits Mitte Mai wurden in $5 \mathrm{~cm}$ Tiefe nur 23 vol\% gemessen. Aufgrund geringer Niederschläge fiel der Bodenwassergehalt bis Ende Juni im Oberboden weiter auf $15 \mathrm{vol} \%$ ab (I. MEIER, mündl. Mitt.). Während in der Vegetationsperiode 2003 die niedrigsten Werte bei 11 vol\% (August) lagen, fielen sie 2004 deutlich weiter ab bis auf Werte von kurzzeitig 2.5 vol\% Mitte August. Somit war der Boden während des ganzen Jahres 2004 deutlich trockener als in der Söhre. Im Juli und August wies die unterste Bodentiefe $(35 \mathrm{~cm})$ die höchste Bodenfeuchte auf (anfangs $20 \mathrm{vol} \%$, später $8 \mathrm{vol} \%$ ). In $5 \mathrm{~cm}$ Bodentiefe erhöhte sich die Bodentrockenheit von 13 auf 2.5 vol\%. Im Oktober fanden sich die höchsten Bodenfeuchten im Oberboden bis $5 \mathrm{~cm}$ Bodentiefe (bis 18 vol\%).

\subsubsection{Beziehung zwischen Bodenwassergehalt und Bodenmatrix- potenzial (Feld-pF-Kurven)}

Abb. 4-2 zeigt die Beziehung zwischen Bodenwassergehalt und Bodenmatrixpotenzial in der Söhre bzw. im Ziegelrodaer Forst in Form einer Feld-pF-Kurve. Hierfür wurden die Messwerte aus $5 \mathrm{~cm}, 20 \mathrm{~cm}$ und $35 \mathrm{~cm}$ Bodentiefe im Verlauf zweier Desorptionsphasen zu Grunde gelegt. 
In allen drei Bodentiefen der Untersuchungsfläche im Ziegelrodaer Forst zeigen Bodenwassergehalt und Bodenmatrixpotenzial über den Verlauf der beobachteten Desorptionsphasen einen linearen Zusammenhang ( $r>0.98)$.

Für die Bodentiefe in $5 \mathrm{~cm}$ ergab sich auf beiden Flächen eine flache Steigung der Kurven, in der Söhre eine Steigung von -0.05 und im Ziegelrodaer Forst eine Steigung von -0.08. Ein deutlich steilerer Verlauf ist bei den Kurven der Bodentiefen $20 \mathrm{~cm}$ (Steigung: -0.19) und $35 \mathrm{~cm}$ (Steigung: -0.46) im Ziegelrodaer Forst zu beobachten.

Die für die Feld-pF-Kurven zu Grunde gelegten Bodenwassergehalte bewegten sich zwischen 19.5 und 30 vol\% in der Söhre und zwischen 26 und 31 vol\% im Ziegelodaer Forst, wobei die Bodentiefe im Ziegelrodaer Forst in $20 \mathrm{~cm}$ die geringsten (26-28 vol\%) und in $35 \mathrm{~cm}$ die höchsten Bodenwassergehalte mit $30-31$ vol\% aufwiesen. Das Matrixpotenzial erreichte im Laufe der Desorptionsphasen Minimalwerte von $-530 \mathrm{hPa}$ $(\mathrm{pF}=2.7)$.

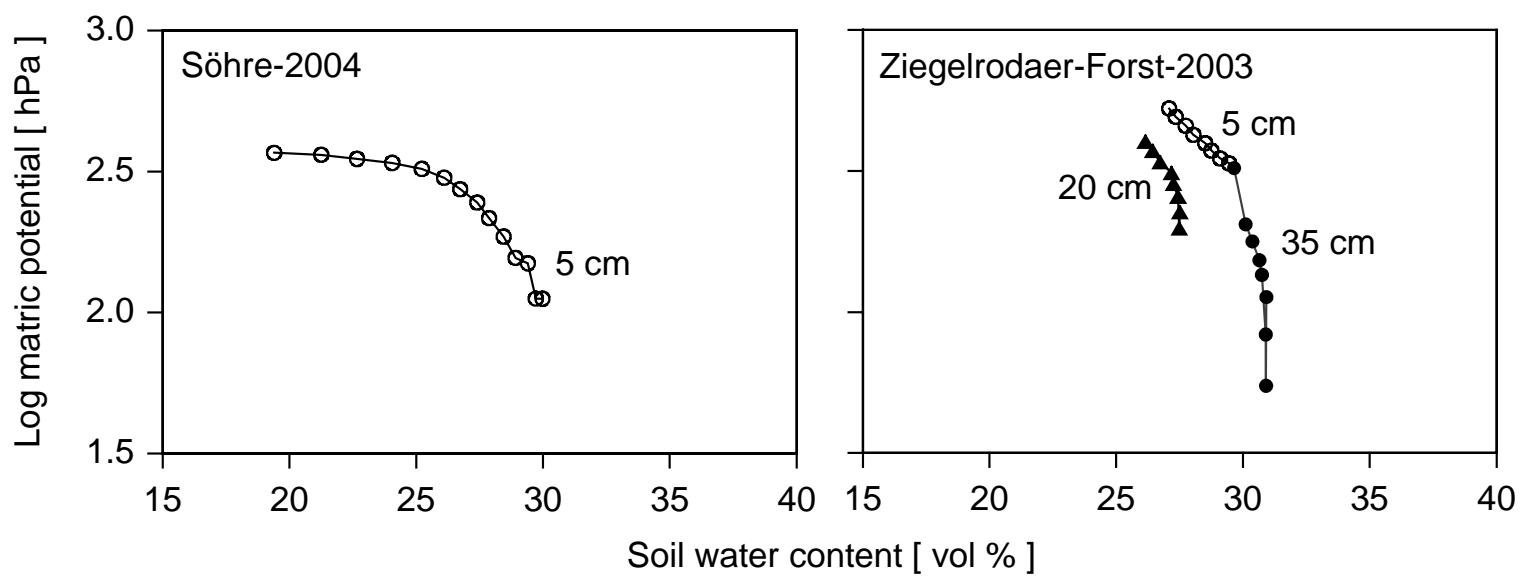

Abb. 4-2. Beziehung zwischen Bodenwassergehalt und Bodenmatrixpotenzial (Feld-pFKurven) während einer Desorptionsphase im Jahr 2004 auf der Untersuchungsfläche in der Söhre in $5 \mathrm{~cm}$ Bodentiefe und einer Desorptionsphase 2003 im Ziegelrodaer Forst in den Bodentiefen $5 \mathrm{~cm}, 20 \mathrm{~cm}$ und $35 \mathrm{~cm}$. 


\subsection{Wurzelwasserpotenzial}

2003

Abb. 4-3 zeigt den saisonalen Verlauf des Wurzelwasserpotenzials auf den beiden untersuchten Flächen im Jahr 2003.

In der Söhre kam es bei allen drei Baumarten zu einem gleichartigen saisonalen Verlauf. An allen drei Terminen wiesen die Birkenwurzeln das negativste Potenzial auf, während die Kiefernwurzeln ihr Potenzial am wenigsten absenkten.

Anfang August erreichte die Kiefer ein Wasserpotenzial von -0.98 MPa. Dies unterschied sich signifikant von dem Wert der Birke mit -2.1 MPa (Tab. 4-1). Die Buche wies mit $-1.58 \mathrm{MPa}$ den mittleren Wert der drei Baumarten auf, mit nicht signifikanten Unterschieden zu den beiden anderen Baumarten. $\mathrm{Zu}$ einem deutlichen Absinken des Wasserpotenzials aller drei Baumarten kam es Ende August 2003. Die Werte der Kiefer sanken bis auf -1.33 MPa, bei der Buche auf -2.55 MPa. Diese beiden Wasserpotenziale unterschieden sich signifikant voneinander.

Die Birke wies mit -3.13 MPa den negativsten Wert auf mit einem signifikanten Unterschied zur Kiefer, nicht aber zur Buche.

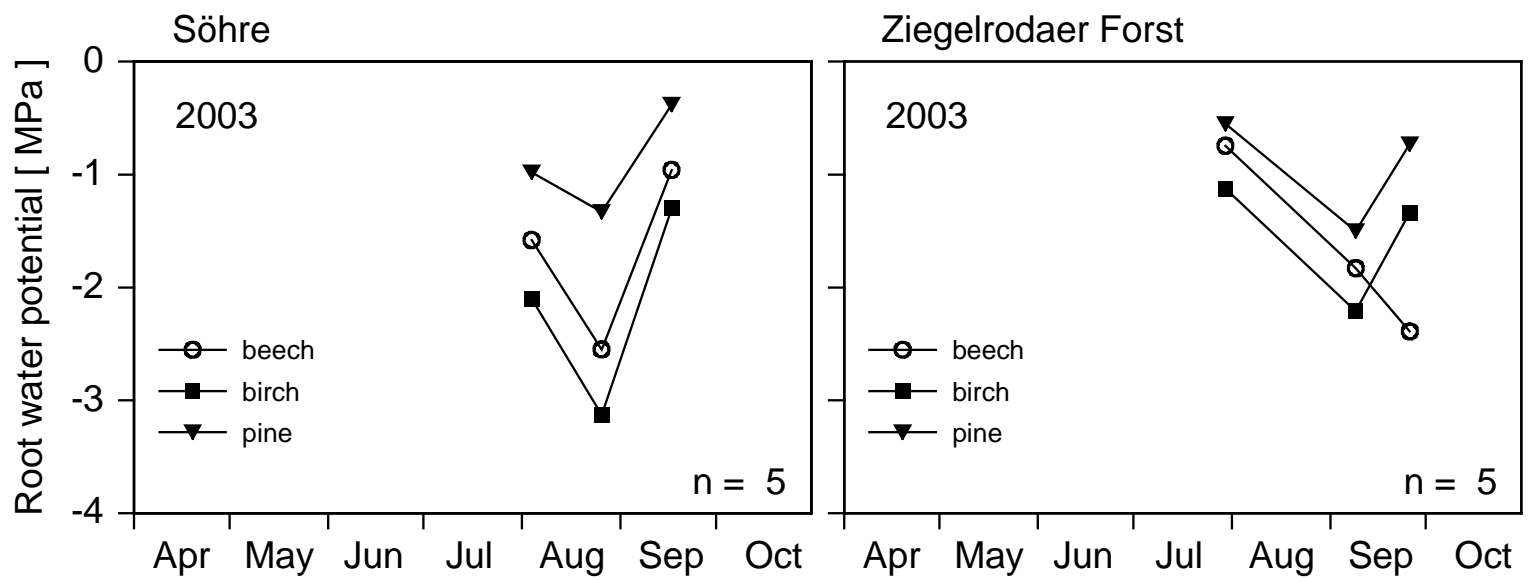

Abb. 4-3. Tagesminima der Wasserpotenziale von Buchen-, Birken- und Kiefernfeinwurzeln in der Söhre und im Ziegelrodaer Forst an jeweils drei Terminen im Jahr 2003 (Scholander-Methode). Statistische Parameter zu den dargestellten Werten in Tab. 4-1. 
Auf der Fläche im Ziegelrodaer Forst kam es im Jahr 2003 zu einem ähnlichen saisonalen Verlauf (Abb.4-3). Während die Werte des Wasserpotenzials im Juli um -1 MPa lagen, fielen sie bis Ende August bei allen drei Baumarten deutlich ab und entspannten sich bis Ende der Vegetationsperiode wieder. Nur bei der Buche sank das Wasserpotenzial auch bis Ende September weiter ab. Die Wasserpotenziale von Buche, Birke und Kiefer unterschieden sich am ersten Messtermin Ende Juli signifikant voneinander (Tab. 4-1). Wie schon in der Söhre wies die Kiefer mit -0.55 MPa, vor der Buche mit -0.75 $\mathrm{MPa}$ und der Birke mit -1.13 MPa die am wenigsten negativen Wasserpotenzialwerte auf. Bis Anfang September sanken die Wasserpotenziale aller drei Baumarten auf ähnliche Werte ab (Buche: -1.83 MPa, Birke: -2.21 MPa, Kiefer: -1.5 MPa ), die sich zu diesem Zeitpunkt nicht signifikant voneinander unterschieden (Tab. 4-1). Das Wasserpotenzial von Kiefer und Birke entspannte sich Ende September deutlich auf -0.73 MPa und -1.34 MPa, ohne signifikante Unterschiede zwischen diesen Werten. Das Wasserpotenzial der Buche hingegen sank weiter ab (-2.39 MPa) und unterschied sich signifikant von den Werten der beiden anderen Baumarten.

Die Jahresmaxima des Wasserpotenzials in den Feinwurzeln unterschieden sich zwischen den drei Baumarten auf einer Untersuchungsfläche nur geringfügig. Die Kiefer wies mit -0.38 MPa in der Söhre und -0.55 MPa im Ziegelrodaer Forst jeweils die höchsten Potenziale auf. Die Buche nimmt mit Potenzialwerten in der Söhre von -0.96 MPa und -0.75 MPa eine Mittelstellung ein. Die Birke wies Maxima in der Söhre von -1.3 MPa und im Ziegelrodaer Forst von -1.1 MPa auf. Insgesamt unterschieden sich bei allen drei Baumarten die Jahresmaxima stark von den Jahresminima des Wasserpotenzials. Die Kiefer wies die positivsten Minimalwerte des Potenzials auf (Söhre: -1.33 MPa und Ziegelrodaer Forst: -1.5 MPa). Die Buche senkte ihr Potenzial in den Wurzeln im „Rekordsommer 2003“ auf beachtliche -2.55 MPa in der Söhre und -2.39 MPa im Ziegelrodaer Forst. Die Birke jedoch wies das negativste Jahresminimum mit -3.13 MPa in der Söhre auf (Ziegelrodaer Forst: -2.11 MPa). 
Tabelle 4-1. Mittlere Wasserpotenziale der Wurzeln von Kiefer, Buche und Birke auf den Untersuchungsflächen Söhre und Ziegelrodaer Forst im Jahr 2003. $\Psi_{\text {root }}$ steht für das Wasserpotenzial der Baumwurzeln (Scholander-Methode). Unterschiedliche Buchstaben kennzeichnen signifikante Unterschiede zwischen den Baumarten am jeweiligen Messtermin $(\mathrm{p}<0.05$, Scheffé; $\mathrm{SE}=$ Standardfehler, $\mathrm{n}=5)$.

\begin{tabular}{|c|c|c|c|c|c|c|c|}
\hline SÖHRE 2 & $\begin{array}{l}003 \\
\Psi_{\text {root }} \\
{[\mathrm{MPa}]}\end{array}$ & SE & & ZIEGELR & $\begin{array}{l}\text { DAER } \\
\Psi_{\text {root }} \\
\mathrm{MPa}]\end{array}$ & $\begin{array}{l}\text { ORS } \\
\text { SE }\end{array}$ & 2003 \\
\hline 4.8 .2003 & & & & 30.7 .2003 & & & \\
\hline Kiefer & -0.98 & 0.15 & $\mathrm{a}$ & Kiefer & -0.55 & 0.03 & $\mathrm{a}$ \\
\hline Buche & -1.58 & 0.3 & $a b$ & Buche & -0.75 & 0.05 & $\mathrm{~b}$ \\
\hline Birke & -2.10 & 0.19 & $b$ & Birke & -1.13 & 0.04 & $\mathrm{c}$ \\
\hline 26.8.2003 & & & & 9.9.2003 & & & \\
\hline Kiefer & -1.33 & 0.18 & $\mathrm{a}$ & Kiefer & -1.5 & 0.11 & $\mathrm{a}$ \\
\hline Buche & -2.55 & 0.23 & $\mathrm{~b}$ & Buche & -1.83 & 0.29 & $\mathrm{a}$ \\
\hline Birke & -3.13 & 0.34 & $\mathrm{~b}$ & Birke & -2.21 & 0.32 & $\mathrm{a}$ \\
\hline 17.9.2003 & & & & 26.9.2003 & & & \\
\hline Kiefer & -0.38 & 0.03 & $\mathrm{a}$ & Kiefer & -0.73 & 0.12 & $\mathrm{a}$ \\
\hline Buche & -0.96 & 0.04 & $\mathrm{a}$ & Buche & -2.39 & 0.29 & $b$ \\
\hline Birke & -1.30 & 0.05 & $\mathrm{a}$ & Birke & -1.34 & 0.21 & $\mathrm{a}$ \\
\hline
\end{tabular}

2004

Im feuchteren Jahr 2004 blieben die Wasserpotenziale an beiden Standorten im saisonalen Verlauf deutlich entspannter (Abb. 4-4). Auch wenn es in den Trockenzeiten zu einem Absinken des Potenzials der drei Baumarten kam, blieben die Werte trotzdem höher als im Jahr 2003.

Auffallend war das vergleichsweise hohe Wasserpotenzial der Buche Ende April 2004 in der Söhre mit -0.27 MPa. Dieser Wert unterschied sich signifikant von den Werten der Birke und Kiefer (Tab. 4-2). In der ersten Phase ausgeprägter Bodentrockenheit sank das Wasserpotenzial von Buche und Birke in der Söhre bis Ende Juni auf Werte von -1.16 und -1.47 MPa ab, während es bei der Kiefer nur auf -0.3 MPa fiel und sich somit von den beiden anderen Baumarten signifikant unterschied. Nach einer Entspannung der Wurzelwasserpotenziale bis Mitte Juli kam es bei einer zweiten ausgeprägten Trockenphase Anfang August erneut zum Absinken der Wasserpotenzialwerte, wobei sich alle drei Baumarten signifikant unterschieden (Buche: -0.96; Birke: -1.36; Kiefer: -0.66 MPa). 


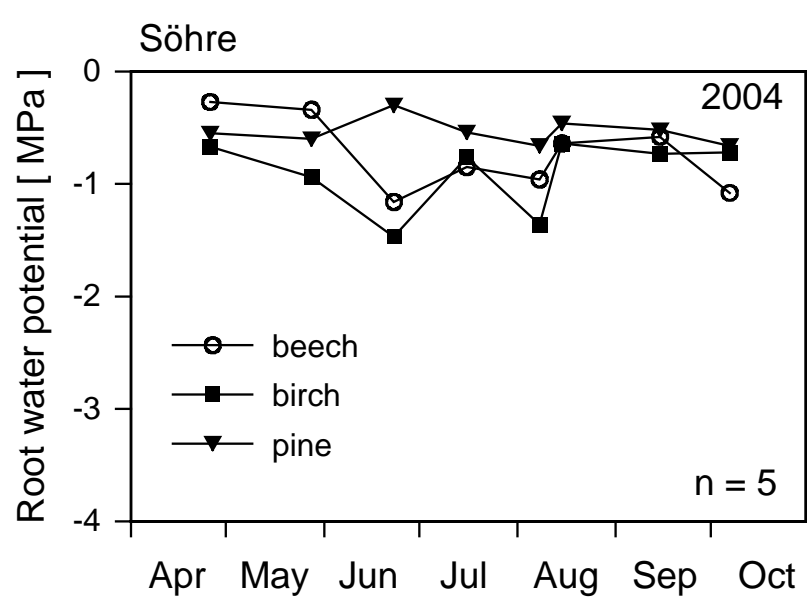
Ziegelrodaer Forst

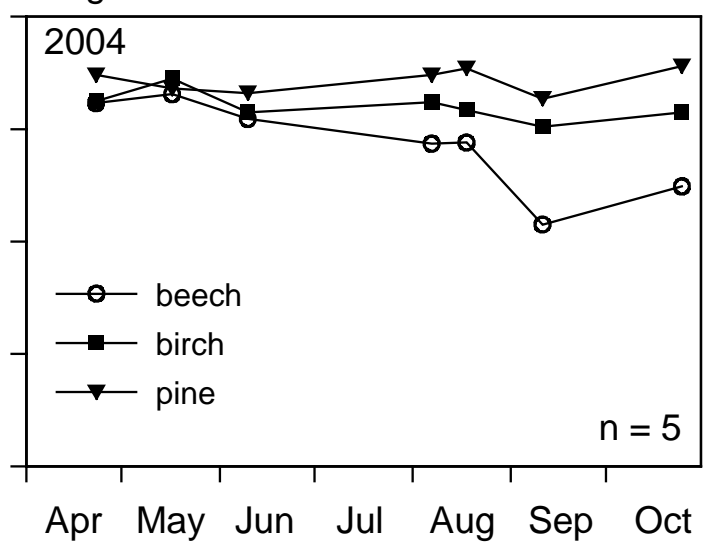

Abb. 4-4. Tagesminima der Wasserpotenziale von Buchen-, Birken- und Kiefernfeinwurzeln in der Söhre und im Ziegelrodaer Forst an jeweils acht bzw. sieben Terminen im Jahr 2004 (Scholander-Methode). Statistische Parameter zu den dargestellten Werten in Tab. 4-2.

Im Ziegelrodaer Forst sank das Wasserpotenzial bei allen drei Baumarten erst Mitte September deutlich ab, wobei sich die Kiefer mit -0.73 MPa signifikant von der Buche mit $-1.85 \mathrm{MPa}$ unterschied. Zwischen Birke und Kiefer konnten dagegen keine signifikanten Unterschiede festgestellt werden. Im Oktober 2004, mit Einsetzen des Niederschlags, entspannten sich die Wurzelwasserpotenziale auf beiden Flächen. Eine Ausnahme bildete die Buche in der Söhre, deren Wasserpotenzial weiter auf -1.08 MPa sank (Abb. 4-4).

Generell wies die Kiefer die entspanntesten Wurzelwasserpotenzialwerte der drei Baumarten auf. So lagen die höchsten Potenzialwerte bei -0.3 MPa am 23.6.2004 in der Söhre bzw. -0.44 MPa am 25.10.2004 im Ziegelrodaer Forst und die negativsten bei -0.73 MPa am 11.9.2004 im Ziegelrodaer Forst bzw. bei -0.66 MPa am 8.8.2004 in der Söhre.

Das insgesamt höchste Wasserpotenzial wurde bei der Buche am 26.4.2004 in der Söhre mit $-0.27 \mathrm{MPa}$ gemessen und war damit noch deutlich weniger negativ als das maximale Potenzial der Buche im Ziegelrodaer Forst (-0.69 MPa). Die negativsten Potenzialwerte aller drei Baumarten wurden im Jahr 2004 bei der Buche im Ziegelrodaer Forst gemessen (-1.85 MPa). In der Söhre erreichte die Buche dagegen nur Werte von -1.16 MPa. Bei der Birke lagen die höchsten Wasserpotenzialwerte auf beiden Flächen in einem ähnlichen Bereich (Söhre: $-0.64 \mathrm{MPa}$, Ziegelrodaer Forst: $-0.55 \mathrm{MPa}$ ), unterschieden sich jedoch stark in den niedrigsten im Jahresverlauf gemessenen Potenzialwerten (Söhre: -1.47 MPa, Ziegelrodaer Forst: -0.98 MPa). 
Tabelle 4-2. Mittlere Wasserpotenziale der Wurzeln von Kiefer, Buche und Birke auf den Untersuchungsflächen Söhre und Ziegelrodaer Forst im Jahr 2004. $\Psi_{\text {root }}$ steht für das Wasserpotenzial der Baumwurzeln (Scholander-Methode).Unterschiedliche Buchstaben kennzeichnen signifikante Unterschiede zwischen den Baumarten am jeweiligen Messtermin ( $p<0.05$, Scheffé; $S E=$ Standardfehler, $n=5)$.

\begin{tabular}{|c|c|c|c|c|c|c|c|}
\hline \multicolumn{4}{|c|}{ SÖHRE 2004} & \multicolumn{4}{|c|}{ ZIEGELRODAER FORST 2004} \\
\hline & $\begin{array}{l}\Psi_{\text {root }} \\
{[\mathrm{MPa}]}\end{array}$ & SE & & & $\begin{array}{l}\Psi_{\text {root }} \\
{[\mathrm{MPa}]}\end{array}$ & $\mathrm{SE}$ & \\
\hline 26.4.2004 & & & & 23.4.2004 & & & \\
\hline Kiefer & -0.55 & 0.04 & $b$ & Kiefer & -0.52 & 0.03 & $\mathrm{a}$ \\
\hline Buche & -0.27 & 0.04 & $\mathrm{a}$ & Buche & -0.77 & 0.10 & $\mathrm{a}$ \\
\hline Birke & -0.67 & 0.03 & $\mathrm{~b}$ & Birke & -0.75 & 0.15 & $\mathrm{a}$ \\
\hline 28.5.2004 & & & & 17.5.2004 & & & \\
\hline Kiefer & -0.60 & 0.10 & $a b$ & Kiefer & -0.64 & 0.06 & $\mathrm{a}$ \\
\hline Buche & -0.34 & 0.04 & $\mathrm{a}$ & Buche & -0.69 & 0.04 & $\mathrm{a}$ \\
\hline Birke & -0.94 & 0.15 & $\mathrm{~b}$ & Birke & -0.55 & 0.02 & $\mathrm{a}$ \\
\hline 23.6.2004 & & & & 10.6.2004 & & & \\
\hline Kiefer & -0.30 & 0.08 & $\mathrm{a}$ & Kiefer & -0.68 & 0.10 & $\mathrm{a}$ \\
\hline Buche & -1.16 & 0.21 & $\mathrm{~b}$ & Buche & -0.91 & 0.13 & $\mathrm{a}$ \\
\hline Birke & -1.47 & 0.18 & $b$ & Birke & -0.85 & 0.12 & $\mathrm{a}$ \\
\hline 16.7.2004 & & & & 16.7.2004 & & & \\
\hline Kiefer & -0.54 & 0.07 & $\mathrm{a}$ & Kiefer & - & - & \\
\hline Buche & -0.85 & 0.05 & $b$ & Buche & - & - & \\
\hline Birke & -0.76 & 0.02 & $b$ & Birke & - & - & \\
\hline 8.8.2004 & & & & 7.8.2004 & & & \\
\hline Kiefer & -0.66 & 0.02 & $\mathrm{a}$ & Kiefer & -0.52 & 0.10 & $\mathrm{a}$ \\
\hline Buche & -0.96 & 0.06 & $b$ & Buche & -1.13 & 0.16 & $\mathrm{~b}$ \\
\hline Birke & -1.36 & 0.09 & $\mathrm{c}$ & Birke & -0.76 & 0.11 & $a b$ \\
\hline 15.8.2004 & & & & 18.8.2004 & & & \\
\hline Kiefer & -0.46 & 0.10 & $\mathrm{a}$ & Kiefer & -0.46 & 0.07 & $\mathrm{a}$ \\
\hline Buche & -0.64 & 0.08 & $\mathrm{a}$ & Buche & -1.12 & 0.09 & $\mathrm{~b}$ \\
\hline Birke & -0.64 & 0.09 & $\mathrm{a}$ & Birke & -0.83 & 0.10 & $b$ \\
\hline 15.9.2004 & & & & 11.9.2004 & & & \\
\hline Kiefer & -0.52 & 0.08 & $\mathrm{a}$ & Kiefer & -0.73 & 0.04 & $\mathrm{a}$ \\
\hline Buche & -0.58 & 0.08 & $\mathrm{a}$ & Buche & -1.85 & 0.07 & $\mathrm{~b}$ \\
\hline Birke & -0.73 & 0.09 & $\mathrm{a}$ & Birke & -0.98 & 0.10 & $\mathrm{a}$ \\
\hline 7.10.2004 & & & & 25.10 .2004 & & & \\
\hline Kiefer & -0.66 & 0.07 & $\mathrm{a}$ & Kiefer & -0.44 & 0.07 & $\mathrm{a}$ \\
\hline Buche & -1.08 & 0.19 & $\mathrm{a}$ & Buche & -1.51 & 0.10 & $\mathrm{~b}$ \\
\hline Birke & -0.72 & 0.09 & $\mathrm{a}$ & Birke & -0.85 & 0.14 & $\mathrm{a}$ \\
\hline
\end{tabular}




\subsection{Wasseraufnahme durch Feinwurzeln}

\subsubsection{Morphologie der Feinwurzeln}

Die spezifische Oberfläche der untersuchten Wurzeln nahm im Jahr 2003 bei allen drei Baumarten Werte von 60-90 $\mathrm{cm}^{2} \mathrm{~g} \mathrm{TM}^{-1}$ ein (Abb. 4-5).

Birken- und Kiefernwurzeln unterschieden sich zwischen den Standorten nicht signifikant voneinander. Jedoch wiesen die spezifischen Oberflächen der Birkenwurzeln auf der Untersuchungsfläche in der Söhre mit $56 \mathrm{~cm}^{2} \mathrm{~g} \mathrm{TM}^{-1}$ geringere Werte auf als im Ziegelrodaer Forst $\left(75 \mathrm{~cm}^{2} \mathrm{~g} \mathrm{TM}^{-1}\right)$.

Buchenwurzeln unterschieden sich zwischen beiden Untersuchungsflächen signifikant voneinander (Söhre: $56 \mathrm{~cm}^{2} \mathrm{~g} \mathrm{TM}^{-1}$ und Ziegelrodaer Forst $73 \mathrm{~cm}^{2} \mathrm{~g} \mathrm{TM}^{-1}$ ). Innerhalb der drei Baumarten je Untersuchungsfläche konnten keine signifikanten Unterschiede in der spezifischen Wurzeloberfläche ermittelt werden.

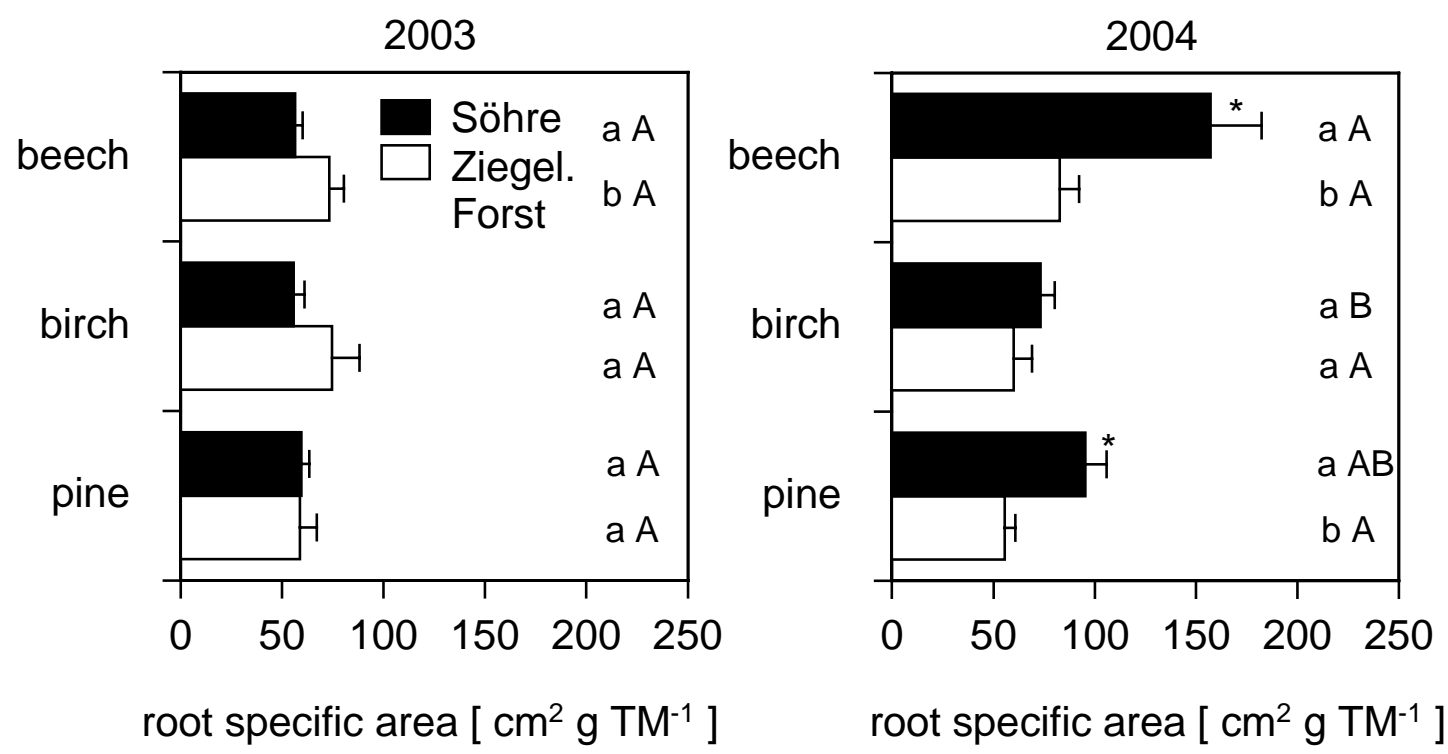

Abb. 4-5. Mittelwerte mit Standardfehler (Messperiode 1, 2 und 3) der spezifischen Oberfläche der Feinwurzeln von Buche, Birke und Kiefer, deren Wasseraufnahme gemessen wurde. Unterschiedliche Kleinbuchstaben markieren signifikante Unterschiede zwischen den Untersuchungsflächen, Großbuchstaben signifikante Unterschiede zwischen den Arten und * signifikante Unterschiede zwischen den Untersuchungsjahren $(p<0.05$, Scheffé). 
Signifikante Unterschiede der spezifischen Oberfläche sind im Jahr 2004 auf der Fläche in der Söhre zu erkennen (Abb. 4-5). Besonders die Buchenwurzeln unterschieden sich mit $157 \mathrm{~cm}^{2} \mathrm{~g} \mathrm{TM}^{-1}$ signifikant von den Birken- und Kiefernwurzeln. Mit weit mehr als der doppelten spezifischen Oberfläche unterschieden sich die 2004 in der Söhre untersuchten Buchenwurzeln signifikant von denen des Vorjahres. Bei den Buchenwurzeln vom Ziegelrodaer Forst kam es zu einer leichten Zunahme der spezifischen Oberfläche im Jahr 2004 ohne signifikante Unterschiede zum Jahr 2003 auf derselben Fläche.

Birken- und Kiefernwurzeln wiesen 2004 ebenfalls eine größere spezifische Wurzeloberfläche auf der Untersuchungsfläche in der Söhre auf. Signifikant waren diese Unterschiede allerdings nur bei den Kiefernwurzeln. Birken- und Kiefernwurzeln vom Ziegelrodaer Forst unterschieden sich zwischen den beiden Jahren nicht signifikant.

\subsubsection{Geländekalibrierung der Saftflusssensoren}

Zur Validierung der Daten der „heat balance-Methode“ wurden am Standort Söhre an vier Buchenwurzeln die mit den Saftfluss-Sensoren ermittelten Flussraten mit einer gleichzeitigen volumetrischen Messung verglichen.

Abb. 4-6 zeigt die Gegenüberstellung der volumetrisch ermittelten Saftflusswerte mit den berechneten Saftflusswerten. Die beiden Methoden zur Bestimmung des Saftflusses in Feinwurzeln stimmen mit einer Korrelation von $r=0.99$ sehr gut überein.

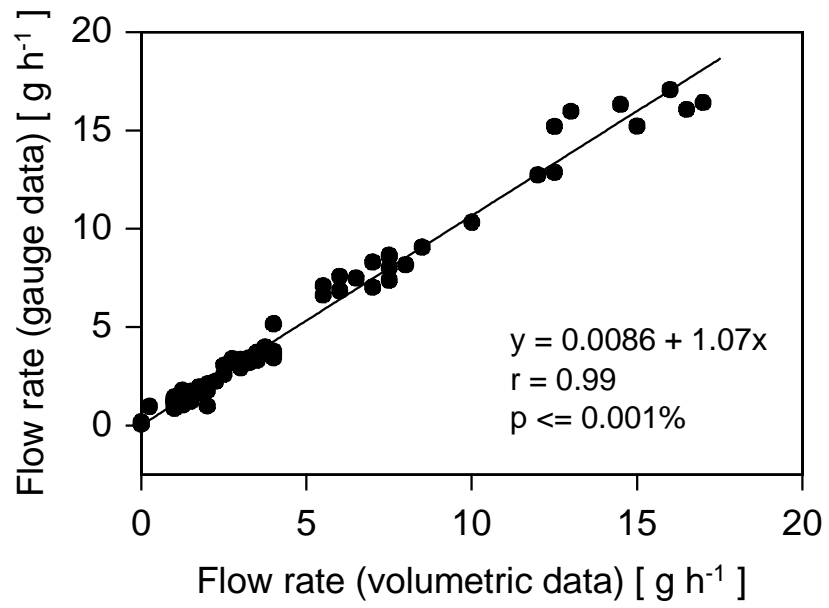

Abb. 4-6. Korrelation der volumetrisch gemessenen Flussraten mit den mittels Saftfluss-Sensoren bestimmten Flussraten von vier Buchenwurzeln (Durchmesser 2-5 mm). Die Messungen fanden im August 2005 auf der Untersuchungsfläche in der Söhre statt. 
Abb. 4-7 zeigt beispielhaft den zeitlichen Verlauf einer volumetrischen Kalibrierung. In der Grafik sind die berechnete Saftflussrate (gauge data) und die volumetrisch gemessene Saftflussrate (volumetric data) gegenübergestellt.

Die mit der "heat balance-Methode“ ermittelte Flussrate stieg direkt nach dem Abschneiden unter Wasser sprunghaft von $1 \mathrm{~g} \mathrm{~h}^{-1}$ auf über $15 \mathrm{~g} \mathrm{~h}^{-1}$ an und sank dann im Verlauf der folgenden 2 Stunden wieder unter $10 \mathrm{~g} \mathrm{~h}^{-1}$. Die nach dem Abschneiden volumetrisch ermittelte Flussrate bestätigt diesen Wertebereich. Ein weitgehend gleichsinniger Verlauf der beiden Flussraten ist gut zu erkennen.

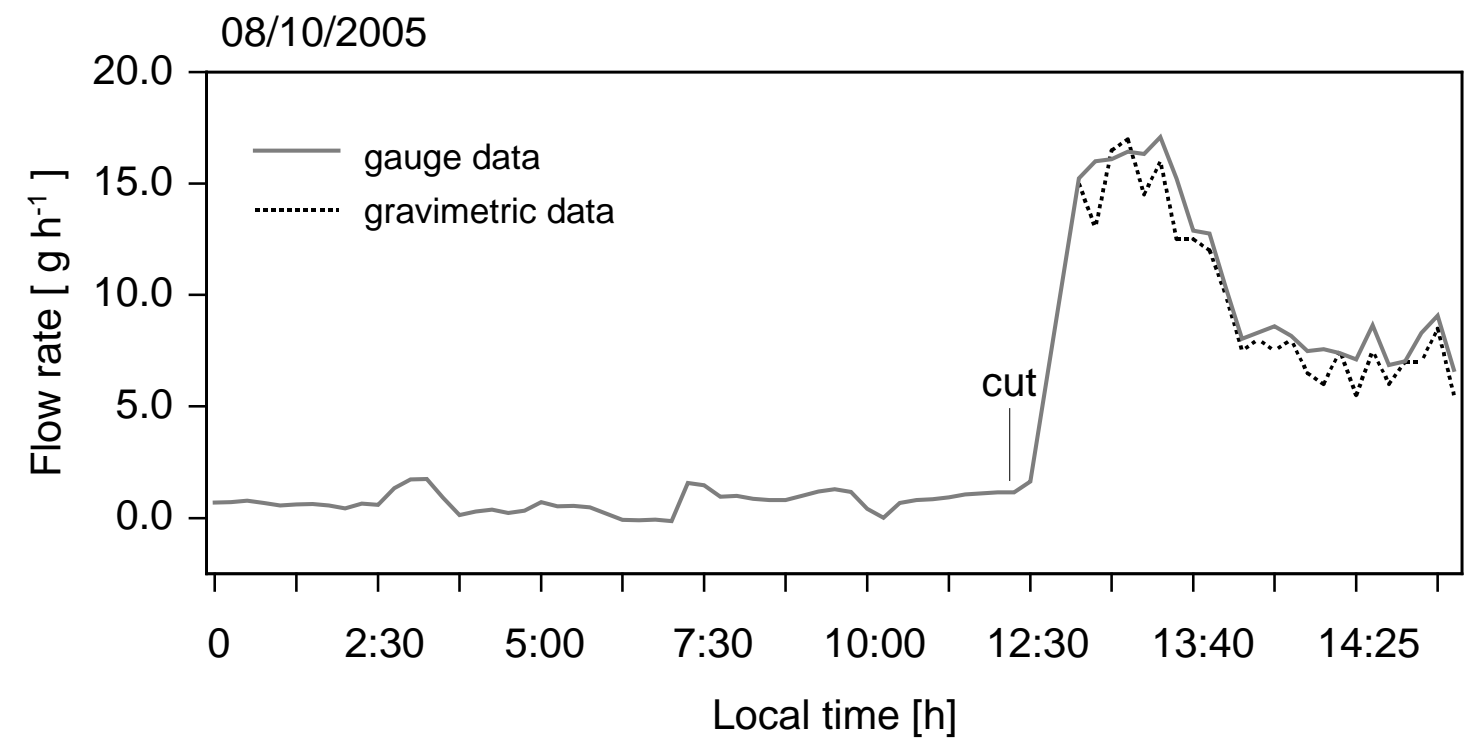

Abb. 4-7. Saftfluss einer Buchenwurzel auf der Untersuchungsfläche in der Söhre im Vergleich zum volumetrisch bestimmten Saftfluss (August 2005). Die Buchenwurzel wurde um 12.30 Uhr unter Wasser abgeschnitten. Parallel zur Saftflussmessung mit dem Miniatur-Saftfluss-Sensor wurde die Wasseraufnahme aus dem Reservoir in 15-min Intervallen volumetrisch bestimmt.

\subsubsection{Saftflussdichten in Buchen-, Birken- und Kiefernwurzeln}

Die querschnittsbezogenen Saftflussdichten der einzelnen Buchenwurzeln des Ziegelrodaer Forstes sowie in der Söhre wiesen im Jahresverlauf von 2003 große witterungsbedingte Schwankungen auf (Abb. 4-8). Hierbei folgten alle untersuchten Buchenwurzeln derselben Fläche einem parallelen Verlauf. 
Bemerkenswert ist die große Spannweite der Saftflussdichten der einzelnen Wurzeln. Die Maximalwerte der Saftflussdichten einzelner Buchenwurzeln lagen im Juni im Ziegelrodaer Forst bei $7 \mathrm{~g} \mathrm{~mm}^{-2} \mathrm{~d}^{-1}$, in der Söhre hingegen nur bei $2.2 \mathrm{~g} \mathrm{~mm}^{-2} \mathrm{~d}^{-1}$.

Besonders auffällig ist die maximal erreichte Saftflussdichte der Wurzel Nr. 4, die im September Werte von über $9 \mathrm{~g} \mathrm{~mm}^{-2} \mathrm{~d}^{-1}$ erreichte.
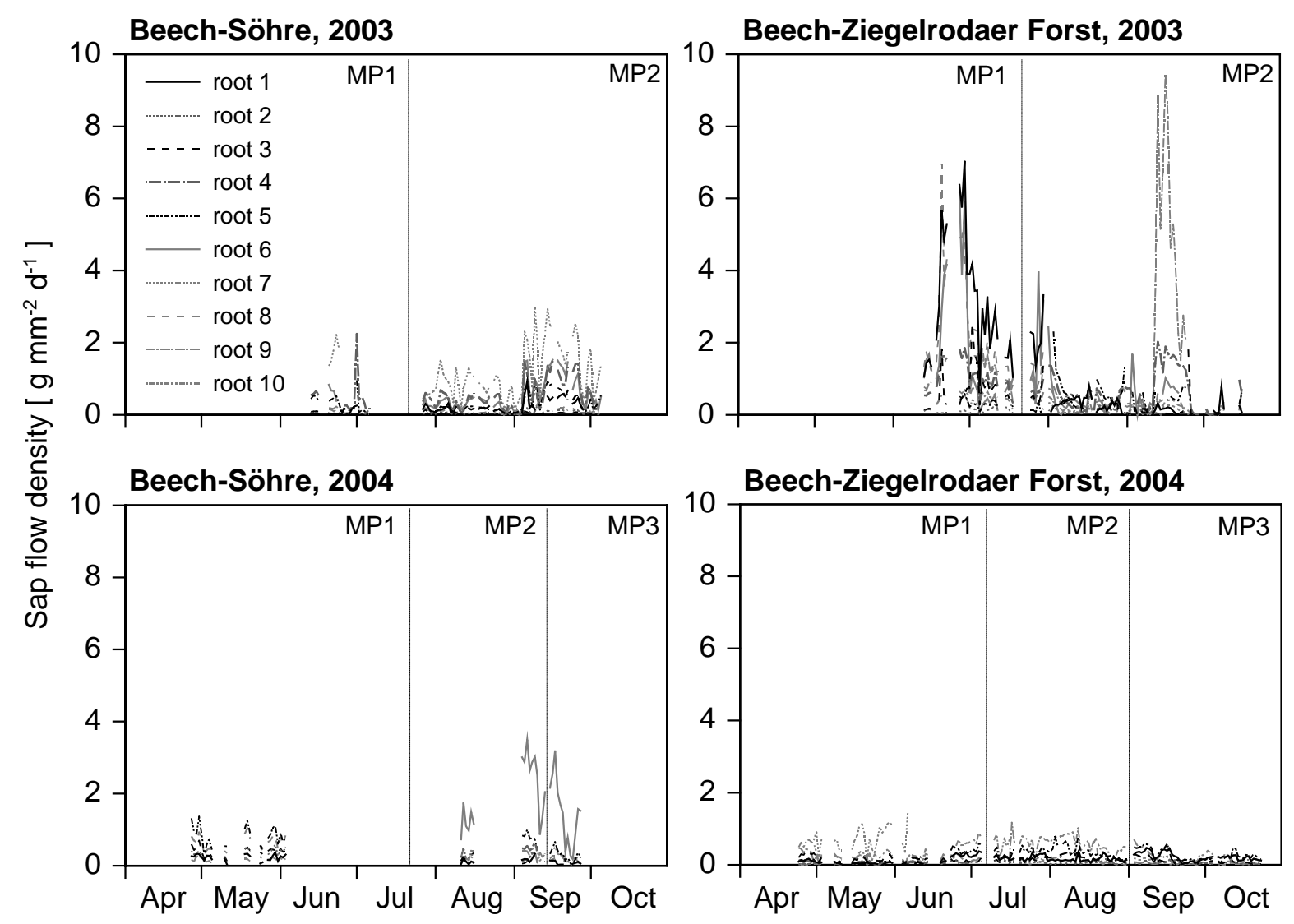

Abb. 4-8. Tageswerte der Saftflussdichte in Buchenwurzeln (Durchmesser 2-5 mm) gemessen in den Jahren 2003 und 2004 auf den Untersuchungsflächen in der Söhre und im Ziegelrodaer Forst. Als Bezugsfläche wurde die Querschnittsfläche der Wurzel am Saftflusssensor herangezogen. Einzelne Messperioden (MP1, MP2 und MP3) sind durch gepunktete Linien getrennt. Abstand der untersuchten Wurzeln vom Messbaum maximal $10 \mathrm{~m}$.

Die querschnittsbezogenen Saftflussdichten der einzelnen Buchenwurzeln in der Söhre von 2003 unterschieden sich zum Jahr 2004 nur wenig. Jedoch spiegelten die einzelnen Buchenwurzeln des Ziegelrodaer Forstes im Jahr 2004 weit geringere Schwankungen in der Saftflussdichte wider als im Jahr 2003 (Abb. 4-8). Insgesamt wiesen die Saftflussdichten der Buchenwurzeln auf dieser Fläche viel geringere Werte auf als 2003. Maximalwerte lagen deutlich unter $2 \mathrm{~g} \mathrm{~mm}^{-2} \mathrm{~d}^{-1}$. 
In der Söhre stieg die Saftflussdichte bei der Wurzel Nr. 6 im September bis auf ein Maximum von etwa $4 \mathrm{~g} \mathrm{~mm}^{-2} \mathrm{~d}^{-1}$ an.

Die querschnittsbezogenen Saftflussdichten der Birkenwurzeln wiesen 2003 im Ziegelrodaer Forst eine wesentlich größere Amplitude auf als in der Söhre (Abb. 4-9). Während in der Söhre einzelne Wurzeln der Birke maximale Saftflussdichten von $1 \mathrm{~g} \mathrm{~mm}^{-2} \mathrm{~d}^{-1}$ erreichten, stiegen die Maximalwerte im Ziegelrodaer Forst im Juni und Juli über $3 \mathrm{~g} \mathrm{~mm}^{-2} \mathrm{~d}^{-1}$ und Anfang August auf fast $5 \mathrm{~g} \mathrm{~mm}^{-2} \mathrm{~d}^{-1}$ deutlich stärker an.

Die erheblichen Schwankungen in der Saftflussdichte bei Birkenwurzeln im Jahr 2003 erreichten auf beiden Flächen oft einen Variationskoeffizienten von über 100\%.
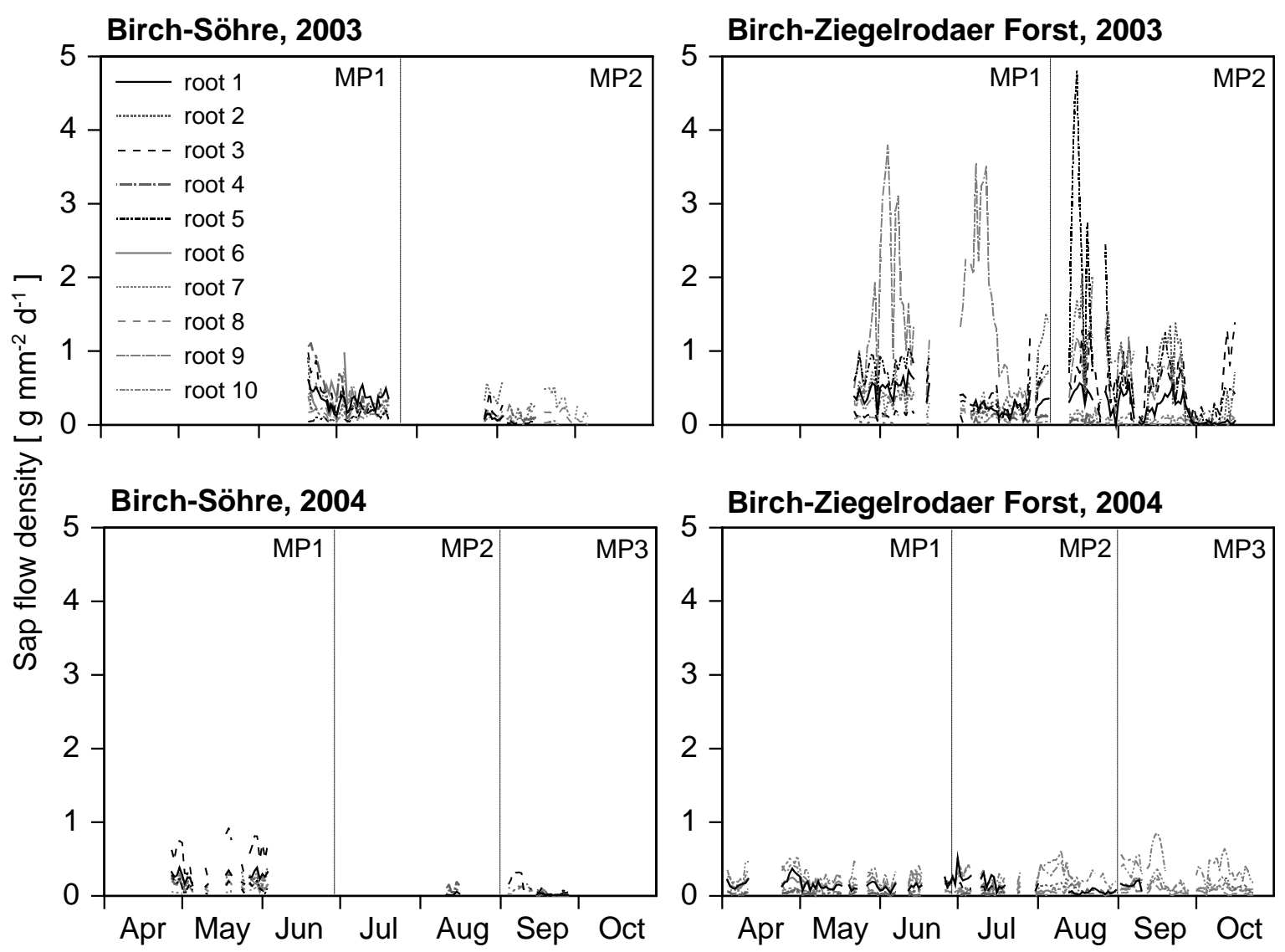

Abb. 4-9. Tageswerte der Saftflussdichte in Birkenwurzeln (Durchmesser 2-5 mm) gemessen in den Jahren 2003 und 2004 auf den Untersuchungsflächen in der Söhre und im Ziegelrodaer Forst. Als Bezugsfläche wurde die Querschnittsfläche der Wurzel am Saftflusssensor herangezogen. Einzelne Messperioden (MP1, MP2 und MP3) sind durch gepunktete Linien getrennt. Abstand der untersuchten Wurzeln vom Messbaum maximal $10 \mathrm{~m}$. 
Im Jahr 2004 kam es nur zu geringen Schwankungen in der Saftflussdichte der einzelnen Birkenwurzeln auf beiden Flächen (Abb. 4-9). Somit erreichten die Birkenwurzeln im Ziegelrodaer Forst weit geringere Saftflussdichten als 2003.

$\mathrm{Zu}$ einem ähnlichen Verlauf wie bei Buchen- und Birkenwurzeln des Jahres 2003 kam es in der querschnittsbezogenen Saftflussdichte bei einzelnen Kiefernwurzeln im Jahr 2003 (Abb. 4-10). Die deutlich größeren Amplituden der Saftflussdichten der einzelnen Wurzeln wurden im Jahresverlauf 2003 im Ziegelrodaer Forst erreicht. Am Anfang der Vegetationsperiode kam es zu Maximalwerten bis $8.5 \mathrm{~g} \mathrm{~mm}^{-2} \mathrm{~d}^{-1}$. Im Juni und Juli wurden sogar Werte von maximal $9.6 \mathrm{~g} \mathrm{~mm}^{-2} \mathrm{~d}^{-1}$ erreicht. Die höchsten Saftflussdichten, die bei Kiefernwurzeln in der Söhre gemessen wurden, lagen dagegen bei Werten von knapp über $1.5 \mathrm{~g} \mathrm{~mm}^{-2} \mathrm{~d}^{-1}$.

Der Verlauf einzelner Saftflussdichten bei Kiefernwurzeln in der Söhre sowie im Ziegelrodaer Forst wies stets eine Parallelität auf.

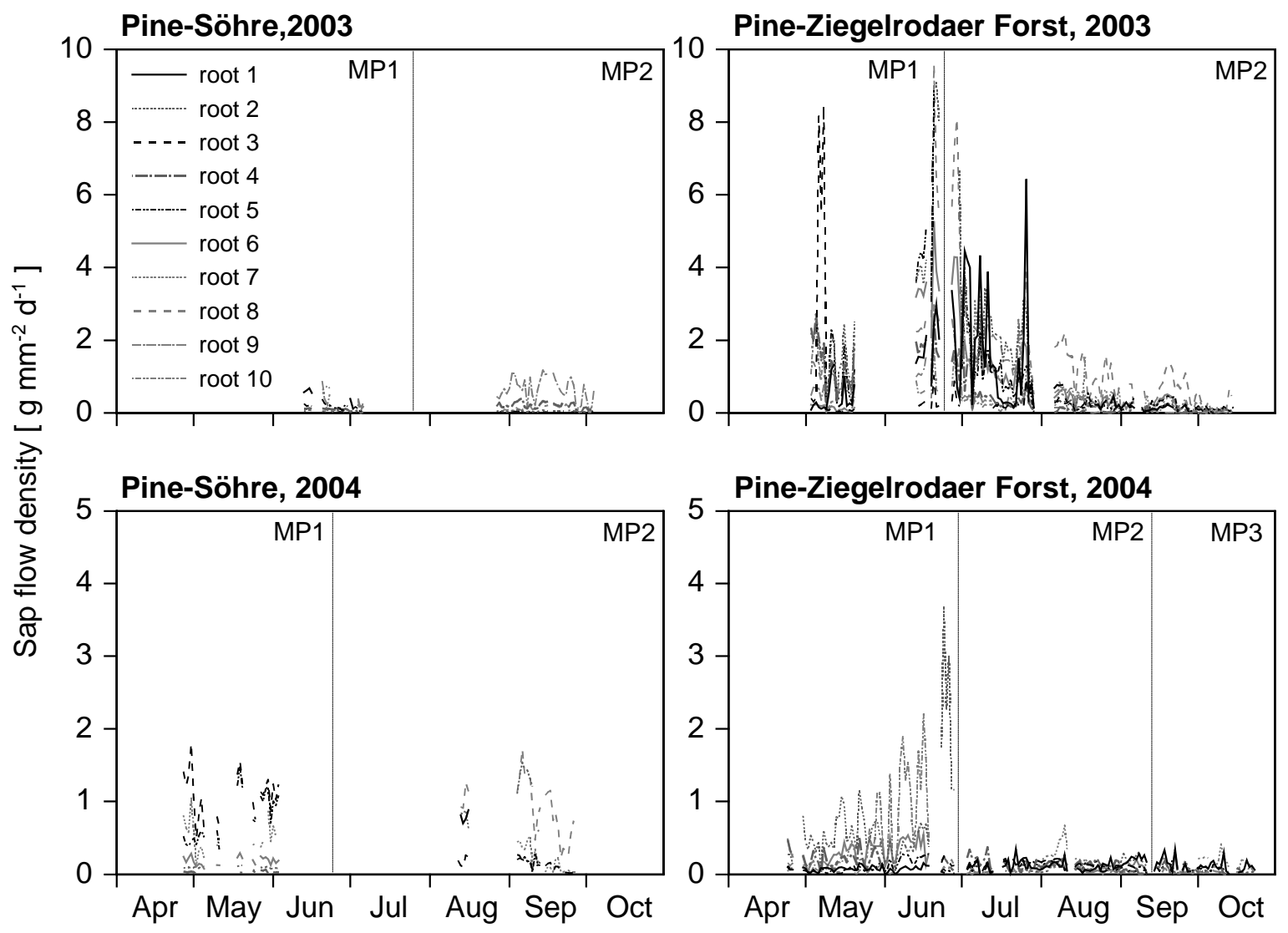

Abb. 4-10. Tageswerte der Saftflussdichte in Kiefernwurzeln (Durchmesser 2-5 mm) gemessen in den Jahren 2003 und 2004 auf den Untersuchungsflächen in der Söhre und im Ziegelrodaer Forst. Als Bezugsfläche wurde die Querschnittsfläche der Wurzel am Saftflusssensor herangezogen. Einzelne Messperioden (MP1, MP2 und MP3) sind durch gepunktete Linien getrennt. Abstand der untersuchten Wurzeln vom Messbaum maximal $10 \mathrm{~m}$. Die Ordinaten für die beiden Messjahre sind unterschiedlich skaliert. 
Das Jahr 2004 unterschied sich hinsichtlich der einzelnen Saftflussdichten bei Kiefernwurzeln deutlich vom Vorjahr. Während im Ziegelrodaer Forst geringere Saftflussdichten gemessen wurden, stiegen sie in der Söhre sogar an. Die Maximalwerte erreichten auf dieser Fläche $1.7 \mathrm{~g} \mathrm{~mm}^{-2} \mathrm{~d}^{-1}$, während im Ziegelrodaer Forst die Maximalwerte ab Juli gerade bei $0.7 \mathrm{~g} \mathrm{~mm}^{-2} \mathrm{~d}^{-1}$ lagen. Im Juni 2004 wurden die höchsten Saftflussdichten im Ziegelrodaer Forst gemessen (Wurzel Nr. 2: $3.6 \mathrm{~g} \mathrm{~mm}^{-2} \mathrm{~d}^{-1}$ ).
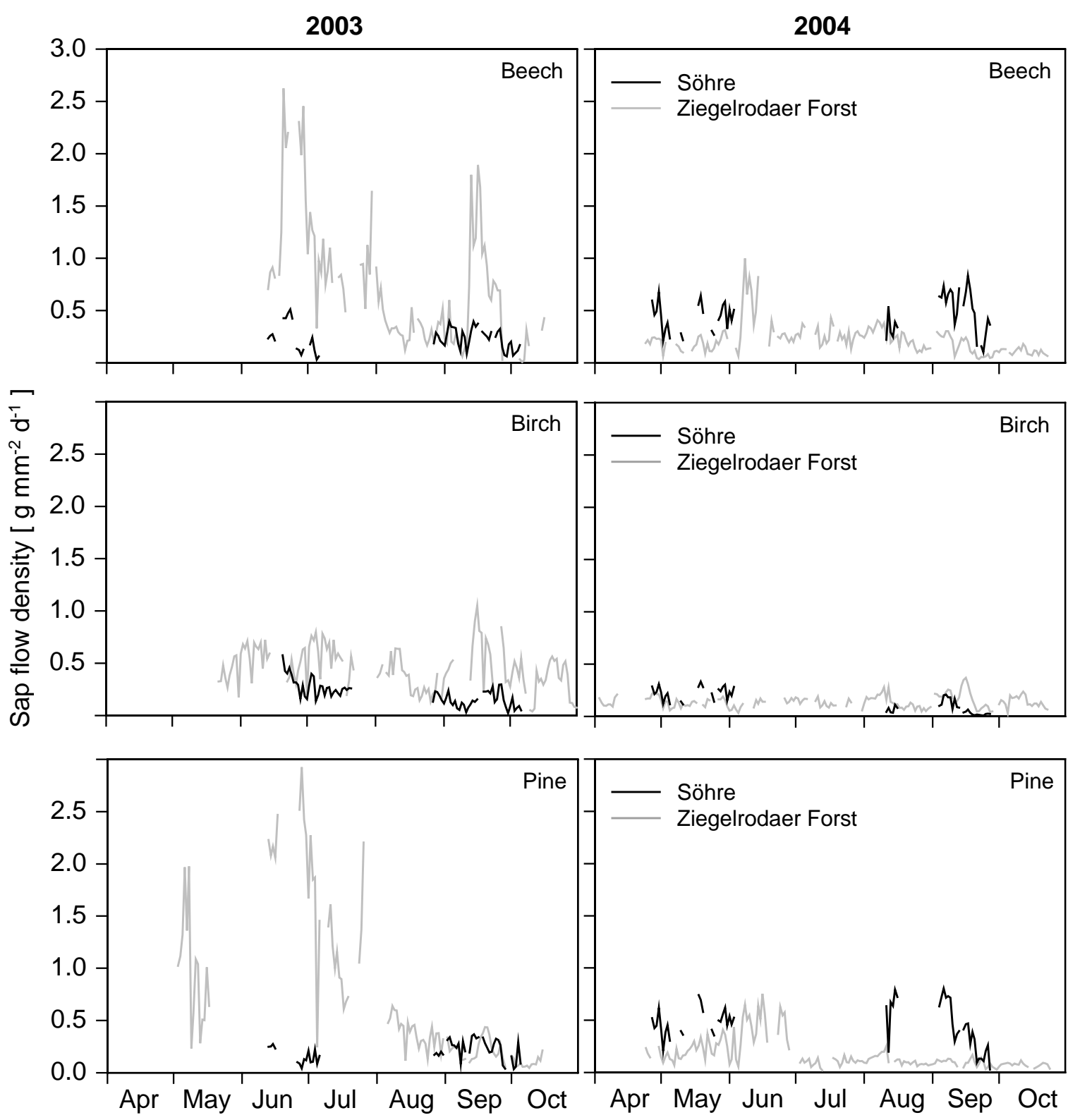

Abb. 4-11. Mittelwerte der Tageswerte der Saftflussdichten in Buchen-, Birken- und Kiefernwurzeln (Durchmesser 2-5 mm) gemessen in den Jahren 2003 und 2004 auf den Untersuchungsflächen in der Söhre und im Ziegelrodaer Forst. Als Bezugsfläche wurde die Querschnittsfläche der Wurzeln am Saftflusssensor herangezogen. Abstand der untersuchten Wurzeln vom Messbaum maximal $10 \mathrm{~m} . \mathrm{n}=5-10$ 
Die mittleren Tageswerte der Saftflussdichten wiesen witterungsbedingt in allen Wurzeln der drei Baumarten große Variationen zwischen den Messtagen des Jahres 2004, insbesondere aber des Jahres 2003 auf (Abb. 4-11).

Diese Schwankungen verliefen besonders im Jahr 2004 auf beiden Flächen bei jeder Baumart annähernd gleich. Kiefer und Buche wiesen in der Saftflussdichte in ihren Wurzeln ähnliche Schwankungsbreiten auf. Die Wurzeln der Birke zeigten auf beiden Untersuchungsflächen im Vergleich $\mathrm{zu}$ den anderen Baumarten die geringsten Schwankungen über das ganze Jahr.

Mit Eintritt des Laubaustriebes Anfang April 2004 kam es zu keinen deutlichen Anstieg der Saftflussdichten der Birkenwurzeln auf der Fläche im Ziegelrodaer Forst. Die mittlere Saftflussdichte der Tageswerte lag jedoch bei Buchen- und Kiefernwurzeln im Ziegelrodaer Forst, besonders aber in der Söhre deutlich höher als im Mai, stieg dann wieder bis Anfang Juni bis auf Maximalwerte (Buche Söhre: $0.7 \mathrm{~g} \mathrm{~mm}^{-2} \mathrm{~d}^{-1}$ ) an, um dann in der Trockenperiode von Juli bis Mitte August deutlich zu fallen. Mit Einsetzen des Niederschlags Anfang September stieg die mittlere Saftflussdichte bei Buchen- und Kiefernwurzeln deutlich, bei Birkenwurzeln in der Söhre nur gering an, um sich am Ende der Vegetationsperiode im Oktober dem Nullpunkt zu nähern. Durch den deutlich trockeneren Boden im Ziegelrodaer Forst, insbesondere im September, kam es in den Wurzeln aller drei Baumarten auf dieser Fläche zu keinem Anstieg vor Ende der Vegetationsperiode.

Ein viel deutlicherer Jahresverlauf der mittleren Saftflussdichte wurde bei Buchen- und Kiefernwurzeln im Jahr 2003 im Ziegelrodaer Forst gemessen. Nach einer ersten Trockenzeit im Mai stiegen die Werte der Saftflussdichten bis Ende Juni auf Maximalwerte von $2.6 \mathrm{~g} \mathrm{~mm}^{-2} \mathrm{~d}^{-1}$ bei der Buche und sogar bis auf Werte von $2.9 \mathrm{~g} \mathrm{~mm}^{-2} \mathrm{~d}^{-1}$ bei der Kiefer, um dann mit Einsetzen des extremen „Jahrhundertsommers“ kontinuierlich bis Anfang September zu fallen. Während die Kiefer ihre Saftflussdichte in den Wurzeln weiter verringerte und bis zum Oktober ihr Minimum erreichte, erhöhte sich die Saftflussdichte in den Buchenwurzeln mit Einsetzen des Niederschlags deutlich, um dann ab Mitte September kontinuierlich zu fallen und so ihre Minimumwerte ebenfalls im Oktober zu erreichen.

Die Wurzeln der Birke im Ziegelrodaer Forst zeigten einen nicht so deutlichen Jahresverlauf wie Buchen- und Kiefernwurzeln. Man erkennt ein deutliches Absenken der Saftflussdichte im „Jahrhundertsommer“ und gegen Ende der Vegetationsperiode mit Einsetzen des Niederschlages Anfang September ein deutliches Ansteigen. Die Saftflussdichte fiel erst gegen Ende Oktober gegen Null.

In den Wurzeln aller drei Baumarten wurden über das gesamte Jahr 2003 geringere mittlere Saftflussdichten in der Söhre als im Ziegelrodaer Forst gemessen. 


\subsubsection{Mittelwerte von Saftflussdichte in Buchen-, Birken und Kiefern- feinwurzeln in ihrer Abhängigkeit von klimatischen Faktoren}

Die Mittelwerte der querschnittsbezogenen Saftflussdichten, der Wurzelwasserpotenziale, des Wasserdampfsättigungsdefizits (VPD), des Bodenwassergehalts und des mittleren Niederschlags zeigten in den verschiedenen Abschnitten der Vegetationsperiode des Jahres 2003 deutliche Unterschiede zwischen den beiden Beständen (Abb. 4-12). Über die gesamte Vegetationsperiode unterschieden sich die querschnittsbezogenen Saftflussdichten von Buchen- und Kiefernwurzeln zwischen beiden Untersuchungsflächen signifikant. In der Trockenperiode konnten jedoch keinerlei signifikante Unterschiede festgestellt werden. Am Ende der Vegetationsperiode, ab Mitte September, traten lediglich in der Saftflussdichte der Buchenwurzeln signifikante Unterschiede zwischen der Fläche in der Söhre und der im Ziegelrodaer Forst auf. Generell konnten bei allen drei Baumarten und in allen Abschnitten der Vegetationsperiode auf der Fläche im Ziegelrodaer Forst deutlich höhere Saftflussdichten beobachtet werden als auf der Fläche in der Söhre.

Die über die entsprechenden Zeiträume ebenfalls untersuchten klimatischen Faktoren VPD und Niederschlag wiesen im Vergleich der beiden Untersuchungsflächen keine signifikanten Unterschiede auf. Bei der Betrachtung des Bodenwassergehalts jedoch wies der Boden im Ziegelrodaer Forst über weite Strecken der Vegetationsperiode einen signifikant höheren Wassergehalt auf als in der Söhre (Abb. 4-12). Am Ende der Vegetationsperiode unterschied sich der Bodenwassergehalt zwischen beiden Untersuchungsflächen nicht signifikant voneinander.

Die Wasseraufnahme am Standort Ziegelrodaer Forst blieb bei Betrachtung der gesamten Vegetationsperiode 2004 bei allen drei Baumarten deutlich geringer als 2003 (Abb. 4-13). Am Standort Söhre jedoch unterschieden sich die Wasseraufnahmen in den beiden Untersuchungsjahren in allen drei Baumarten nicht deutlich voneinander.

Beachtlich ist die mittlere Saftflussdichte in Kiefernwurzeln über die gesamte Vegetationsperiode (Abb. 4-13). Hier wiesen die Wurzeln in der Söhre signifikant höhere Aufnahmeraten auf als im Ziegelrodaer Forst, gerade umgekehrt als im Jahr 2003. Auch die Birkenwurzeln wiesen deutlich höhere Aufnahmeraten am Standort Söhre im Jahr 2004 auf als im Ziegelrodaer Forst, jedoch ohne signifikanten Unterschied.

Interessant ist die signifikant höhere Wasseraufnahme in Kiefernwurzeln in der Trockenperiode am Standort Söhre im Jahr 2004. Im Jahr 2003 unterschied sich keine Baumart signifikant zwischen den Untersuchungsflächen in der Trockenperiode. Im Jahr 2004 ließen sich weder in Buchen- noch in Birkenwurzeln (4.9.-27.9.) signifikante Unterschiede in der Saftflussdichte zwischen den Untersuchungsflächen erkennen (Abb. 4-12 und Abb. 4-13). 


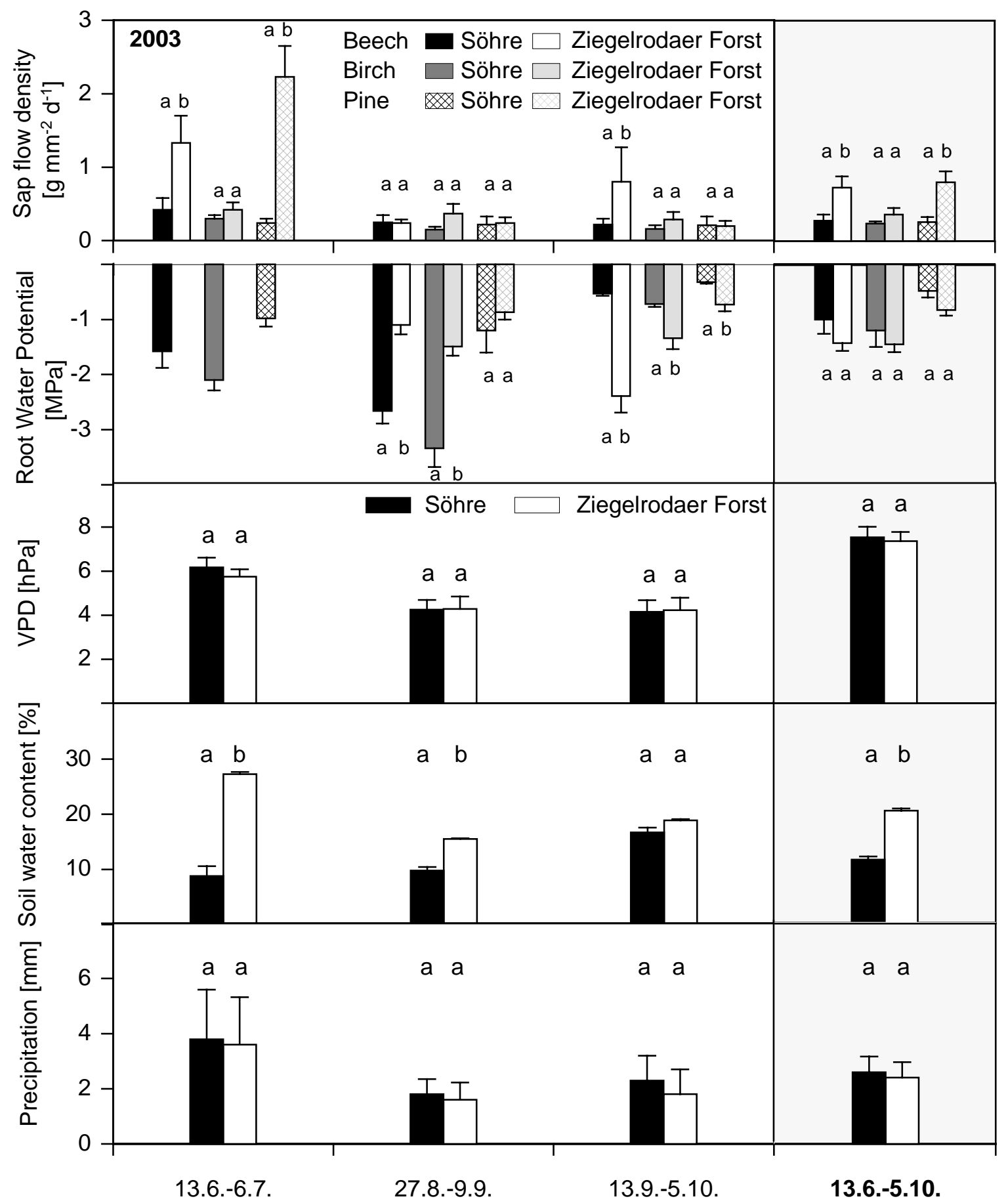

Abb. 4-12. Mittelwerte der Saftflussdichte und des Wasserpotenzials von Buchen-, Birken- und Kiefernfeinwurzeln auf den Flächen in der Söhre und im Ziegelrodaer Forst sowie Mittelwerte von VPD (Daten DWD), Bodenwassergehalt (in $5 \mathrm{~cm}$ Bodentiefe) und täglichem Niederschlag (Daten DWD) im Jahr 2003. Mittelwerte sind angegeben für die Zeiträume: Frühsommer (13.6.-6.7.), Trockenperiode (27.8.-9.9.) und Wiederbefeuchtung am Ende der Vegetationsperiode (13.9.-5.10); gesamte Vegetationsperiode (13.6.-5.10; grau hinterlegt). Unterschiedliche Kleinbuchstaben markieren signifikante Unterschiede zwischen den beiden Flächen $(\mathrm{p}<0.05$, Scheffé). 


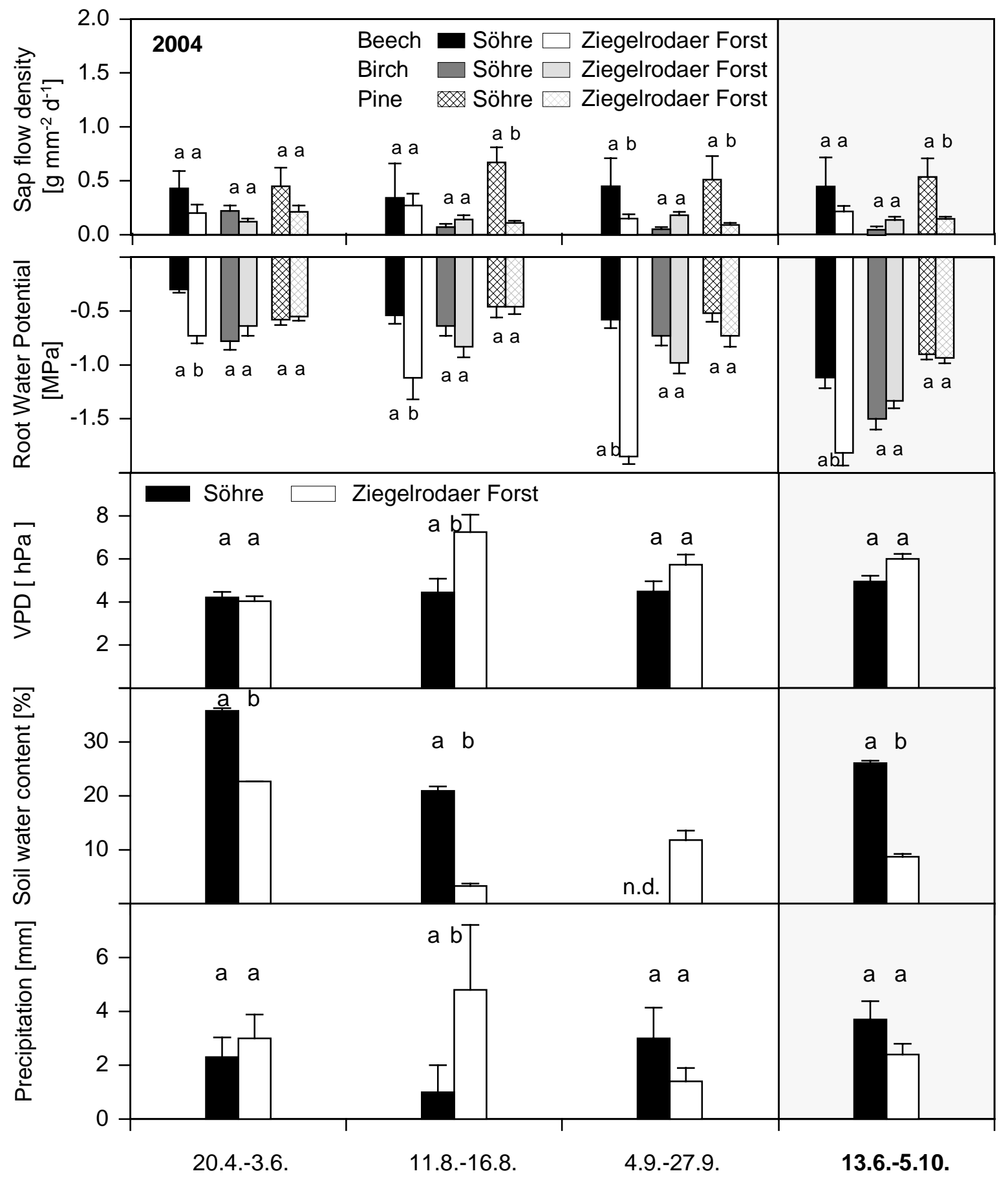

Abb. 4-13. Mittelwerte der Saftflussdichte und des Wasserpotenzials von Buchen-, Birken- und Kiefernfeinwurzeln auf den Flächen in der Söhre und im Ziegelrodaer Forst sowie Mittelwerte von VPD (Daten DWD), Bodenwassergehalt (in $5 \mathrm{~cm}$ Bodentiefe) und täglichem Niederschlag (Daten DWD) im Jahr 2004. Mittelwerte sind angegeben für die Zeiträume: Anfang der Vegetationsperiode (20.4.-3.6.), Trockenperiode (11.8.16.8.) und Wiederbefeuchtung am Ende der Vegetationsperiode (4.9.-27.9); gesamte Vegetationsperiode (13.6.-5.10; grau hinterlegt). Unterschiedliche Kleinbuchstaben markieren signifikante Unterschiede zwischen den beiden Flächen $(\mathrm{p}<0.05$, Scheffé). 


\title{
4.3.4 Oberflächenbezogener Saftfluss in Buchen-, Birken- und Kiefernfeinwurzeln
}

Durch den Bezug der gemessenen Saftflussraten $\left[\mathrm{g} \mathrm{d}^{-1}\right]$ auf die aufnehmende Wurzeloberfläche $\left[\mathrm{m}^{2}\right]$ können oberflächenspezifische Saftflussraten bestimmt werden. Diese wichen teilweise deutlich von den wurzelquerschnittsbezogenen Saftflussdichten ab (Abb. 4-14 - Abb. 4-16).

Die einzelnen Buchenwurzeln wiesen auf der Untersuchungsfläche im Ziegelrodaer Forst im Untersuchungsjahr 2003 deutlich größere Amplituden der oberflächenspezifischen Saftflussraten auf als in der Söhre, wo zudem die oberflächenspezifischen Saftflussraten vor allem am Anfang der Vegetationsperiode erheblich geringer waren (Abb. 4-14). Gegen Ende der Vegetationsperiode, ab Ende August, wiesen die einzelnen Buchenwurzeln auf beiden Flächen etwa gleich hohe oberflächenspezifische Saftflussraten auf (um $500 \mathrm{~g} \mathrm{~m}^{-2} \mathrm{~d}^{-1}$ ).
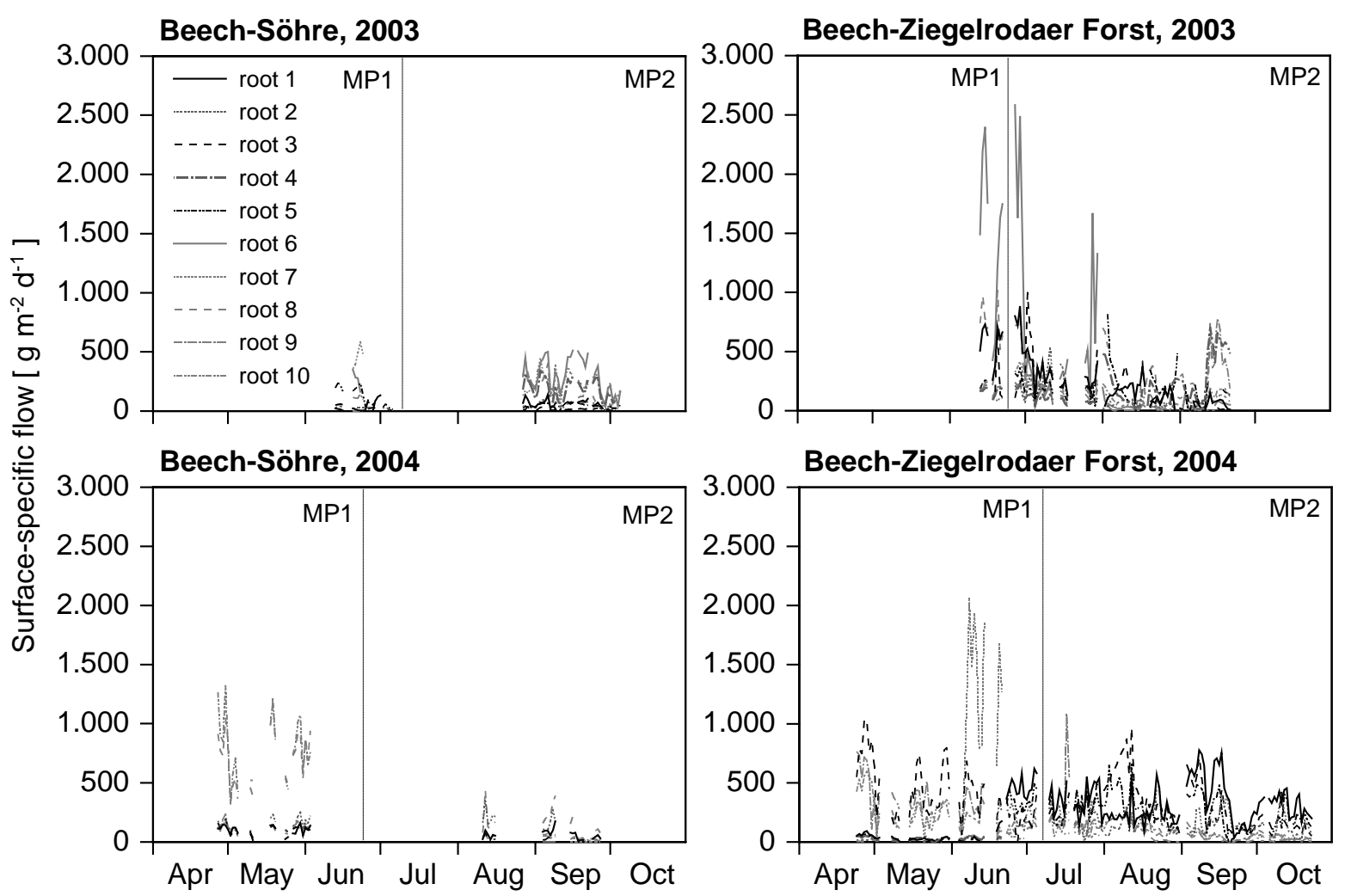

\begin{abstract}
Abb. 4-14. Tageswerte des oberflächenbezogenen Saftflusses in Buchenwurzeln (Durchmesser 2-5 mm) gemessen in den Jahren 2003 und 2004 auf den Untersuchungsflächen in der Söhre und im Ziegelrodaer Forst. Als Bezugsfläche wurde die gesamte aufnehmende Wurzeloberfläche herangezogen. Einzelne Messperioden (MP1, MP2) sind durch gepunktete Linien getrennt. Abstand der untersuchten Wurzeln vom Messbaum maximal $10 \mathrm{~m}$.
\end{abstract}


Auffallend ist der deutliche Wiederanstieg der oberflächenbezogenen Wasseraufnahme mit Eintritt des Niederschlages Mitte September am Standort Ziegelrodaer Forst bis auf Werte um $750 \mathrm{~g} \mathrm{~m}^{-2} \mathrm{~d}^{-1}$. Auf beiden Standorten sinkt der Saftfluss aller Buchenwurzeln am Ende der Vegetationsperiode gegen Null.

Am Anfang der Vegetationsperiode von 2004 stieg der oberflächenspezifische Saftfluss auf beiden Standorten ähnlich stark an (bis $1000 \mathrm{~g} \mathrm{~m}^{-2} \mathrm{~d}^{-1}$ ). Während in der Söhre im September nur noch Werte von deutlich unter $500 \mathrm{~g} \mathrm{~m}^{-2} \mathrm{~d}^{-1}$ erreicht wurden, wiesen im Ziegelrodaer Forst die einzelnen Buchenwurzeln während der gesamten Vegetationsperiode mit kurzzeitig witterungsbedingten Schwankungen oberflächenspezifische Saftflussraten bis zu etwa $1000 \mathrm{~g} \mathrm{~m}^{-2} \mathrm{~d}^{-1}$ auf.

Die oberflächenspezifischen Saftflussraten der einzelnen Birkenwurzeln blieben am Standort Söhre in beiden Untersuchungsjahren meist unter $500 \mathrm{~g} \mathrm{~m}^{-2} \mathrm{~d}^{-1}$, während im Ziegelrodaer Forst deutlich höhere Wasseraufnahmeraten gemessen wurden.
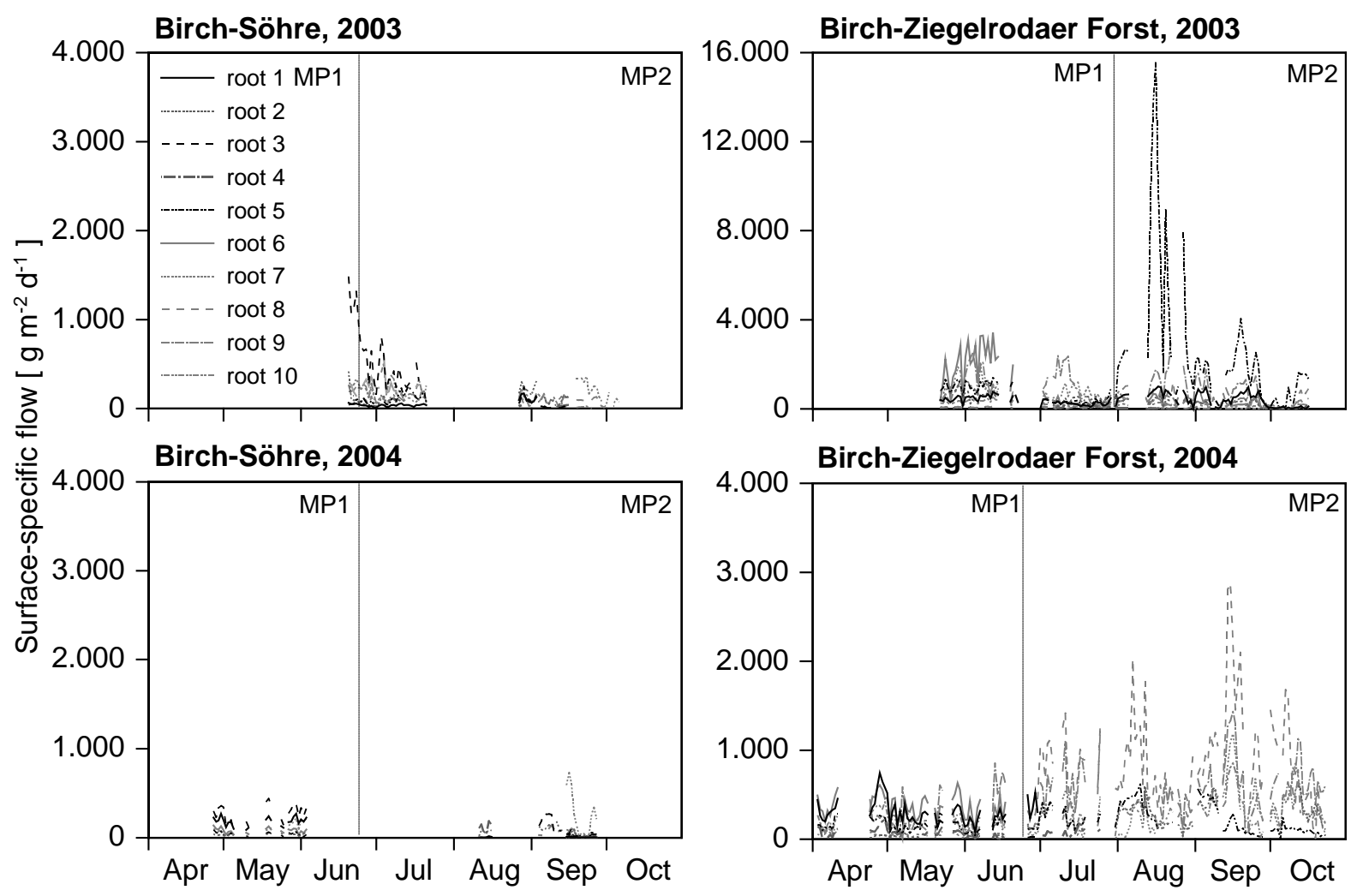

Abb. 4-15. Tageswerte des oberflächenbezogenen Saftflusses in Birkenwurzeln (Durchmesser 2-5 mm) gemessen in den Jahren 2003 und 2004 auf den Untersuchungsflächen in der Söhre und im Ziegelrodaer Forst (unterschiedliche Skalierung). Als Bezugsfläche wurde die gesamte aufnehmende Wurzeloberfläche herangezogen. Einzelne Messperioden (MP1, MP2) sind durch gepunktete Linien getrennt. Abstand der untersuchten Wurzeln vom Messbaum maximal $10 \mathrm{~m}$. 
Hier konnten die größten oberflächenspezifischen Saftflussraten im sogenannten „Jahrhundertsommer“ 2003 ermittelt werden. Die Birkenwurzel Nr. 5 erreichte Saftflussraten bis $16.000 \mathrm{~g} \mathrm{~m}^{-2} \mathrm{~d}^{-1}$ (Abb. 4-15). Auch im darauffolgenden Untersuchungsjahr konnten oberflächenspezifische Saftflussraten von deutlich über 500 bis $3000 \mathrm{~g} \mathrm{~m}^{-2} \mathrm{~d}^{-1}$ gemessen werden.

Einzelne Kiefernwurzeln erreichten auf der Untersuchungsfläche im Ziegelrodaer Forst im Juni 2003 oberflächenspezifische Wurzelwasseraufnahmeraten bis $14.000 \mathrm{~g} \mathrm{~m}^{-2} \mathrm{~d}^{-1}$. Alle oberflächenspezifischen Saftflussraten sanken an diesem Standort bei allen Kiefernwurzeln bis Mitte Oktober deutlich ab. Ein Wiederanstieg im September 2003, wie bei Buche und Birke beobachtet, konnte bei der Kiefer nicht festgestellt werden.

Insgesamt wurden am Standort Söhre deutlich geringere oberflächenspezifische Saftflussraten gemessen als im Ziegelrodaer Forst, wo im Jahr 2004 über den gesamten Jahresverlauf Aufnahmeraten von bis zu $4000 \mathrm{~g} \mathrm{~m}^{-2} \mathrm{~d}^{-1}$ gemessen wurden (Abb. 4-16).
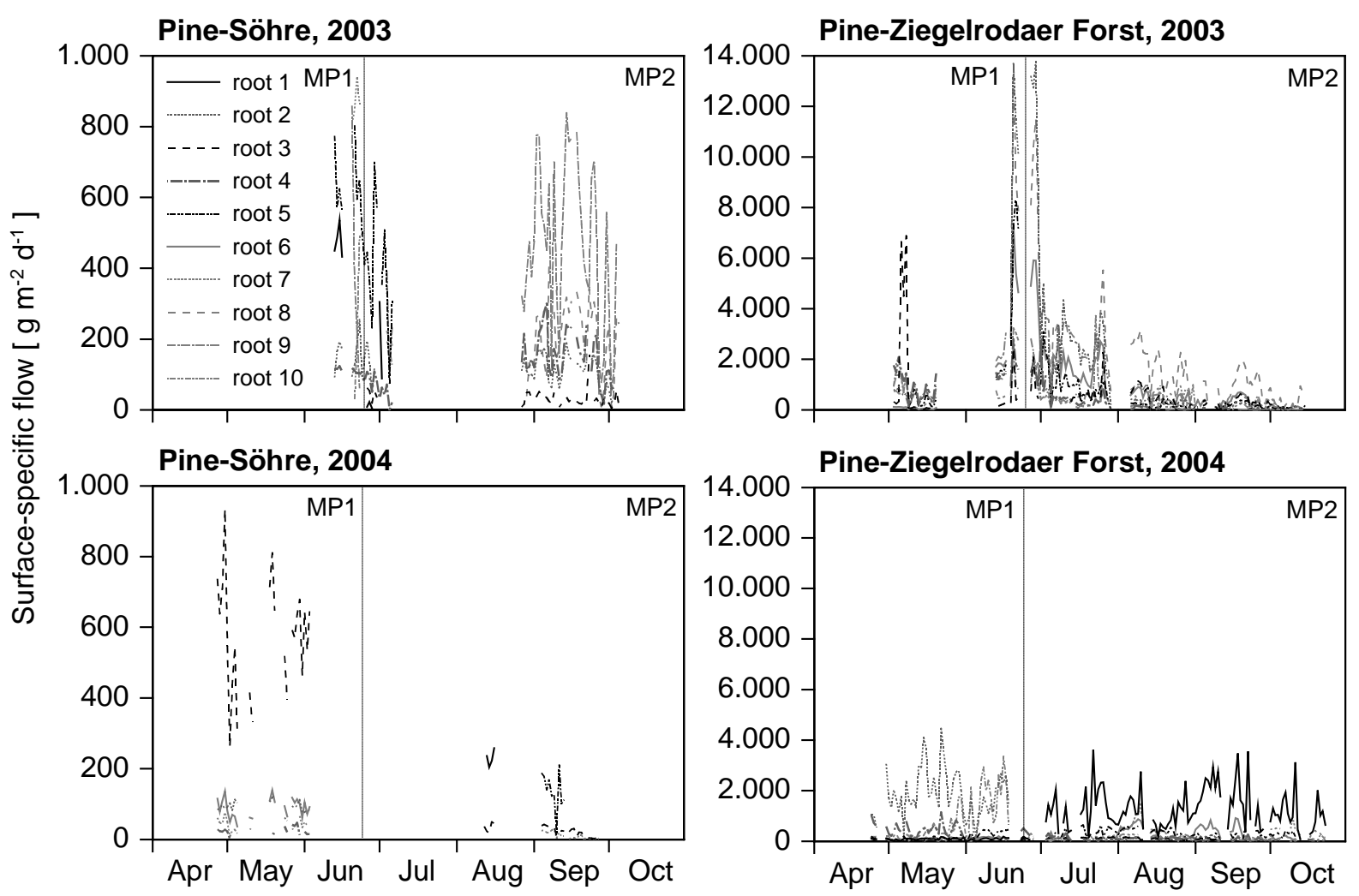

Abb. 4-16. Tageswerte des oberflächenbezogenen Saftflusses in Kiefernwurzeln (Durchmesser 2-5 mm) gemessen in den Jahren 2003 und 2004 auf den Untersuchungsflächen in der Söhre und im Ziegelrodaer Forst (unterschiedliche Skalierung). Als Bezugsfläche wurde die gesamte aufnehmende Wurzeloberfläche herangezogen. Einzelne Messperioden (MP1, MP2) sind durch gestrichelte Linien getrennt. Abstand der untersuchten Wurzeln vom Messbaum maximal $10 \mathrm{~m}$. 
Im saisonalen Verlauf fällt in beiden Untersuchungsjahren die weitgehend synchron verlaufende Dynamik auf beiden Untersuchungsflächen auf. Bei allen drei Baumarten blieb in beiden Untersuchungsjahren die oberflächenspezifische Wasseraufnahme (eine Ausnahme bilden die Buchenwurzeln 2004) am Standort Söhre merklich geringer als im Ziegelrodaer Forst (Abb. 4-17).

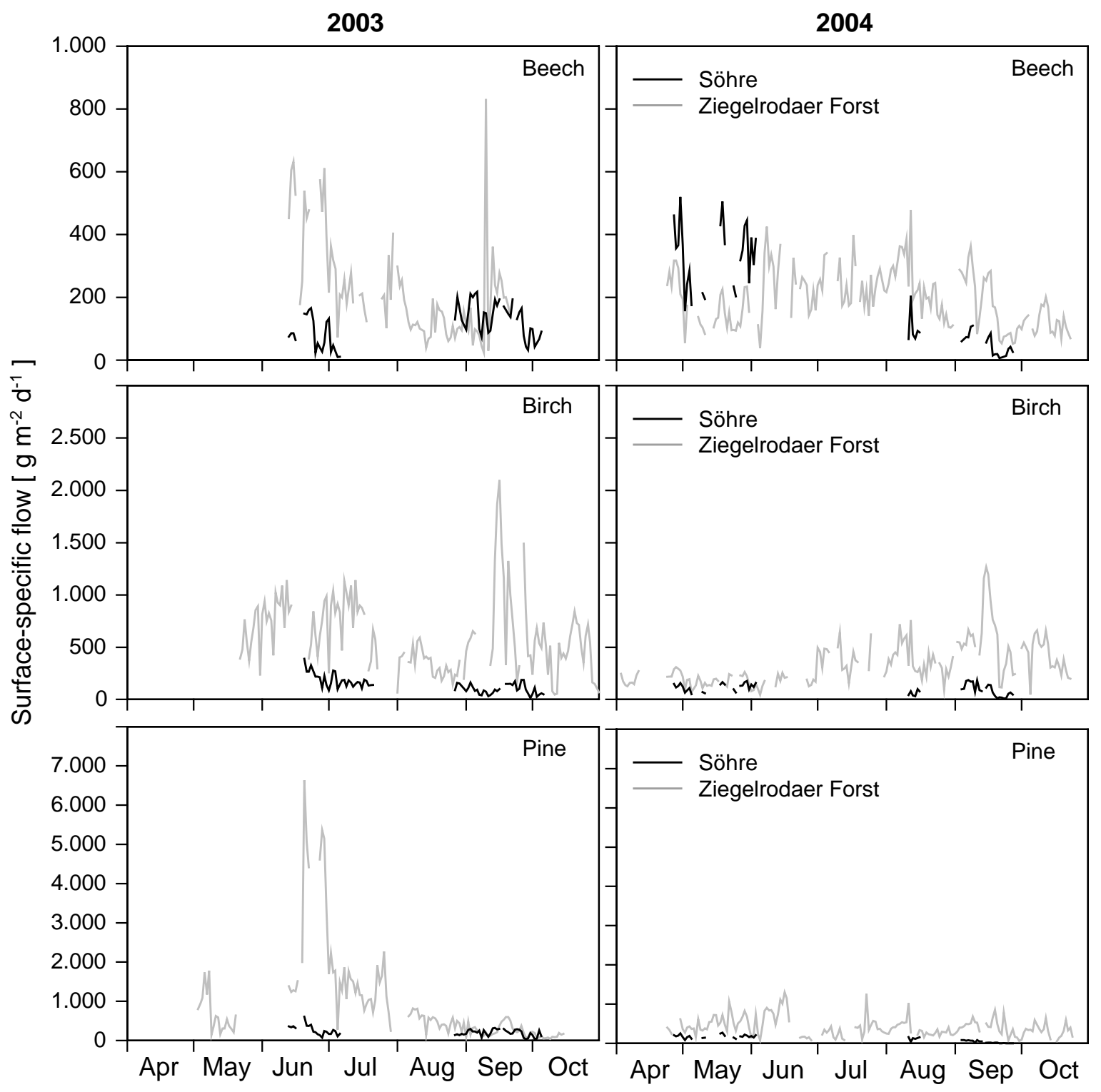

Abb. 4-17. Mittelwerte der Tageswerte des oberflächenbezogenen Saftflusses in Buchen-, Birken- und Kiefernwurzeln (Durchmesser 2-5 mm) gemessen in den Jahren 2003 und 2004 auf den Untersuchungsflächen in der Söhre und im Ziegelrodaer Forst (unterschiedliche Skalierung). Als Bezugsfläche diente die gesamte Wurzeloberfläche. Abstand der untersuchten Wurzeln vom Messbaum maximal $10 \mathrm{~m}$. $\mathrm{n}=5-10$. 
Interessant ist das Absinken der oberflächenspezifischen Saftflussrate bei Buchen-, Birken- und Kiefernwurzeln am Standort Ziegelrodaer Forst vom Frühsommer bis zur Trockenperiode Ende August/Anfang September im Jahr 2003 und der Wiederanstieg bei Buchen- und Birkenwurzeln mit Einsetzen des Niederschlags Anfang September. Im Gegensatz $\mathrm{zu}$ den Laubbaumarten reduzieren die Kiefernwurzeln ihre Wasseraufnahmeraten auch nach der Trockenperiode weiter bis zum Ende der Vegetationsperiode.

Die insgesamt höchsten mittleren oberflächenspezifischen Saftflussraten aller untersuchten Wurzeln einer Art wurden für Kiefernwurzeln auf der Untersuchungsfläche im Ziegelrodaer Forst ermittelt. Dort wurden Mittelwerte bis über $6000 \mathrm{~g} \mathrm{~m}^{-2} \mathrm{~d}^{-1}$ erreicht.

Birken- und Kiefernwurzeln wiesen am Standort Ziegelrodaer Forst im Untersuchungsjahr 2004 erheblich geringere oberflächenspezifische Saftflussraten auf als 2003. Am Standort Söhre unterschieden sich die Aufnahmeraten von 2003 und 2004 nicht.

Die Birkenwurzeln am Standort Ziegelrodaer Forst nahmen Mitte September 2004 als einzige der untersuchten Wurzeln deutlich mehr Wasser auf als im gesamten vorherigen Zeitabschnitt.

\subsubsection{Vergleich der Einflussfaktoren auf den oberflächenbezogenen Saftfluss und die Saftflussdichte}

Durch die Faktoren Baumart, Standort, Vegetationsphase und Jahr lassen sich fast ein Fünftel des oberflächenbezogenen Saftflusses und weniger als ein Achtel der Saftflussdichte mittels Varianzanalyse erklären (Tab. 4-3).

Tabelle 4-3. Varianzanalyse für alle in den Vegetationsperioden 2003 und 2004 an Buche, Birke und Kiefer gemessenen Wurzelsaftflussraten hinsichtlich der Einflussfaktoren Baumart (Tree species), Standort (Plot), Vegetationsphase (Dry/moist) und Jahr (Year). $\mathrm{J}_{\text {surf-spec: }}$ Varianzanteil des oberflächenbezogenen Saftflusses, $\mathrm{J}_{\text {density: }}$ : Varianzanteil der Saftflussdichte aller Wurzeln, $\mathrm{p}=$ Signifikanz. Varianzanalyse nach GLM.

\begin{tabular}{lcccc}
\hline & $\mathbf{J}_{\text {surf-spec }}$ & $\mathbf{p}$ & $\mathbf{J}_{\text {density }}$ & $\mathbf{p}$ \\
\hline Tree species & 6.6 & $<0.001$ & 1.3 & $<0.05$ \\
Plot & 5.4 & $<0.001$ & 1.0 & $<0.01$ \\
Dry/moist & 2.7 & $<0.05$ & 2.0 & $<0.01$ \\
Year & 4.1 & $<0.001$ & 3.2 & $<0.001$ \\
Total variance & 18.8 & $<0.001$ & 7.5 & $<0.001$ \\
\hline
\end{tabular}


Der größte Anteil der Varianz wird dabei mit 6.6\% durch die Baumarten beim oberflächenbezogenen Saftfluss erklärt. Ein etwas geringerer Varianzanteil von 5.4\% erklären die Standorte gefolgt vom Jahr (4.1\%). Nur 2.7\% erklären die Vegetationsphasen für den oberflächenbezogenen Saftfluss aller Wurzeln. In der Saftflussdichte wird die Varianz durch Baumarten, Standort und Vegetationsphase mit 1-2\% erklärt. Das Jahr nimmt mit 3.2\% den höchsten Anteil der Varianz für die Erklärung der Saftflussdichte ein.

Tabelle 4-4. Ergebnisse der dreifaktoriellen Varianzanalyse bezugnehmend auf die Baumarten (Tree species). $J_{\text {surf-spec }}$ : Varianzanteil des oberflächenbezogenen Saftflusses,

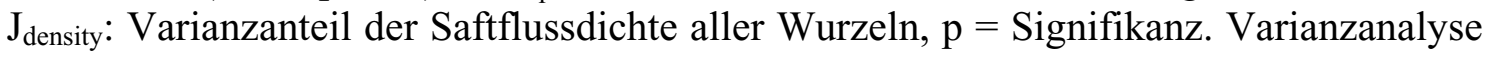
nach GLM.

\begin{tabular}{lcccc}
\hline & $\mathbf{J}_{\text {surf-spec }}$ & $\mathbf{p}$ & $\mathbf{J}_{\text {density }}$ & $\mathbf{p}$ \\
\hline Beech & & & & \\
Plot & - & $<0.05$ & - & $<0.05$ \\
Dry/moist & - & $<0.05$ & - & $<0.05$ \\
Year & 3.4 & $<0.05$ & 6.5 & $<0.05$ \\
Total variance & 3.4 & $<0.05$ & 6.5 & $<0.03$ \\
Birch & & & & \\
Plot & 16.1 & $<0.001$ & 6.1 & $<0.05$ \\
Dry/moist & - & $<0.05$ & - & $<0.05$ \\
Year & 6.6 & $<0.05$ & 24.0 & $<0.001$ \\
Total variance & 22.7 & $<0.01$ & 30.1 & $<0.001$ \\
Pine & & & & \\
Plot & 7.4 & $<0.01$ & - & $<0.05$ \\
Date & 13.4 & $<0.01$ & 15.6 & $<0.01$ \\
Year & 8.2 & $<0.01$ & 6.8 & $<0.05$ \\
Total variance & 28.9 & $<0.01$ & 22.4 & $<0.01$ \\
\hline
\end{tabular}

In Tabelle 4-4 sind die Ergebnisse der dreifaktoriellen Varianzanalyse für jede Baumart aufgetragen. Der oberflächenbezogene Saftfluss der Birke wird durch fast ein Viertel aller Faktoren in der Gesamtvarianz und der der Kiefer durch fast ein Drittel aller Faktoren in der Gesamtvarianz erklärt. Auch die Saftflussdichte beider Baumarten werden durch alle Faktoren in der Gesamtvarianz bei Birke mit 30.1\% und bei Kiefer mit $22.4 \%$ erklärt. 
Für die Buche spielt jeweils nur das Untersuchungsjahr eine Rolle und erklärt hier auch nur $3.4 \%$ bzw. $6.5 \%$ der Varianz in den oberflächenbezogenen Saftfluss bzw. der Saftflussdichte. Dieser Varianzanteil wird jeweils nur durch Unterschiede in den Jahren erklärt.

Ein hoher Varianzanteil im oberflächenbezogenen Saftfluss und in der Saftflussdichte der Kiefer wird durch Unterschiede zwischen der feuchten und der trockenen Vegetationsphase erklärt. Für die Saftflussdichte der Birke wird der höchste erklärte Varianzanteil mit $24.0 \%$ für Unterschiede zwischen den Jahren und für den oberflächenbezogenen Saftfluss der Birke für Unterschiede zwischen den Standorten $(16.1 \%)$ erklärt.

Tabelle 4-5. Ergebnisse der dreifaktoriellen Varianzanalyse bezugnehmend auf den Standort (Plot). $\mathrm{J}_{\text {surf-spec }}$ : Varianzanteil des oberflächenbezogenen Saftflusses, $\mathrm{J}_{\text {density: }}$ : Varianzanteil der Saftflussdichte aller Wurzeln, $\mathrm{p}=$ Signifikanz. Varianzanalyse nach GLM.

\begin{tabular}{lcccc}
\hline & $\mathbf{J}_{\text {surf-spec }}$ & $\mathbf{p}$ & $\mathbf{J}_{\text {density }}$ & $\mathbf{p}$ \\
\hline Söhre & & & & \\
Tree species & - & $<0.05$ & 6.9 & $<0.05$ \\
Dry/moist & - & $<0.05$ & - & $<0.05$ \\
Year & 6.5 & $<0.01$ & - & $<0.05$ \\
Total variance & 6.5 & $<0.01$ & 6.9 & $<0.05$ \\
Ziegelrodaer Forst & & & & \\
Tree species & 9.8 & $<0.001$ & - & $<0.001$ \\
Dry/moist & 4.5 & $<0.05$ & 8.3 & $<0.001$ \\
Year & 6.4 & $<0.05$ & 14.9 & $<0.001$ \\
Total variance & 20.7 & $<0.001$ & 23.2 & $<0.05$ \\
\hline
\end{tabular}

Am niederschlagsreicheren Standort Söhre erklärt die Varianz nur 6.5\% für den oberflächenbezogenen Saftfluss durch Jahresunterschiede und fast $7 \%$ durch Unterschiede zwischen den Baumarten (Tab. 4-5).

Am niederschlagsärmeren Standort Ziegelrodaer Forst erklären die Faktoren Baumarten, Vegetationsphasen und Unterschiede in den Jahren fast ein Viertel des oberflächenbezogenen Saftflusses und der Saftflussdichte.

Im oberflächenbezogenen Saftfluss kommt es zum höchsten erklärten Varianzanteil auf dieser Untersuchungsfläche mit fast 10\% Unterschied bezüglich der Baumarten. 15\% der Varianz bei der Saftflussdichte gehen auf das Messjahr zurück. 
Ein deutlich höherer Anteil der Varianz konnte für den oberflächenbezogenen Saftfluss (22.7\%) und für die Saftflussdichte (19.4\%) im Jahr 2003 erklärt werden (Tab. 4-6). Dabei spielten Unterschiede zwischen den Baumarten, Unterschiede zwischen den Vegetationsphasen und Unterschiede zwischen den Jahren für den oberflächenbezogenen Saftfluss mit 7-8\% eine gleich große Bedeutung, während für die Saftflussdichte der höchste Varianzanteil durch Unterschiede in den Vegetationsphasen $(10.4 \%)$ gefolgt von den Jahresunterschieden $(9.0 \%)$ erklärt werden kann.

Tabelle 4-6. Ergebnisse der dreifaktoriellen Varianzanalyse bezugnehmend auf das Jahr (Year). $\quad \mathrm{J}_{\text {surf-spec: }}$ Varianzanteil des oberflächenbezogenen Saftflusses, $\mathrm{J}_{\text {density: }}$ : Varianzanteil der Saftflussdichte aller Wurzeln, $\mathrm{p}=$ Signifikanz. Varianzanalyse nach GLM.

\begin{tabular}{lcccc}
\hline & $\mathbf{J}_{\text {surf-spec }}$ & $\mathbf{p}$ & $\mathbf{J}_{\text {density }}$ & $\mathbf{p}$ \\
\hline 2003 & & & & \\
Tree species & 7.7 & $<0.01$ & - & $<0.05$ \\
Dry/moist & 7.0 & $<0.01$ & 10.4 & $<0.001$ \\
Plot & 8.0 & $<0.01$ & 9.0 & $<0.001$ \\
Total variance & 22.7 & $<0.01$ & 19.4 & $<0.001$ \\
2004 & & & & \\
Tree species & - & $<0.05$ & 7.2 & $<0.01$ \\
Dry/moist & - & $<0.05$ & - & $<0.05$ \\
Plot & 8.1 & $<0.01$ & 10.1 & $<0.001$ \\
Total variance & 8.1 & $<0.01$ & 17.3 & $<0.001$ \\
\hline
\end{tabular}

In Tabelle 4-7 sind die Varianzanteile für eine feuchte Vegetationsphase und eine trockene Vegetationsphase aufgetragen, erklärt mit der dreifaktoriellen Varianzanalyse für die Faktoren Baumart, Standort und Jahr.

In der Trockenperiode ist der mit den betrachteten Parametern erklärte Varianzanteil mit $8 \%$ für den oberflächenbezogenen Saftfluss sehr gering. Keinen Einfluss haben die untersuchten Faktoren auf die Saftflussdichte in den Trockenperioden, während in den feuchten Vegetationsphasen insgesamt ein Drittel der Faktoren Einfluss auf die Saftflussdichte haben. Den höchsten Varianzanteil nimmt hier der Jahresunterschied mit $14.8 \%$ ein.

Auch der oberflächenbezogene Saftfluss wird in der Gesamtvarianz durch ein Drittel aller Faktoren erklärt. Den größten Einfluss nehmen hier die Unterschiede zwischen den Baumarten mit 13.4\% erklärbarer Varianz ein. 
Tabelle 4-7. Ergebnisse der dreifaktoriellen Varianzanalyse bezugnehmend auf das

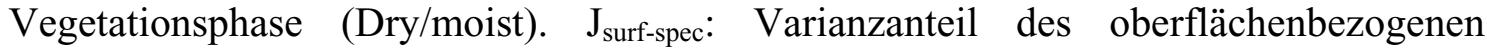

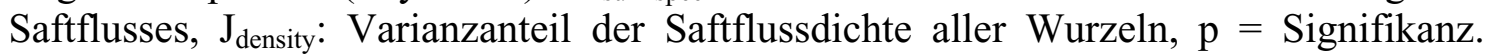
Varianzanalyse nach GLM.

\begin{tabular}{lcccc}
\hline & $\mathbf{J}_{\text {surf-spec }}$ & $\mathbf{p}$ & $\mathbf{J}_{\text {density }}$ & $\mathbf{p}$ \\
\hline Date (moist season) & & & & \\
Tree species & 13.4 & $<0.001$ & 7.7 & $<0.01$ \\
Plot & 7.4 & $<0.001$ & 8.8 & $<0.001$ \\
Year & 9.1 & $<0.001$ & 14.8 & $<0.001$ \\
Total variance & 29.9 & $<0.001$ & 31.3 & $<0.001$ \\
Date (dry season) & & & & \\
Tree species & - & $<0.05$ & - & $<0.05$ \\
Plot & 8.3 & $<0.01$ & - & $<0.05$ \\
Year & - & $<0.05$ & - & $<0.05$ \\
Total variance & 8.3 & $<0.05$ & - & $<0.05$ \\
\hline
\end{tabular}

\subsubsection{Wasseraufnahme in Abhängigkeit von Globalstrahlung, VPD und Bodenfeuchte}

Am niederschlagsreicheren Standort in der Söhre bestand im Jahr 2003 bei Buchen- und Kiefernwurzeln keinerlei Abhängigkeit der Saftflussdichte vom VPD (Tab. 4-8). Am deutlich trockeneren Standort Ziegelrodaer Forst konnte die Saftflussdichte der Buchenwurzeln in einer feuchten Periode (Juni/Juli) jedoch mit knapp 60\% durch das VPD erklärt werden, in der Trockenperiode (August) schied dieser Parameter hier ebenfalls aus. Auch auf die Wasseraufnahme der Kiefernwurzeln am niederschlagsärmeren Standort hatte das VPD keinerlei Einfluss. In der Trockenperiode 2003 kann das Modell die Wasseraufnahme bei Buchenwurzeln im Ziegelrodaer Forst mit fast $80 \%$ durch die Globalstrahlung erklären, bei Kiefernwurzeln in der feuchten Periode durch 40\%. Ansonsten zeigten die Saftflussdichten der Kiefernwurzeln keinerlei Abhängigkeit am trockenem Standort von den aufgenommenen Umweltparametern.

Der Bodenwassergehalt erklärt in allen drei Baumarten am trockenem Standort nicht die geringe Wasseraufnahme. Hier müssen andere Parameter eine Rolle spielen für die geringe Wasseraufnahme im Trockenzeitraum 2003.

Die Saftflussdichte der Birkenwurzeln ist am feuchten Messtermin (Juni/Juli) am am feuchten Standort durch 40\% durch das VPD zu erklären. In der Trockenperiode steigt dieser Einfluss des VPD auf 68\% bzw. 75\% am trockenen bzw. feuchten Standort. Die Saftflussdichte der Birkenwurzeln am trockenem Standort wird im Messzeitraum 
Juni/Juli zu 65\% durch die Globalstrahlung erklärt. Alle anderen gemessenen Parameter hatten bei der Wasseraufnahme der Birkenwurzeln keinerlei Einfluss.

Tabelle 4-8. Erklärter Varianzanteil der Saftflussdichte von Buchen-, Birken- und Kiefernwurzeln durch die Faktoren Globalstrahlung (Gs, Tagesmittelwerte, Klimastation Weimar, nach DWD), Wasserdampfsättigungsdefizit (VPD, Tagesmittelwerte, Klimastationen Kassel und Artern) und Bodenwassergehalt $(\Theta)$ in drei Bodentiefen $(5 \mathrm{~cm}, 20 \mathrm{~cm}$ und $35 \mathrm{~cm})$ in verschiedenen Abschnitten der Vegetationsperiode: $\mathrm{I}=\mathrm{Juni} / \mathrm{Juli}$ (feuchte Periode) (13.6.-6.7.), II = Trockenphase (27.8.-3.9.) 2003 und 2004 am Standort Ziegelrodaer Forst (Z) und Standort Söhre (S). Nach Ergebnissen einer multiplen Regressionsanalyse (forward elimination, $p<0.05$ ). $\mathrm{n}=$ 4-10 Wurzeln. - bedeutet keinen Einfluss auf die Saftflussdichte, n.d. = not determined (durch fehlende Messwerte keine entsprechende Berechnung möglich).

\section{3}

2004

Gs $\quad$ VPD $\quad \begin{array}{lllllllllllllllll}5 & \Theta 20 & \Theta & 35 & & \text { Gs } & \text { VPD } & \Theta & 5 & \Theta & 20 & \Theta & 35\end{array}$

\section{Ziegelrodaer Forst}

$\begin{array}{llcccccccccc}\text { Beech } & \text { I } & - & 58.1 & 7.0 & - & 7.3 & - & 68.2 & \text { n.d. } & \text { n.d. } & \text { n.d. } \\ \text { Beech } & \text { II } & 78.4 & - & - & - & - & - & - & - & - & - \\ \text { Birch } & \text { I } & 65.3 & - & - & - & - & - & 33.0 & \text { n.d. } & \text { n.d. } & \text { n.d. } \\ \text { Birch } & \text { II } & - & 67.6 & - & - & - & - & - & - & - & 42.3 \\ \text { Pine } & \text { I } & 41.6 & - & - & - & - & - & 39.7 & \text { n.d. } & \text { n.d. } & \text { n.d. } \\ \text { Pine } & \text { II } & - & - & - & - & - & - & - & - & - & 95.1\end{array}$

\begin{tabular}{|c|c|c|c|c|c|c|c|c|c|c|c|}
\hline Söhre & & & & & & & & & & & \\
\hline Beech & I & 31.4 & - & - & - & - & 74.6 & - & - & - & - \\
\hline Beech & II & - & - & - & - & - & 75.4 & - & - & 2.7 & - \\
\hline Birch & I & - & 39.1 & - & - & - & 83.6 & - & - & - & - \\
\hline Birch & II & - & 75.4 & - & - & - & - & - & - & - & - \\
\hline Pine & I & - & - & - & - & - & 74.4 & - & - & - & - \\
\hline Pine & II & - & - & - & 82.2 & - & - & - & - & - & - \\
\hline
\end{tabular}

In der Trockenperiode 2004 beeinflusste am trockenem Standort bei Birken- und Kiefernwurzeln der Bodenwassergehalt mit 40 bzw. 95\% die Wasseraufnahme deutlich (Tab. 4-8). Am feuchten Standort konnten in der Trockenperiode aber keiner der aufgeführten klimatischen oder edaphischen Parameter die Wasseraufnahme dieser beiden Baumarten erklären. Die Globalstrahlung erklärte jedoch hier $75 \%$ der Wasseraufnahme der Buche in der Trockenperiode, bei der Kiefer und Birke 75 bzw. $84 \%$ in der feuchten Periode. Am trockenem Standort hatte die Globalstrahlung für die Wasseraufnahme der drei Baumarten keinerlei Einfluss. Hier beeinflusste das VPD mit $68 \%$ in der feuchten Periode (Juni/Juli) die Wasseraufnahme der Buche stark. 


\subsection{Anatomische und chemische Eigenschaften der Wurzeln}

\subsubsection{Anatomische Untersuchung des Wurzelperiderms}

Alle untersuchten Wurzeln befanden sich im sekundären Stadium des Dickenwachstums. Somit konnte keine Endodermis isoliert werden. Bei Wurzeln mit einem Durchmesser von $<1 \mathrm{~mm}$ wurden stichprobenartig die Jahresringe gezählt. Diese Untersuchung ergab, dass selbst diese dünnen Wurzelsegmente bereits 3-4 Jahre alt sein mussten (Daten nicht dargestellt) und also etwa im Jahr 2000 angelegt worden waren.

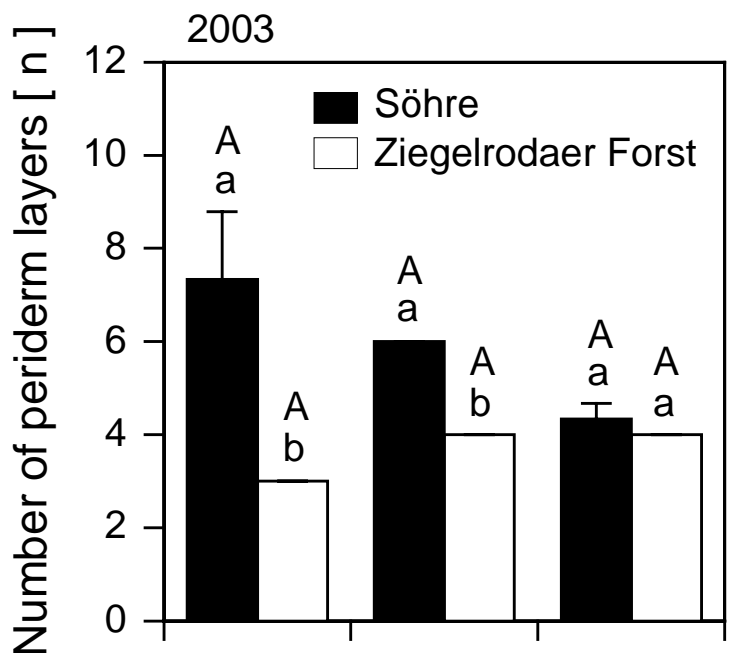

Beech Birch Pine

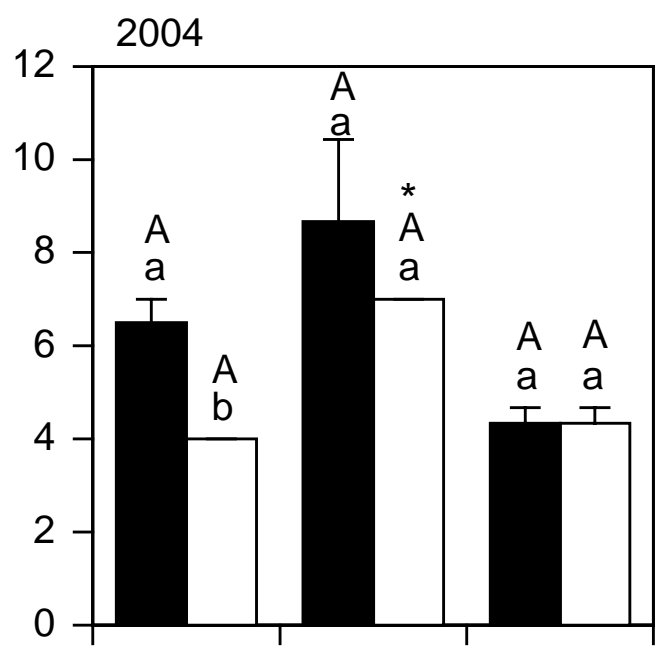

Beech Birch Pine

Abb. 4-18. Anzahl der Peridermschichten in Buchen-, Birken- und Kiefernfeinwurzeln mit einem Durchmesser von $<1 \mathrm{~mm}$ auf den beiden Untersuchungsflächen in der Söhre und im Ziegelrodaer Forst in den Jahren 2003 und 2004. Unterschiedliche Kleinbuchstaben markieren signifikante Unterschiede zwischen den Untersuchungsflächen, Großbuchstaben signifikante Unterschiede zwischen den Arten und * signifikante Unterschiede zwischen den Untersuchungsjahren $(\mathrm{p}<0.05$, Scheffé). Aufgetragen sind die Mittelwerte aus jeweils drei untersuchten Wurzeln pro Baumart mit dem Standardfehler.

\section{3}

In allen Wurzeln bestand die Peridermschicht aus 3-9 Zelllagen (Abb. 4-18). Dabei waren im Untersuchungsjahr 2003 am Standort Söhre oft nur tendenzielle, aber keine signifikanten Unterschiede zwischen den Arten (Buche $>$ Birke $>$ Kiefer) festzustellen. 
Mit 7 bzw. 6 Zellschichten im Periderm wiesen Buche und Birke in der Söhre deutlich mehr Zelllagen auf als am trockeneren Standort Ziegelrodaer Forst; die Flächen unterscheiden sich diesbezüglich signifikant.

Allgemein wiesen die Wurzeln der Kiefer sehr wenige Zelllagen auf, ohne signifikante Unterschiede zwischen den Flächen und den Untersuchungsjahren zu zeigen. Auf der Untersuchungsfläche im Ziegelrodaer Forst erkennt man für das Jahr 2003 keinen deutlichen Unterschied zwischen den drei Baumarten. Birke und Kiefer wiesen mit je 4 Zelllagen nur geringe Unterschiede zur Buche auf, deren Wurzelperiderm im Mittel aus 3 Zelllagen bestand.

$\mathrm{Zu}$ tendenziellen Unterschieden kam es 2004 auf der Untersuchungsfläche in der Söhre zwischen den drei Baumarten (Birke $>$ Buche $>$ Kiefer) ohne statistische Signifikanz.

Die Buche hatte mit 7 Zelllagen in der Söhre signifikant höhere Werte als im Ziegelrodaer Forst mit 4 Zelllagen. Demgegenüber wies die Birke mit der größten Anzahl der Peridermschichten (Söhre: 9 und Ziegelrodaer Forst: 7) wie auch die Kiefer keine signifikanten Unterschiede zwischen den beiden Standorten auf. Zwischen den Arten wiesen die Birken- vor den Buchen- und Kiefernwurzeln tendenziell die meisten Zelllagen im Periderm auf (Unterschiede nicht signifikant).

Statistisch signifikante Unterschiede der Peridermschicht-Anzahl zwischen den Untersuchungsjahren waren nur bei der Birke auf der Untersuchungsfläche in der Söhre festzustellen. Die anderen Baumarten zeigten keine signifikanten Unterschiede zwischen den Untersuchungsjahren.

\subsubsection{Chemische Zusammensetzung des Wurzelperiderms von Buche, Birke und Kiefer}

\subsubsection{Gesamtsuberinmengen von Buchen-, Birken- und Kiefernwurzeln}

2003

Im Jahr 2003 war kein signifikanter Unterschied im Suberingehalt der Buchenwurzeln zwischen den beiden Untersuchungsflächen Söhre und Ziegelrodaer Forst zu erkennen (Abb. 4-19).

In Birkenwurzeln traten zwar auf den beiden Untersuchungsflächen unterschiedliche Suberingehalte auf, der Unterschied war jedoch nicht statistisch abzusichern. 
Mit $350 \mu \mathrm{g} \mathrm{cm}^{-2}$ im Mittel wiesen die Birkenwurzeln im Ziegelrodaer Forst mehr Suberin auf als die Birkenwurzeln in der Söhre $\left(203 \mu \mathrm{g} \mathrm{cm}^{-2}\right)$, allerdings ohne dass die Unterschiede signifikant waren (Abb. 4-19).

Die Kiefernwurzeln mit den insgesamt kleinsten Gesamtsuberinmengen zeigten wie auch die Buchenwurzeln keine signifikanten Unterschiede im Gesamtsuberingehalt zwischen den beiden Untersuchungsflächen.

In der Söhre wiesen die drei Baumarten keine signifikanten Unterschiede der Feinwurzel-Suberingehalte auf. Auf der Fläche im Ziegelrodaer Forst unterschied sich lediglich die Kiefer von der Birke signifikant in ihren Suberingehalten.
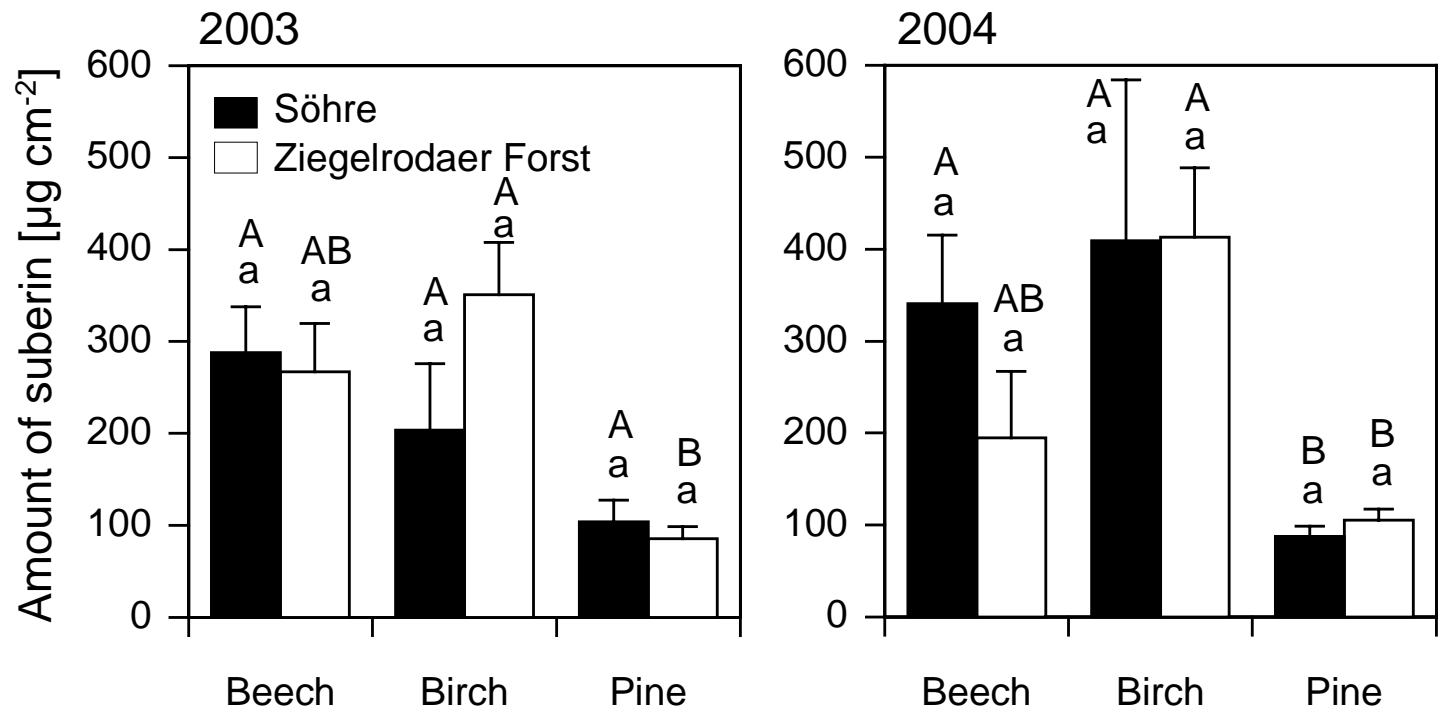

\begin{abstract}
Abb. 4-19. Suberingesamtmengen $\left(\mu \mathrm{g} \mathrm{cm}^{-2}=\mu \mathrm{g}\right.$ pro Wurzeloberfläche) in Buchen-, Birken- und Kiefernfeinwurzeln mit einem Durchmesser von $<1 \mathrm{~mm}$. Unterschiedliche Kleinbuchstaben markieren signifikante Unterschiede zwischen den Untersuchungsflächen, Großbuchstaben signifikante Unterschiede zwischen den Arten und * signifikante Unterschiede zwischen den Untersuchungsjahren $(p<0.05$, Scheffé). Aufgetragen sind die Mittelwerte aus jeweils drei untersuchten Wurzeln pro Baumart mit dem Standardfehler.
\end{abstract}

\title{
2004
}

Auch im Jahr 2004 kam es bei Buchen-, Birken- und Kiefernwurzeln zu keinen signifikanten Unterschieden des Suberingehalts zwischen den beiden Untersuchungsflächen (Abb. 4-19). Allerdings wurden für die Buche in der Söhre mit $340 \mu \mathrm{g} \mathrm{cm}^{-2}$ 
deutlich höhere Werte des Gesamtsuberingehalts ermittelt als im Ziegelrodaer Forst $\left(195 \mu \mathrm{g} \mathrm{cm}^{-2}\right)$.

Die Birkenwurzeln wiesen vor den Buchenwurzeln den höchsten Gesamtsuberingehalt auf. Mit $87 \mu \mathrm{g} \mathrm{cm}^{-2}$ in der Söhre und $105 \mu \mathrm{g} \mathrm{cm}^{-2}$ im Ziegelrodaer Forst wies die Kiefer in ihren Wurzeln die geringsten Gesamtsuberingehalte auf. Auf der Fläche in der Söhre war zwischen den drei Baumarten kein signifikanter Unterschiede zu erkennen. Im Ziegelrodaer Forst unterschieden sich nur die Suberingehalte der Birken- und der Kiefernfeinwurzeln signifikant voneinander, für die anderen Baumarten konnten keine signifikanten Unterschiede ermittelt werden.

Die Suberingehalte der untersuchten Feinwurzeln zeigten bei keiner Baumart und auf keiner der beiden Untersuchungsflächen signifikante Unterschiede zwischen den Untersuchungsjahren.

\subsubsection{Suberinmengen pro Peridermschicht von Buchen-, Birken- und Kiefernwurzeln}

Im deutlich trockeneren Jahr waren zwischen den beiden Untersuchungsflächen bei Buchenwurzeln ebenso wie bei Birkenwurzeln signifikante Unterschiede im Suberingehalt pro Periderm-Zelllage zu erkennen (Abb. 4-20). Die Kiefer wies wie im Gesamtsuberingehalt keine signifikanten Unterschiede zwischen den beiden Flächen auf.

2004 unterschieden sich alle drei Baumarten hinsichtlich ihres Suberingehalts pro Periderm-Zelllage nicht signifikant voneinander. Zwischen den beiden Untersuchungsflächen waren bei Buchen-, Birken- und Kiefernwurzeln ebenso keine signifikanten Unterschiede im Suberingehalt pro Periderm-Zelllage zu erkennen. 

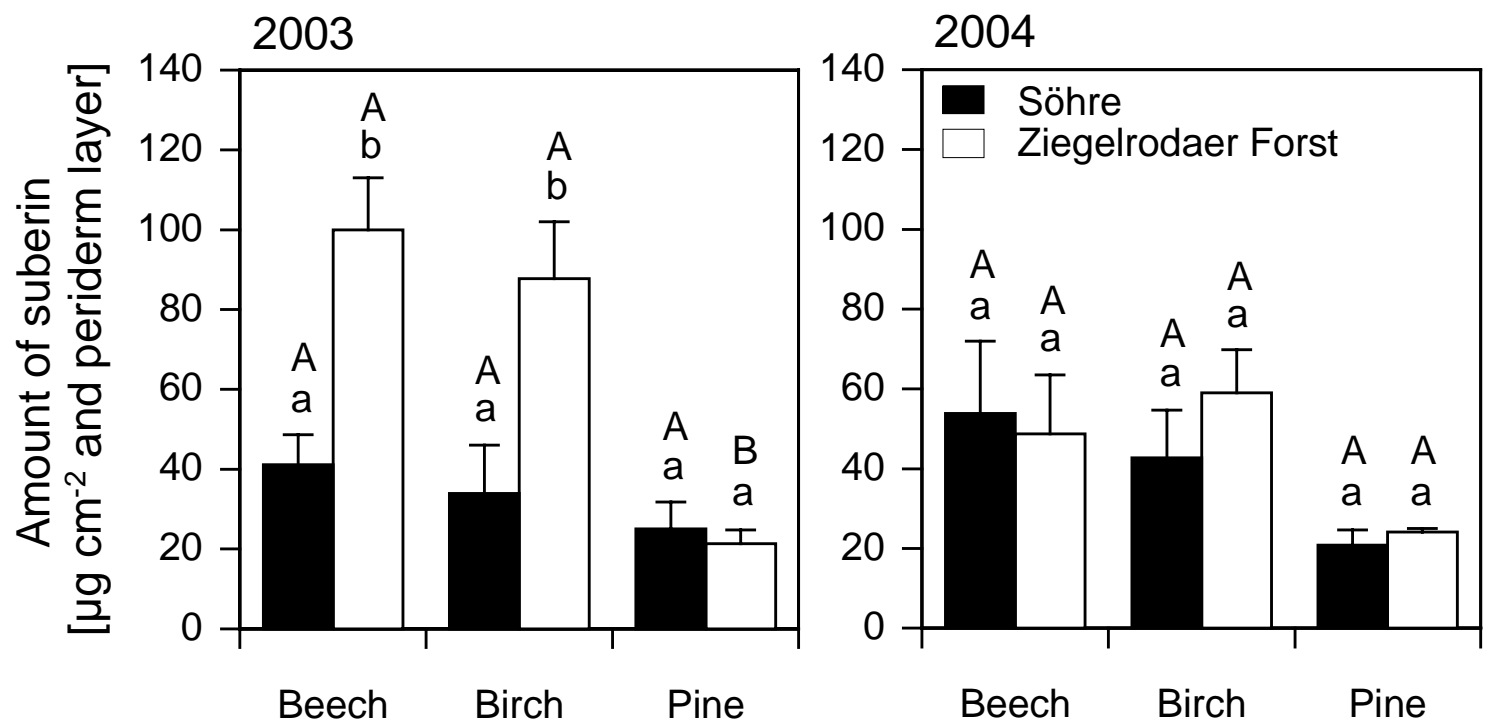

Abb. 4-20. Suberinmenge pro Periderm-Zelllage in Buchen-, Birken- und Kiefernfeinwurzeln mit einem Durchmesser von $<1 \mathrm{~mm}$. Unterschiedliche Kleinbuchstaben markieren signifikante Unterschiede zwischen den Untersuchungsflächen, Großbuchstaben signifikante Unterschiede zwischen den Arten und * signifikante Unterschiede zwischen den Untersuchungsjahren $(\mathrm{p}<0.05$, Scheffé). Aufgetragen sind die Mittelwerte aus jeweils drei untersuchten Wurzeln pro Baumart mit dem Standardfehler.

\subsubsection{Suberinzusammensetzung von Buchen-, Birken- und Kiefern- wurzeln}

Die Feinwurzeln der untersuchten Baumarten unterschieden sich deutlich in der Suberinzusammensetzung ihrer Peridermschichten. In Abb. 4-21 sind die Mengenanteile der einzelnen Substanzklassen für die untersuchten Baumarten aufgetragen.

In den untersuchten Buchenwurzeln kamen bis auf ungesättigte organische Säuren alle identifizierten Stoffklassen vor. Carbonsäuren, Alkohole, 2-OH-Säuren und Zimtsäurederivate nahmen jeweils einen Anteil von deutlich unter $10 \%$ ein. Die Hauptkomponenten bildeten die Trihydroxysäuren mit 39\% und die $\omega$-OH-Säuren mit $37 \%$ des Suberingesamtgehalts.

In den Birkenwurzeln fehlten Carbonsäuren, ungesättigte Säuren, Alkohole und 2-OHSäuren in allen Einzelproben. Zimtsäurederivate (5,3\%) und $\omega$-Dicarbonsäuren (1.5\%) 
lagen anteilig weit unter $10 \%$. Die Trihydroxysäuren hatten einen prozentualen Anteil von 19\%. Die Hauptkomponente bildeten mit 74\% die $\omega-\mathrm{OH}-\mathrm{Säuren}$.

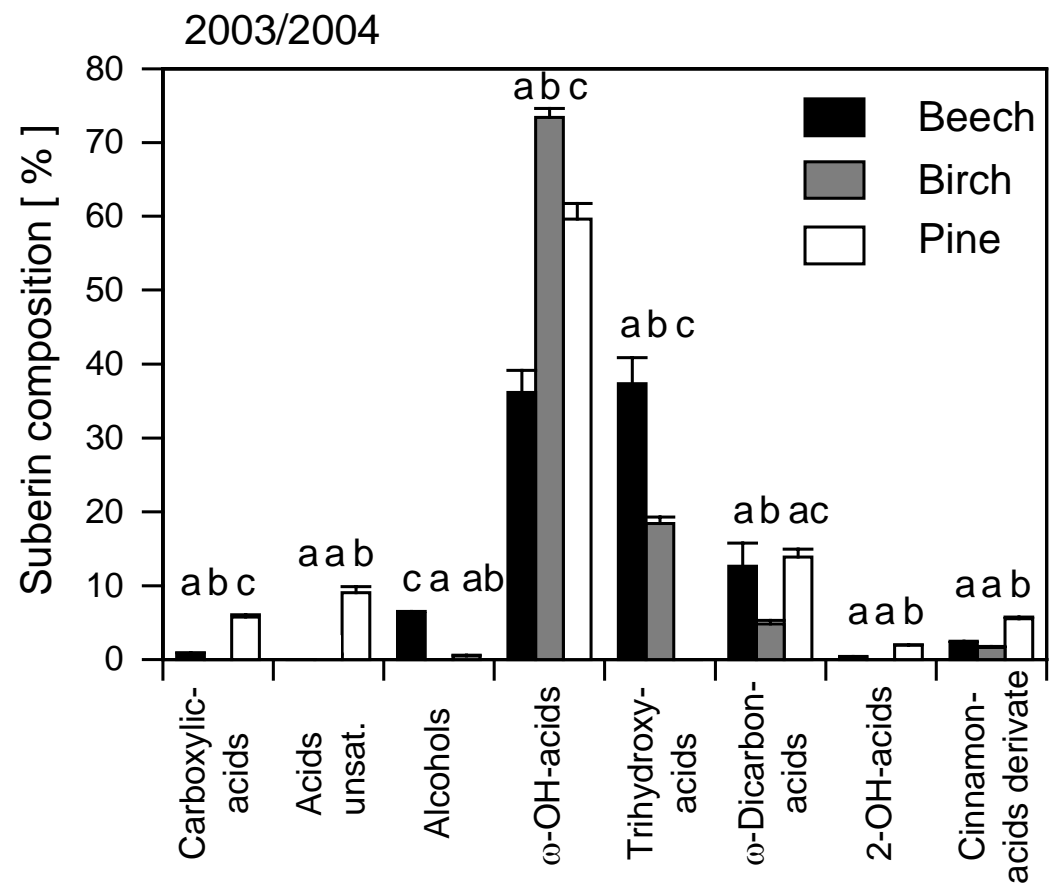

Abb. 4-21. Suberinzusammensetzung der untersuchten Buchen-, Birken- und Kiefernfeinwurzeln mit einem Durchmesser $<1 \mathrm{~mm}$. Angegeben sind die prozentualen Anteile einzelner Stoffklassen am Gesamtsuberin. Mittelwerte von jeweils 12 untersuchten Wurzelproben pro Baumart mit dem Standardfehler. Unterschiedliche Buchstaben markieren signifikante Unterschiede zwischen den Baumarten bezüglich einer Stoffklasse $(\mathrm{p}<0.05$, Scheffé)

In den Kiefernwurzeln fehlten die Trihydroxysäuren, was einen deutlichen Unterschied der Nadelbaumart zu den zwei untersuchten Laubbaumarten darstellte. Alkohole (0.5\%), 2-OH-Säuren (2\%), Zimtsäurederivate (5.8\%) und Carbonsäuren (6.0\%) nahmen nur geringe Anteile ein. Die Hauptkomponente mit $61.4 \%$ bildeten auch hier die $\omega$-OH-Säuren.

Der Anteil von Carbonsäuren, $\omega-\mathrm{OH}-\mathrm{Säuren}$ und Trihydroxysäuren unterschied sich in allen drei Baumarten signifikant voneinander. Der Anteil von ungesättigter Säure, 2-OH-Säure und Zimtsäurederivat dagegen war zwischen Buchen- und Birkenwurzeln nicht signifikant unterschiedlich. Zwischen den Mengenanteilen dieser drei Suberinbestandteile war jedoch ein signifikanter Unterschied zwischen Kiefernwurzeln und den Wurzeln der beiden anderen Laubbaumarten zu erkennen. 


\subsubsection{Suberinzusammensetzung von Buchen-, Birken- und Kiefern- wurzeln im Jahresvergleich 2003 und 2004}

In den Jahren 2003 und 2004 wurde kein signifikanter Unterschied zwischen den beiden Untersuchungsflächen in den einzelnen Stoffklassen errechnet (Abb. 4-22).

Den häufigsten Suberinbestandteil in Buchenwurzeln im Jahr 2003 nahm die Trihydroxysäure ein. Diese stellte im Ziegelrodaer Forst mit 40.5\% einen größeren Suberinbestandteil als in der Söhre (33\%) (Abb. 4-22).

Die $\omega$-OH Säure, zweithäufigster Suberinbestandteil, nahm einen Anteil von 34\% in der Söhre und $38 \%$ im Ziegelrodaer Forst ein.

Das Vorkommen von $\omega$-Dicarbonsäuren wies auf beiden Flächen deutliche Unterschiede auf. $\omega$-Dicarbonsäuren kamen mit einem Anteil von 21\% in der Söhre häufiger vor als im Ziegelrodaer Forst (10\%), jedoch ohne signifikante Unterschiede aufzuweisen. Die Alkohole unterschieden sich im Mengenanteil im Suberin der Buchenwurzeln nur gering von beiden Flächen (Söhre: 7\% und Ziegelrodaer Forst: 6\%). Zimtsäurederivate kamen insgesamt nur in geringsten Anteilen vor (2\%). Carbonsäuren enthält das Wurzelsuberin ebenfalls nur in geringen Anteilen $(0.7 \%$ in der Söhre bzw. $0.8 \%$ im Ziegelrodaer Forst). Ungesättigte Säuren wurden auf beiden Flächen in den Buchenwurzeln nicht nachgewiesen.

Im Jahr 2004 dominierte in den Buchenwurzeln die $\omega-\mathrm{OH}$ Säure mit einem Anteil von $36 \%$ in der Söhre und 44\% im Ziegelrodaer Forst, gefolgt von der Trihydroxysäure mit je 33\% auf beiden Flächen. Im Jahr 2004 konnte für die $\omega$-Dicarbonsäure kein Unterschied zwischen den beiden Untersuchungsflächen nachgewiesen werden. Der Anteil der $\omega$-Dicarbonsäure betrug auf beiden Untersuchungsflächen jeweils $9 \%$ des Gesamtsuberins in Buchenwurzeln. Der Anteil der Alkohole vom Gesamtsuberin der Buchenwurzeln unterschied sich nicht signifikant zwischen den beiden Flächen (Söhre: 5.5\% und Ziegelrodaer Forst: 7\%). Zimtsäurederivate und Carbonsäuren nahmen jeweils einen Anteil deutlich unter 3\% in Buchenwurzeln der Untersuchungsflächen ein und spielten somit eine untergeordnete Rolle bei der Zusammensetzung des Gesamtsuberins.

In den Birkenwurzeln dominierten im Jahr 2003 deutlich $\omega$-OH Säuren. Mit Werten von $75 \%$ in der Söhre und $76 \%$ im Ziegelrodaer Forst nahmen sie fast drei Viertel der Gesamtsuberinbestandteile ein. Signifikante Unterschiede zwischen den beiden Flächen wurden nicht festgestellt. Trihydroxysäure stellte mit jeweils $17 \%$ auf beiden Flächen den zweitgrößten Bestandteil des Gesamtsuberins in Birkenwurzeln. 
$\omega$-Dicarbonsäuren kamen mit einem Anteil von $4 \%$ in den Birkenwurzeln beider Untersuchungsstandorte vor und Zimtsäurederivate nahmen mit unter $2 \%$ ebenfalls einen geringen Anteil am Gesamtsuberin der Birkenwurzeln ein. Carbonsäuren, ungesättigte Säuren, Alkohole und 2-OH Säuren fehlten in allen Einzelproben der Birkenwurzeln.
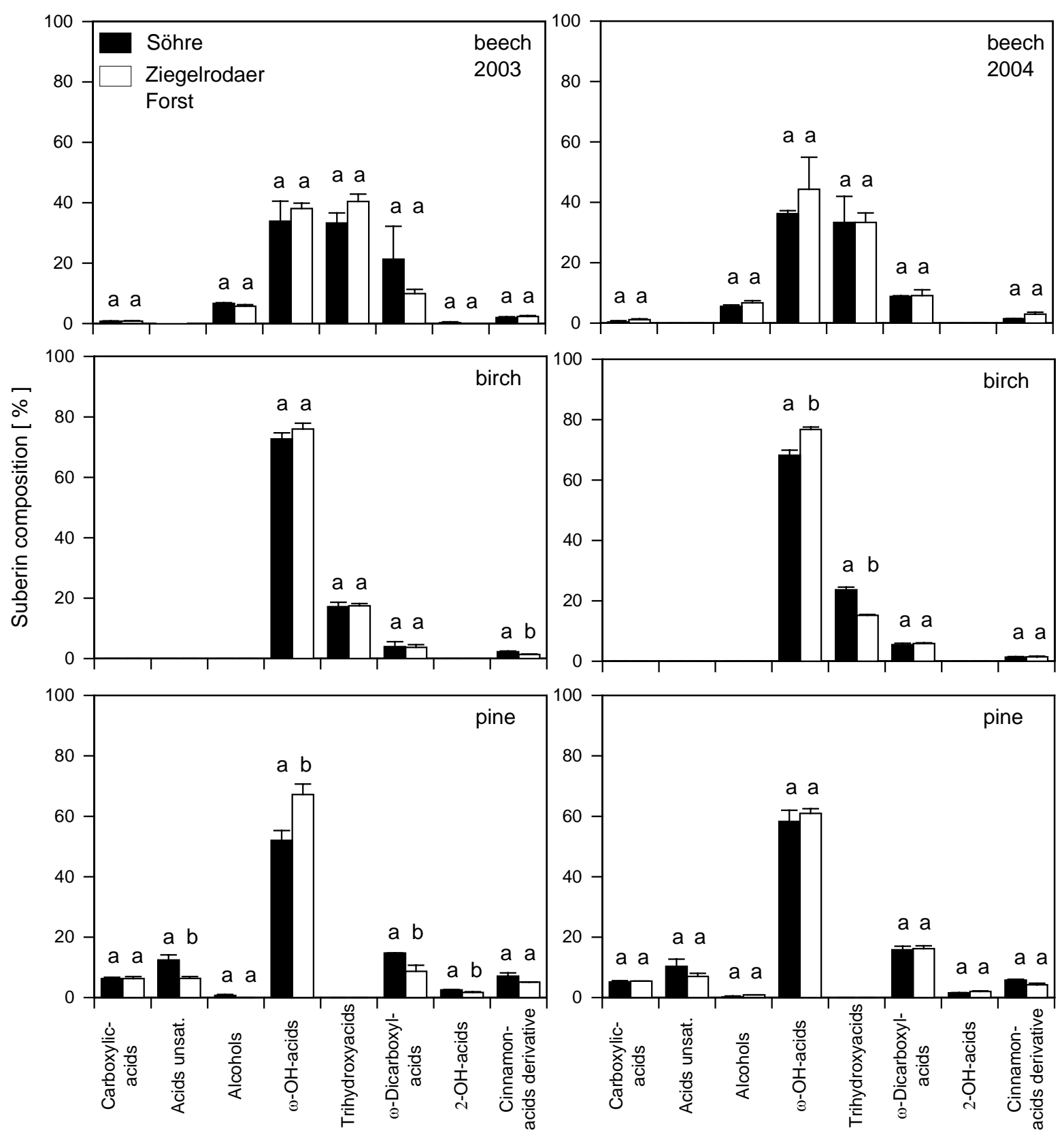

Abb. 4-22. Suberinzusammensetzung der untersuchten Buchen-, Birken- und Kiefernfeinwurzeln mit einem Durchmesser $<1 \mathrm{~mm}$. Angegeben sind die prozentualen Anteile einzelner Stoffklassen am Gesamtsuberin in den Jahren 2003 und 2004. Mittelwerte von jeweils 3 untersuchten Wurzelproben pro Baumart mit dem Standardfehler. Unterschiedliche Buchstaben markieren signifikante Unterschiede zwischen den Baumarten bezüglich einer Stoffklasse ( $p<0.05$, Scheffé). 
$\omega$-Dicarbonsäuren nahmen in Birkenwurzeln einen Anteil von jeweils $4 \%$ je Untersuchungsfläche ein und Zimtsäurederivate nahmen mit unter 2\% einen geringeren Anteil am Gesamtsuberin ein. Carbonsäuren, ungesättigte Säuren, Alkohole und 2-OH Säuren wurden in allen Einzelproben der Birkenwurzeln nicht nachgewiesen.

Im Jahr 2004 dominierten wieder deutlich die $\omega$-OH Säuren, jedoch mit signifikanten Unterschieden zwischen den beiden Untersuchungsflächen (Söhre: 68\% und Ziegelrodaer Forst: 77\%). Auch der Anteil der Trihydroxysäuren ergab signifikante Unterschiede zwischen den Untersuchungsflächen (Söhre: 24\% und Ziegelrodaer Forst: 15\%). $\omega$-Dicarbonsäuren nahmen in den Birkenwurzeln einen Gesamtanteil von jeweils $6 \%$ pro Untersuchungsfläche ein und Zimtsäurederivate nahmen mit unter $1.5 \%$ nur einen geringen Anteil am Gesamtsuberin ein.

In Kiefernwurzeln wurden in beiden Jahren auf beiden Untersuchungsflächen alle untersuchten Stoffklassen des Suberins nachgewiesen, mit Ausnahme der in den Laubbaumarten dominierenden Trihydroxysäure, die in allen Einzelproben der Kiefernwurzeln fehlte.

Im Jahr 2003 nahmen die $\omega$-OH Säuren den größten Mengenanteil am Gesamtsuberin ein. Der Anteil der $\omega$-OH Säuren im Suberin der Kiefernwurzeln aus der Söhre (52 \%) unterschied sich signifikant von demjenigen im Ziegelrodaer Forst $(67 \%)$. Der Mengenanteil der ungesättigten Säuren, $\omega$-Dicarbonsäuren und 2-OH Säuren unterschied sich zwischen den beiden Untersuchungsflächen vom Gesamtsuberin der Kiefernwurzeln signifikant.

2004 wurde in allen untersuchten Stoffklassen kein signifikanter Unterschied bezüglich des Anteils vom Gesamtsuberin in Kiefernwurzeln zwischen den Flächen errechnet.

\subsubsection{Zusammensetzung des Suberins pro Peridermschicht in Buchen-, Birken- und Kiefernwurzeln}

2003

Durch den Bezug der Gesamtmenge der einzelnen Stoffklassen des Suberins pro Peridermschicht-Zelllage der Wurzeln (Abb. 4-23) wurden besonders bei Buche und Birke Unterschiede zwischen den Untersuchungsflächen im Jahr 2003 deutlich. $\omega-\mathrm{OH}$ Säuren waren in Buchenwurzeln des Ziegelrodaer Forstes mit $31 \mu \mathrm{g} \mathrm{cm}^{-2}$ in deutlich höheren Mengen enthalten als in der Söhre $\left(15 \mu \mathrm{g} \mathrm{cm}{ }^{-2}\right.$ ), jedoch ohne signifikante Unterschiede aufzuweisen. 

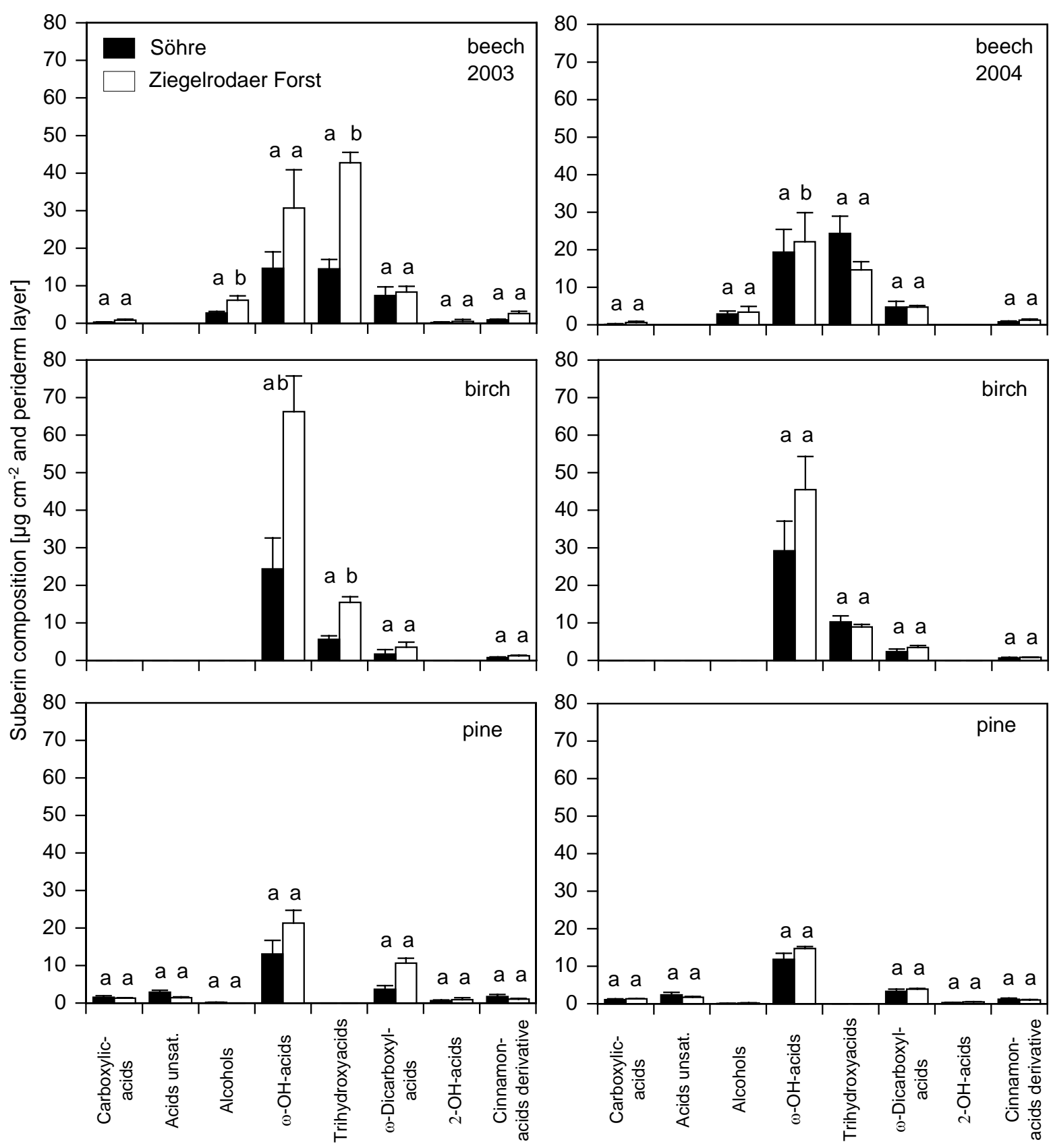

Abb. 4-23. Zusammensetzung des Suberins von Buchen-, Birken- und Kiefernwurzeln (Durchmesser $<1 \mathrm{~mm}$ ) bezogen pro Peridermschicht-Zelllage auf den Untersuchungsflächen in der Söhre und im Ziegelrodaer Forst in den Jahren 2003 und 2004. Unterschiedliche Buchstaben markieren signifikante Unterschiede zwischen den beiden Flächen $(p<0.05$, Scheffé $)$. Dargestellt sind die Mittelwerte $(n=3)$ und der Standardfehler.

Signifikante Unterschiede zwischen den Untersuchungsflächen konnten für die Trihydroxysäuren ermittelt werden (Söhre: $15 \mu \mathrm{g} \mathrm{cm}^{-2}$ und Ziegelrodaer Forst: $43 \mu \mathrm{g} \mathrm{cm}^{-2}$ ). Auch der Mengenanteil der Alkohole im Suberin pro Peridermschicht- 
Zelllage wies in Buchenwurzeln zwischen den beiden Untersuchungsflächen signifikante Unterschiede auf (Söhre: $3 \mu \mathrm{g} \mathrm{cm}^{-2}$ und Ziegelrodaer Forst: $6 \mu \mathrm{g} \mathrm{cm}^{-2}$ ). Der Gehalt an Carbonsäuren, $\omega$-Dicarbonsäuren, 2-OH Säuren und Zimtsäurederivate pro Peridermschicht-Zelllage im Suberin der Buchenwurzeln unterschied sich zwischen beiden Untersuchungsflächen nicht signifikant voneinander.

Die Birkenwurzeln unterschieden sich im Jahr 2003 signifikant zwischen den beiden Flächen. Die $\omega-\mathrm{OH}$ Säuren nahmen in den Birkenwurzeln im Ziegelrodaer Forst mit 66 $\mu \mathrm{g} \mathrm{cm}^{-2}$ einen erheblich höheren Anteil im Suberin pro Peridermschicht ein als die $\omega$ $\mathrm{OH}$ Säuren in der Söhre $\left(24 \mu \mathrm{g} \mathrm{cm}^{-2}\right)$. Die Trihydroxysäuren, die zweithäufigste Gruppe, nahmen mit $15 \mu \mathrm{g} \mathrm{cm}^{-2}$ in den Birkenwurzeln im Ziegelrodaer Forst einen höheren Anteil ein als in den Birkenwurzeln in der Söhre $\left(6 \mu \mathrm{g} \mathrm{cm}^{-2}\right)$. Die Kiefernwurzeln unterschieden sich bezüglich der Stoffklassen des Suberins pro Peridermschicht zwischen den beiden Flächen und den beiden Jahren nicht signifikant voneinander.

2004 kam es lediglich bei $\omega-\mathrm{OH}$ Säuren in Buchenwurzeln zu einem signifikanten Unterschied zwischen der Fläche in der Söhre $\left(19 \mu \mathrm{g} \mathrm{cm}^{-2}\right)$ und der trockeneren Fläche im Ziegelrodaer Forst $\left(22 \mu \mathrm{g} \mathrm{cm}^{-2}\right)$.

\subsubsection{Mengenanteile der häufigsten Stoffklassen des Suberins: $\omega-O H$ Säuren und Trihydroxysäuren}

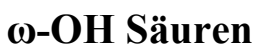

In Abb. 4-24 und Abb. 4-25 sind die prozentualen Mengenanteile der einzelnen $\omega-\mathrm{OH}$ Säuren in den beiden Untersuchungsjahren aufgetragen. Am häufigsten in allen drei Baumarten kam die 18-OH Octadecan 9-en Säure vor. Sie nahm einen mengenmäßig großen Anteil von 50\% (Buche) bis beinahe 80\% (Birke und Kiefer) ein. 22-OH Docosansäure, 18-OH Octadecansäure, 20-OH Eicosansäure und 16-OH Hexadecansäure wurden in Birken- und Kiefernwurzeln mit einem Anteil von mindestens jeweils $5 \%$ bis $15 \%$ nachgewiesen. In Buchenwurzeln konnte 16-OH Hexadecansäure auf beiden Flächen in beiden Jahren in erhöhten Anteil nachgewiesen werden (20-25\%). In nur sehr geringen Anteilen $(<2 \%)$ kam die 24-OH Tetracosansäure in Birken- und Kiefernwurzeln vor, die in Buchenwurzeln ganz fehlte. 


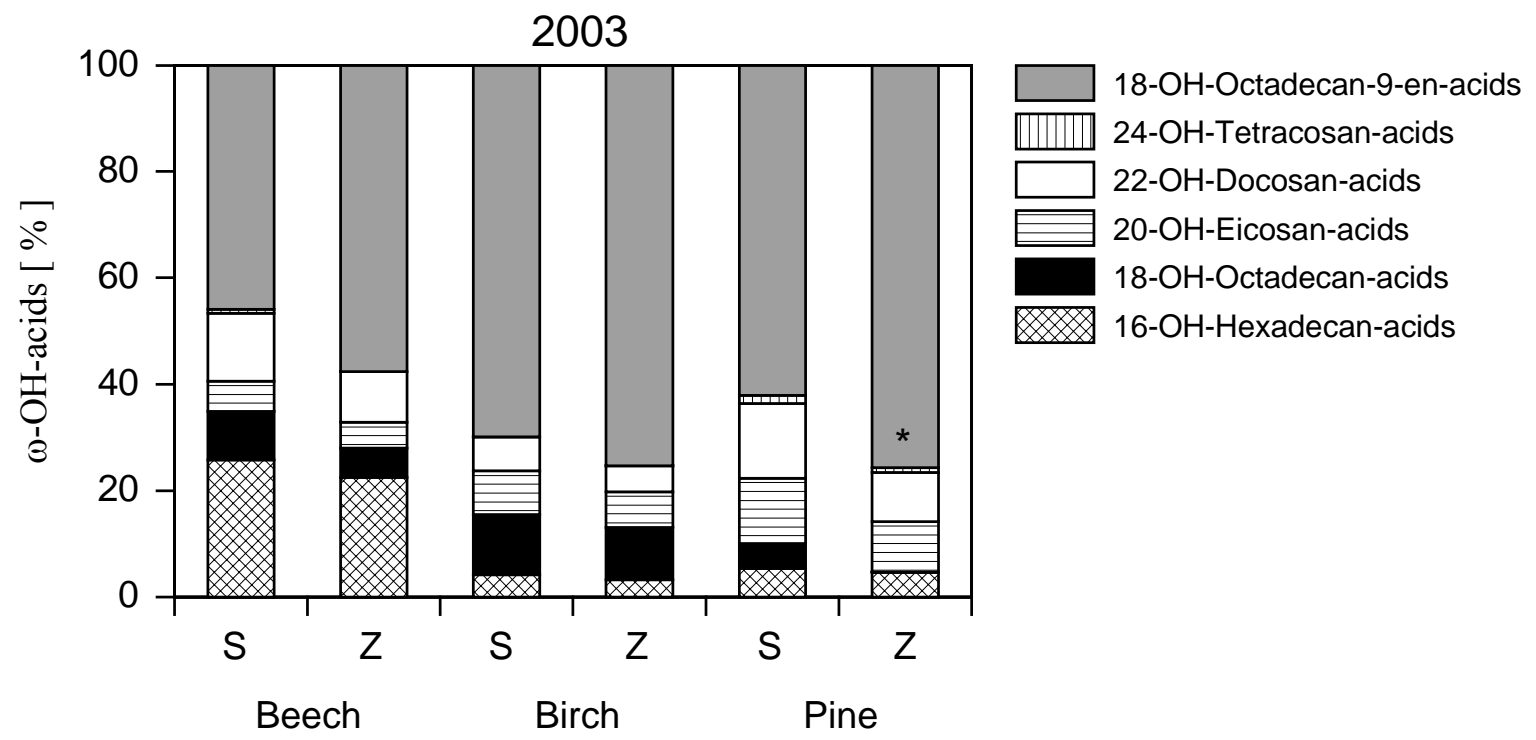

Abb. 4-24. $\omega-\mathrm{OH}-\mathrm{Säure-Zusammensetzung} \mathrm{in} \mathrm{Prozent} \mathrm{vom} \mathrm{Gesamtgehalt} \mathrm{der} \omega-\mathrm{OH}-$ Säure bei Buchen-, Birken- und Kiefernwurzeln mit einem Durchmesser $<1 \mathrm{~mm}$ auf den Untersuchungsflächen Söhre (S) und Ziegelrodaer Forst (Z) im Jahr 2003. Signifikante Unterschiede der Baumarten zwischen den Flächen sind mit einem * gekennzeichnet $(\mathrm{p}<0.05$, Scheffé), $\mathrm{n}=3$.

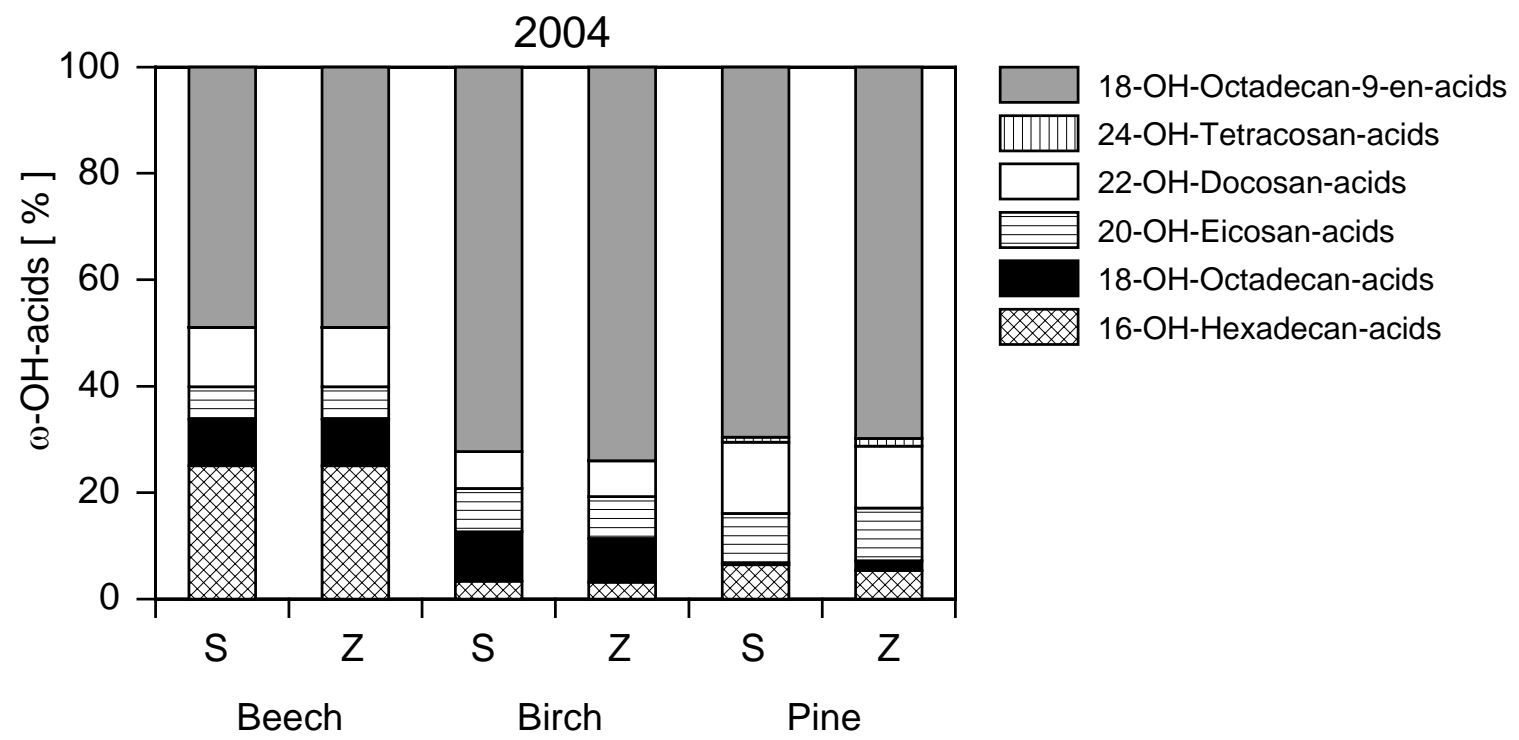

Abb. 4-25. $\omega-\mathrm{OH}-\mathrm{Säure-Zusammensetzung} \mathrm{in} \mathrm{Prozent} \mathrm{vom} \mathrm{Gesamtgehalt} \mathrm{der} \omega-\mathrm{OH}-$ Säure bei Buchen-, Birken- und Kiefernwurzeln mit einem Durchmesser $<1 \mathrm{~mm}$ auf den Untersuchungsflächen Söhre (S) und Ziegelrodaer Forst (Z) im Jahr 2004. Signifikante Unterschiede der Baumarten zwischen den Flächen sind mit einem * gekennzeichnet $(\mathrm{p}<0.05$, Scheffé), $\mathrm{n}=3$. 
Signifikante Unterschiede zwischen den Stoffklassen der $\omega-\mathrm{OH}$ Säuren waren zwischen den Untersuchungsflächen und zwischen den Untersuchungsjahren bei keiner Baumart zu erkennen. Eine Ausnahme bildete der Anteil der 18-OH Octadecan 9-en Säure in den Wurzeln der Kiefer im Jahr 2003, der sich zwischen den beiden Untersuchungsflächen signifikant unterschied.

\section{Trihydroxysäuren}

Im Jahr 2003 nahm die 2 TMS (Trimethylsilyl) in Buchenwurzeln sowie in Birkenwurzeln auf beiden Flächen einen Gesamtanteil der Trihydroxysäuren von über 80\% ein (Abb. 4-26). Buchenwurzeln sowie Birkenwurzeln unterschieden sich dabei zwischen den Flächen nicht signifikant.

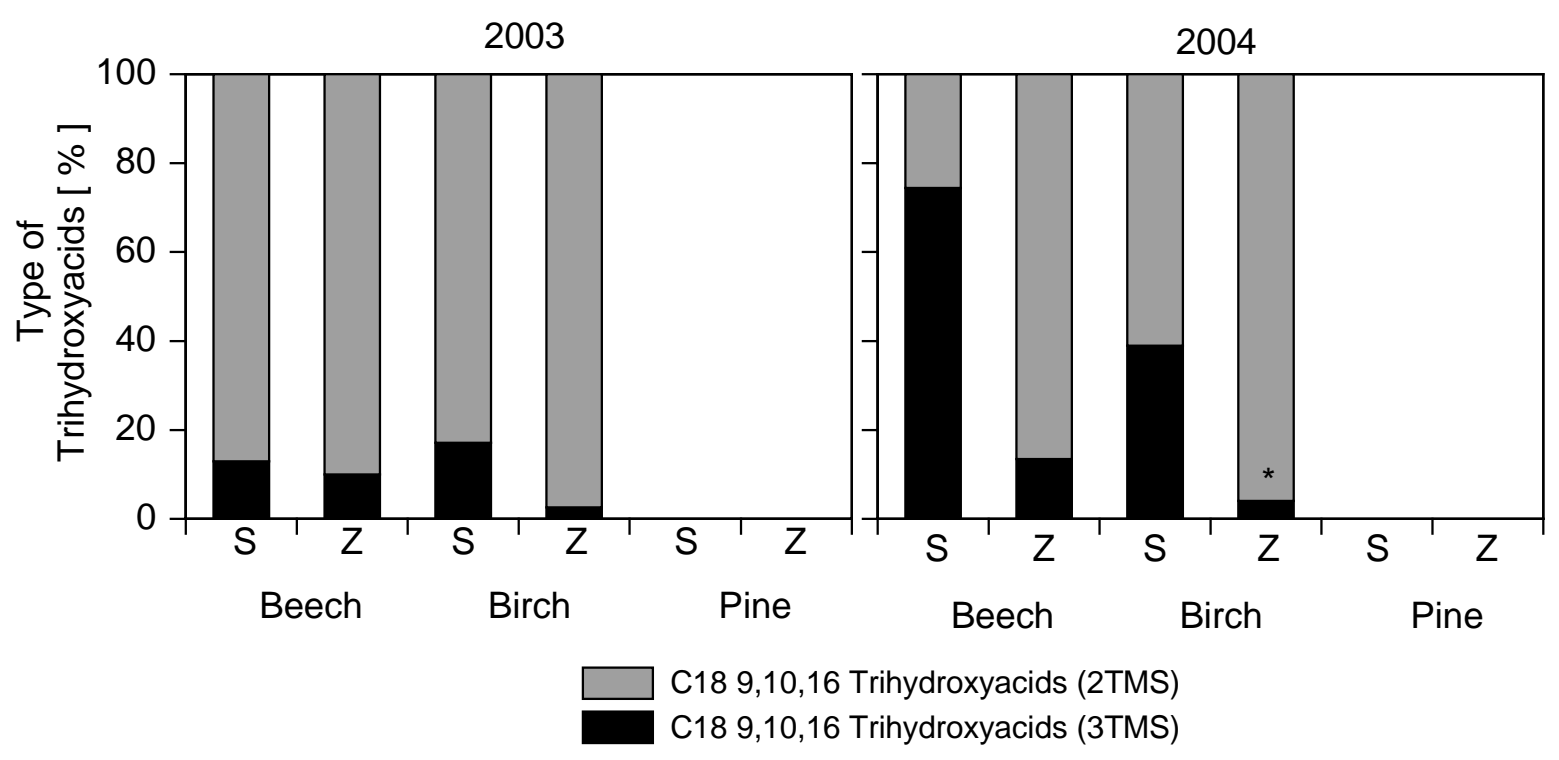

Abb. 4-26. Trihydroxy-Säure-Zusammensetzung in Prozent vom Gesamtgehalt an Trihydroxy-Säure in Buchen-, Birken- und Kiefernwurzeln mit einem Durchmesser $<1$ mm auf den Untersuchungsflächen in der Söhre (S) und im Ziegelrodaer Forst (Z) im Jahr 2003 und 2004. Signifikante Unterschiede der Baumarten zwischen den Flächen sind mit einem * gekennzeichnet $(\mathrm{p}<0.05$, Scheffé $), \mathrm{n}=3$.

Die Wurzeln von Buche und Birke aus dem Jahr 2004 wiesen nur auf der Fläche im Ziegelrodaer Forst mehr als 80\% 2 TMS vom Gesamtgehalt der TMS-Säuren auf. Bei Buchenwurzeln in der Söhre nahmen die 3 TMS den weit größeren Teil ein vom Gesamtgehalt der TMS-Säuren, über 75\% und bei Birkenwurzeln $40 \%$, wobei sich die 
Birkenwurzeln zwischen den beiden Flächen signifikant unterschieden. Auf keinen Untersuchungsflächen und bei keinen der beiden untersuchten Baumarten waren in den Wurzeln signifikante Unterschiede der Anteile von 2 TMS und 3 TMS zwischen den Untersuchungsjahren nachzuweisen. Lediglich die Buchenwurzeln in der Söhre unterschieden sich im Anteil von 3 TMS signifikant zwischen den beiden Untersuchungsjahren. 


\section{DISKUSSION}

\subsection{Mitteleuropa im Klimawandel}

Im Verlauf des 20. Jahrhunderts war eine überdurchschnittliche Temperaturzunahme um $0.8 \mathrm{~K}$ in Europa zu beobachten (BENISTON et al. 1998), in Deutschland sogar um $0.9 \mathrm{~K}$ (Klimastatement 2003). Neben einer weiteren Temperaturerhöhung wird eine geänderte Verteilung der Niederschläge im Jahresverlauf prognostiziert, wobei im Winter eine Zunahme um bis $\mathrm{zu}$ 30\% und im Sommer eine Abnahme um 20-30\% erwartet wird (RAPP 2002 in: DWD-Klimastatusbericht 2001, Klimastatement 2003). Neueste Modelle prognostizieren für das Ende des 21. Jahrhunderts eine Zunahme der Winterniederschläge um bis zu 40\% und eine Abnahme der Sommerniederschläge um bis zu 50\% gegenüber 1961-1990 (RÄISÄNEN et al. 2004).

Angesichts dieser sich ändernden Niederschlagsverhältnisse, verbunden mit einer Temperaturzunahme, ist eine erhebliche Erhöhung der Trockenstressbeanspruchung für Pflanzen in Mitteleuropa zu erwarten (LEUSCHNER \& SCHIPKA 2004). Über die Wirkung erhöhter Sommertrockenheit auf das Wurzelsystem von Altbäumen in Deutschland ist vergleichsweise wenig bekannt.

\subsubsection{3 als Beispiel für den vorhergesagten Klimatrend}

Das Klima des trocken-warmen Jahres 2003 wich an beiden untersuchten Standorten deutlich vom langjährigen Mittel ab. Dieses äußerte sich in einer erhöhten Jahresmitteltemperatur von $+1.1 \mathrm{~K}$ und vor allem in überdurchschnittlich hohen Niederschlagswerten im Januar (Kassel: 125\% und Artern: 141\%) bei einem sehr trockenen Sommer (Kassel: 32\% und Artern: 22\%) im Vergleich zum langjährigen Mittel. Das Jahr 2003 kann also als gutes Beispieljahr für die Prognosen bezüglich des Klimawandels angesehen werden.

Als gutes Vergleichsjahr zum Extremjahr 2003 kann das Jahr 2004 betrachtet werden: Der Jahresniederschlag lag mit $108 \%$ in Kassel und 93\% in Artern sehr nahe am langjährigen Mittel. Zudem kam es 2004 zu keiner Sommertrockenheit, lagen doch die Niederschläge im Juli/August an beiden Klimastationen sogar deutlich über dem langjährigen Mittel (Kassel: 141\%, Artern: 124\%). 


\subsubsection{Wasserversorgung der beiden Untersuchungsbestände}

\section{Regionalklima}

Die primäre Wasserversorgung der Bestände wird nicht durch die Jahressumme der Niederschläge bestimmt, sondern durch die Höhe der Niederschläge während der Vegetationsperiode. Das langjährige Mittel der Vegetationsperiode von Mai bis September liegt für den niederschlagsreicheren Standort Söhre bei $327 \mathrm{~mm}$, für den trockeneren Standort Ziegelrodaer Forst im Regenschatten des Harzes lediglich bei $258 \mathrm{~mm}$.

Besonders das Untersuchungsjahr 2003 erwies sich in der Vegetationsperiode als äußerst warm und trocken. Mit nur $245 \mathrm{~mm}$ Niederschlag am Standort Söhre und 188 $\mathrm{mm}$ Niederschlag in der Vegetationsperiode am Standort Ziegelrodaer Forst wiesen beide Flächen 2003 einen bedeutend geringeren Niederschlag auf als im langjährigen Mittel. Die Niederschläge im darauffolgenden Jahr 2004 lagen auf beiden Untersuchungsflächen etwas höher als im langjährigen Mittel und stellten daher bezüglich der Wasserversorgung einen guten Kontrast und Vergleich dar.

Die beiden Untersuchungsstandorte waren einer nur geringfügig unterschiedlichen Beanspruchung durch die Atmosphäre ausgesetzt.

In der Vegetationsperiode 2003 wies das VPD etwas geringere Werte für die Untersuchungsfläche im Ziegelrodaer Forst als für die Untersuchungsfläche in der Söhre auf. Das VPD lag 2004 am trockeneren Standort geringfügig höher als am feuchteren Standort, jedoch an beiden Standorten niedriger als im Vorjahr. Dabei muss beachtet werden, dass beide VPD-Werte von den jeweils nächstgelegenen Klimastationen Kassel und Artern stammen. Es ist anzunehmen, dass das VPD direkt über den Waldbeständen der beiden Untersuchungsstandorte jeweils etwas niedriger sein dürfte, als an der Freilandmessstation des Deutschen Wetterdienstes.

Obwohl Kassel und Artern sich hinsichtlich der Niederschlagsmenge stark unterscheiden, sind bemerkenswerter Weise die VPD-Werte nahezu identisch.

\section{Bodenwassergehalt}

Das Niederschlagsregime und die vorhandene Vegetation wirken sich bestimmend auf den Bodenwassergehalt aus.

In geschlossenen Waldbeständen ist die oberste Bodenschicht von besonderer Bedeutung für die Wasseraufnahme (LEUSCHNER 1998, CONERS 2001). Das organische Material der Humusschicht ist in der Lage, das Vielfache des Eigengewichtes an Wasser zu binden. Die 5-8 cm dicke Humusauflage am Standort Söhre deckt einen größeren 
Teil des Wasserbedarfs für den Bestand ab als die deutlich geringmächtigere $(2 \mathrm{~cm})$ Humusschicht am Standort Ziegelrodaer Forst.

Da 2003 klimatologisch ein Extremjahr war, wurden besonders im Sommer geringe Bodenwassergehalte von unter 15 vol\% im Ziegelrodaer Forst gemessen. Die dagegen deutlich geringeren Bodenwassergehalte von zeitweise 7 vol\% in der Trockenperiode 2003 am niederschlagsreicheren Standort Söhre sind auf geringere Niederschläge in den Wintermonaten zurückzuführen. Dies führte am niederschlagsreicheren Standort Söhre zu einer geringeren Aufsättigung des Bodens im Frühjahr als am trockeneren Standort im Ziegelrodaer Forst.

Die geringen Bodenwassergehalte im Juli und August 2003 sind vornehmlich durch die geringen Niederschläge auf beiden Untersuchungsflächen zu erklären und nicht durch den Wasserverbrauch durch die Vegetation, da an beiden Standorten das VPD annähernd gleich war.

Die extremen Trockenmonate im Sommer 2003 wirkten sich teilweise sogar noch auf das Jahr 2004 aus. Zu Beginn der Vegetationsperiode wurde an beiden Untersuchungsstandorten der hier untersuchte Boden in $35 \mathrm{~cm}$ Tiefe durch die reichlichen Winterniederschläge 2004 aufgesättigt. Am Standort Söhre konnten keine sichtbaren Nachwirkungen von 2003 festgestellt werden. Bemerkenswert war hingegen die Austrocknungsphase im Ziegelrodaer Forst 2004. Hier wurden Bodenwassergehalte von 2.5 vol\% gemessen, also weitaus geringere Werte als 2003 in der Trockenperiode (unter 15 vol\%). Die Austrocknungsphase fiel somit extremer aus als in 2003, als weniger Regen fiel.

Aufgrund der deutlich trockeneren oberen Bodenhorizonte am niederschlagsärmeren Standort im Ziegelrodaer Forst wird vermutet, dass besonders die Kiefer, aber auch die Buche und Birke ihren Wasservorrat an diesem Standort aus tieferen Bodenhorizonten decken. Dies kann ein potentieller Grund dafür sein, dass der Boden im Ziegelrodaer Forst keinen Wasserspeicher in den unteren Bodenschichten aufweist.

Durch das flach anstehende Gestein in der Söhre hingegen nutzen Buche, Birke und Kiefer hauptsächlich das oberflächennahe Wasser, so dass das Wasser in tiefere Bodenschichten nachsickern kann. Im Ziegelrodaer Forst dagegen sind die drei untersuchten Baumarten aufgrund des insgesamt trockeneren Bodens auf das Wasser der unteren Bodenschichten angewiesen. Ein Wasserspeicher in noch tiefer gelegenen Bodenschichten liegt deshalb vermutlich am Standort Ziegelrodaer Forst nicht vor. In der Söhre, wo Wasser gut nachsickern kann, wird hingegen ein größerer Wasservorrat in den tiefer gelegenen Bodenhorizonten erwartet. Ein weiterer Grund für die starke Austrocknung des Bodens 2004 am Standort Ziegelrodaer Forst ist ein nicht aufgesättigter Unterboden, während am Standort Söhre der Unterboden durch deutlich höhere Niederschläge im langjährigen Mittel aufgesättigt ist. 
Die hohe Sickerrate des Wassers am niederschlagsarmen Standort bewirkt trotz hoher Frühjahrsniederschläge keine langanhaltende Wasserspeicherung in den oberen Bodenschichten. Am niederschlagsreicheren Standort in der Söhre reichen hohe Frühjahrsniederschläge aus, um die Wasserspeicherung im Boden für die Vegetationsperiode $\mathrm{zu}$ erhalten. So trockneten die tieferen Bodenschichten hier vermutlich weniger aus und konnten mit den hohen Frühjahrsniederschlägen von 2004 wieder aufgefüllt werden. Daraus ist zu schließen, dass sich Extremereignisse wie 2003 auf einen deutlich trockeneren Boden schwerwiegender auswirken als auf Böden niederschlagsreicher Standorte.

Ein ähnlich starkes Absinken des Bodenwassergehaltes konnte im Jahr 2004 im Nationalpark Hainich, wahrscheinlich auch hier als Folge des extremen Trockenjahres 2003, beobachtet werden (JungKUNST, mündl. Mitt.). Der Hainich liegt klimatisch zwischen den beiden untersuchten Standorten Ziegelrodaer Forst und Söhre. Im langjährigen Mittel weist der Niederschlag im Hainich $669 \mathrm{~mm}$ auf (Klimastation Weberstedt, DWD 2001). Im Jahr 2003 fielen jedoch nur 81\% und 2004 114\% Niederschlag des langjährigen Mittels (MPI, Jena).

\subsection{Charakterisierung der drei untersuchten Baumarten}

\section{Rotbuche (Fagus sylvatica L.)}

Die Rotbuche gehört $\mathrm{zu}$ den weitverbreiteten Waldbaumarten der nördlichen Hemisphäre. Ihre mesomorphen Blätter und mäßig geschützten Winterknospen begünstigen ihr Vorkommen im atlantischen bis subkontinentalen Klima. Durch ihre enorme Konkurrenzstärke in Mitteleuropa charakterisiert KÖPPEN (1931) dieses Klima regelrecht als „Buchenklima“ und auch LEUSCHNER (1998) bezeichnet die Rotbuche als erfolgreichste Baumart Mitteleuropas. PETERS (1997) beschreibt die Buche als schattentoleranter als ihre laubwerfenden Konkurrenten. Weiterhin weist sie bei ausreichender Wasserversorgung eine breite Toleranz bezüglich Makroklima und Boden auf. Darüber hinaus toleriert sie mehrere Phasen der Unterdrückung in ihrem Lebenszyklus und besitzt eine vergleichsweise variable Wachstumsstrategie (große Schwankungsbreite des Höhe-Durchmesser-Verhältnisses).

Trotz der großen Toleranzbreite der Rotbuche erweist sich die Wasserversorgung in vielen Untersuchungen als limitierender Faktor. Dies tritt verstärkt in Regionen mit unregelmäßigen oder nicht ausreichenden sommerlichen Niederschlägen auf (Ellenberg 1996, Peters 1997). Kramer (1988) und Pfadenhauer (1993) sehen das Minimum des Jahresniederschlages bei $600 \mathrm{~mm}$, LEIBUNDGUT (1991) sogar bei 600- 
$700 \mathrm{~mm}$. Dennoch sind Rotbuchenbestände im Untersuchungsbestand im Ziegelrodaer Forst im Regenschatten des Harzes bei einem langjährigen Mittel des Niederschlages von $474 \mathrm{~mm}$ zu finden. Die Interpretation von Jahresniederschlagssummen sollte also nur im Zusammenhang mit edaphischen Faktoren erfolgen (vgl. ELLENBERG 1996). Peters (1997) gibt für die Verbreitung von Fagus sylvatica eine Spannweite des Niederschlages zwischen 471 bis $2000 \mathrm{~mm}$ an. Die Buchen im Ziegelrodaer Forst befinden sich aufgrund der geringen Niederschläge dort also offenbar an ihrer Verbreitungsgrenze hinsichtlich des Wasserangebotes.

Die Buche gilt von den drei untersuchten Baumarten als „Wassersparer“. Sie verbraucht im Mittel $169 \mathrm{~g}$ Wasser für die Erzeugung von $1 \mathrm{~g}$ Trockensubstanz (nach PoLSTER, H. 1951, in KRAMER 1988).

Einen weiteren bedeutenden limitierenden Faktor für das Vorkommen von Rotbuchen stellt die Temperatur dar. Sehr empfindlich reagiert die Buche auf Spätfröste im Frühjahr und starke Winterfröste (ELLENBERG 1996). Durch ihre große standörtliche Toleranz kommt es zur Entstehung von einer überaus großen Anzahl von Lokalrassen (LEIBUNDGUT 1991).

Die Buche weist ein typisches Herzwurzelsystem auf (KöSTLER et al. 1968).

\section{Hängebirke (Betula pendula Roth)}

Die Birke tritt in Mitteleuropa als ausgesprochene Pionierbaumart auf. Aufgrund ihrer geringen standörtlichen Ansprüche ist sie in der Nordhemisphäre von Europa über

Sibirien, Kaukasus, Kleinasien bis Nordpersien $\mathrm{zu}$ finden. Ihren Verbreitungsschwerpunkt erreicht sie in borealen Birken-Kiefernwäldern (AAS et al. 1992, MAYER 1992). Sie gedeiht auf sehr trockenen, nährstoffarmen, sauren Böden ebenso wie auf Böden mit hoher Bodenfeuchtigkeit. Abgesehen von ihrem hohen Lichtbedarf besitzt die Birke eine weite ökologische Amplitude. Ihre Ansprüche an Bodeneigenschaften sind mittel bis gering. Aufgrund ihrer Konkurrenzschwäche wird sie von konkurrenzstärkeren Baumarten auf Extremstandorte (z.B. Sandböden) verdrängt (RÖHRIG \& BARTSCH 1992, WAGNER 1994). Die Birke zählt mit einem Verbrauch von durchschnittlich $317 \mathrm{~g}$ Wasser für die Erzeugung von $1 \mathrm{~g}$ Trockensubstanz zu den „Wasserverschwendern“ (nach POLSTER, H. 1951, in KRAMER 1988).

\section{Waldkiefer (Pinus sylvestris L.)}

Die Waldkiefer ist in beinahe ganz Europa und Nordasien beheimatet, so dass sie das größte Verbreitungsgebiet unserer einheimischen Baumarten aufweist. Durch ihre außergewöhnlich weite Verbreitung kommt es ebenfalls wie bei der Buche zur 
Ausbildung zahlreicher Lokalrassen, die sich morphologisch und physiologisch erheblich unterscheiden (LEIBUNDGUT 1991).

Die Waldkiefer braucht viel Licht, ist aber ansonsten ein sehr anspruchsloser Baum hinsichtlich Klima und Boden, der trockene Sommer an der Steppengrenze sowie Winterfröste in Sibirien erträgt. Sie vermag Extremstandorte wie trockene Sandböden, nasse Moore, Kalk- oder Kieselböden zu besiedeln (LEIBUNDGUT 1991, MAYER 1992). Lehmige Sandböden und sandige Lehmböden stellen die idealen Wuchsbedingungen für die Waldkiefer dar (AAS et al. 1992, MAYER 1992).

Die Waldkiefer ist in der Lage, eine Pfahlwurzel bis in tiefe Bodenregionen auszubilden. Somit macht sie sich weitgehend unabhängig vom Wasser- und Nährstoffangebot des Oberbodens. Ein weiterer Vorteil ist ihre Toleranz gegenüber extremen Temperaturen.

Der mittlere Wasserverbrauch der Kiefer für die Erzeugung von 1 g Trockensubstanz liegt bei $300 \mathrm{~g}$ (nach POLSTER, H. 1951 in KRAMER 1988).

\subsection{Anpassung der Wasseraufnahme an Trockenstress}

\subsubsection{Reaktion auf Trockenstress}

Aus dendrochronologischen Untersuchungen ist bekannt, dass Wassermangel vielerorts das Dicken- und Höhenwachstum mitteleuropäischer Bäume limitiert (BROCKMANN et al. 1987, FELBERMEIER 1993). Aufgrund von Dürreperioden kommt es in Stangenhölzern zum Teil zu starken Zuwachsverlusten. WIEDEMANN (1923, in HÖLLERL 2004) begründet dies unter anderem durch das Absterben von Feinwurzeln und nur langsame Erholung. Auch Utschig et al. (2004) und AvEMARK \& SchÖPfER (1988) kommen angesichts der Auswirkungen des Trockenjahres 1976 zu der Ansicht, dass es in den Folgejahren nach Dürrezeiten zu starken Zuwachsrückgängen kommt. Zuwachseinbußen konnten ebenfalls an Buche, Esche, Linde und Hainbuche im Nationalpark Hainich im Jahr 2004 beobachtet werden (FRECH, mündl. Mitt.).

Pflanzen können sich an Trockenheit durch eine Vergrößerung des Wurzelsystems, eine Verbesserung des Wasserleitvermögens, eine Verkleinerung der transpirierenden Oberfläche, eine Erhöhung der Spaltöffnungsdichte, die Produktion eines Haarfilzes auf den Blättern und die Apoptose der Assimilationsorgane (Blattabwurf zu Beginn der Trockenzeit) anpassen. Mit Beginn einer Austrocknungsphase reagieren die Wurzeln auf abnehmende Bodenwasserverfügbarkeit mit Abgabe von Signalstoffen (z.B. Abscisinsäure, $\mathrm{Ca}^{2+}$ oder ph-Wert-Änderung des Xylemsaftes). Diese erreichen über 
den Xylemsaft die Blätter und bewirken dort das frühzeitige Schließen der Stomata (KozlowsKi \& PALlaRdy 1997). Die Buche begegnet einer Wasserverknappung mit einer sensiblen Stomataregulation und einer effektiven Einschränkung der Transpiration (BACKES 1996), während die Birke bei eingeschränkter Wasserversorgung mit Stomataschluss, verbunden mit einer eingeschränkten Photosynthese, reagiert (GREVE \& TERBORG 1993).

Feinwurzelwachstum und Feinwurzelmortalität werden u.a. von der Bodentemperatur, aber auch von der Bodenfeuchte mitbestimmt (PREGITZER et al. 1993). Trockenheit kann die Feinwurzelmortalität von Bäumen erhöhen (u.a. KoNÓPKA et al. 2005). KLEINER et al. (1992) geben als Anpassung an Trockenheit eine Erhöhung der Feinwurzelbiomasse an. Hertel (1999), GIEGER (2002) und REwAld (mündl. Mitt.) konnten ebenfalls eine Erhöhung der Feinwurzelbiomasse bei Buche und Eiche nach einer Trockenperiode nachweisen, während HEILMEIER et al. (2001) keine Veränderung der Feinwurzelbiomasse bei Prunus dulcis nach einem Austrocknungsversuch feststellen konnten. ASPELMEIER \& LEUSCHNER (2006) dokumentierten dagegen eine Erhöhung der Mortalität bei Feinwurzeln und die Reduktion der Feinwurzelneubildung nach Trockenheit.

\subsubsection{Wasseraufnahme}

\subsubsection{Potenzial und Limitierungen derzeit verfügbarer Methoden}

In den letzten Jahren wurden an einzelnen Wurzeln Wasserflussmessungen in Laboratorien mit der NMR-Technik (Nuclear Magnetic Resonance) erfolgreich durchgeführt (u.a. MACFALL et al. 1991, ASSENG et al. 2000). Es ist mit dieser Methode jedoch nicht möglich, im Gelände unter natürlichen Bedingungen Saftfluss an Wurzeln zu messen. Die Wasseraufnahme durch Wurzeln wird durch verschiedene externe und pflanzen-interne Faktoren beeinflusst, z.B. durch Temperatur, Nährstoffverfügbarkeit, Konzentration von Salzen an der Wurzeloberfläche, Mykorrhizierungsgrad und Wurzelkonkurrenz (u.a. MARKHART et al. 1980, EVERAD \& DREW 1989, PASSIOURA \& TANNER 1985, STEUDLE \& HENZLER 1995). Manipulative Laborexperimente verändern in der Regel jedoch stark den Potenzial-Gradienten Boden-Pflanze-Atmosphäre (SPAC) als die wesentliche Kraft der Wasseraufnahme (FERNANDEZ et al. 2000).

Es gibt allerdings Methoden für Saftflussmessungen, die auch im Gelände durchführbar sind. In Tracer-Studien z.B. mit H-Isotopen oder O-Isotopen (u.a. BINGHAM et al. 2000) kann die Wasseraufnahme nur an wenigen ausgewählten Zeitpunkten quantifiziert 
werden - ein kontinuierliches „real-time Monitoring“ ist damit jedoch nicht möglich. Durch die Zugabe von markiertem Wasser kommt es zudem zu einer Änderung der Bodenfeuchte und somit zu einem Eingriff ins System.

Einen wesentlichen Fortschritt bei Wasseraufnahmemessungen stellte das MiniaturSaftfluss-System von SENOCK \& HAM (1993) dar. Diese Methode ist unter Feldbedingungen einsetzbar, so dass im ungestörten Wurzelbereich mit Wurzelkonkurrenz, Mykorrhizierung und natürlichem Bodengefüge die Wasseraufnahme an Altbäumen direkt im Bestand gemessen werden kann.

SENOCK \& LEUSCHNER (1999), CONERS (2001), KORN (2004) und CONERS \& LEUSCHNER (2005) verwendeten erstmals Miniatur-Saftflusssensoren für Saftflussmessungen an Feinwurzeln (2-5 mm). Für kleine Flussraten $<2 \mathrm{~g} \mathrm{~h}^{-1}$, wie sie vor allem in Trockenperioden und am Morgen bzw. am Abend auftreten, bestimmte CONERS (2001) einen empirischen Faktor, welcher die Flüsse aus der axialen Temperaturdifferenz ableitet. Anhand umfangreicher Eichversuche im Gelände und im Labor konnte CONERS (2001) die Eignung dieser Methode auch für kleine Saftflüsse $\left(<2 \mathrm{~g} \mathrm{~h}^{-1}\right)$ zeigen. Damit konnte eine Messgenauigkeit erreicht werden, die bisher bei geringen Saftflussraten mit keinem anderen Messverfahren möglich war.

In der vorliegenden Arbeit wurde bei einer Kalibrierung der Saftflusssensoren im Gelände mit Saftflussraten $<2 \mathrm{~g} \mathrm{~h}^{-1}$ eine Übereinstimmung der volumetrisch bestimmten Flussraten mit den mittels Saftfluss-Sensoren bestimmten Flussraten mit einem Korrelationsfaktor von $r=0.99$ bestätigt. Die Notwendigkeit für die Messung von geringen Saftflüssen ergibt sich zum einen aus dem Wunsch, möglichst dünne Wurzeln zu untersuchen, die mit vertretbarem Aufwand für die Bestimmung der Oberfläche freigelegt werden können. Zum anderen treten geringe Saftflussraten in Trockenperioden und auf extrem trockenen Standorten, wie z.B. der Untersuchungsfläche im Ziegelrodaer Forst, auf.

Radiale Flüsse können mit dieser Methode nicht direkt erfasst werden. Auch kann mit dieser Methode nicht der exakte Aufnahmeort des Wassers entlang der Wurzel bestimmt werden. Es ist bisher noch unklar, an welchem Wurzelabschnitt die Wasseraufnahme erfolgt. Weiterhin ist eine Verbesserung der Saftflusssensoren für noch kleinere Flüsse, d.h. für kleinere Wurzeldurchmesser wünschenswert, um exakt die Wurzelzonen mit unterschiedlich hohen Aufnahmeraten bestimmen zu können. 


\subsubsection{Veränderung des Wasserpotenzials im Wurzelxylem bei Trockenheit}

Das Potenzialgefälle im Kontinuum Boden-Pflanze-Atmosphäre (SPAC = Soil-plantatmosphere-continuum) dient als treibende Kraft für den Wassertransport in der Pflanze (u.a. SteudLE 1995, ZimMERMANN \& TYREE 2002). Einige Kritiker dieser Theorie (u.a. ZIMMERMANN et al. 2002) diskutieren zusätzliche Mechanismen, wie der Wasserfluss durch die Pflanze angetrieben werden könnte.

Kommt es bei Bodentrockenheit zu einer Absenkung des Bodenwasserpotenzials, muss auch das Wurzelwasserpotenzial weiter sinken, um weiterhin Wasser aus dem Boden aufnehmen zu können (SPOLLEN \& SHARP 1991).

Nur wenige Messungen liegen über Wasserpotenzialwerte von Wurzeln temperater Baumarten vor. In Tabelle 5-1 ist ein Literaturvergleich der Blatt- und Wurzelwasserpotenziale von Buche, Birke und Kiefer zusammengestellt.

Tabelle 5-1. Literaturvergleich von Minimum-Wasserpotenzialwerten $\left(\Psi_{\min }\right)$ in Blättern und Wurzeln der drei in dieser Studie untersuchten Baumarten.

\begin{tabular}{|c|c|c|c|}
\hline \multirow[t]{2}{*}{ Tree species } & \multicolumn{2}{|c|}{$\Psi_{\min }[\mathrm{MPa}]$} & \multirow[t]{2}{*}{ Author } \\
\hline & leaf & root & \\
\hline \multirow{9}{*}{ Fagus sylvatica } & -1.75 & & ROBERTS \& ROSIER (1994) \\
\hline & -2.20 & & LEUSCHNER et al. (2001a) \\
\hline & -2.19 & & BACKES (1996) \\
\hline & -2.25 & & SCHIPKA (2002) \\
\hline & & -1.78 & CONERS (2001) \\
\hline & & -1.53 & KORN (2004) \\
\hline & & -1.34 & PRIGGE (2005) \\
\hline & & $-2.55(2003)$ & This study \\
\hline & & $-1.85(2004)$ & This study \\
\hline \multirow[t]{4}{*}{ Betula pendula } & -1.91 & & BACKES (1996) \\
\hline & -1.60 & & RANNEY et al. (1991) \\
\hline & & $-3.13(2003)$ & This study \\
\hline & & $-1.47(2004)$ & This study \\
\hline \multirow[t]{9}{*}{ Pinus sylvestris } & -1.79 & & BACKES (1996) \\
\hline & -1.70 & & BENGTSON (1980) \\
\hline & -1.80 & & WARING et al. (1979) \\
\hline & -1.20 & & HELLKVIST et al. (1980) \\
\hline & -1.73 & & PERSSON (1980) \\
\hline & -1.50 & & JACKSON et al. (1995) \\
\hline & -1.35 & & RIECK \& RENGER (1994) \\
\hline & & $-1.50(2003)$ & This study \\
\hline & & $-0.73(2004)$ & This study \\
\hline
\end{tabular}


Während die Wasserpotenzialwerte der Wurzeln bei Buche im Jahr 2004 mit denen in der angegebenen Literatur gut übereinstimmen, wiesen die Wurzeln im deutlich trockeneren Jahr 2003 negativere Werte auf. Das Wurzelwasserpotenzial war im Minimum sogar noch negativer als vergleichbare Werte des Blattwasserpotenzials. Dies ist eine weitere Bestätigung für die extreme Ausprägung des Trockenstresses an den untersuchten Standorten im Jahr 2003. Für das Wurzelwasserpotenzial von Birke und Kiefer liegen keine vergleichbaren Ergebnisse aus anderen Untersuchungen vor. Vergleicht man aber das Blattwasserpotenzial aus der Literatur mit den Wurzelwasserpotenzialen, stellt man auch bei Birke und Kiefer fest, dass im Jahr 2003 wesentlich negativere Werte in den Wurzeln gemessen wurden als angesichts der LiteraturBlattwasserpotenziale zu erwarten gewesen wären. Besonders die Ergebnisse an Birkenwurzeln vom Standort Söhre fallen mit -3.13 MPa auf. Dieser sehr negative Wert kann bis zu einem gewissen Grade methodisch bedingt sein: Zum einen variieren die Einzelergebnisse aus Druckkammermessungen stark, weshalb bei den Messungen jeweils fünf Parallelwerte aufgenommen wurden. Eine Erhöhung der Parallelenzahl innerhalb des Zeitraums des Mittags-Minimums war wiederum nicht möglich, weil strikt auf die Einhaltung einer geringen Druckerhöhungsrate von $\leq 0.3 \mathrm{MPa} \mathrm{min}{ }^{-1}$ bei der Messung geachtet wurde. Auch dieser relativ langsame Druckanstieg kann unter Umständen immer noch zu einer Unterschätzung des Potenzials führen. Eine weitere Ursache für eine methodisch bedingte Unterschätzung des Wasserpotenzials hin zu negativeren Werten, könnte in einem sehr hohen Cavitierungsgrad der Wurzeln im sehr trockenen Oberboden liegen: Möglicherweise waren nur noch sehr wenige Xylemgefäße mit Wasser gefüllt. Dadurch wird aufgrund der geringen Menge austretenden Wassers bei der optischen Kontrolle gegebenenfalls zu spät, also bei höher angelegtem Druck, ein Befeuchten der Schnittfläche erkannt.

Vergleicht man die drei Baumarten untereinander, so waren an beiden Standorten in beiden Untersuchungsjahren immer die am wenigsten negativ ausgeprägten Wurzelwasserpotenziale bei der Kiefer zu finden. Die Kiefer weist als Nadelbaumart eine durch ihre Blattanatomie eingeschränkte Transpiration auf und kann aus diesem Grund nur ein geringes Wasserpotenzial in ihren Wurzeln aufbauen. Für 40-50 jährige Kiefernbestände liegen jährliche Transpirationsraten zwischen 240-300 mm vor (LYR et al. 1967). CONERS (2001) beobachtete in einer Trockenperiode 1999 bei der Fichte die positivsten Wurzelwasserpotenzialwerte von -0.6 MPa gegenüber -1.8 $\mathrm{MPa}$ und -1.2 MPa bei der zeitgleich untersuchten Buche und Eiche.

Eine weitere wichtige Anpassung an Trockenperioden ist die Speicherung von Wasser im Stamm. Besonders groß scheint dabei die Bedeutung von stamminternen Wasserspeichern bei Nadelbäumen zu sein (ROBERTS 1976, WRONSKY et al. 1985, TYREE \& YANG 1990). ZWEIFEL et al. (2000, 2001) kamen in ihren Untersuchungen an 
Picea abies zum Schluss, dass bei dieser Baumart 2-15\% bzw. sogar bis zu 65\% der Transpiration aus internen Stammwasservorräten gespeist werden. BACKES (1996) dagegen erhielt bei ihren Untersuchungen an den drei Laubbaumarten (Betula pendula, Fagus sylvatica, Quercus petraea) mit 0.1-0.7 \% im Stamm gespeichertem Wasser deutlich geringere Werte.

In der vorliegenden Arbeit wurden bei der Birke die negativsten Werte gemessen. Die Birke als eine Baumart mit hohen Transpirationsraten kann das Wurzelwasserpotential verstärkt in den negativen Bereich absenken. Kommt es jedoch zu einer verringerten Wasserverfügbarkeit, ist die Birke nicht in der Lage, durch physiologische Anpassungen die Trockenheit zu überwinden. Durch eine deutliche Einschränkung des Wasserumsatzes mittels Stomataregulation und schließlich durch Abwurf der Blätter ist sie in der Lage Trockenperioden zu überstehen (BACKES 1996). LYR et al. (1967) geben für die Hängebirke eine Jahrestranspiration von 430-480 mm an. Die Buche nimmt hier eine Mittelstellung ein: Für Buchenbestände variieren Jahrestranspirationsraten zwischen 178 mm und 393 mm (LyR et al. 1967, ROBERTS \& ROSIER 1994, SCHIPKA 2002).

Über die schon angesprochene Wasserpotenzialdifferenz Boden-Atmosphäre wird die Wasseraufnahme durch die Wurzeln angetrieben. Bei feuchtem Boden reichen wenig negative Potenziale für hohe Saftflüsse im Ziegelrodaer Forst aus. Je trockener der Boden wird, desto mehr müssen die Bäume in ihren Wurzeln das Potenzial absenken, um dem Boden Wasser zu entziehen. Dies war besonders im Trockenjahr $2003 \mathrm{zu}$ beobachten. Buche und Birke kamen auf der trockeneren Untersuchungsfläche in ihren Wurzeln bis auf kritische Werte von $-1.8 \mathrm{MPa}$ bzw. $-2.2 \mathrm{MPa}$, am niederschlagsreicheren Standort in der Söhre sogar auf -2.6 MPa bzw. -3.1 MPa. Unter dieser erhöhten Anspannung des Wassertransports kann es zum Zusammenbruch des Unterdrucks kommen. Der Wasserfaden reißt aufgrund von Cavitation ab (COCHARD 2002, HACKE 2003, BRÉDA et al. 1993, TYREE \& SPERRY 1989). Nach LARCHER (2001) gelten Wurzelwasserpotenziale von -2 bis $-4 \mathrm{MPa}$ bei Waldbäumen als niedrigste in Mitteleuropa bisher gemessene Werte. Auch FisCus (1972) gibt für den Ausgleich von Trockenperioden ein deutliches Absenken des Wasserpotenzials in Mais-Wurzeln an.

Bleibt das Bodenmatrixpotenzial in den oberen Bodenhorizonten über längere Zeit stark negativ, wie im Trockensommer 2003, reicht auch ein deutlich negatives Wasserpotenzial in den Wurzeln nicht mehr aus, um genügend Wasser durch die Feinwurzeln der oberen Bodenschicht aufzunehmen.

Während in der Söhre zu diesem Zeitpunkt die Buchen unter sichtbarem Trockenstress litten (frühzeitiger Abwurf der Blätter bereits im Sommer, erhöhter Wollläusebefall; eigene Beobachtung) kam es bei den Buchen im Ziegelrodaer Forst nicht zu so auffälligen Anzeichen für Trockenstress. Durch das weitere Absenken des 
Wurzelwasserpotenzials am trockeneren Standort war die Buche hier deutlich besser in der Lage, dem Trockenstress entgegenzuwirken. Des weiteren ist eine Wasseraufnahme durch Wurzeln aus tieferen Bodenschichten $\mathrm{zu}$ vermuten, die besonders in Trockenzeiten relevant wird. In diesem Fall könnte also eine langfristige Anpassung auf Ebene der Morphologie des Wurzelsystems der trockenheitssensiblen Buche an Trockenstress am trockenen Standort vorliegen. Reaktionen des Transpirationsstromes auf sinkende Bodenwassergehalte konnte STÖHR (2003) besonders bei Esche, jedoch nicht bei Ahorn feststellen. Er vermutete ebenfalls, dass Bäume ausreichende Wasservorräte in tieferen Bodenschichten erschließen, um so besser sommerliche Trockenperioden überstehen zu können.

Nach der Trockenperiode 2003 entspannten sich die Potenziale in den Wurzeln aller drei Baumarten auf beiden Untersuchungsflächen deutlich. Nur die Buche im Ziegelrodaer Forst senkte ihr Potenzial weiter und erreichte dabei Werte bis -2.4 MPa. Dadurch war sie in der Lage, dem bereits wiederbefeuchteten Boden bedeutende Wassermengen zu entziehen. Bei Buche und Birke im Ziegelrodaer Forst konnte in den Wurzeln nach dieser Trockenperiode tatsächlich ein erhöhter Saftfluss gemessen werden. Der Birke reichten zu diesem Zeitpunkt bereits Potenziale in ihren Wurzeln von -1.34 MPa aus, um Wasser aus den oberen Bodenhorizonten aufzunehmen, während die Buche bedeutend negativere Potenziale benötigte.

Bei der Kiefer war in den Wurzeln keine Reaktion auf die Wiederbefeuchtung festzustellen. Möglicherweise war sie als immergrüne Nadelbaumart nicht so wie die beiden anderen Laubbäume darauf angewiesen, dieses herbstliche Wasserangebot zu nutzen. Zum anderen könnten die hier untersuchten oberflächennahen Wurzeln langfristigere Schäden davongetragen haben, die nicht so kurzfristig repariert werden konnten wie bei Buche und Birke. Am niederschlagsreicheren Standort in der Söhre war keine der drei untersuchten Baumarten bei Trockenheit in der Lage, über ihre Wurzeln in den oberen Bodenhorizonten Wasser aufzunehmen. Es kann angenommen werden, dass die Buche am Standort Ziegelrodaer Forst kurzfristig auf Trockenheit reagieren kann, indem sie ihr Wurzelwasserpotenzial deutlich weiter absenkt.

Zusammenfassend kann geschlussfolgert werden, dass die Kiefer trotz ihrer am wenigsten negativen Wurzelwasserpotenziale in der Lage ist, die höchsten Wassermengen am trockenen Standort durch ihre Wurzeln aufzunehmen. Die Ursache dürfte in der relativ hohen hydraulischen Leitfähigkeit der Kiefer, verglichen mit den anderen beiden Baumarten, liegen. Die Birke mit den zeitweise negativsten Potenzialen ist nicht in der Lage, solch hohe Saftflüsse wie die Kiefer zu erreichen. Es wird vermutet, dass dies bedingt ist durch eine sehr geringe Leitfähigkeit. Die Buche mit den geringsten Saftflüssen benötigt mittlere Potenzialwerte, muss aber am trockenen Standort im trockeneren Jahr ihr Potenzial deutlich negativer senken als beide anderen 
Baumarten, um die geringen Saftflussraten erhalten zu können. Die starken saisonalen und interannuellen Unterschiede in der Wasseraufnahme sind somit recht deutlich durch die Schwankungen des Wurzelwasserpotenzials zu erklären. Diese Annahme stützt die Hypothese, dass die Wasseraufnahme durch Feinwurzeln von Altbäumen am natürlichen Standort entscheidend vom atmosphärischen Wasserzustand gesteuert wird (Kapitel 5.3.2.4).

\subsubsection{Einfluss von Embolien auf die hydraulische Leitfähigkeit}

Experimentelle Untersuchungen an Zweigen lassen annehmen, dass einerseits für die meisten Pflanzen eine positive Beziehung zwischen der Gefäßgröße und der axialen hydraulischen Leitfähigkeit und andererseits der Empfindlichkeit gegenüber Cavitation in den Gefäßen besteht. Hohe Leitfähigkeiten stehen demnach mit einer größeren Emboliegefahr in Verbindung. STEVENSON (2004) fand heraus, dass durch einen hohen Prozentsatz enger Leitgefäße im Holz von Wurzeln trockenkultivierter Kakteenpflanzen selbst bei Cavitation der großen Gefäße eine ausreichende Menge an engen Gefäßen wassergefüllt und damit funktional bleibt.

Untersuchungen an mehreren Baumarten (SPERRY \& SALIENDRA 1994 und ALDER et al. 1996) deuten weiterhin auf eine höhere Cavitationsgefährdung von Wurzeln im Vergleich zu Zweigen hin, weil die Differenz zwischen dem tiefsten gemessenen Wasserpotenzial im Wurzelxylem und der experimentell bestimmbaren Potentialschwelle, an der Cavitation auftritt, bei Wurzeln geringer ist. Nach SPERRY \& SALIENDRA (1994) und FrouX et al. (2005) treten tatsächlich in den Wurzeln schneller Embolien auf als in Zweigen. Dies wird in Analogie zu elektrischen Stromkreisen als eine Art „Sicherung“ bei der Wasseraufnahme durch Wurzeln interpretiert, bei der die Teile des Wurzelsystems ihre Leitfähigkeit dann verlieren, wenn der Boden stark austrocknet. Ähnlich wie dies bei Zweigen gefunden wurde (u.a. POCKMAN \& SPERRY 2000), wäre dann zu erwarten, dass die Wurzeln trockenheitsempfindlicher Baumarten (z.B. Buche) früher (also bei positiveren Potenzialen) an die Cavitationsschwelle gelangen als trockenheitsunempfindlichere Baumarten wie Birke und vor allem Kiefer.

Die Nadelbaumart Kiefer ist durch die Ausbildung der engeren Tracheiden weniger cavitationsgefährdet als die beiden Laubbaumarten Buche und Birke mit ihren großlumigen Tracheen. SPERRY et al. (1994) stellten bei einer Untersuchung an ringporigen (Quercus sp.) und zerstreutporigen Baumarten (Alnus, Betula, Populus spp.) und Coniferen (Picea, Larix, Abies spp.) fest, dass in Laubbaumarten im Winter mehr Embolien auftraten als in Nadelbaumarten.

Buchen bilden wie die Birken als zerstreutporige Baumarten im gesamten Jahrring im Mittel gleich große Gefäße aus. Durch das gehäufte Auftreten von Embolien im 
Stammbereich in den inneren Gefäßen (SPERRY et al. 1988, GLAVAC et al. 1990) kommt es zur Verlagerung des Transpirationsstromes nach außen in die Randbereiche. Diese jünger angelegten Gefäße sind weniger emboliegefährdet. Durch das Auftreten von Embolien wird die hydraulische Leitfähigkeit im Stamm bzw. in den Wurzeln herabgesetzt.

Der deutlich höhere Saftfluss in den Kiefernwurzeln kann durch eine wahrscheinlich geringere Embolisierungsrate dieser Baumart erklärt werden. Trotz geringer Transpirationsleistung der Kiefer aufgrund der geringen Oberfläche ihrer Nadeln, war sie in der Lage, auf der trockeneren Fläche am Standort Ziegelrodaer Forst deutlich höhere Saftflussraten im Jahr 2003 zu erreichen als Buche und Birke.

Mit Fortschreiten der Vegetationsperiode bis in die Trockenmonate Juli/August nahm die Wasseraufnahme bei allen drei Baumarten im Jahr 2003 am Standort Ziegelrodaer Forst stetig ab. Der Verlust an hydraulischer Leitfähigkeit während einer Vegetationsperiode ist ein natürlicher Prozess (LÖSCH 1999). Embolien treten nach Verlust eines Blattes oder eines ganzen Astes (Wind, Fraß) auf und sind daher gewissermaßen immer in Pflanzen zu finden. Mit dem natürlichen Alterungsprozess, bei dem die Tüpfelmembranelastizität abnimmt, steigt die Cavitationsgefährdung deutlich an (SPERRY et al. 1991). Somit kann neben der Bodenaustrocknung auch die Zunahme von Embolien für die Abnahme der Wasseraufnahme mit Fortschreiten der Vegetationsperiode eine Rolle spielen. Jedoch kam es im September bei Buche und Birke zu einem erneuten Anstieg der Wasseraufnahme. Dies deutet darauf hin, dass cavitierte Gefäße nach Auffüllen von Wasser wieder funktionsfähig werden können. Auch YANG \& TYReE (1992) und PerKs et al. (2004) konnten nachweisen, dass sich nach weniger intensivem Trockenstress embolierte Gefäße in lebenden Wurzeln wiederbefüllen.

\subsubsection{Artspezifische Wasseraufnahmeraten von Buche, Birke und Kiefer}

\section{Variabilität der Wasseraufnahme}

In vorangehenden Studien fanden die meisten Messungen von Flussraten an Wurzeln mit einem Durchmesser über $10 \mathrm{~mm}$ statt. Hierbei wurde die Wasseraufnahme also integrierend über relativ große Teile des Wurzelsystems untersucht. Betrachtet wurden besonders wirtschaftlich bedeutende Baumarten (Malus, Acinidia, Olea), die künstlich bewässert wurden (u.a. GREEN \& CLOTHIER 1995, GREEN et al. 2003, MORENO et al. 1996). 
Die in der vorliegenden Studie für dünne Feinwurzelstränge gefundenen hohen Variationskoeffizienten von $165-176 \%$ an benachbarten Wurzeln stehen im Einklang mit bisherigen vergleichbaren Untersuchungen. So stellten LEUSCHNER et al. (2004) an Buchen- und Eichenwurzeln, sowie KORN (2004) an Buche, Bergahorn, Esche, Linde, Hainbuche und Stieleiche ebenfalls Variationskoeffizienten in der Größenordnung von $109-168 \%$ fest.

Die in der vorliegenden Arbeit gemessenen Wurzelwasseraufnahmeraten von Buche, Birke und Kiefer zeigten auch eine große zeitliche Variabilität, verursacht hauptsächlich durch Veränderungen der Klimafaktoren VPD und Globalstrahlung und weniger durch den Bodenwassergehalt. Dies deckt sich mit den Ergebnissen anderer Untersuchungen für Buche, Eiche und Fichte (CONERs 2001) und Buche, Bergahorn, Esche, Linde, Hainbuche und Stieleiche (KORN 2004). Schwankten in eigenen Untersuchungen die Flussraten in den Buchenwurzeln zwischen $0.5 \mathrm{~g} \mathrm{~mm}^{-2} \mathrm{~d}^{-1}$ und $6.9 \mathrm{~g} \mathrm{~mm}^{-2} \mathrm{~d}^{-1}$, kam es besonders in Kiefernwurzeln aber auch in Birkenwurzeln $\mathrm{zu}$ deutlich höheren Aufnahmeraten einzelner Wurzeln. Diese deutlichen Unterschiede wurden ebenfalls im Hinblick auf die oberflächenbezogenen Wasseraufnahmeraten von Wurzeln gemessen. Solche von CONERS (2001) als „high capacity roots“ bezeichneten Wurzeln könnten verantwortlich sein für die erhöhte Wasseraufnahme aus tiefen Bodenschichten besonders in Trockenperioden.

Eine weitere Erklärung für die hohe Variabilität in der Wasseraufnahme eng benachbarter Wurzeln könnte die kleinräumige Heterogenität des Bodenwassergehaltes sein. Durch die heterogene Verteilung des Bodenwassers stehen den Wurzeln unterschiedliche Mengen an Wasser für die Aufnahme bereit.

\section{Artspezifische Wasseraufnahmeraten}

Unter vergleichbaren Umweltbedingungen wiesen die Wurzeln der drei Baumarten deutlich unterschiedliche Wasseraufnahmeleistungen hinsichtlich der oberflächenbezogenen Aufnahmeraten auf, die sich um den Faktor 2-10 unterschieden. Die Kiefer erreichte mit $>2000 \mathrm{~g} \mathrm{H}_{2} \mathrm{O} \mathrm{m}^{-2} \mathrm{~d}^{-1}$ weit höhere Raten als die Birke (ca. $1000 \mathrm{~g} \mathrm{H}_{2} \mathrm{O}$ $\mathrm{m}^{-2} \mathrm{~d}^{-1}$ ). Bei der Buche lagen die Werte meist deutlich unter $500 \mathrm{~g} \mathrm{H}_{2} \mathrm{O} \mathrm{m} \mathrm{m}^{-2}$. Aus diesen Ergebnissen kann man die Schlussfolgerung ziehen, dass Baumarten mit relativ hoher gesamter Feinwurzelbiomasse und -oberfläche (Buche) geringere spezifische Aufnahmeraten erreichen als Baumarten mit kleiner Feinwurzelbiomasse wie die Kiefer.

In Trockenperioden in den Jahren 2003 und 2004 wiesen alle drei Baumarten nur eine geringe Wasseraufnahme auf. Am Ende der Vegetationsperiode 2003 konnte jedoch nach Wiederbefeuchtung bei Buche und Birke am niederschlagsarmen Standort eine erhöhte Wasseraufnahme gegenüber der Trockenperiode gemessen werden. Es wird 
vermutet, dass die Kiefer bei Trockenheit ihr Wasser den tieferen Bodenschichten entzieht. Die Wurzeln dieser tiefliegenden Bodenschichten wurden jedoch nicht untersucht.

CONERS (2001) untersuchte die Wasseraufnahme von Buchen- und Eichenwurzeln in verschiedenen Bodenhorizonten und stellte am Standort Ziegelrodaer Forst eine deutlich höhere Wasseraufnahme bei Wurzeln aus dem unteren Mineralbodenhorizont fest als bei Wurzeln aus der organischen Auflage. Dies steht im Zusammenhang mit der geringmächtigen organischen Auflage an diesem niederschlagsärmeren Standort, die nicht in der Lage ist, ausreichend Wasser zu speichern. Untersuchungen von STROBEL (1997) zeigten eine schnelle Entleerung der organischen Auflage an diesem Standort. Von 50 vol\% Sättigung im Frühjahr sank der Wassergehalt bis auf 4-13 vol\% während der Vegetationsperiode. In den eigenen Messungen fiel der Bodenwassergehalt 2004 sogar noch stärker bis auf Werte von 2.5 vol\%. Durch die deutlich geringeren Wassergehalte am niederschlagsärmeren Standort Ziegelrodaer Forst, verursacht durch die geringe Mächtigkeit der organischen Auflage und ein frühzeitigeres Entleeren des Wasserspeichers durch die Wurzeln, sind hier die Wurzeln auf eine vermehrte Wasseraufnahme aus tieferen Bodenhorizonten angewiesen. ZOTH \& BLOCK (1992) fanden an Untersuchungen an Wurzelballen sturmgeworfener Kiefern Durchwurzelungstiefen bis $2.00 \mathrm{~m}$ bzw. bei Buchen bis $1.70 \mathrm{~m}$. Besonders die Kiefer vermag vermutlich ihren Wasserhaushalt bei Trockenheit aus tieferen Bodenschichten $\mathrm{zu}$ decken. Buche und Birke sind anscheinend hinsichtlich ihrer Wasseraufnahme verstärkt auf die oberen Bodenhorizonte angewiesen (Kapitel 5.3.3).

\subsubsection{Wasseraufnahme in Abhängigkeit von Globalstrahlung, VPD und Bodenfeuchte}

Vorangegangene Studien zur Untersuchung des Wasserhaushaltes von Waldökosystemen kamen zu dem Ergebnis, dass die Globalstrahlung und das Sättigungsdefizit der Luft (VPD) maßgeblich die Höhe der Bestandestranspiration und somit die Wasserleitung im Baum beeinflussen (u.a. BACKES 1996, WULLSCHLEGER et al. 2000, KÖSTNER 2001, WilsON et al. 2001, HÖLSCHER et al. 2004). SEVANTO et al. (2005) stellten zusätzlich eine hohe Abhängigkeit der täglichen Varianz des Xylemdurchmessers vom VPD fest, welche sich bedeutend auf die Wasserleitung auswirkt.

CONERS (2001) und KORN (2004) stellen deutliche Zusammenhänge zwischen der Wasseraufnahme von Buchen-, Eichen- und Fichtenwurzeln bzw. Wurzeln von Buchen, Eichen, Bergahorn, Hainbuchen, Linden und Eschen und klimatisch-edaphischen 
Umweltfaktoren fest. CONERS (2001) hebt dabei besonders die starke Abhängigkeit des Wurzelsaftflusses vom atmosphärischen Sättigungsdefizit (VPD) hervor. Er berechnet für Buchen- und Eichenwurzeln dafür eine Abhängigkeit über 70\%. KORN (2004) fand für Buchenwurzeln eines anderen Standortes eine ähnlich starke Abhängigkeit vom VPD und konnte diesen Zusammenhang auch für andere Baumarten nachweisen. Zu fast 30\% waren die Wasseraufnahmeraten bei Buchenwurzeln dagegen durch die Bodenfeuchte erklärbar.

Dieser eindeutige Zusammenhang konnte in der vorliegenden Untersuchung nicht bestätigt werden. Ein nachweisbarer Einfluss des VPD auf die Wasseraufnahme war in weniger als einem Drittel der untersuchten Konstellationen nachweisbar.

Insgesamt zeigten sich die geringsten Abhängigkeiten der aufgenommenen Umweltparameter in den Trockenperioden 2003 und 2004. Die geringe Abhängigkeit der Wasseraufnahme vom VPD bei Buchen-, Birken- und Kiefernwurzeln der vorliegenden Arbeit könnten erklärt werden durch die Klimadaten der Messstationen. CONERS (2001) und KORN (2004) konnten für die VPD-Werte eigene Klimamesswerte von Messstationen oberhalb oder in unmittelbarer Nähe der untersuchten Bestände für die Berechnung verwenden. Die in der vorliegenden Studie verwendeten Messdaten kamen zum Teil von weiter entfernt gelegenen Stationen, was zu einem gewissen Fehler führen dürfte.

Bemerkenswert ist die hohe Abhängigkeit der Saftflussdichte bei Kiefernwurzeln von $82 \%$ vom Bodenwassergehalt in $20 \mathrm{~cm}$ Bodentiefe am Standort Söhre in der Trockenperiode 2003. Weitere Abhängigkeiten der Saftflussdichte vom Bodenwassergehalt in $35 \mathrm{~cm}$ Bodentiefe wurden in der Trockenperiode 2004 am niederschlagsärmeren Standort Ziegelrodaer Forst für Birkenwurzeln (42\%) und Kiefernwurzeln (95\%) gefunden. Dies bestätigt die Annahme, dass Kiefernwurzeln besonders in der Trockenperiode am niederschlagsärmeren Standort Ziegelrodaer Forst ihren Wassergehalt aus tieferen Bodenschichten decken. Auch KORN (2004) fand in Trockenperioden höhere Abhängigkeiten vom Bodenwassergehalt als in feuchteren Vegetationsabschnitten.

Darüber hinaus ist zu erwarten, dass besonders im trockenen Sommer 2003, der sich im Ziegelrodaer Forst sogar noch auf das Folgejahr auswirkte, die hier untersuchten oberflächennahen Wurzeln aufgrund der starken Bodenaustrocknung kaum noch für die Wasserversorgung des Baumes relevant sein dürften.

Aus der Varianz kann geschlussfolgert werden, dass besonders in Trockenperioden andere Faktoren als Baumart, Standort und Jahr einen höheren Einfluss auf die Wasseraufnahme haben. Auch im darauffolgenden Jahr des „Jahrhundertsommers“ von 2003 kam es zu geringeren Einflüssen der genannten Faktoren. Auch hier spielen andere Einflussfaktoren für die Wasseraufnahme der drei Baumarten eine Rolle. 


\subsubsection{Morphologische Anpassung der Wurzeln an Trockenheit}

Neben physiologischen Anpassungen der Wurzeln an Trockenheit spielt die morphologische und anatomische Struktur der Wurzeln eine entscheidende Rolle für die Gewährleistung der Wasserversorgung der Bäume auf Standorten mit verschiedenen Niederschlagsangeboten.

Buche und Birke bilden ein Herzwurzelsystem und die Kiefer ein Pfahlwurzelsystem aus (KUTSCHERA 2002). BIBELRIETHER (1966) weist darauf hin, dass die Ausbildung des Wurzelsystems jedoch entscheidend abhängig ist von der Bodenart, der Nährstoffverteilung und dem Wasserhaushalt. Bei reichlicher Oberbodenfeuchte infolge hoher Niederschläge ist die Ausbreitung der Wurzelmasse ausschließlich auf die oberen Bodenschichten begrenzt (KUTSCHERA 2002). Eine Abnahme der Feuchtigkeit in den oberen Bodenschichten bewirkt eine Erweiterung des Wurzelsystems in die unteren Bodenhorizonte.

Es wird vermutet, dass am niederschlagsärmeren Standort im Ziegelrodaer Forst die Wasseraufnahme durch Wurzeln hauptsächlich aus den unteren Bodenhorizonten erfolgt. Besonders in Trockenmonaten kam der Saftfluss in den hier ausschließlich untersuchten Wurzeln des Oberbodens fast völlig zum Erliegen. Während er mit Einsetzen des Niederschlages bei Buche und Birke in den oberflächennahen Wurzeln wieder ansteigt, bleibt die Saftflussdichte auch am Ende der Vegetationsperiode bei der Kiefer nahezu bei Null. Hier wird vermutet, dass die Kiefer ihren Wasserbedarf aus den unteren Bodenhorizonten decken kann, während Buche und Birke auf eine Wasseraufnahme aus den oberen Bodenschichten angewiesen sind.

Eine Tiefenverlagerung der Durchwurzelung am niederschlagsärmeren Standort Ziegelrodaer Forst wird als eine Trockenheitsanpassung gewertet. Eine höhere Wurzelbiomasse in der organischen Auflage wurde indes am niederschlagsreicheren Standort in der Söhre beobachtet. Hier deckten die Bäume einen Großteil ihrer Wasseraufnahme aus den oberen Bodenschichten. Die deutlich dickere Humusschicht an diesem Standort ist daher in der Lage, mehr Wasser zu speichern.

Nach KUTSCHERA (2002) sind Feinwurzeln von Pflanzen im Allgemeinen auf feuchteren Standorten länger und weniger verzweigt als auf trockeneren Standorten.

Jedoch konnten nach dem Trockenjahr 2003 erhöhte spezifische Wurzeloberflächen von Birkenwurzeln besonders aber signifikant höhere spezifische Wurzeloberflächen der Kiefernwurzeln und Buchenwurzeln am niederschlagsreicheren Standort in der Söhre gemessen werden. Die daraus resultierende stärkere Verzweigung der Wurzeln kann besonders bei der trockenheitsempfindlichen Buche als mögliche Reaktion an die Trockenheit des extremen „Jahrhundertsommers“ 2003 gewertet werden. 


\subsubsection{Anatomische und chemische Anpassung an Trockenstress}

\subsubsection{Suberin als Barriere für den Wassertransport in Wurzeln}

In den unterirdisch wachsenden Pflanzenorganen, insbesondere den Wurzeln, finden sich suberinisierte Barrieren (apoplastische Transportbarrieren), die neben der Schutzfunktion gegen Pathogene (BERNARDS \& LEWIS 1998) vor allem auch eine wichtige Funktion als Schutz vor Austrocknung bei Bodentrockenheit besitzen. STEUDLE (1994) nimmt an, dass die Wasseraufnahme durch Wurzeln über einen breiten Bereich der Wurzelspitzen erfolgt, welcher sich hinter der Wurzelhaarzone befindet. Eine zusätzliche Wasseraufnahme kann über die meristematischen Bereiche der Seitenwurzeln erfolgen.

Es wird angenommen, dass auf der einen Seite ein hoher Suberingehalt zur Trockenheitstoleranz beitragen kann und dass auf der anderen Seite durch hohe Suberingehalte in der Peridermschicht die Wasseraufnahme durch die Wurzel gehemmt wird. Doch bereits KRAMER (1946) vermutet, dass eine Wasseraufnahme durch suberinisiertes Gewebe möglich ist, z.B. durch Durchlasszellen. Eine Wasseraufnahme durch verholzte Schwach- und Grobwurzeln konnte in vorangegangenen Studien bestätigt werden (u.a. CHUnG \& Kramer 1975, VAnReEs \& COMERFORD 1990, MACFALL et al. 1991). Denkbar ist ebenfalls die Wasseraufnahme durch Risse in der Zellwand oder durch Durchlasszellen von suberinisierten Peridermschichten toter Wurzeln (MCKENZIE \& PETERSON 1995).

Um die Frage zu klären, ob Baumwurzeln bereits an terminalen Wurzelspitzen suberinisiertes sekundäres Abschlussgewebe aufweisen, wurden in der vorliegenden Arbeit anatomische Querschnitte von Feinwurzeln $<1 \mathrm{~mm}$ angefertigt.

Alle drei Baumarten wiesen in den Untersuchungen in ihren Wurzeln ein suberinisiertes sekundäres Abschlussgewebe auf, das bis in die terminalen Wurzelspitzen reichte. Eine Wurzelhaarzone sowie das Primärstadium der Wurzelentwicklung mit Stele, Endodermis, Cortex und Exodermis konnten bei keinem der drei Baumarten in den Wurzelspitzen $<1 \mathrm{~mm}$ gefunden werden.

LEUSCHNER et al. (2003) untersuchten Wurzelspitzen von Fagus sylvatica und Quercus petraea und stellten auch bei diesen Baumarten ein suberinisiertes sekundäres Abschlussgewebe bis an die terminale Wurzelspitze fest, während dies bei Sämlingen anderer Arten (Pinus banksiana und Eucalyptus pilularis) dagegen in den terminalen 6-11 cm der Wurzelenden nicht nachgewiesen wurde (MCKeNZIE \& PETERSON 1995). Auch Wilson \& Peterson 1983, Schreiber et al. 1999 und Hartmann et al. 2002 
konnten Suberin in endodermalen und hypodermalen Zellen von Primärwurzeln nachweisen.

Die bisher gängige Lehrbuchmeinung, dass die Suberinschicht für Wasser undurchlässig ist, kann mit diesen anatomisch-chemischen Befunden kaum in Einklang gebracht werde: Wenn bereits direkt hinter den Wurzelspitzen suberinisiertes sekundäres Abschlussgewebe vorliegt, muss es möglich sein, dass Wasser auch durch suberinisierte Peridermschichten in die Wurzel gelangen kann. Hierbei spielen nach Peterson \& Enstone (1996) die Durchlasszellen eine bedeutende Rolle. Um die Frage zu klären, ob hohe Suberingehalte mit geringen Wasseraufnahmeraten verbunden sind, wurden die Suberingehalte von Feinwurzeln $<1 \mathrm{~mm}$ der drei untersuchten Baumarten bestimmt.

In bisherigen Zellwandanalysen wurden chemische Analysedaten auf die Masse bezogen (u.a. ZIMMERMANN et al. 2000). HARTMANN (2002) und LEUSCHNER et al. (2003) konnten erstmalig die Suberingehalte für Buchen-, Eichen- und Fichtenwurzeln auf die Wurzeloberfläche beziehen. Der Vorteil der Berechnung oberflächenbezogener Suberingehalte liegt in einem deutlich besseren Vergleich für unterschiedliche Baumarten, da hier ein Massenbezug durch unterschiedlich dickes Periderm der Baumarten die Ergebnisse verfälschen könnte. In der vorliegenden Arbeit wurden oberflächenbezogene Suberingehalte in Buchen-, Birken- und Kiefernwurzeln von zwei unterschiedlich wasserversorgten Standorten bestimmt.

Die drei Baumarten wiesen zwar tendenzielle Unterschiede in ihrem Gesamtsuberin auf, jedoch ohne systematische Unterschiede zwischen den Laubbaumarten. Die Kiefer wies mit $100 \mu \mathrm{g} \mathrm{cm}^{-2}$ als Nadelbaumart die signifikant geringsten Suberingehalte auf. LEUSCHNER et al. (2003) konnten im Fichtenwurzelperiderm, also ebenfalls einer Nadelbaumart, einen Suberingehalt von $40 \mu \mathrm{g} \mathrm{cm}^{-2}$ nachweisen. In Buchenwurzeln konnten in der vorliegenden Arbeit Gesamtsuberingehalte bis $340 \mu \mathrm{g} \mathrm{cm}^{-2}$ nachgewiesen werden. Diese Werte decken sich mit den in der Literatur angegebenen Werten von $300 \mu \mathrm{g} \mathrm{cm}^{-2}$ (LEUSCHNER et al. 2003). Durch die hohen Suberingehalte bei Birke $\left(400 \mu \mathrm{g} \mathrm{cm}^{-2}\right)$ und die geringen Suberingehalte bei der ebenfalls trockenheitstoleranten Kiefer kann somit nicht geschlussfolgert werden, dass hohe Suberingehalte im Wurzelperiderm ein Merkmal sind, dass mit der Trockenheitstoleranz einer Baumart korreliert.

Obwohl die komplette Suberinisierung der gesamten Wurzelachse eine absolute Impermeabilität des Periderms in Frage stellt, scheint es doch eine gewisse Korrelation zwischen Suberinmenge und Wasseraufnahmevermögen zu geben. So konnten die Kiefernwurzeln mit ihrem geringen Suberinisierungsgrad im Ziegelrodaer Forst trotz geringer Wasserpotenzialgradienten die höchsten Wasseraufnahmeraten erzielen. 
KORN (2004) hingegen fand keinen Zusammenhang zwischen der Anzahl suberinisierter Peridermschichten und der Wasseraufnahme. Sie stellte fest, dass die Esche trotz vieler Peridermschichten viel Wasser durch ihre Feinwurzeln aufnahm, während die Hainbuche bei einem geringen sekundären Abschlussgewebe, wenig Wasser über die Feinwurzeln aufnahm. Dies konnte mit den eigenen Messungen bestätigt werden. Während es deutliche Unterschiede in der Menge der Wasseraufnahme gab, konnten keine signifikanten Unterschiede in der Anzahl der Peridermschichten zwischen den Baumarten festgestellt werden. Daraus kann geschlussfolgert werden, dass nicht unbedingt geringe Suberingehalte mit hohen Wasseraufnahmeraten verbunden sein müssen.

Bemerkenswert sind jedoch die signifikant höheren Suberingehalte pro Peridermschicht bei Buchen- und Birkenwurzeln im trockenen Sommer 2003 am trockenen Standort. Dies kann als eine kurzzeitige Anpassung an Trockenheit interpretiert werden. Somit kann der Suberinisierungsgrad der Peridermschichten in Zusammenhang mit der Trockenheitsresistenz der Wurzeln stehen. In einigen Studien konnte ebenfalls nach Einwirkung von Trockenheit oder osmotischem Stress eine Erhöhung des Suberingehaltes gezeigt werden (CRUZ et al. 1992, NORTH \& NOBEL 1996).

\subsubsection{Suberinkomponenten als Biomarker}

Suberin ist als ein Biopolymer sehr komplex aufgebaut und besteht aus zwei Hauptkomponenten, einem aliphatischen und einem aromatischen Anteil (KolatTUKUdy 1980). Die aliphatische Komponente von Baumwurzeln besteht vornehmlich aus gesättigten und ungesättigten $\omega$-Hydroxysäuren, Disäuren, 2-Hydroxysäuren, gesättigten und ungesättigten Carbonsäuren und Alkoholen mit einer Kettenlänge von 16-32 Kohlenstoffatomen, während im aromatischen Anteil in erster Linie Zimtsäurederivate (Ferulasäure, Cumarsäure) zu finden sind (u.a. HARTMANN 2002, SCHREIBER et al. 2005).

HARTMANN (2002) stellte fest, dass die Suberinzusammensetzung des Wurzelperiderms von Buchen (Fagus sylvatica), Eichen (Quercus petraea) und Fichten (Picea abies) artspezifisch ist. Dies konnte mit den eigenen Untersuchungsergebnissen an Buchen-, Birken- und Kiefernwurzeln bestätigt werden: Während in Buchen- und Birkenwurzeln als Hauptbestandteil die Trihydroxysäure vorgefunden wurde, fehlte sie in Kiefernwurzeln gänzlich. Auch HARTMANN (2002) wies im Fichtenwurzelperiderm einen sehr geringen Anteil an Trihydroxysäure nach, die in den beiden verglichenen Laubbaumarten Buche und Eiche den Hauptbestandteil darstellte. Möglicherweise ist 
ein geringer Anteil bzw. ein Fehlen dieser Substanz ein typisches Merkmal für Nadelbaumarten.

Über dieses eindeutige Fehlen von Trihydroxysäure bei Coniferen hinaus deuten sich artspezifische Muster in der anteiligen Zusammensetzung des Suberins an. So kamen in den untersuchten Buchenwurzeln bis auf ungesättigte organische Säuren alle identifizierten Stoffklassen vor. Die Hauptkomponenten bildeten die Trihydroxysäure mit 39\% und die $\omega$-OH-Säuren mit 37\% des Suberingesamtgehalts. Dies entspricht der Zusammensetzung, die HARTMANN (2002) in Buchenwurzeln von einem sandigen Standort in der norddeutschen Tiefebene fand.

In den Birkenwurzeln hingegen fehlten Carbonsäuren, ungesättigte Säuren, Alkohole und 2-OH-Säuren in allen Einzelproben. Zimtsäurederivate $(5,3 \%)$ und $\omega$ Dicarbonsäuren (1.5\%) lagen anteilig weit unter 10\%. Die Trihydroxysäure hatte bei Birkenwurzeln einen prozentualen Anteil von 19\%. Die Hauptkomponente bildeten hier mit $74 \%$ die $\omega$-OH-Säuren.

In den Kiefernwurzeln fehlte die Trihydroxysäure. Alkohole, 2-OH-Säuren, Zimtsäurederivate und Carbonsäuren nahmen nur geringe Anteile ein. Die Hauptkomponente mit $61.4 \%$ bildeten auch hier die $\omega$-OH-Säuren.

Während die Menge an Suberin und die Verteilung in der Wurzel je nach Herkunft, Alter und klimatischen Bedingungen stark variieren kann, scheint also die chemische Zusammensetzung aus den einzelnen Stoffklassen ein artspezifisches Merkmal zu sein und könnte ähnlich wie DNA- oder Isoenzymmuster als Biomarker herangezogen werden. 


\section{ZUSAMMENFASSUNG}

1. An drei forstwirtschaftlich und ökologisch bedeutenden Baumarten (Rotbuche, Hängebirke, Waldkiefer) wurden oberflächenbezogene Wurzelwasseraufnahmeraten mit Miniatursaftflusssystemen nach der "heat balance“ Methode gemessen. Die Untersuchungen fanden in einer trockenen Vegetationsperiode 2003 und einer feuchten Vegetationsperiode 2004 auf zwei unterschiedlich wasserversorgten Standorten in situ an Altbäumen statt.

2. Es sollte geklärt werden, wie sich die Feinwurzeln der relativ trockenheitsempfindlichen Buche sowie der relativ trockenheitstoleranten Arten Birke und Kiefer hinsichtlich ihrer physiologischen, morphologischen, anatomischen und chemischen Eigenschaften unterscheiden und ob die Baumarten in der Lage sind, ihr Feinwurzelsystem an trockene Standorte anzupassen, um eine ausreichende Wasseraufnahme zu gewährleisten.

3. Die oberflächenbezogenen Wurzelwasseraufnahmeraten zeigten eine große zeitliche Variabilität, verursacht hauptsächlich durch Witterungseinflüsse wie VPD und Globalstrahlung und weniger durch den Bodenwassergehalt.

4. Am trockeneren Standort wurden bei allen drei Baumarten höhere oberflächenbezogene Wasseraufnahmeraten im Wurzelsystem gemessen als am deutlich feuchteren Standort. Diese sind vornehmlich auf höhere VPD-Werte und einen höheren Wasserpotenzialgradienten im Baum zurückzuführen.

5. Unter vergleichbaren Umweltbedingungen wiesen die Wurzeln der drei Baumarten deutlich unterschiedliche oberflächenbezogene Wasseraufnahmeleistungen auf, die sich um den Faktor 2-10 unterschieden. Die Kiefer erreichte mit $>2000 \mathrm{~g} \mathrm{H}_{2} \mathrm{O} \mathrm{m}^{-2} \mathrm{~d}^{-1}$ weit höhere Raten als die Birke (ca. $1000 \mathrm{~g} \mathrm{H}_{2} \mathrm{O} \mathrm{m}^{-2} \mathrm{~d}^{-1}$ ). Bei der Buche lagen die Werte meist deutlich unter $500 \mathrm{~g} \mathrm{H}_{2} \mathrm{O} \mathrm{m} \mathrm{m}^{-2}$. Aus diesen Ergebnissen kann man die Schlussfolgerung ziehen, dass Baumarten mit relativ hoher Feinwurzelbiomasse und -oberfläche (Buche) geringere spezifische Aufnahmeraten erreichen als Baumarten mit kleiner Feinwurzelbiomasse wie die Kiefer.

6. Im trockenen Sommer 2003 senkten alle drei Baumarten ihr Wurzelwasserpotenzial am stärksten ab. Die Kiefer wies in ihren Wurzeln stets das am wenigsten negative Potenzial auf, die Birke das negativste. Die Buche nahm in der Regel eine Mittelstellung ein, fiel aber am trockenen Standort durch eine spätsommerliche Absenkung ihres Wurzelwasserpotenzials auf. 
7. Die starken saisonalen und interannuellen Unterschiede der Wasseraufnahme können gut mit den Schwankungen der Wurzelwasserpotenziale erklärt werden. Hier wies die Kiefer trotz geringer Potenzialabsenkung die höchsten Aufnahmeraten auf. Daraus wird geschlossen, dass die Kiefer eine höhere radiale Leitfähigkeit besitzt als Buche oder Birke. Diese Vermutungen sollten jedoch noch durch Laborversuche überprüft werden.

8. $\mathrm{Zu}$ tendenziellen Unterschieden kam es in der Anzahl der Peridermschichten und des Gesamtsuberingehaltes zwischen den Wurzeln der drei Arten. Die trockenheitstolerante Kiefer wies hierbei die geringsten Suberingehalte in ihrem sekundären Wurzelgewebe auf. Hohe Suberingehalte sind also offenbar nicht korreliert mit einer Trockenheitsanpassung. Die Anzahl der Peridermschichten in den Feinwurzeln steht vermutlich in keiner Beziehung zur Trockenheit des Standortes. Allerdings können die signifikant höheren Suberingehalte pro Peridermschicht im trockenen Sommer 2003 bei Buchen- und Birkenwurzeln am trockenen Standort als Anpassung an den trockenen Boden interpretiert werden.

9. Zusammenfassend lässt sich schlussfolgern, dass sich die Feinwurzeln mitteleuropäischer trockenheitstoleranter und trockenheitsempfindlicher Baumarten hinsichtlich ihrer Anatomie und ihres Suberingehaltes nicht systematisch unterscheiden. Einzelne Suberinkomponenten könnten jedoch als Biomarker für die Feinwurzeln bestimmter Baumgattungen oder -arten gelten. Als deutlichste Antwort auf Trockenheit zeigten die Baumarten ein zum Teil starkes Absenken des Wasserpotenzials in ihren Wurzeln. Die Wurzelwasseraufnahme am natürlichen Standort ist also hauptsächlich durch den Potenzialgradienten Wurzelxylem-Boden gesteuert. 


\section{SUMMARY}

1. Surface-related root water uptake rates were assessed for three tree species (Fagus sylvatica, Betula pendula, Pinus sylvestris) that are important for forestry and ecology. The measurements were done on mature trees using miniature sap flow gauges according to the heat balance method. The measurements took place in two different periods: a dry vegetation period (2003) and a wet vegetation period (2004) at two stands varying in water supply.

2. The aim was to find out, in which way fine roots of the relatively drought sensitive beech and the relatively drought tolerant birch and pine are different in respect to physiological, morphological, anatomical and chemical properties and if they are capable of adjusting their fine root system to dry locations in order to ensure sufficient water uptake.

3. The surface dependent water uptake rates of roots showed a large time-dependent variability caused mainly by climatic factors like vpd and global radiation and less by soil water content.

4. All three tree species showed higher surface-related water uptake rates at the dryer location compared to the significantly wetter location, caused mainly by higher vpd and higher water potential gradients inside the trees.

5. Under comparable environmental conditions, the roots of the three species showed significant differences in surface-related water uptake capacity, varying by a factor of 2 to 10 . With $>2000 \mathrm{~g} \mathrm{H}_{2} \mathrm{O} \mathrm{m}^{-2} \mathrm{~d}^{-1}$ pine had a much higher uptake rate than birch (approx. $1000 \mathrm{~g} \mathrm{H}_{2} \mathrm{O} \mathrm{m}^{-2} \mathrm{~d}^{-1}$ ). Beech root water uptake rates were $500 \mathrm{~g} \mathrm{H}_{2} \mathrm{O} \mathrm{m}^{-2} \mathrm{~d}^{-1}$ or less. Based on these results we conclude that species with a relatively high fine root biomass and surface area, like beech, can have lower specific uptake rates than species with less fine root biomass like pine.

6. In the dry summer of 2003 all three species had their steepest decrease of root water potential. The least negative water potential was measured in pine, whereas most negative values were found in birch. Beech root water potential was usually intermediate with the exception of a striking decrease in late summer at the driest site.

7. The strong seasonal and interannual differences in water uptake can well be explained by variations in root water potential. Pine had the highest uptake of the three species, despite of the smallest decrease in potential. This could lead to the conclusion that pine has a higher radial conductivity than beech or birch. However this should be confirmed by further laboratory experiments. 
8. A tendency of difference in the amount of periderm layers and suberin was observed between the roots of the three species. The drought-tolerant pine was the species with the least suberin in its secondary root tissue. Thus, suberin amounts do not seem to correlate with the adaption to drought. However the significant higher amount of suberin per periderm layer in the roots of beech and birch, as observed in the dry summer of 2003, can be interpreted as an adaption to dry soil conditions.

9. This leads to the following conclusions: Fine roots of central European drought-tolerant and drought-resistant tree species are not systematically different in respect to their anatomy and their suberin content. However some components of suberin could be considered as species-specific biomarkers for fine roots. In the three tree species the most significant response to drought was a decrease in root water potential. Thus, water uptake of fine roots in natural surroundings is mainly controlled by the potential gradient between root xylem and soil. 


\section{LITERATUR}

Aas, G., BaAsch, R., Blaschke, H., Dobner, M., Krug, E., Maier, J., Schill, H., SchUCK, H.J., SchÜTt, P. \& STIMM, B. (1992): Lexikon der Forstbotanik. Morphologie, Pathologie, Ökologie \& Systematik wichtiger Baum- und Straucharten. Landsberg/Lech, Ecomed, $581 \mathrm{~S}$.

Alder, N., Sperry, J. S., Pockmann, W. (1996): Root and stem xylem embolism, stomatal conductance, and leaf turgor in Acer grandidentatum populations along a soil moisture gradient. Oecologia 105: 293-301.

ASPELMEIER, S., LEUSCHNER, C. (2006): Genotypic variation in drought response of silver birch (Betula pendula Roth): leaf and root morphology and carbon partitioning. Trees 20: 42-52.

Asseng, S., Aylmore, L.A.G., MacFall, J.S., Hopmans, J.W., Gregory, P.J. (2000): Computer-assisted tomography and magnetic resonance imaging. In: Smith, A.L. et al. (eds.) Root Methods. Springer, Berlin, S. 343-363.

AVEmARK, W., SchÖPFER, W. (1988): Abrupte Zuwachsänderung von Fichten und Tannen. Forst und Holz, 43.Jg, H6, S.123-128.

BACKES, K. (1996): Der Wasserhaushalt vier verschiedener Baumarten der HeideWald-Sukzession. Cuvillier-Verlag, Göttingen, 134 S.

Bengtson, C. (1980) : Effects of water stress on Scots pine. In: Persson, T. (Hrsg.): Structure and function of northern coniferous forests - an ecosystem study. Ecological-Bulletins 32: 205-213.

Beniston, M., Keller, F., Tol, R.S.J., Delécolle, R., Hoermann, G., Iglesias, A., Innes, J., McMichael, A.J., Martens, W.J.M., Nemesova, I., Nicholls, R., TоTH, F.L. (1998): The regional impacts of Climate Change: Europe. In „The regional Impacts of Climate Change: An Assessment of Vulnerability. Intergovernmental Panel on Climate Change Working Group II" (Watson, R.T., Zinyowera, M.C. and Moss, R.H., Eds), S. 149-185. Cambridge Univ. Press, Cambridge. 
Bernards, M. A., Lewis, N. G. (1998): The macromolecular aromatic domain in suberized tissues. A changing paradigm. Phytochemistry 47: 915-933.

BibelRIETHER, H. (1966): Die Bewurzelung einiger Baumarten in Abhängigkeit von Bodeneigenschaften. Allg. Forstz. Der Wald 21: 808-815.

Bingham, I.J., Glass, A.D.M., Kronzucker, H.J., Robinson, D., Srimgeour, C.M. (2000): Isotope techniques. In: Smith, A.L. et al. (eds) Root Methods. Springer, Berlin, S. 365-399.

BöHM, W. (1979): Methods of Studying Root Systems, Springer, Berlin, Heidelberg, New York, $188 \mathrm{~S}$.

Bréda, N., Cochard, H., Dreyer, E., Granier, A. (1993): Field comparison of transpiration, stomatal conductance and vulnerability to cavitation of Quercus petraea and Quercus robur under water stress. Annals of Forest Science 50: 571-582.

Brockmann, W. G., Eckstein, D., Aniol, R. W. (1987): Dendroklimatologische Untersuchungen zur Bedeutung des Produktionsfaktors Wasser für das Baumwachstum. Forstw. Cbl. 106: 340-354.

Cermak, J., Deml M. \& Penka M. (1973): A new method of sap flow rate determination in trees. Biologia Plantarum (Praha) 15(3): 171-178.

Chung, H. H., Kramer, P. J. (1975): Absorption of water and ${ }^{32} \mathrm{P}$ through suberized and unsuberized roots of loblolly pine. Can. J. For. Res. 5: 229-235.

Cochard, H. (2002): Xylem embolism and drought-induced stomatal closure in maize. Planta 215 (3): 466-471.

CONERS, H. (2001): Wasseraufnahme und artspezifische hydraulische Eigenschaften der Feinwurzeln von Buche, Eiche und Fichte: In situ-Messungen an Altbäumen. Forschungszentrum Waldökosysteme, Göttingen, Bd. 178, 118 S.

CONERS, H., Leuschner, C. (2002): In situ water absorption by tree fine roots measured in real time using miniature sap-flow gauges. Functional Ecology 16: 696-703. 
CONERS, H., LEUSCHNER, C. (2005): In situ measurement of fine root water absorption in three temperate tree species - Temporal variability and control by soil and atmospheric factors. Basic and Applied Ecology 6: 395-405.

Cruz, R. T., Jordan, W. R., Drew, M. C. (1992): Structural changes and associated reduction of hydraulic conductance in roots of Sorghum bicolor L. following exposure to water deficit. Plant Physiol. 99, 203-213.

EllenberG, H. (1996): Vegetation Mitteleuropas mit den Alpen. Ulmer Verlag, Stuttgart, $1095 \mathrm{~S}$.

Everad, J. D., Drew, M. C. (1989): Mechanism controlling changes in water movement through the roots of Helianthus annuus L. during continuous exposure to oxygen deficiency. J. Exp. Bot. 40: 95-104.

FELBERMEIER, B. (1993): Der Einfluß von Klimaveränderungen auf die Areale von Baumarten. Methodenstudie und regionale Abschätzung für die Rotbuche (Fagus sylvatica L.) in Bayern. - Schr. R. Forstwiss. Fak. Univ. München Bd. 134.

Fernandez, J. E., Clothier, B. E., van NoordwiJk, M. (2000): Water uptake. In: Smith, A. L. et al. (Hrsg.) Root methods. Springer, Berlin. 461-507.

FISCUS, E. L. (1972): In Situ Measurements of Root-Water Potential. Plant Physiol. 50: 191-193.

Froux, F., Ducrey, M., Dreyer, E. Huc, R. (2005): Vulnerability to embolism differs in roots and shoots and among three Mediterranean conifers: consequences for stomatal regulation of water loss? Trees-Structure and Function 19 (2): 137-144.

GIEGER, T. (2002): Auswirkungen von Trockenheit und Entlaubung auf den Wasserhaushalt von Stiel- und Traubeneiche. Dissertation, Albrecht-von-HallerInstitut für Pflanzenwissenschaften, Universität Göttingen.

Glavac, V., Koenies, H., EbBen, U. (1990): Auswirkung sommerlicher Trockenheit auf die Splintholz-Wassergehalte im Stammkörper der Buche (Fagus sylvatica L.). Holz Roh Werk., 48: 437-441. 
Green, S. R., ClothieR, B. E. (1995): Root water uptake by kiwifruit vines following partial wetting of the root zone. Plant and Soil 173: 317-328.

Green, S. R., Clothier, B. E., McLeod, D. J. (1997): The response of sap flow in apple roots to localised irrigation. Agricultural water management 33: 63-78.

Green, S. R., Vogeler, I., Clothier, B. E., Mills, T. M., Van den Dijssel, C. (2003): Modeling water uptake by a mature apple tree. Australien Journal of Soil Research 41: 365-380.

Greve, A., Terborg, O. (1993): Carbon assimilation of two early and two latesuccessional tree species in a heathland-forest succession in NW Germany. Scripta Geobot. 21: 101-104.

HACKE, U. G. (2003): Limits to xylem refilling under negative pressure in Laurus nobilis and Acer negundo. Plant Cell and Environment 26 (2): 303-311.

HARTMANN, K. (2002): Struktur, Funktion und chemische Zusammensetzung suberinisierter Transportbarrieren im Apoplasten höherer Pflanzen. Dissertation, Universität Bonn, 219 S.

Hartmann, K., Peiter, E., Koch, K., Schubert, S., Schreiber, L. (2002): Chemical composition and ultrastructure of broad bean (Vicia faba L.) nodule endodermis in comparison to the root endodermis. Planta 215: 14-25.

Heilmeier, H., Erhard, M., Wartinger, A., Brinckmann, E., Horn, R., Schulze, E.D. (2001): Biomass partitioning in response to soil drought: A pot experiment with Prunus dulcis trees during four years. Basic and Applied Ecology 2: 165175.

Hellkvist, J., Hillerdal-Hagströmer, K., Mattson-Djos, E. (1980): Field studies of water relations and photosynthesis in Scots pine using manual techniques. In: PERSSON, T. (Hrsg.): Structure and function of northern coniferous forests - an ecosystem study. Ecological-Bulletins 32: 183-204.

Hertel, D. (1999): Das Feinwurzelsystem von Rein- und Mischbeständen der Rotbuche: Struktur, Dynamik und interspezifische Konkurrenz. Diss. Botanicae 317, J. Cramer, $190 \mathrm{~S}$. 
HöLLERL, S. (2004): „,...völlig verdorrt und zu Grunde gegangen“ LWF aktuell 43: 2122.

Hölscher, D., Koch, O., Korn, S., Leuschner, C. (2004): Sap flux of five cooccurring tree species in a temperate broad-leaved forest during seasonal drought. Trees 19: 628-637.

Holloway, P.J. (1982): The chemical constitution of plant cutins. In: CuTLER, D.F., Alvin, K.L., Price, C.E. (Eds.), The Plant Cuticle. Academic Press, London, pp. 45-85.

JACKSON, G. E., IRvine, J., GRACE, J. (1995): Xylem cavitation in two mature Scots pine forests growing in a wet and a dry area of Britain. Plant, Cell Environ. 18: 1411-1418.

Kleiner, K.W., Abrams, M.D. \& SchultZ, J.C. (1992): The impact of water and nutrient deficiencies on the growth, gas exchange and water relations of red oak and chestnut oak. Tree Physiology 11: 271-287.

Klimastatement 2003 der Deutschen Meteorologischen Gesellschaft (DMG), der Österreichischen Gesellschaft für Meteorologie (ÖGM) und der Schweizerischen Gesellschaft für Meteorologie (SGM) (SCHÖNWIESE, C-D., Bader, S., Böhm, R., Claussen, M., Cubasch, U., Gärtner, U., Graßl, H., RAHMSTORF, S., SÜNDERMANN, J., KROMP-KolB, H., RiCHnER, H.)

KÖPPEN, W. (1931): Grundrisse der Klimakunde. 2. verbesserte Auflage der Klimate der Erde. W. de Gruyter, Berlin, 388 S.

KÖSTLER J., BRÜCKNER E. \& BieBelRIETHER H. (1968): Die Wurzeln der Waldbäume, Parey, Hamburg, Berlin.

KÖSTNER, B. (2001): Evaporation and transpiration from forests in Central Europe relevance of patch-level studies. Meteorol. Atmos. Phys. 76: 69-82.

KolatTuKUdy, P.E. (1980): Biopolyester of plants: cutin and suberin. Science 1: 125129. 
Konópka, B., Yuste, J. C., Janssens, I. A., Ceulemans, R. (2005) : Comparison of fine root dynamics in Scots pine and Pedunculate oak in sandy soil. Plant and Soil 276 (1-2): 33-45.

KORN, S. (1999): Untersuchungen zu den Mechanismen der Wasseraufnahme von Eichenwurzeln in einem Altbestand, Diplomarbeit, Universität Kassel.

KORN, S. (2004): Experimentelle Untersuchung der Wasseraufnahme und der hydraulischen Eigenschaften des Wurzelsystems von sechs heimischen Baumarten. Dissertation, Albrecht-von-Haller-Institut für Pflanzenwissenschaften, Universität Göttingen.

Kozlowski, T. T., Kramer, P. J., Pallardy, S. G. (1991): The physiological ecology of woody plants. Academic press. San Diego, California.

Kozlowski, T. T., Pallardy, S. G. (1997): Physiology of Woody Plants. Academic press. San Diego, S. 411.

KRAMER, H. (1988): Waldwachstumslehre - Ökologische und anthropogene Einflüsse auf das Wachstum des Waldes, seine Massen- und Wertleistung und die Bestandessicherheit. Unter Mitarbeit von H.-A.Gussone \& R. ScHOBER. Verlag Paul Parey, Hamburg.

Kramer, P. J. (1946): Absorption of water through suberised roots of trees. Plant Physiol. 21: 37-41.

KUTSCHERA, L., LiCHTENEGGER, E. (2002): Wurzelatlas mitteleuropäischer Waldbäume und Sträucher. Leopold Stocker Verlag, Graz, 604 S.

LARCHER, W. (2001): Ökophysiologie der Pflanzen. 6.Aufl., Ulmer Verlag, Stuttgart, $408 \mathrm{~S}$.

LeIBUNDGUT, H. (1991): Unsere Waldbäume: Eigenschaften und Leben. Haupt, Bern, Stuttgart, $173 \mathrm{~S}$.

LEUSCHNER, C. (1998): Mechanismen der Konkurrenzüberlegenheit der Rotbuche. Ber. D. Reinh.-Tüxen-Ges. 10: 5-18. 
Leuschner, C., Backes, K., Hertel, D., Schipka, F., Schmitt, U., Terborg, O., Runge, M. (2001a): Drought responses at leaf, stem and fine root levels of competitive Fagus sylvatica L. and Quercus petraea (Matt.) Liebl. trees in dry and wet years. Forest Ecology and Management 149: 33-46.

LEUSCHNER, C., CONERS, H., ICKE, R. (2004): In situ measurement of fine root water absorption in three temperate tree species. II. Species differences and differential activity of superficial and deep reaching roots. Tree Physiology 24 (12): 13591367.

Leuschner, C., Coners, H., Icke, R., Hartmann, K., Effinger, N. D., Schreiber, L. (2003): Chemical composition of the periderm in relation to in situ water absorption rates of oak, beech and spruce fine roots. Ann. For. Sci. 60: 763-772.

Leuschner, C., Hertel, D., Coners, H. \& Büttner, V. (2001b): Root competition between beech and oak: a hypothesis. Oecologia, 126, 276-284.

Leuschner, C., SchipKA, F. (2004): Klimawandel und Naturschutz in Deutschland. Vorstudie. BfN-Skripten 115. 35 S.

LÖSCH, R. (1999): Plant water relations. In: Progress in Botany. EsSER, K., KADEREIT, J.W., LÜtTGe, U., Runge, M. (Hrsg.), Vol. 60, Springer-Verlag, Berlin, S. 193233.

Lyr, H., Polster, H., FiedLeR, H. J. (1967): Gehölzphysiologie. Fischer-Verlag, Jena.

MacFall, J.S., Johnson, G.A., Kramer, P.J. (1991): Comperative water uptake by roots of different ages in seedlings of loblolly pine (Pinus taeda L.). New Phytol 119: 551-560.

Markhart, A. H., Peet, M. M., Sionit, N., Kramer, P. J. (1980): Low temperature acclimation of root fatty acid composition, leaf water potential, gas exchange and growth of soybean seedlings. Plant, Environ. 3: 435-441.

MAYER, H. (1992): Waldbau auf soziologisch-ökologischer Grundlage. Gustav Fischer, Stuttgart, Jena, New York, 522 S. 
McKenzie, B., Peterson, C. A. (1995): Root browning in Pinus banksiana Lamb. and Eucalyptus pilularis Sm. 2. Anatomy and permeability of the cork zone. Bot. Acta 108: 138-143.

Möhren, G. M. J., Kramer, K. (1997): Simulation of direct effects of $\mathrm{CO}_{2}$ and temperature increase on forest growth: The LTEEF project. In: MÖHREN, G. M. J., Kramer, K., Sabaté, S., Dordrecht, S. (Hrsg.) Impacts of global change on tree physiology and forest ecosystem. Kluwer Academic Publishers. 372 S.

Moreno, F., Fernandez, E., Clothier, B. E., Green, S. R. (1996): Transpiration and root water uptake by olive trees. Plant and Soil 184: 85-96.

North, G. B., Nobel, P.S. (1996) Radial hydraulic conductivity of individual root tissues of Opuntia ficus-indica (L.) Miller as soil moisture varies. Ann. Bot. 77, 133-142.

OELKE, E. (1997): Sachsen-Anhalt mit einem Anhang Fakten-Zahlen-Übersichten. Klett-Perthes-Verlag, 1.Aufl., $423 \mathrm{~S}$.

OnG, C. K., KHAN, A. A. H. (1993): The direct measurement of water uptake by individual tree roots. Agroforestry Today 5: 2-5.

PAssiourA, J. B., TANNER, C. B. (1985): Oscillations in apparent hydraulic conductance of cotton plants. Aust. J. Plant Physiol. 12: 455-461.

Perks, M. P., Irvine, J., Grace, J. (2004): Xylem acoustic signals from mature Pinus sylvestris during an extended drought. Ann. For. Sc. 61 (1): 1-8.

Persson, H. (1980): Spatial distribution of fine root-growth, mortality and decomposition in a young Scots pine stand in central Sweden. Oikos 34: 77-87.

Peters, R. (1997): Beech Forests. Kluwer Academic Publishers. Dordrecht, 169 S.

Peterson, C. A., Enstone, D. E. (1996): Functions of passage cells in the endodermis and exodermis of roots. Physiol. Plantarum 97: 592-598.

Pfadenhauer, J. (1993): Vegetationsökologie - Ein Skriptum. IHW-Verlag, Eching, $301 \mathrm{~S}$. 
Pockman, W. T., Sperry, J. S. (2000): Vulnerability to xylem cavitation and the distribution of Sonoran desert vegetation. Am. J. Bot. 87: 1287-1299.

Pregitzer, K.S., Hendrick, R.L., Fogel, R. (1993): The demography of fine roots in response to patches of water and nitrogen. New Phytol 125: 575-580.

Prigge, M. (2005): Physiologische und morphologische Anpassung von Buchen- und Traubeneichenfeinwurzeln an experimentell erhöhte Bodentrockenheit. Diplomarbeit, Universität Göttingen.

RÄisÄnen, J., Hansson, U., Ullerstieg, A., Doscher, R., Graham, L.P., Jones, C., Meier, H. E. M., SAmuelsson, P., Willen, U. (2004): European climate in the late twenty-first century: regional simulations with two driving global models and two forcing scenarios. Climate Dynamics 22, 13-31.

Ranney, T. G., BIR, R. E., Skroch, W. A. (1991): Comperative drought resistance among six species of birch (Betula): influence of mild water stress on water relations and leaf gas exchange. Tree Physiol. 8 (4): 351-360.

RAPP, J. (2002): Regionale Klimatrends in Deutschland im 20. Jahrhundert. In „, Klimastatusbericht 2001“ (Deutscher Wetterdienst, Ed.), Offenbach, S. 175-184.

RIECK, W., Renger, M. (1994): Der Wasserhaushalt der Kiefer (Pinus sylvestris) als Funktion von Boden und Klimaparametern in den Berliner Forsten. Forstarchiv 65: 167-171.

ROBERTS, J. (1976): An examination of the quantity of water stored in mature Pinus sylvestris L. trees. J. Exp. Bot. 27: 473-479.

Roberts, J., Rosier, P. T. W. (1994): Comparative estimates of transpiration of ash and beech forest at a chalk site in southern Britain. Journal of Hydrology 162: $229-245$.

RÖHRIG, E. \& BARTSCH, N. (1992): Waldbau auf ökologischer Grundlage. Band I: Der Wald als Vegetationsform und seine Bedeutung für den Menschen. Parey, Hamburg, Berlin, 6. Edt., $350 \mathrm{~S}$. 
SAKURATANI, T. (1984): Improvement of the probe for measuring water flux in the stem of intact plants. J. Agr. Meteorol. 40: 273-277.

SCHIPKA, F. (2002): Blattwasserzustand und Wasserumsatz von vier Buchenwäldern entlang eines Niederschlagsgradienten in Mitteldeutschland. Dissertation, Albrecht-von-Haller-Institut für Pflanzenwissenschaften, Universität Göttingen.

Scholander P., Hammel H., Bradsteet E. \& Hemmingsen E. (1965): Sap flow pressure in vascular plants. Science 148: 339-346.

Scholz, F. (1993): Anforderungen an die forstliche Forschung aufgrund der prognostizierten Klimaveränderungen. AFZ/ Der Wald 12: 592-595.

Schraml, C., RennenberG, H. (2000): Sensitivity of different ecotypes of beech trees (Fagus sylvatica L.) to drought stress. Forstwissenschaftliches Zentralblatt 119 (1-2): 51-61.

Schraml, C., Rennenberg, H. (2002): The different reactions of beech tree (Fagus sylvatica L.) ecotypes to drought stress. Forstwissenschaftliches Zentralblatt 121 (2): 59-72.

Schreiber, L., Breiner, H.-W., Riederer, M., Düggelin, M., Guggenheim, R. (1994): The casparian strip of Clivia miniata Reg. roots: isolation, fine structure and chemical nature. Bot. Acta. 107: 353-361.

Schreiber, L., Hartmann, K., Skrabs, M., Zeier, J. (1999): Apoplastic barriers in roots: chemical composition of endodermal and hypodermal cell walls. J. Exp. Bot. 50 (337): 1267-1280.

Schreiber, L., Franke, R., Hartmann, K.-D., Ranathunge, K., Steudle, E. (2005): The chemical composition of suberin in apoplastic barriers affects radial hydraulic conductivity differently in the roots of rize (Oryza sativa L. cv. IR64) and corn (Zea mays L. cv. Helix). J. Exp. Bot. 56 (415): 1427-1436.

Schulze, E.-D., BeCK, E., Müller-Hohenstein, K. (2002): Pflanzenökologie. Spektrum, Akad. Verl., 2002. 
SENOCK, R. \& HAM, J. (1993): Heat balance sap flow gauge for small diameter stems. Plant, Cell Environ. 16: 593-601.

SENOCK, R. \& HAM, J. (1995): Measurements of water use by prairie grasses with heat balance sap flow gauges. J. Range Manage. 48: 150-158.

SENOCK, R. S., LEUSCHNER, C. (1999): Water flux dynamics in small diameter roots of a fast growing tropical tree. Plant and Soil 208: 57-71.

Serrano, L., Penuelas, J. (2005): Contribution of physiological and morphological adjustments to drought resistance in two Mediterranean tree species. Biol. Plant. 49 (4): 551-559.

Sevanto, S., Holtta, T., Markkanen, T, Peramaki, M., NikinmaA, E., Vesala, T. (2005): Relationships between diurnal xylem diameter variation and environmental factors in Scots pine. Boreal Environ. Research 10 (5): 447-458.

Sperry, J. S., Donnelly, J.R., Tyree, M. T. (1988): Seasonal occurrence of xylem embolism in sugar maple (Acer saccharum). Am. J. Bot., 75: 1212-1218.

Sperry, J. S., Nichols, K. L., Sullivan, J. E. M., Eastlack, S. E. (1994): Xylem embolism in ring-porous, diffuse-porous, and coniferous trees of northern Utah and Interior Alaska. Ecology 75 (6): 1736-1752.

SPerry, J. S., Perry, A., Sullivan, J.E.M. (1991): Pit membrane degradation and air embolism formation in ageing xylem vessels of Populus tremuloides Michx.. J. Exp. Bot. 42: 1399-1406.

Sperry, J. S., SALIENDRA, N. Z. (1994): Intra- and inter-plant variation in xylem cavitation in Betula occidentalis. Plant Cell Environ. 17: 1233-1241.

SPOLlEN, W.G., SHARP, R.E. (1991): Spatial-distribution of turgor and rooth-growth at low water potentials. Plant Physiol. 96:438-443.

SteinberG, S. L., VAn BAVel, C. H. M., McFarland, M. J. (1990): Improved sap flow gauge for woody and herbaceous plants. Agronomy J. 82: 851-854. 
STEUdLE, E. (1994): The regulation of plant water at the cell, tissue, and organ level: Role of active processes and of compartimentation. In: Schulze, E.-D. (Hrsg.) Flux control in biological systems. Academic Press, San Diego. S. 237-302.

STEUDLE, E. (1995): Trees under tension. Nature 378: 663-664.

STEudle, E., HenzleR, T. (1995): Water channels in plants - do basic concepts of water transport change. J. Exp. Bot. 46 (290): 1067-1076.

SteVenson, J. F., MAuseth, J. D. (2004) : Effects of environment on vessel characters in cactus wood. Int. J. of Pl. Sc. 165 (3): 347-357.

STÖHR, A. (2003): Der Wasserhaushalt von Fraxinus excelsior und Acer pseudoplatanus in einem Eschen-Ahorn-Schluchtwald. Dissertation, Universität Düsseldorf.

Strobel, J. (1997): Der Wasserhaushalt eines Buchenwaldes im mitteldeutschen Trockengebiet. Diplomarbeit, Universität Göttingen.

Tyree, M. T., Sperry, J. S. (1989): Vulnerability of xylem to cavitation and embolism. Annual Review of Plant Physiology and Plant Molecular Biology 40: 19-38.

TyreE, M. T., YANG, S. (1990): Water-storage capacity of Thuja, Tsuga and Acer stems measured by dehydration isotherms. Planta 182: 420-426.

Utschig, H., Bachmann, M., Pretzsch, H. (2004): Das Trockenjahr 1976 bescherte langjährige Zuwachseinbrüche. LWF aktuell Nr. 43, S. 17-18.

VAN ReEs, K. C. J., COMERFord, N., B. (1990): The role of woody roots of slash pine seedlings in water and potassium absorption. Can. J. For. Res. 20: 1183-1191.

VOß, S. (1998): Belaubungsdichte und Blattmasse in Abhängigkeit von bodenchemischen Faktoren in verschiedenen Buchenwäldern Nordhessens. Diplomarbeit. Universität - GH Kassel.

WAGNER, S. (1994): Einbringung von Waldbaumarten in Kiefernbeständen auf armen Sanden im Nordosten Niedersachsens. Forstarchiv 65: 3-9. 
WARING, R. H., WhITEHEAD, D., JARVIS, P. G. (1979): The contribution of stored water to transpiration in Scots pine. Plant, Cell Environ. 2: 309-317.

Wilson, K. B., Hanson, P. J., Mulholland, P. J., Baldocchi, D. D., WullschleGER, S. D. (2001): A comparison of methods for determining forest evapotranspiration and its components: sap-flow, soil water budget, eddy covariance and catchment water balance. Agr. For. Met. 106: 153-168.

Wilson, C. A., Peterson, C. A. (1983): Chemical composition of the epidermal, hypodermal, endodermal and intervening cortical cell walls of various plant roots. Annals of Botany 51: 759-769.

Wronsky, E. B., Holmes, J.W., Turner, N. C. (1985): Phase and amplitude relations between transpiration, water potential and stem shrinkage. Plant Cell Environ. 8: 613-622.

Wullschleger, S. D., Wilson, K. B., HAnson, P. J. (2000): Environmental control of whole plant transpiration, canopy conductance and estimates of the decoupling coefficient for large red maple trees. Agr. For. Met. 104: 157-168.

YANG, S., TYREE, M. (1992): A theoretical model of hydraulic conductivity recovery from embolism with comparison to experimental data on Acer saccharum. Plant Cell Environ. 15: 633-643.

Zimmermann, H., Hartmann, K-D., Schreiber L., Steudle E. (2000): Chemical composition of apoplastic transport barriers in relation to radial hydraulic conductivity of corn roots (Zea mays L.). Planta 210: 302-311.

Zimmermann, U., Schneider, H., Wegner, L. H., WAGNer, H.-J., Szimtenings, M., HAASE, A., Bentrup, F.-W. (2002): What are the driving forces for water lifting in the xylem conduit? Physiol. Plant. 114: 327-335.

Zimmermann, M. H., Tyree, M. T. (2002): Xylem Structure and the ascent of sap. 2. Aufl., Springer Verlag, Berlin, 283 S.

ZоTH, R., BLOCK, J. (1992): Untersuchungen an Wurzelballen sturmgeworfener Bäume in Rheinland Pfalz. Forst und Holz 47 (18): 566-571. 
ZWeifel, R., Item, H., HÄSleR, R. (2000): Stem radius changes and their relation to stored water in stems of young Norway spruce trees. Trees 15: 50-57.

ZWEIFEL, R., ITEM, H., HÄSLER, R. (2001): Link between diurnal stem radius changes and tree water relations. Tree Physiol. 21: 869-877. 


\section{ABBILDUNGSVERZEICHNIS}

2.1 a) Habitus der Buche mit Herzwurzelsystem b) Habitus der Birke mit Senkerwurzelsystem c) Habitus der Kiefer mit Pfahlwurzelsystem . . . . . . . . 7

2.2 Topographische Lage der Untersuchungsbestände in der Söhre und im Ziegelrodaer Forst $\ldots \ldots \ldots \ldots \ldots \ldots \ldots \ldots \ldots \ldots \ldots \ldots \ldots \ldots$

2.3 Klimadiagramme (langjährige Mittel von 1961-1990) der beiden Messstationen Artern und Kassel . . . . . . . . . . . . . . . . . . . . . . . . 11

2.4 Niederschlagswerte (Kronentraufe) in der Söhre und im Ziegelrodaer Forst in den Jahren 2003 und 2004 . . . . . . . . . . . . . . . . . . . . . . . . . . . . . . . . 13

2.5 Wasserdampfsättigungsdefizit der Luft (VPD), Lufttemperatur und relative Luftfeuchte (Tagesmittelwerte) in den Untersuchungsbeständen in der Söhre und im Ziegelrodaer Forst in den Vegetationsperioden 2003 und 2004 . . . . . 14

2.6 Globalstrahlung für die Untersuchungsbestände Ziegelrodaer Forst und Söhre in den Jahren 2003 und 2004 . . . . . . . . . . . . . . . . . . . . . . 16

3.1 Schematische Darstellung der Messeinrichtung zur Bestimmung der Bodenwasserverfügbarkeit a) TDR-Messungen in drei Bodentiefen. b) TensiometerMessungen in drei Bodentiefen . . . . . . . . . . . . . . . . 18

3.2 Schematische Darstellung des Miniatur-Saftflusssensors . . . . . . . . . . . 23

3.3 Schematische Darstellung der Wurzelsaftflussmessungen nach der Methode

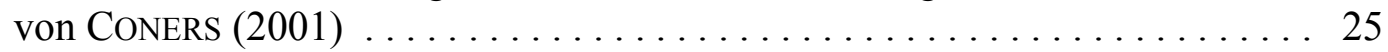

3.4 Methanolumesterung eines $\omega$-OH-Säureesters aus dem Polymer . . . . . . . . 28

3.5 Beispiel-Chromatogramme der freigesetzten Suberinmonomere einer $\mathrm{BF}_{3}-\mathrm{MeOH}$ Umesterungsreaktion von Buchen-, Birken-, und

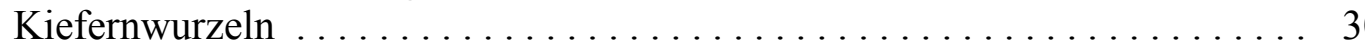

4.1 Volumetrischer Bodenwassergehalt und Bodenmatrixpotenzial in der Söhre und im Ziegelrodaer Forst in den Jahren 2003 und 2004 . . . . . . . . . . . . 33

4.2 Bodenwassergehalt und Bodenmatrixpotenzial (Feld-pF-Kurven) . . . . . . . 35

4.3 Tagesminima der Wasserpotenziale von Buchen-, Birken- und Kiefernfein- 36 wurzeln in der Söhre und im Ziegelrodaer Forst im Jahr 2003 
4.4 Tagesminima der Wasserpotenziale von Buchen-, Birken- und Kiefernfeinwurzeln in der Söhre und im Ziegelrodaer Forst im Jahr 2004 . . . . . . . . . . 39

4.5 Spezifische Oberfläche von Buchen-, Birken und Kieferfeinwurzeln . . . . . . 41

4.6 Korrelation der volumetrisch gemessenen Flussraten mit den mittels Saftfluss-Sensoren bestimmten Flussraten von vier Buchenwurzeln . . . . . . . . 42

4.7 Saftfluss einer Buchenwurzel auf der Untersuchungsfläche in der Söhre im Vergleich zum volumetrisch bestimmten Saftfluss (August 2005) . . . . . . 43

4.8 Tageswerte der Saftflussdichte in Buchenfeinwurzeln in den Jahren 2003 und 2004 auf den Standorten in der Söhre und im Ziegelrodaer Forst . . . . . . 44

4.9 Tageswerte der Saftflussdichte in Birkenfeinwurzeln in den Jahren 2003 und 2004 auf den Standorten in der Söhre und im Ziegelrodaer Forst . . . . . 45

4.10 Tageswerte der Saftflussdichte in Kiefernfeinwurzeln in den Jahren 2003 und 2004 auf den Standorten in der Söhre und im Ziegelrodaer Forst . . . . . . 46

4.11 Mittelwerte der Tageswerte der Saftflussdichten in Buchen-, Birken- und und Kiefernfeinwurzeln in den Jahren 2003 und 2004 auf den Untersuchungsflächen in der Söhre und im Ziegelrodaer Forst . . . . . . . . . . . . . . . 4

4.12 Mittelwerte der Saftflussdichte und des Wasserpotenzials von Buchen-, Birken- und Kiefernfeinwurzeln auf den Flächen im Vergleich zu Mittelwerten von VPD, Bodenwassergehalt und täglichem Niederschlag im Jahr

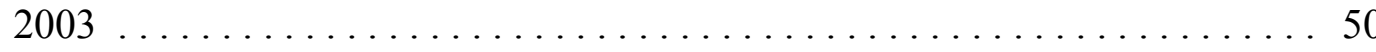

4.13 Mittelwerte der Saftflussdichte und des Wasserpotenzials von Buchen-, Birken- und Kiefernfeinwurzeln auf den Flächen im Vergleich zu Mittelwerten von VPD, Bodenwassergehalt und täglichem Niederschlag im Jahr 2004 . . . . . . . . . . . . . . . . . . . . . . . . . . . . . . . . . . . . . 5

4.14 Tageswerte des oberflächenbezogenen Saftflusses in Buchenfeinwurzeln in den Jahren 2003 und 2004 auf den Untersuchungsflächen in der Söhre

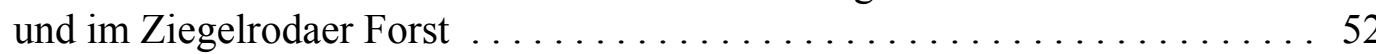

4.15 Tageswerte des oberflächenbezogenen Saftflusses in Birkenfeinwurzeln in den Jahren 2003 und 2004 auf den Untersuchungsflächen in der Söhre und $\mathrm{im}$ Ziegelrodaer Forst $\ldots \ldots \ldots \ldots \ldots \ldots \ldots \ldots \ldots \ldots \ldots \ldots \ldots \ldots \ldots$

4.16 Tageswerte des oberflächenbezogenen Saftflusses in Kiefernfeinwurzeln in den Jahren 2003 und 2004 auf den Untersuchungsflächen in der Söhre

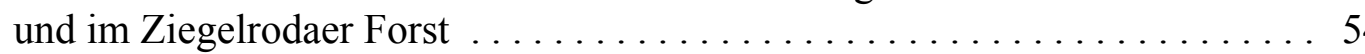

4.17 Mittelwerte der Tageswerte des oberflächenbezogenen Saftflusses in Buchen-, Birken- und Kiefernfeinwurzeln in den Jahren 2003 und 2004 auf den Untersuchungsflächen in der Söhre und im Ziegelrodaer Forst . . . . . . . 55 
4.18 Anzahl der Peridermschichten in Buchen-, Birken- und Kiefernfeinwurzeln mit einem Durchmesser von $<1 \mathrm{~mm}$ auf den beiden Untersuchungsflächen in der Söhre und im Ziegelrodaer Forst in den Jahren 2003 und 2004 . . . . . . . 62

4.19 Suberingesamtmengen ( $\mu \mathrm{g} \mathrm{cm}^{-2}=\mu \mathrm{g}$ pro Wurzeloberfläche) in Buchen-, Birken- und Kiefernfeinwurzeln mit einem Durchmesser von $<1 \mathrm{~mm}$. . . . . . 64

4.20 Suberinmenge pro Periderm-Zelllage in Buchen-, Birken- und Kiefernfeinwurzeln mit einem Durchmesser von $<1 \mathrm{~mm} \ldots \ldots \ldots \ldots 6$

4.21 Suberinzusammensetzung der untersuchten Buchen-, Birken- und Kiefernfeinwurzeln mit einem Durchmesser $<1 \mathrm{~mm}$. Angegeben sind die prozentualen Anteile einzelner Stoffklassen am Gesamtsuberin . . . . . . . . . 67

4.22 Suberinzusammensetzung der untersuchten Buchen-, Birken- und Kiefernfeinwurzeln mit einem Durchmesser $<1 \mathrm{~mm}$. Angegeben sind die prozentualen Anteile einzelner Stoffklassen am Gesamtsuberin in den Jahren 2003 und 2004 . . . . . . . . . . . . . . . . . . . . . . . . . . . . . . . . . 69

4.23 Zusammensetzung des Suberins von Buchen-, Birken- und Kiefernwurzeln (Durchmesser $<1 \mathrm{~mm}$ ) bezogen pro Peridermschicht-Zelllage auf den Untersuchungs-flächen in der Söhre und im Ziegelrodaer Forst in den Jahren 2003 und 2004 . . . . . . . . . . . . . . . . . . . . . . . . . . . . . . . . . . . . . 71

$4.24 \omega-\mathrm{OH}-\mathrm{Säure}-\mathrm{Zusammensetzung} \mathrm{in} \mathrm{Prozent} \mathrm{vom} \mathrm{Gesamtgehalt} \mathrm{der} \omega-\mathrm{OH}-$ Säure bei Buchen-, Birken- und Kiefernwurzeln von 2003 . . . . . . . . . . . 73

$4.25 \omega-\mathrm{OH}-\mathrm{Säure}-\mathrm{Zusammensetzung} \mathrm{in} \mathrm{Prozent} \mathrm{vom} \mathrm{Gesamtgehalt} \mathrm{der} \omega-\mathrm{OH}-$ Säure bei Buchen-, Birken- und Kiefernwurzeln von 2004 . . . . . . . . . . . . 73

4.26 Trihydroxy-Säure-Zusammensetzung in Prozent vom Gesamtgehalt an Trihydroxy-Säure in Buchen- und Birkenwurzeln . . . . . . . . . . . . 74 


\section{TABELLENVERZEICHNIS}

2.1 Geologische und pedologische Charakteristika der Untersuchungsbestände . . 7

2.2 Monatliche Niederschlagssummen in den Jahren 2003 und 2004 der Klimastationen Kassel und Artern mit Angabe des prozentualen Anteils vom lang-

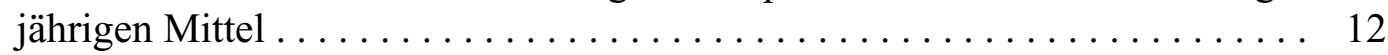

4.1 Wasserpotenzial der Wurzeln von Kiefer, Buche und Birke auf den Untersuchungsflächen Söhre und Ziegelrodaer Forst im Jahr 2003 . . . . . . . . . . . 38

4.2 Wasserpotenzial der Wurzeln von Kiefer, Buche und Birke auf den Untersuchungsflächen Söhre und Ziegelrodaer Forst im Jahr 2004 . . . . . . . . . . . 40

4.3 Ergebnisse der vierfaktoriellen Varianzanalyse der Einflussfaktoren Baumart,

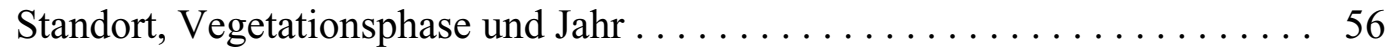

4.4 Ergebnisse der dreifaktoriellen Varianzanalyse bezugnehmend auf die

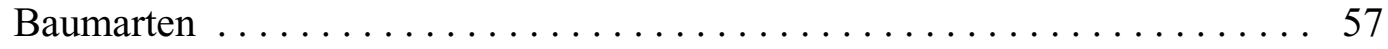

4.5 Ergebnisse der dreifaktoriellen Varianzanalyse bezugnehmend auf den

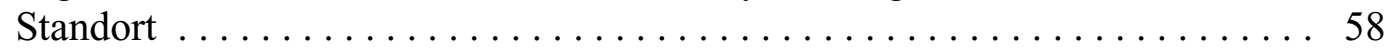

4.6 Ergebnisse der dreifaktoriellen Varianzanalyse bezugnehmend auf das Jahr . . 59

4.7 Ergebnisse der dreifaktoriellen Varianzanalyse bezugnehmend auf die Vegetationsphase ......................... 60

4.8 Erklärter Varianzanteil der Saftflussdichte von Buchen-, Birken- und Kiefernwurzeln durch die Faktoren Globalstrahlung, Wasserdampfsättigungsdefizit (VPD) und Bodenwassergehalt

5.1 Literaturvergleich von Minimum-Wasserpotenzialwerten $\left(\Psi_{\min }\right)$ von Blättern und Wurzeln der drei in dieser Studie untersuchten Baumarten . . . . . . . . . 84 


\section{ABKÜRZUNGSVERZEICHNIS}

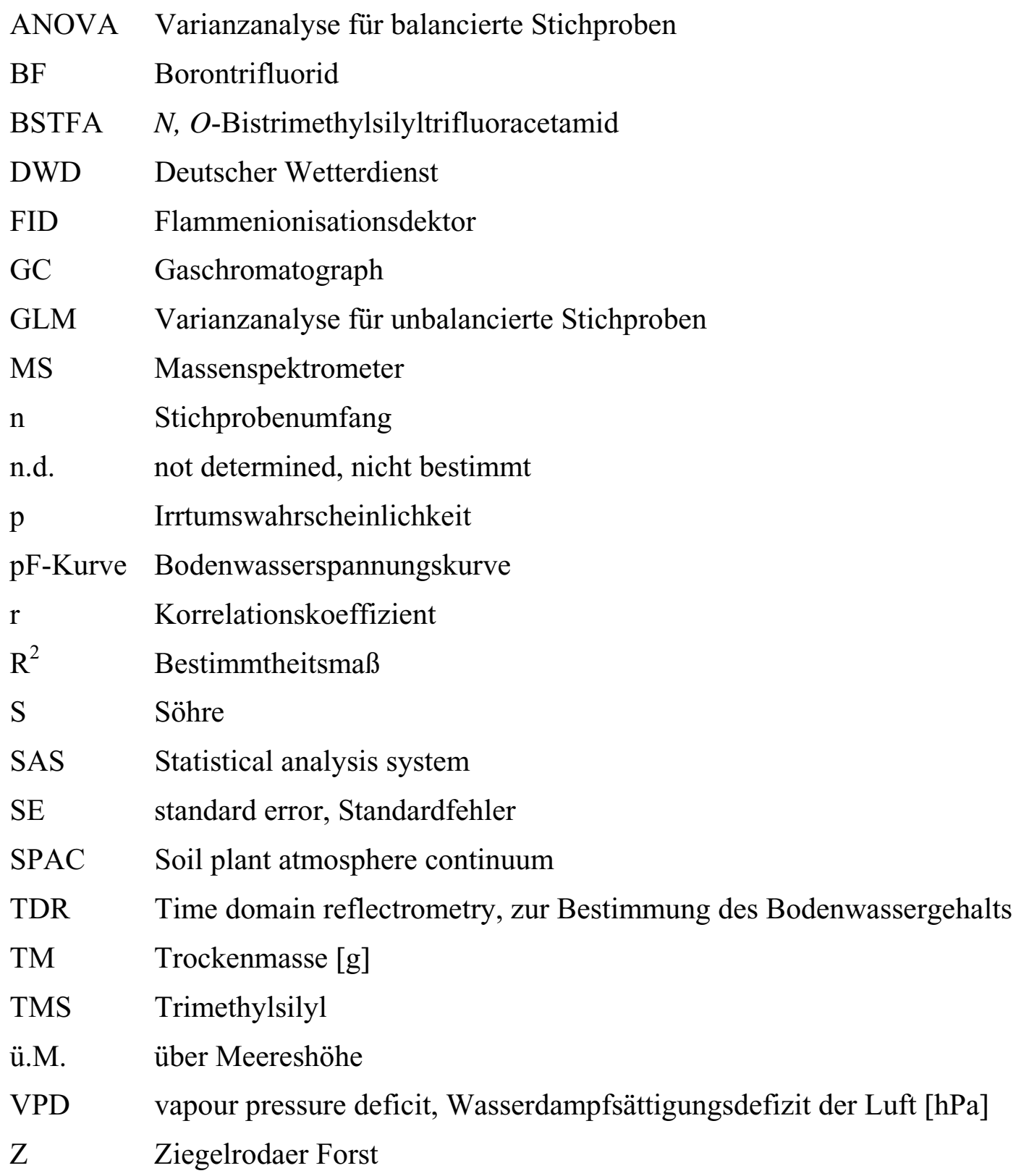




\section{Lebenslauf}

\section{Persönliche Angaben}

$\begin{array}{ll}\text { Name } & \text { Doris Burk } \\ \text { Geburtsdatum } & 8.6 .1977 \\ \text { Geburtsort } & \text { Pirna } \\ \text { Staatsangehörigkeit } & \text { deutsch }\end{array}$

\section{Bildungsgang}

$\begin{array}{ll}\text { 1984-1988 } & \text { Grundschule Prossen } \\ 1988-1992 & \text { Mittelschule Prossen } \\ \text { 1992-1994 } & \begin{array}{l}\text { Friedrich-Schiller-Gymnasium Pirna } \\ \text { Außenstelle Bad Schandau }\end{array} \\ 1994-1996 & \text { Allgemeine Hochschulreife am Goethe-Gymnasium Sebnitz } \\ 1996-1998 & \text { Grundstudium Biologie an der TU-Dresden } \\ 1998-2002 & \text { Hauptstudium Biologie an der TU-Dresden } \\ 2002 & \text { Abschluss als Diplombiologe } \\ 2002-2006 & \text { Vorbereitung auf die Promotion }\end{array}$

